\title{
THE FISHERY OF THE LOWER MISSOURI RIVER, MONTANA
}

STATE DOCUMENTS COLLECTION

SEP 161988

William M. Gardner

MONTANA STATE LIBRARY

1515 E. ETh AVE.
HELENA, MONTANA 59620

Phillip A. Stewart

Montana Department of Fish, Wildlife \& Parks
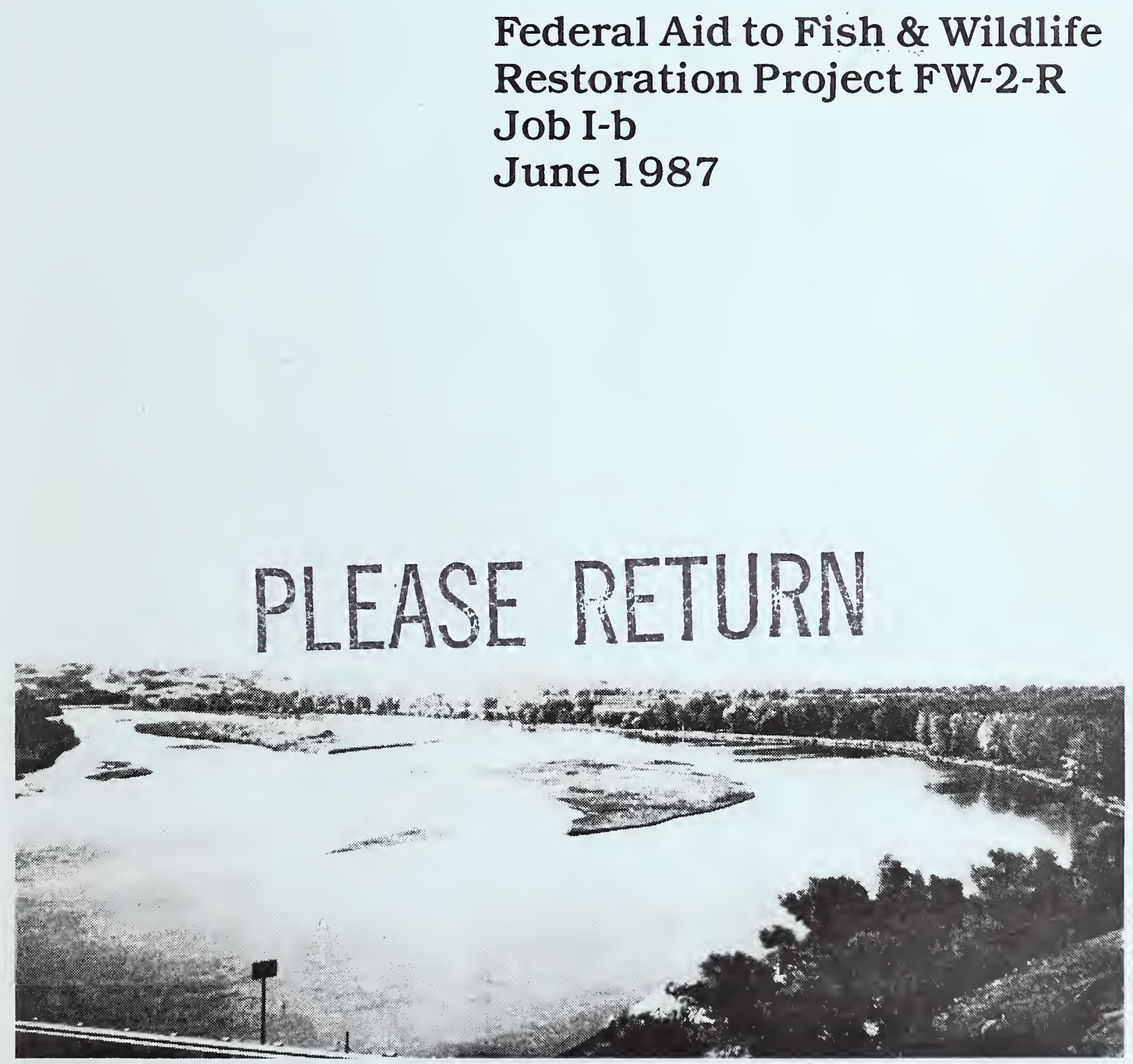
MAY 8 1990

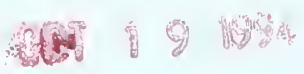

APE 20999

MONTANA STATE LIBRARY

${ }_{308640014} 40794$

19y 20

MAY 152002

APR 202006 
MONTANA STATE UBRARY
ISISE. GH AVE.

HELENA, MONTANA 59820

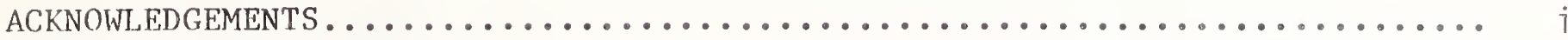

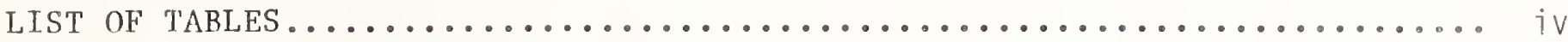

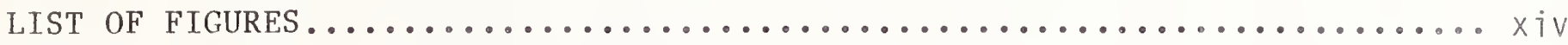

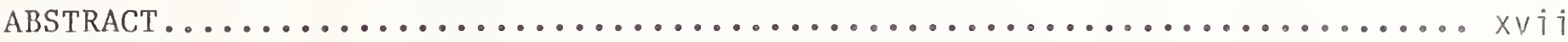

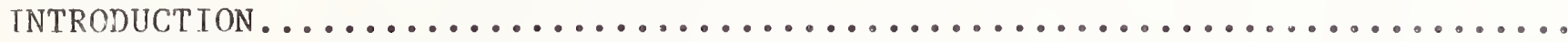

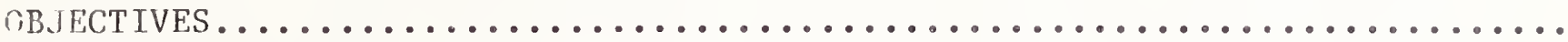

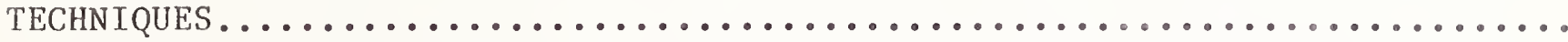

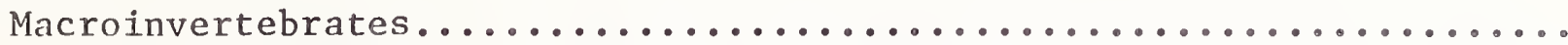

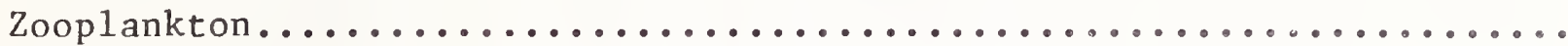

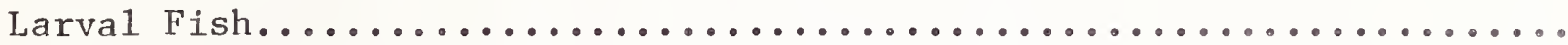

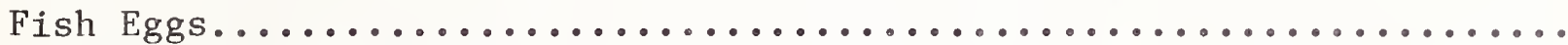

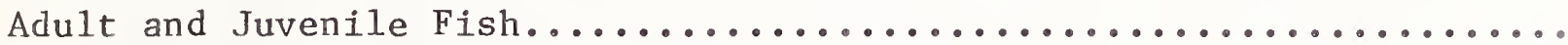

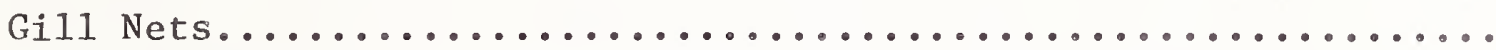

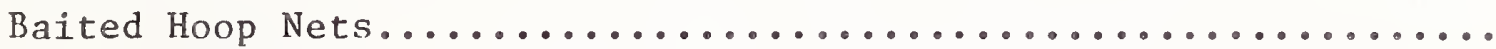

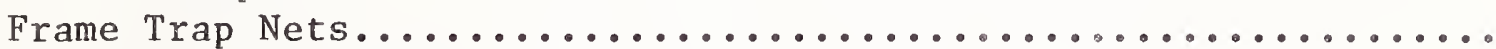

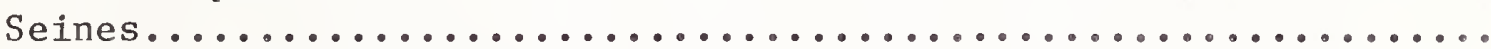

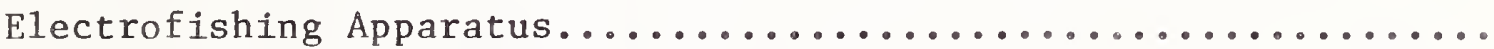

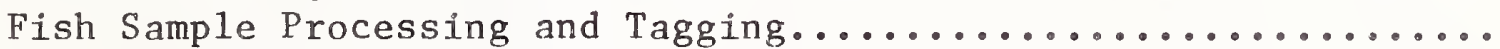

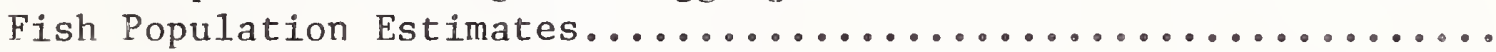

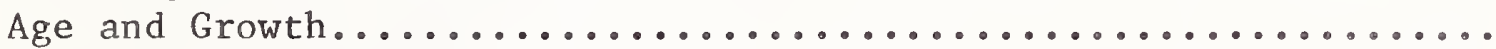

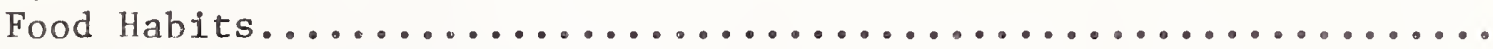

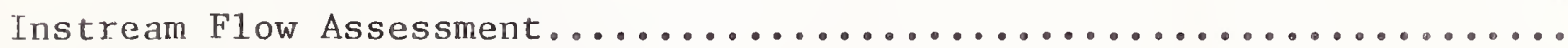

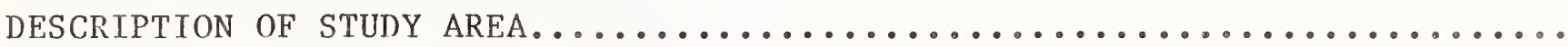

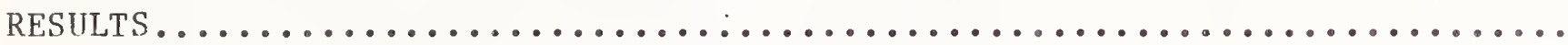

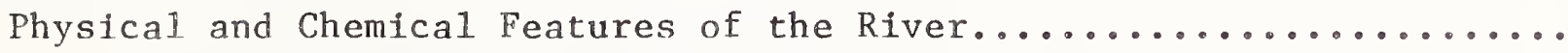

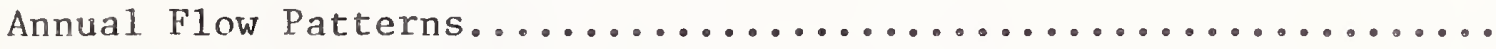

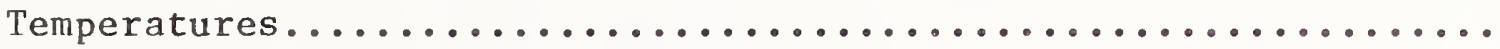

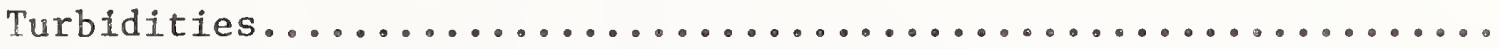

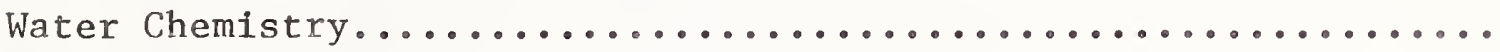

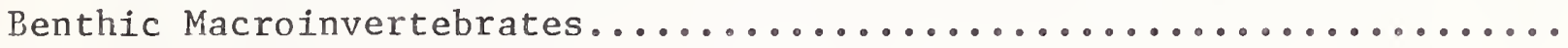

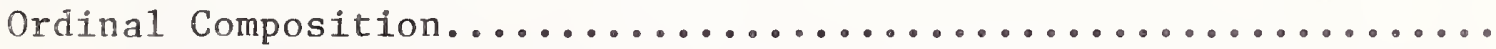

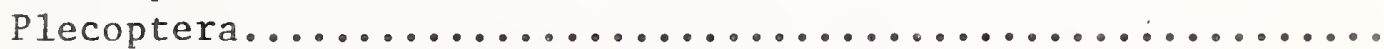

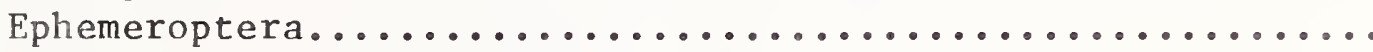

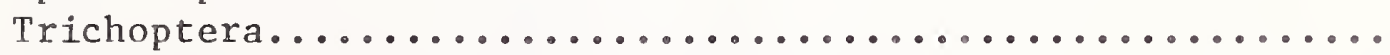

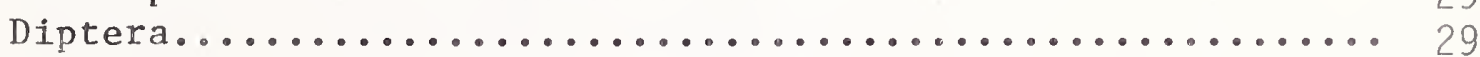

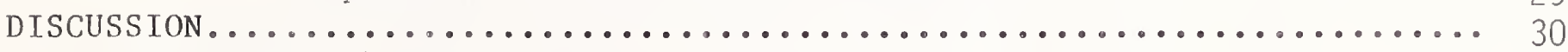

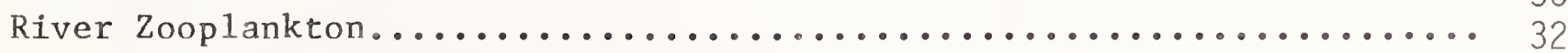

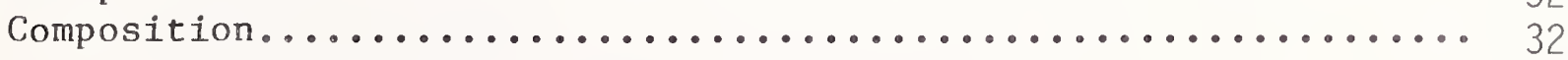

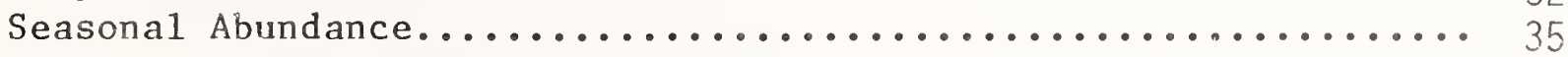

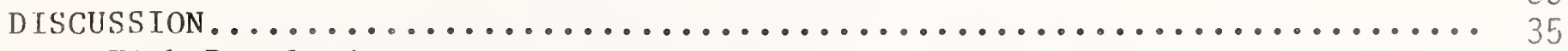

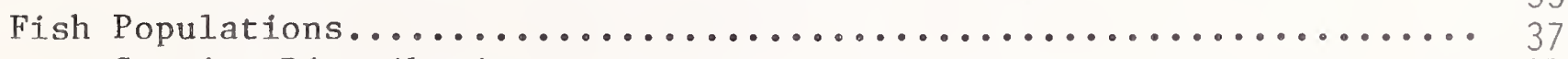

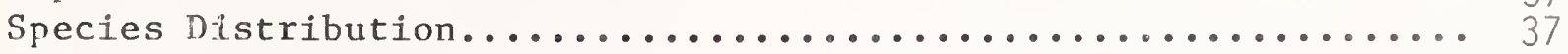

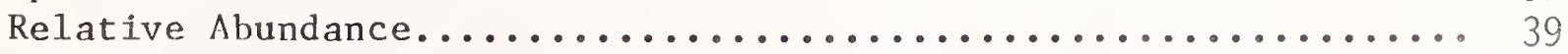

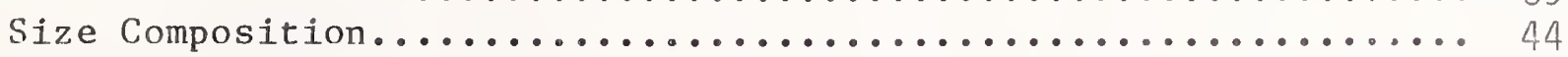

Population Estimates.............................. 47

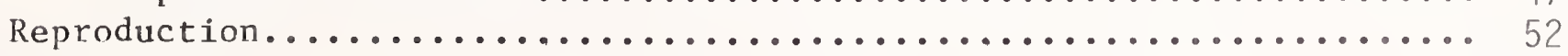

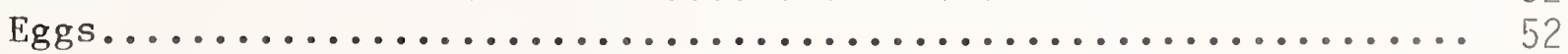

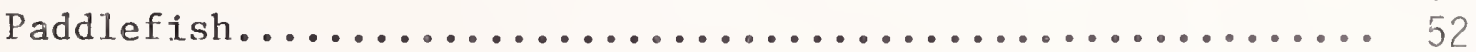

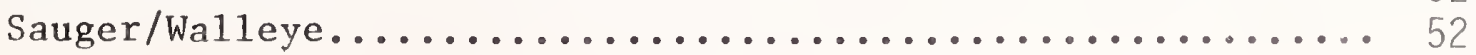




\section{Digitized by the Internet Archive in 2016}




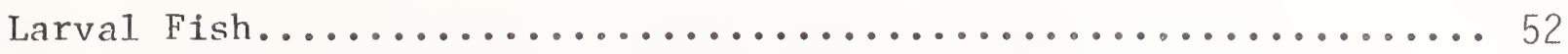

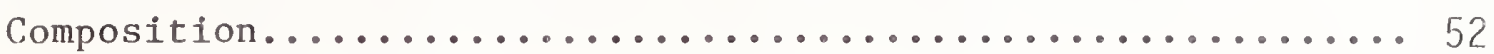

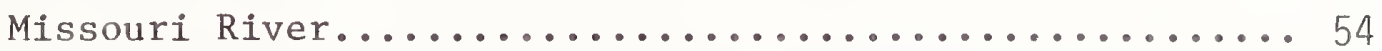

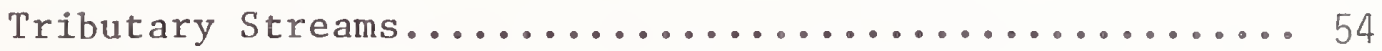

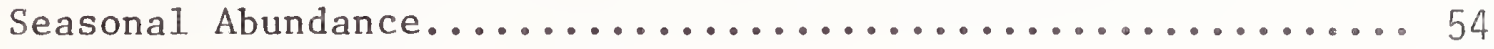

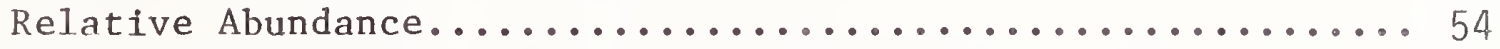

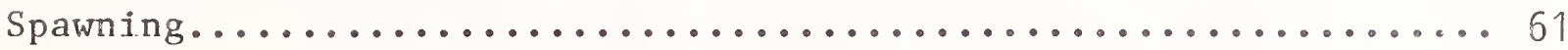

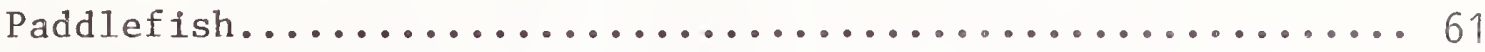

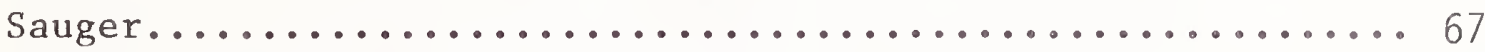

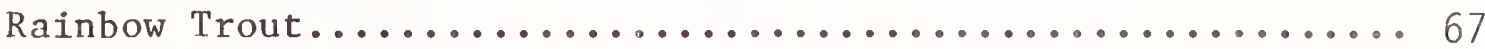

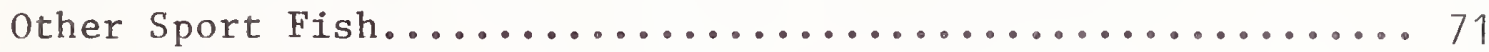

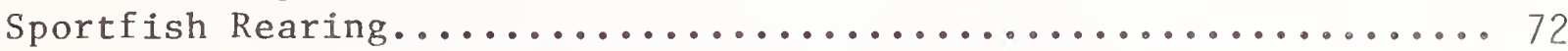

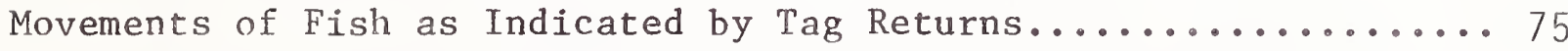

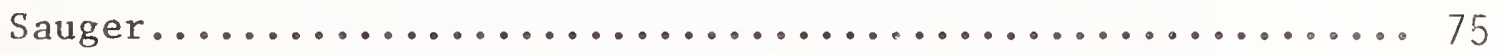

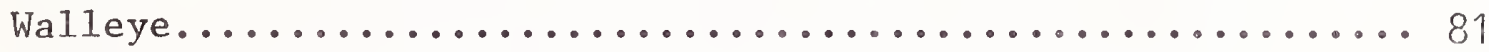

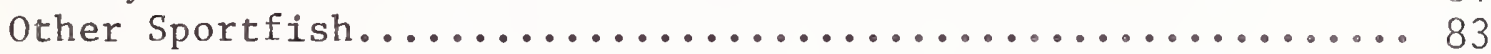

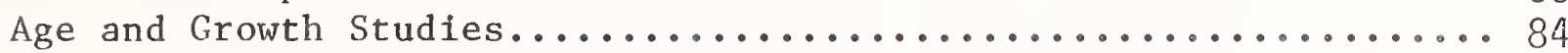

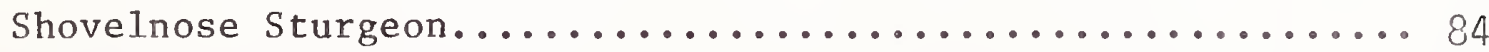

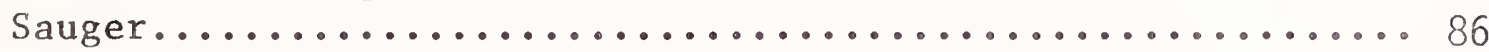

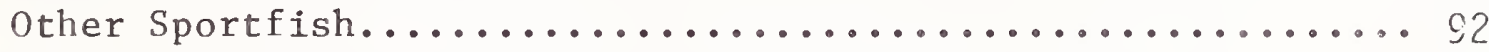

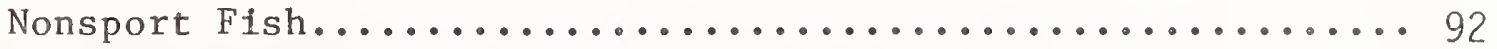

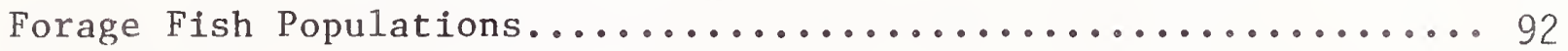

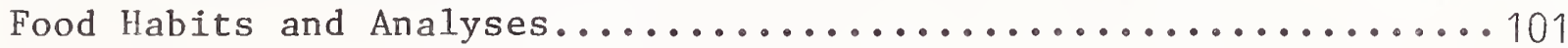

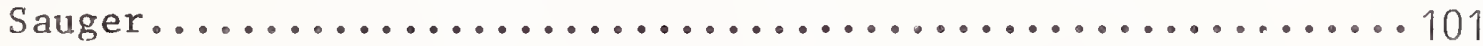

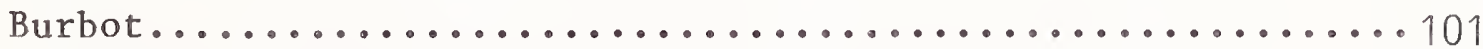

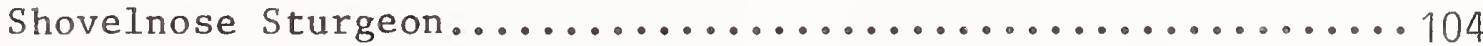

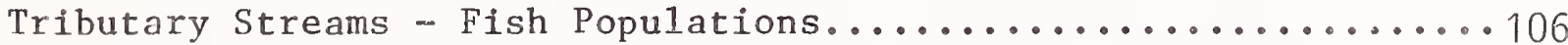

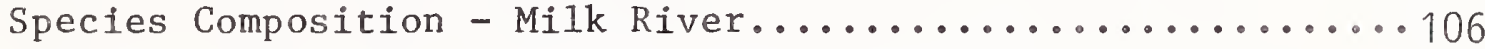

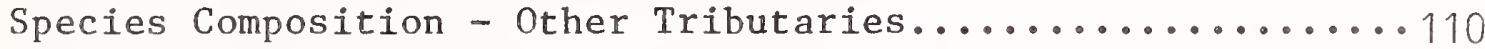

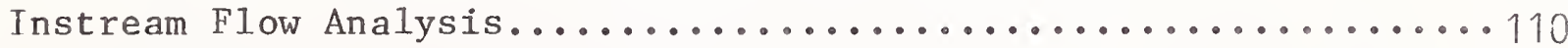

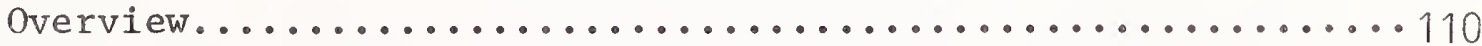

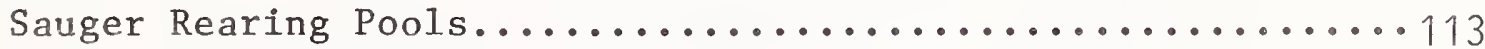

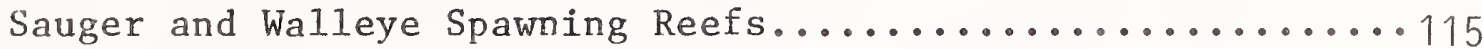

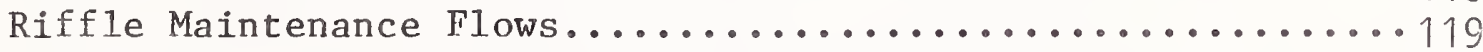

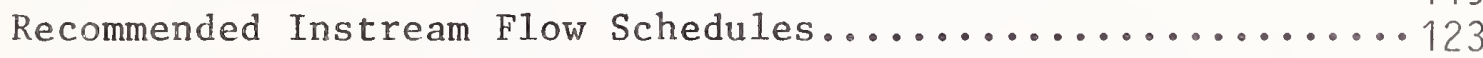

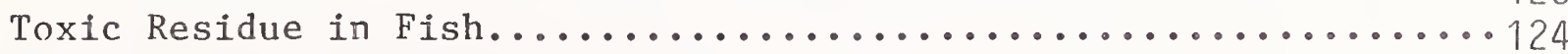

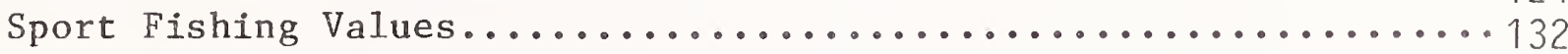

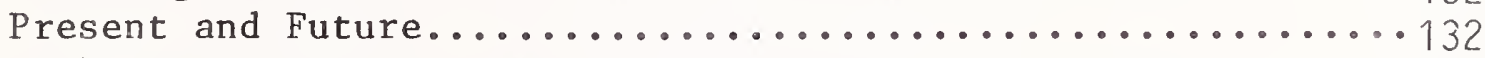

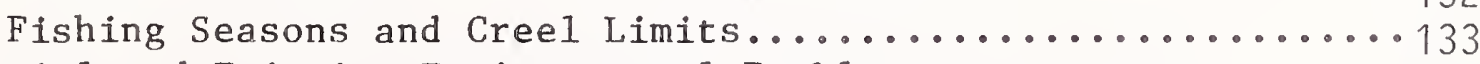

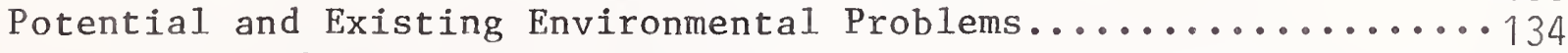

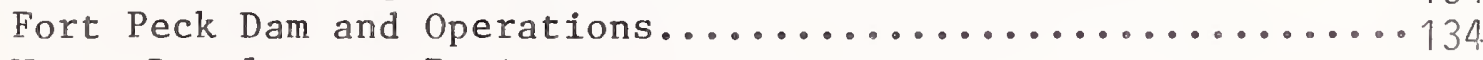

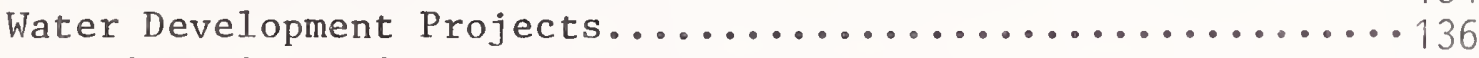

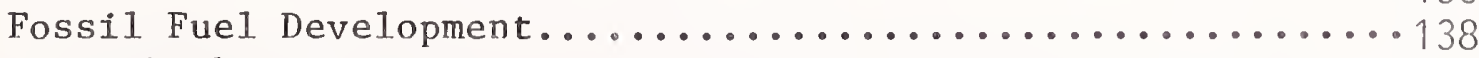

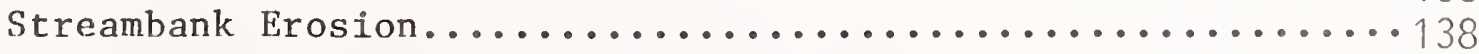

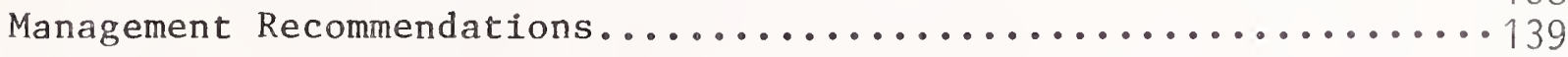

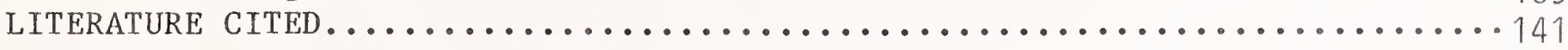

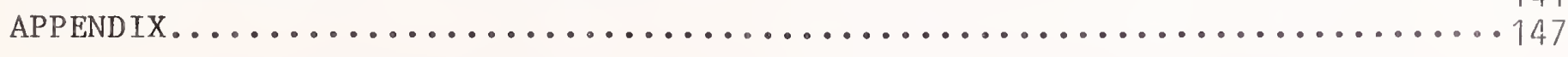



1 Study section locations and gradients of the lower Missouri

River from Fort Peck Dam to near the state border............

Average monthly flows (cfs) for the Missouri and Milk rivers a/ 1979-84 and fifty percentile monthly flows (for the years

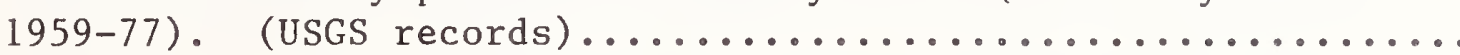

3 Comparisons of daily river stage fluctuations between three USGS stream gauging stations on the lower Missouri River during a nine day period in August, 1985. (Range values are in parentheses). (USGS unpubl. data). (Note; stream transit times

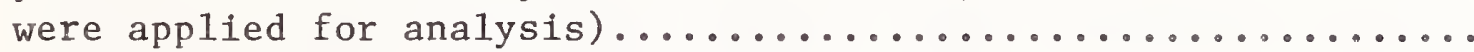

4 June maximum and annual maximum flows (cfs) of major tributary streams in the lower Missouri River basin. Data is for the two highest surface run-off years during the study period. (USGS

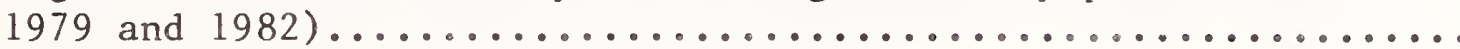

5 Average monthly temperatures $\left({ }^{\circ} \mathrm{F}\right)$ for the Missouri and Milk

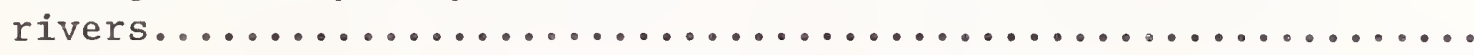

Average monthly turbidities (JTU) from October, 1974 to September, 1977 for the Missouri and Milk rivers. (USGS

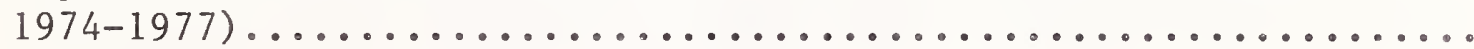

7 Average values and ranges (in parentheses) of selected water quality parameters for the Missouri, Milk and Poplar rivers sampled during six periods throughout the 1982 season. (USGS, 1982)

8 Average numerical percent composition (by order) and range (in parentheses) of the macroinvertebrate communities sampled by the traveling kick method in the lower Missouri River, March 24,

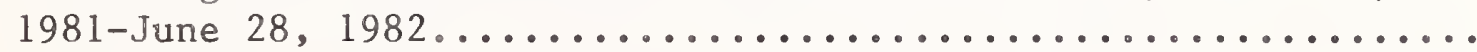

9 Average number and total number (in parentheses) of taxa in the aquatic macroinvertebrate communities sampled in the lower Missouri River, March 24, 1981-June 28, 1982...............

10 Longitudinal distribution and relative abundance of aquatic macroinvertebrates in the lower Missiouri River, March 24,

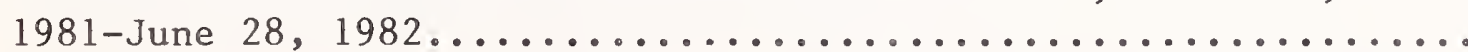

11 Percent composition of zooplankton genera and average zooplankton densities for samples collected in main channel and off-channel pool habitats in the Missouri River, $1984 \ldots \ldots \ldots \ldots$

12 Zooplankton densities by season, in main channel and off-channel pool habitats at three reaches of the Missouri River, 1984..... 


\section{LIST OF TABLES (Cont.)}

Table

Page

13 Seasonal comparisons of zooplankton densities in three habitat areas of the Missouri River and Fort Peck Reservoir. A11. samples taken concurrently during $1984 \ldots \ldots \ldots \ldots \ldots \ldots \ldots \ldots$

14 Distribution and abundance of adult fish species found in the

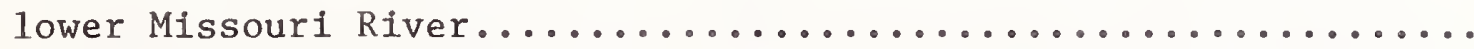

15 Catch rate summary for sport fish species sampled by electrofishing on the lower Missouri River, expressed as number

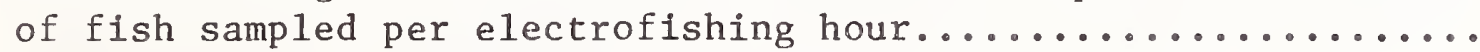

16 Catch rate summary for fish sampled by experimental gill netting on the lower Missouri River, 1979 and 1980, expressed as number

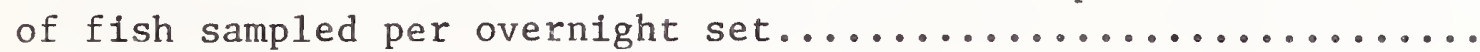

17 Catch rate and size statistics for channel catfish caught in baited hoop nets fished in the lower Missouri River during 1979

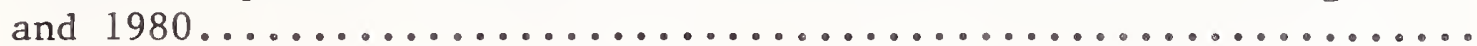

18 Catch rate summary for nonsport fish species sampled by electrofishing on the lower Missouri River, 1981, expressed as number of fish sampled per electrofishing hour..............

19 Greatest average weights, maximum weights and locations of the five most common sport fish sampled by electrofishing in the

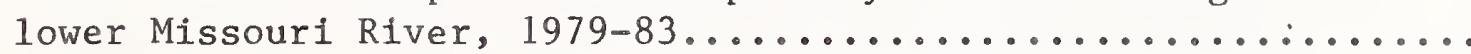

20 Sizes of paddlefish sampled by electrofishing in the study area during 1979-81 compared to other major Montana paddlefish

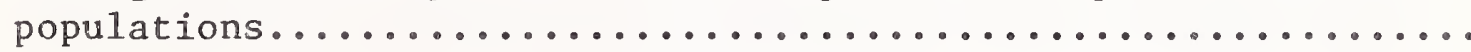

Average size and ranges of fish species for which population

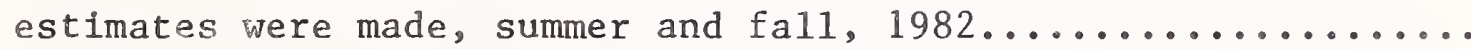

Modified Schnabel population estimates for sauger obtained by electrofishing in the Missouri River, 1982................

Modified Schnabel population estimates for goldeye and shorthead redhorse obtained by electrofishing in the Missouri River, 1982.

Occurrence of Stizostedion sp. eggs sampled in the study

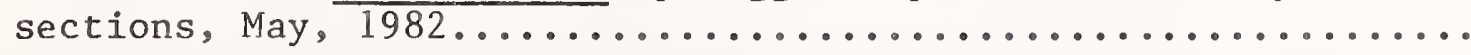

Average percent composition of fish larvae coilected in the

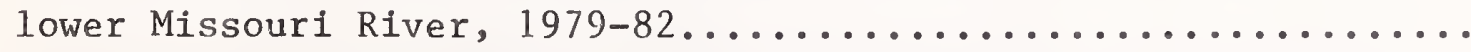

26 Average percent composition of fish larvae collected in the Milk, Redwater and Poplar rivers and Big Muddy Creek (near the mouths), $1979-82 \ldots \ldots \ldots \ldots \ldots \ldots \ldots \ldots \ldots \ldots \ldots \ldots \ldots \ldots$ 
, 


\section{LIST OF TABLES (Cont.)}

Table

$\underline{\text { Page }}$

27 Larval fish densities sampled in the Missouri River, 1979.....

28 Larval fish densities sampled in tributary streams of the

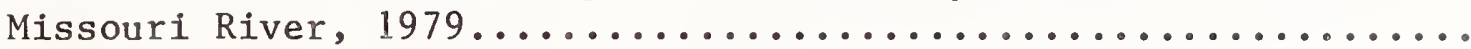

29 Average monthly flows in the Missouri River (at Wolf Point) and Milk River (near mouth) and condition of paddlefish spawning

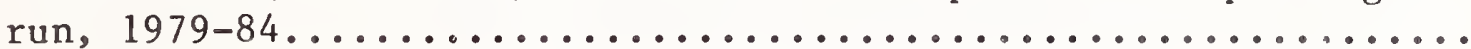

30 Total number of Stizostedion sp. larvae collected at sampling

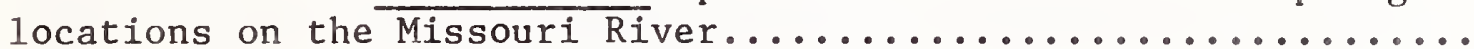

31 Catch rates of sauger sampled in the Missouri River, April 1-May $24,1980-82 \ldots \ldots \ldots \ldots \ldots \ldots \ldots \ldots \ldots \ldots \ldots \ldots \ldots \ldots \ldots \ldots \ldots \ldots . . \ldots \ldots$

32 Average sizes and catch rates of walleye and northern pike sampled by electrofishing in the Missouri River during $1982 \ldots \ldots$

33 Gonad condition of shovelnose sturgeon in the Missouri River, 1982, as determined by internal examination...............

34 Catch summary for young-of-the-year sauger seined in backwaters and channel margins of the Missouri River, September, 1980-83...

Percentage of recaptured tagged fish which exhibited a designated movement pattern in the lower Missouri River

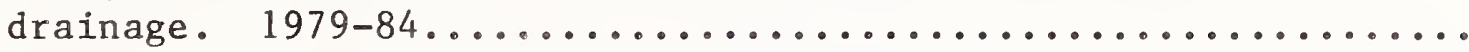

36 Age-frequency of shovelnose sturgeon collected from the lower Missouri River during 1983 and 1984 with average lengths and

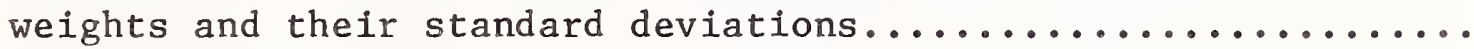

37 Observed growth of shovelnose sturgeon sampled in the lower Missouri River during 1983-84 compared to observed growth in

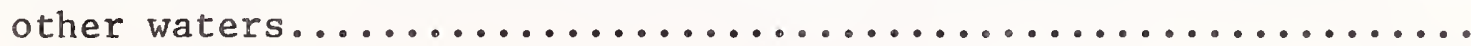

Observed age and growth of sauger sampled in the lower Missouri River during the $f a 11,1979 \ldots \ldots \ldots \ldots \ldots \ldots \ldots \ldots \ldots \ldots$

39 Comparisons of calculated sauger growth rates in the lower Missouri River during 1979 with other sauger populations.......

40 Comparison of Missouri River sauger length, weight and age structure for ages 0+ through 6+, in fall 1979 and Fall 1981...

41 Age and growth of Missouri River northern pike collected in summer and $f a 11,1982 \ldots \ldots \ldots \ldots \ldots \ldots \ldots \ldots \ldots \ldots \ldots \ldots \ldots$

42 Age and growth of 115 burbot collected from the Missouri River,

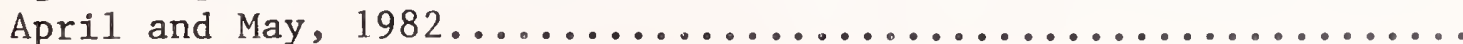





\section{LIST OF TABLES (Cont.)}

Table

$\underline{\text { Page }}$

43 Age and growth and average length and weight for Missouri River

nonsport fish species sampled in August, 1981..............

44 Longitudinal distribution and relative abundance (avg. number of fish per haul) of forage fish species seined in the lower

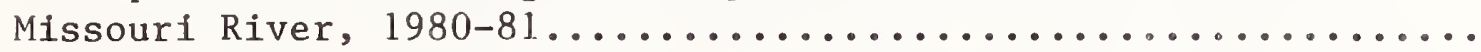

45 Stomach content results (number and percentages) for sauger age $1+$ and older sampled in the Missouri River, 1982............

46 Stomach content results (number and percentages) for

young-of-the-year sauger collected in the Missouri River, 1982..

47 Stomach content results (number and percentages) for burbot less than 20 inches in total length sampled in the Missouri River,

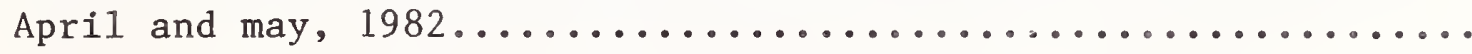

48 Stomach content results (number and percentages) for burbot 20 inches or greater in total length sampled in the Missouri River,

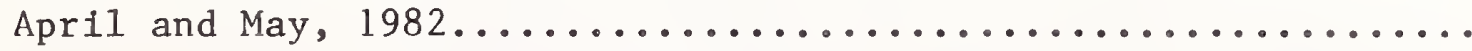

49 Stomach content results (number and percentages) for shovelnose

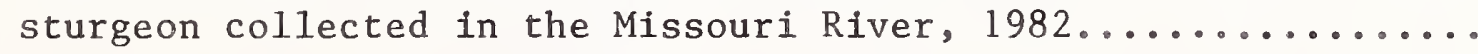

50 Comparison of sportfish a/ catch rates between Missouri River tributaries (sampled near mouth) and nearby mainstem study sections.

51 Catch rate summary for sport fish species sampled by electrofishing in the lower reaches of Missouri River tributary streams during spring and early summer, 1979-82 and 1984, expressed as number of fish sampled per electrofishing hour....

52 Catch rate summary for fish sampled by experimental gill netting on tributaries of the Missouri River, 1979, 1980 and 1984, expressed as number of fish caught per overnight set. Sampling

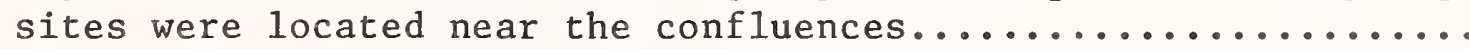

53 Summary of the catch from seven hauls with a 4-foot X 25-foot seine in the Milk River about 20 miles above the mouth, 1977.

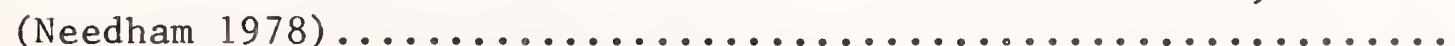

54 Predicted water elevations and corresponding flows at which four monitored pools are at suitable maintenance conditions.........

River stage height and corresponding flows required to maintain adequate sauger spawning conditions at two representative spawning/incubation reefs. 
56 River discharges where the wetted-perimeter inflection points occur for a composition, of, or single riffles..............

57 The schedule of recommended instream flows for the Missouri river at the Fort Peck Dam USGS gauging station. The fifty percentile flow (1959-77 records) at this gauging station and the fifty percentile flow (1960-78 records) of the Missouri River entering Fort Peck Reservoir are provided for comparison..

58 The schedule of recommended instream flows for the Missouri River at the Wolf Point USGS gauging station. The fifty percentile flow (1959-77 records) is also provided for

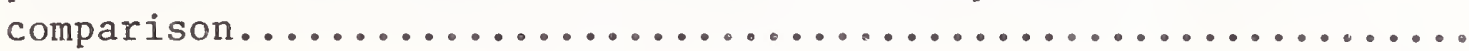

59 The schedule of recommended instream flows for the Missouri River at the Culbertson USGS gauging station. The fifty percentile flow (1959-77 records) is also provided for

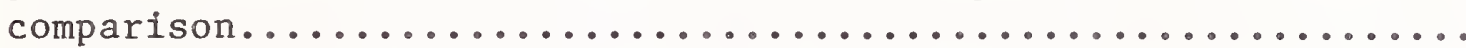

Concentrations of chlorinated hydrocarbons and mercury in rainbow trout and shovelnose sturgeon collected in the Missouri

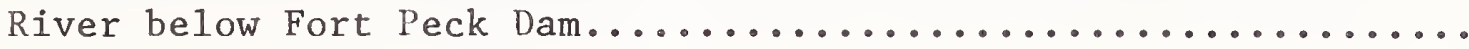

61 Average annual and combined harvest rates (percentage) for sport fish populations in the lower Missouri River, as indicated by

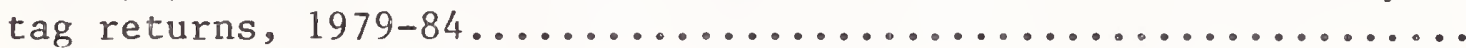

62 Water use for irrigation in the lower Missouri and lower Yellowstone rivers during 1980. (Source - Dept. of Nat. Res.

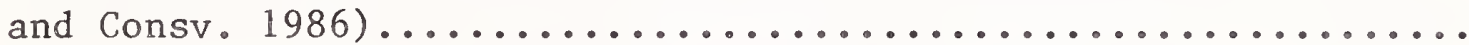

\section{APPENDIX}

1 Daily minimum and maximum water temperatures (degrees $F$ ) for the Missouri River near Wolf Point, MT during 1980. (USGS 1980)....

Daily minimum and maximum water temperatures (degrees $F$ ) for the Missouri River near Wolf Point, MT during 1982. (USGS 1982-83)..

Daily minimum and maximum water temperatures (degrees $F$ ) for the Missouri River near Wolf Point, MT during 1983. (USGS 1983-84)..

Daily minimum and maximum water temperatures (degrees F) for the Missouri River near Wolf Point, MT during 1984. (USGS 1984)....

Numbers of aquatic macroinvertebrates collected (per sample period) at the tailwaters of Fort Peck Dam Stations, March 1981

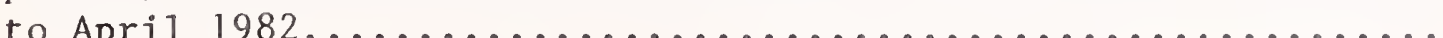


6 Numbers of aquatic macroinvertebrates collected (per sample period) at the Wiota Pumping Station, March 1981 to Apri1 1982..

7 Numbers of aquatic macroinvertebrates collected (per sample period) at the Highway 13 Bridge Station, March 1981 to Apri1

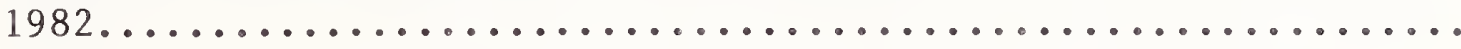

8 Numbers of aquatic macroinvertebrates collected (per sample period) at the Highway 16 Bridge Station, March 1981 to April 1982

9 Numbers of aquatic macroinvertebrates collected (per sample period) at the Nohly Bridge Station, March 1981 to Apri1 1982...

10 Zooplankton densities sampled at the upper reach station of the

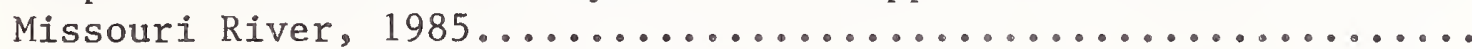

11 Zooplankton densities sampled at the middle reach station of the

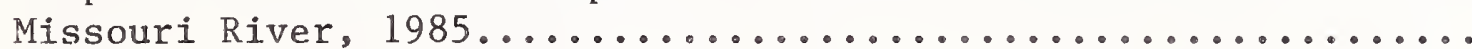

12 Zooplankton densities sampled at the lower reach station of the

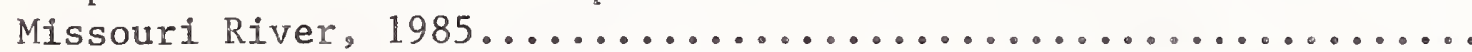

13 Sportfish composition, number and size of fish sampled by electrofishing in the lower Missouri River study sections, 1979

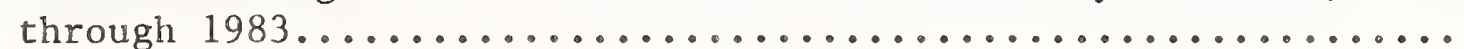

14 Species composition, number and size of fish sampled by experimental gill nets in the Fort Peck (dredge ponds) study

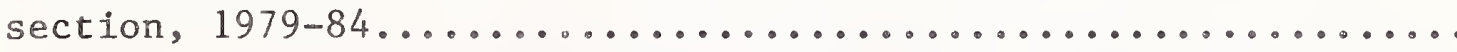

15 Species composition, number and size of fish sampled by experimental gill nets in the Nickels Ferry study section, 1980 .

16 Species composition, number and size of $\mathrm{fish}$ sampled by experimental gill nets in the Frazer study section, 1979-80....

17 Species composition, number and size of fish sampled by experimental gill nets in the Wolf Point study section, 1979-80.

18 Species composition, number and size of fish sampled by experimental gill nets in the Chelsea study section, 1979-80....

19 Species composition, number and size of fish sampled by experimental gil1 nets in the Brockton study section, 1979-80... 



\section{APPENDIX (Cont.)}

21 Nonsport fish species composition, number and size of fish sampled by electrofishing in the Fort Peck study section, 1981..

22 Nonsport fish species composition, number and size of fish sampled by electrofishing in the Nickels Ferry study section, 1981

23 Nonsport fish species composition, number and size of fish sampled by electrofishing in the Frazer study section, 1981....

24 Nonsport fish species composition, number and size of fish sampled by electrofishing in the Wolf Point study section, 1981.

25 Nonsport fish species composition, number and size of fish sampled by electrofishing in the Chelsea study section, 1981...

26 Nonsport fish species composition, number and size of fish sampled by electrofishing in the Sprole study section, 1981....

27 Nonsport fish species composition, number and size of fish sampled by electrofishing in the Brockton study section, 1981...

28 Nonsport fish species composition, number and size of fish sampled by electrofishing in the Culbertson study section,

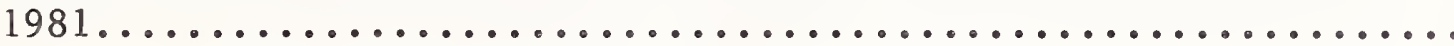

29 Numbers of larval fish collected (total for year) in the Fort Peck Dam section of the Missouri River, 1979-82.............

30 Numbers of larval fish collected (total for year) in the Nickels Ferry section of the Missouri River, $1979-82 \ldots \ldots \ldots \ldots \ldots \ldots \ldots$

31 Numbers of larval fish collected (total for year) in the Frazer section of the Missouri River, $1979-82 \ldots \ldots \ldots \ldots \ldots \ldots \ldots \ldots \ldots$

32 Numbers of larval fish collected (total for year) in the Wolf Point section of the Missouri River, 1979-82...............

33 Numbers of larval fish collected (total for year) in the Chelsea

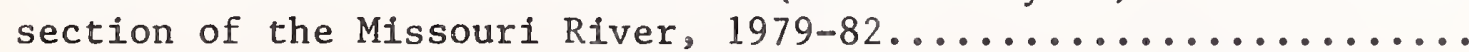

Numbers of larval fish collected (total for year) in the Sprole section of the Missouri River, $1979-82 \ldots \ldots \ldots \ldots \ldots \ldots \ldots \ldots \ldots \ldots$

Numbers of larval fish collected (total for year) in the Brockton section of the Missouri River, 1979-82............. 

APPENDIX (Cont.)

37 Numbers of larval fish collected (total for year) in the Milk River section near the confluence with the Missouri River,

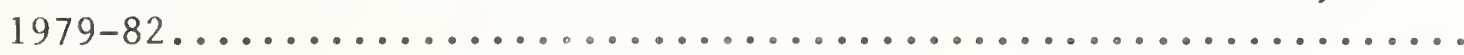

38 Numbers of larval fish collected (total for year) in the Poplar River near the confluence with the Missouri River, 1979-82.....

39 Numbers of larval fish collected (total for year) in the Redwater River near the confluence with the Missouri River,

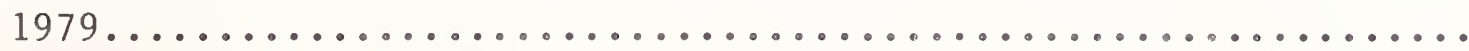

40 Numbers of larval fish collected (total for year) in the Big Muddy Creek near the confluence with the Missouri River,

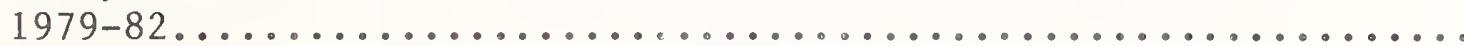

41 Number of paddlefish counted in electrofishing surveys of the Missouri River during $1979 \ldots \ldots \ldots \ldots \ldots \ldots \ldots \ldots \ldots$

42 Number of paddlefish counted in electrofishing surveys of the

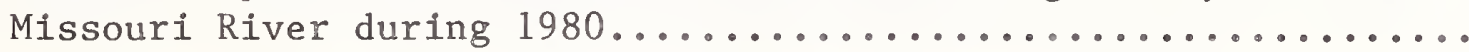

43 Number of paddlefish counted in electrofishing surveys of the

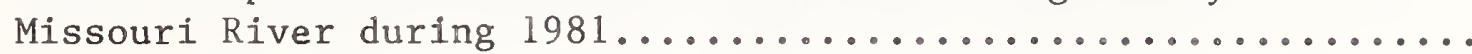

44 Number of paddlefish counted in electrofishing surveys of the Missouri River during $1982 \ldots \ldots \ldots \ldots \ldots \ldots \ldots \ldots \ldots \ldots$

45 Number of paddlefish counted in electrofishing surveys of the

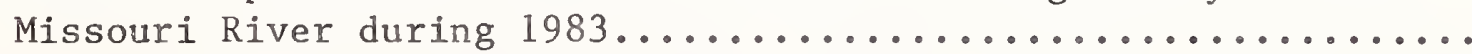

46 Number of paddlefish counted in electrofishing surveys of the

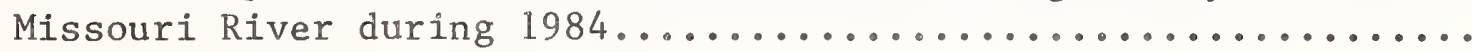

47 Daily maximum and minimum temperatures $\left({ }^{\circ} \mathrm{F}\right)$ recorded in the rainbow trout spawning side channel (Duck Island) three miles

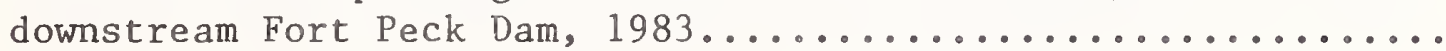

48 Movement of tagged fish in the lower Missouri River during the study period from May, 1979 through October, 1984............

49 Sportfish composition, numbers and size of fish sampled by electrofishing in the lower reaches of tributary streams to the

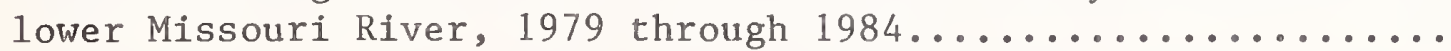

50 Species composition, numbers and size of fish sampled by experimental gill nets in the Milk River - Glasgow study section, 1984. (A total of four overnight sets)............. 


\section{APPENDIX (Cont.)}

$\underline{\text { Table }}$

Page

51 Species composition, numbers and size of fish sampled by experimental gill nets in the Milk River - Nashua study section,

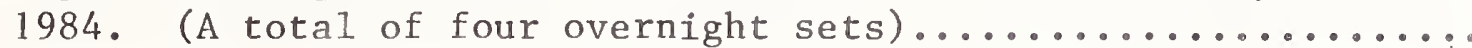

52. Species composition, numbers and size of fish sampled by experimental gill nets in the Milk River confluence study section, 1980 and 1984. (A total of eight overnight sets).....

53 Species composition, numbers and size of fish sampled by experimental gill nets in the Little Porcupine Creek near its confluence, 1979-80. (A total of two overnight sets).........

54 Species composition, numbers and size of fish sampled by experimental gill nets in the Redwater River near its confluence, 1979-80. (A total of three overnight sets)........

55 Species composition, numbers and size of fish sampled by experimental gill nets in the Poplar River near its confluence 1979-80. (A total of four overnight sets).

56 Species composition, numbers and size of fish sampled by experimental gill nets in the Big Muddy Creek near its confluence, 1980. (A total of four overnight sets)..........

57 River flows with corresponding stage height (ft) for the six cross sections established at sauger spawning/incubation reefs

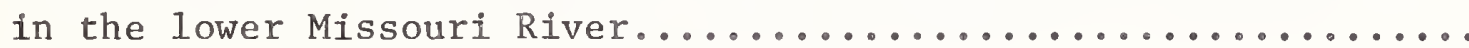

58 A summary of shovelnose sturgeon tagging and harvest data from the lower Missouri and lower Milk rivers, 1979-84. Total number harvested and harvest rate percentage (in parentheses) are given

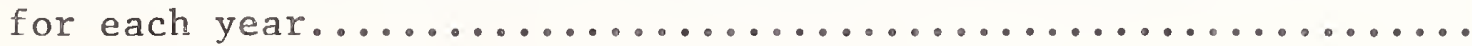

59 A summary of paddlefish tagging and harvest data from the lower Missouri River, 1979-84. Total number harvested and harvest rate percentage (in parentheses) are given for each

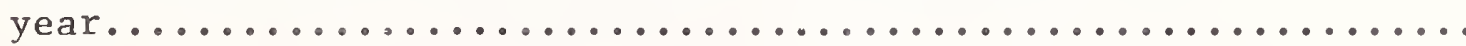

60 A summary of rainbow trout tagging and harvest data from the lower Missouri River, 1979-84. Total number harvested and harvest rate percentage (in parentheses) are given for each

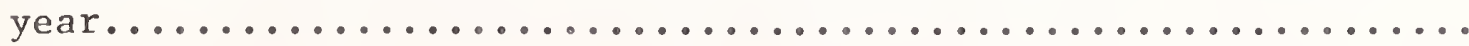

61 A summary of northern pike tagging and harvest data from the lower Missouri and lower Milk rivers, 1979-84. Total number harvested and harvest rate percentage (in parentheses) are given

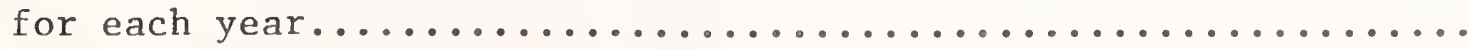


62 A summary of channel catfish tagging and harvest data from the lower Missouri and lower Milk rivers, 1979-84. Total number harvested and harvest rate percentage (in parentheses) are given

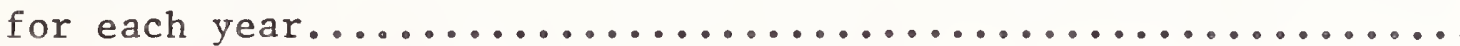

53 A summary of burbot tagging and harvest data from the lower Missouri and lower Milk rivers, 1979-84. Total number harvested and harvest rate percentage (in parentheses) are given for each

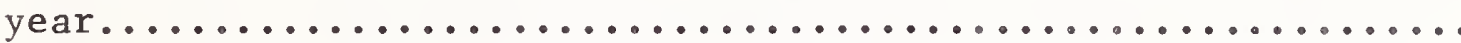

64 A summary of sauger tagging and harvest data from the lower Missouri and lower Milk rivers, 1979-84. Total number harvested and harvest rate percentage (in parentheses) are given for each

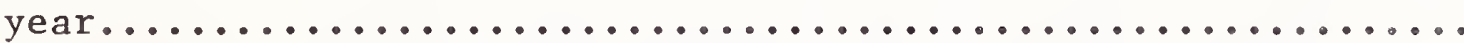

65 A summary of walleye tagging and harvest data from the lower Missouri and lower Milk rivers, 1979-84. Total number harvested and harvest rate percentage (in parentheses) are given for each

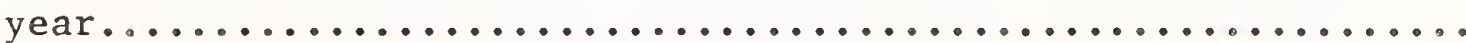



1 Fort Peck Dam Completed in 1936 impounds about 19 million acre-feet of water and completely regulates flows in the lower

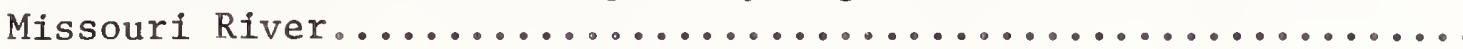

4 Longitudinal profile of the lower Missouri River stream gradient in comparison to the middle Missouri and Yellowstone rivers.....

Relationship between average length (inches) of fish and study

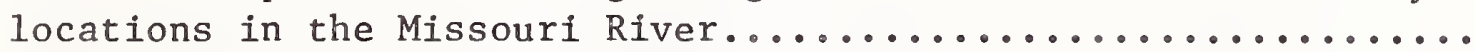

Relative percent composition of larval fish numbers collected in the Missouri River at three reaches and in three tributary

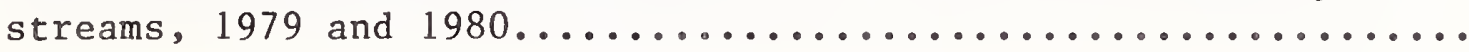

7 Relative percent composition of larval fish numbers collected in the Missouri River at three reaches and in three tributary

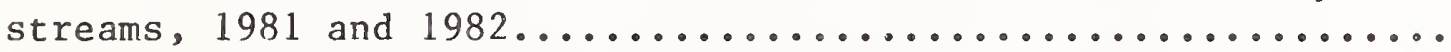

8 Comparison between flows in the Missouri River and a tributary (Milk River) stream, and larval fish catches...............

Number of paddlefish counted in each study section by electrofishing in the Missouri River, April-June. (N=the total number of paddlefish counted for a given year)..............

10 Seasonal distribution and abundance of paddlefish in three

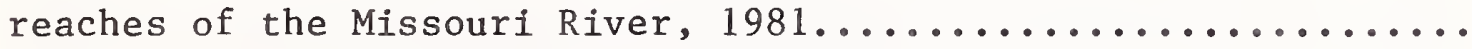

11 Spawning condition of sauger sampled in the lower Missouri River

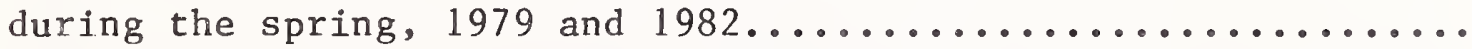

12 Spawning condition of sauger sampled in the Milk River near its confluence with the Missouri River during spring, 1979-82 and

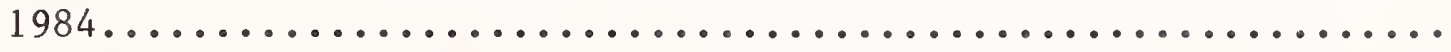

13 Young-of-the-year sauger were typically found in these types of

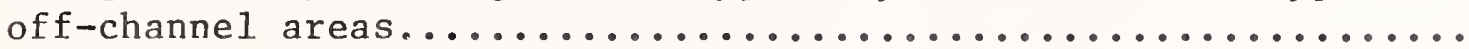

14 Length-frequency histogram for shovelnose sturgeon sampled in the Missouri River, $1979-83 . \ldots \ldots \ldots \ldots \ldots \ldots \ldots \ldots \ldots \ldots \ldots$

15 The relationship of sauger/walleye abundance in the Fort Peck dredge cuts/tailwater area to that of rainbow smelt abundance... 


\section{LIST OF FIGURES (Cont.)}

16 The Milk River restores some of the warmwater river characteristics of the Missouri and this confluence area was found to be one of the most important biological zones in the

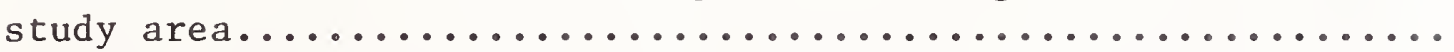

17 Diagrammatic representation of the habitat areas where instream

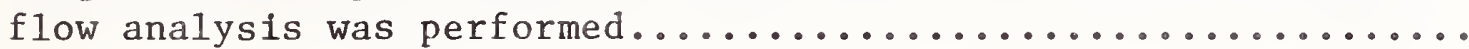

18 A representation of two cross section profiles of the same rearing pool showing river stage heights and flow which will

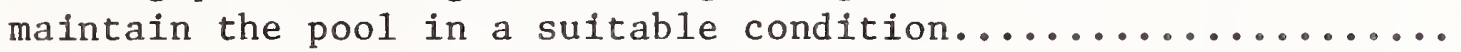

19 Sauger spawned in these types of reef areas. The photo was taken when the river was flowing about $7200 \mathrm{cfs} . \ldots \ldots \ldots \ldots \ldots$

Hydrograph of all the recommended instream flows at the Fort

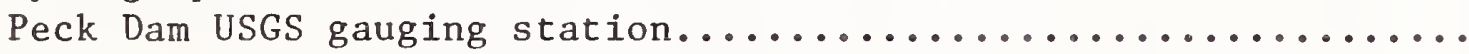

21 Hydrograph of all the recommended instream flows at the Wolf

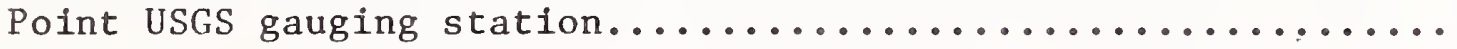

22 Hydrograph of all the recommended instream flows at the Culbertson USGS gauging station....................

\section{APPENDIX}

1 Cross section profiles of the Sprole rearing pool and river flow and corresponding stage height which will maintain the pool at

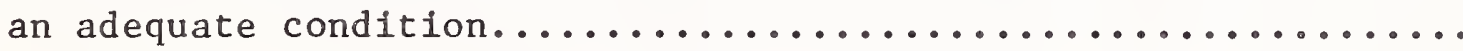

2 Cross section profiles of the Brockton 1 rearing pool and river flow and corresponding stage height which will maintain the pool

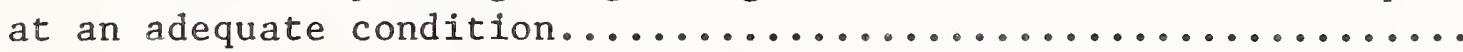

3 Cross section profiles of the Brockton 2 rearing pool and river flow and corresponding stage height which will maintain the pool

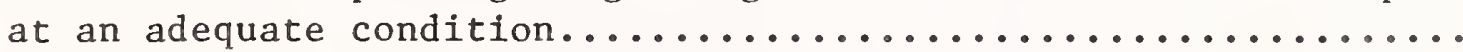

4 Cross section profiles of the Culbertson rearing pool and riverflow and corresponding stage height which will maintain the

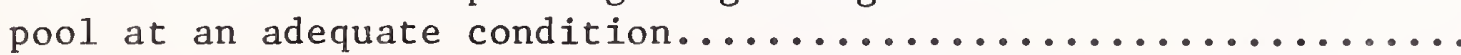

5 Wetted perimeter-discharge relationships for three different riffle sites located on the Missouri River in the Fort Peck section. Each curve is a composite of two or three cross

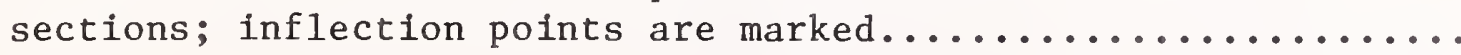




\section{APPENDIX (Cont.)}

6 Wetted perimeter-discharge relationships for three different riffle sites located on the Missouri River in the Nickels Ferry and Frazer study sections. Each curve represents one or a composite of two cross sections; inflection points are marked....

7 Wetted perimeter-discharge relationship for a composite of three riffle cross sections located on the Missouri River in the

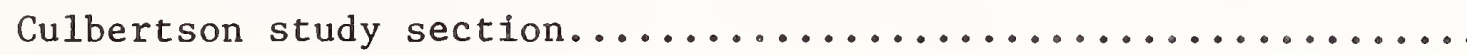





\section{ABSTRACT}

Fish and food organisms along with an analysis of instream flows were studied in a 180 mile reach of the Missourt River from Fort Peck Dam to the Montana-North Dakota border. Size composition, longitudinal distribution, relative abundance and limited population estimate data were determined for the fish populations in the study area. Forty-three fish species were sampled in the lower Missouri River with sauger being the most common sport fish, and goldeye, carp and a varfety of minnows and suckers being the common nonsport fish sampled.

Life cycle requirements were studied for several sport fish. A paddlefish spawning migration from Lake Sakakawea Reservoir was identified and monitored. Evidence of successful reproduction was noted in the Milk River, a tributary to the Missouri River. Sauger were found to spawn in the lower reaches of the study area. Evidence of sauger spawning was also noted in the Milk River and the Milk/Missouri River confluence area. Young-of-the-year sauger reared in the lower off-channel pool areas, found mostly in the lower end of the study area. Movements of several sport fish species were evaluated. Results indicated there was considerable interchange between the Missouri River, and both Lake Sakakawea and Yellowstone River for the more mobile species including paddlefish, shovelnose sturgeon, channel catfish, sauger and walleye. Rainbow trout, northern pike and burbot tended to exhibit restricted movement patterns. Age and growth, food habits and forage fish populations were also studied.

The aquatic macroinvertebrate communities were investigated. Communities were most diverse at the lower sites and least at the upper site near the dam. River zooplankton studies indicated that along with substantial quantities of plankton originating from Fort Peck Reservoir, plankton production in the off-channel river areas was also an important source during the summer. Distribution and relative abundance of larval fish were monitored. It appeared there was a positive correlation between spring run-off conditions and gross number of larval fish collected. Instream flow evaluations were determined for sauger spawning/incubation and rearing. Evaluations were also determined for riffle maintenance. 



\section{INTRODUCTION}

The aquatic biology in general, and, in particular, the fish populations of the lower Missouri River in Montana have received little attention over the past years. Prior to this study a basic inventory of the aquatic resources did not exist. Little was known concerning the vulnerability of resident fish species to various water development plans, importance of tributary streams and particular river reaches, or physical, hydrological and biological factors of importance to the fisheries.

Water withdrawals in the Missouri River which could affect fish populations here, are likely to occur in the near future. There are plans for considerable expansion of the present irrigation systems and possibilities of developing the large reserves of coal in the basin would require water development. The most likely sources for water development would either be from Fort Peck Reservoir or the Missouri River downstream. Other likely water sources in the area such as the Yellowstone River basin has already had a large portion of its water allocated and limited supplies for development remain. The Missouri above Fort Peck Reservoir is a designated Wild and Scenic River and therefore water development would most likely be limited.

A better comprehension of the Missouri River's aquatic ecosystem is essential for sound management of the fisheries resources and addressing possible enviornmental conflicts which may occur in the future. Responding to this need the Montana Department of Fish, Wildlife and Parks (MDFWP) initiated a planning and inventory study on May, 1979, to investigate the fisheries resources in this area. This report presents the results of that study. 


\section{OBJECTIVES}

Overall project objectives consist of the inventory of sport and nonsport fish populations, determination of important factors upon which sport fish depend, location of critical river reaches and tributary streams for the sport fish species and formulation of instream flow recommendations to protect fish populations. The results from this study will be used for aquatic resource management of the lower Missouri River.

Specific objectives were:

1) To gather and summarize important physical/chemical data describing water quality conditions.

2) To determine the benthic macroinvertebrate composition and distribution.

3) To determine river zooplankton composition and distribution.

4) To determine sport and nonsport fish species composition and spatial and seasonal distributions.

5) To complete population estimates of sauger, goldeye and shorthead redhorse in two river sections.

6) To determine location, timing and success of spawning of important fish species in the Missouri River by sampling for incubating eggs and fish larvae.

7) To identify and monitor spawning migrations and activities of paddlefish, sauger, rainbow trout and other sport fish.

8) To determine sauger young-of-the-year abundance and locate rearing areas.

9) To tag sportfish with individually numbered tags to determine angler harvest and monitor movement patterns.

10) To determine age and growth of shovelnose sturgeon, northern pike, burbot, sauger and other fish species.

11) To investigate the food habits of some of the major sportfish species and the rainbow smelt.

12) To survey resident fish populations in the lower reaches of important tributary streams.

13) To collect a sample of resident fish for pesticides, PCB and mercury residue analyses.

14) To complete river channel profile measurements as an aid in determining instream flows.

All objectives stated above except for determination of rainbow smelt food habits were accomplished.

Food habits for rainbow smelt could not be determined because the were present in the study area in substantial numbers and duration only during one year; this year being prior to when efforts could be made to sample them. Findings of the other objectives are presented in the appropriate sections of this completion report. 


\section{TECHNIQUES}

Macroinvertebrates

Aquatic macroinvertebrate samples were collected by the traveling kick sample method. Riffle areas of the river were for a duration of about five minutes. Organisms collected were transferred to jars and preserved with 10 percent formaldehyde solution.

In the laboratory, the samples were washed on a US series No. 30 screen. Material retained by the screen was transferred to a sorting pan where the macroinvertebrates were separated from vegetation and bottom materials. Macroinvertebrates were identified to the lowest taxon practical using taxonomic keys by Edmondson (1959), Merritt and Cummins (1978), Baumann et al. (1977) and Pennak (1953). All macroinvertebrate identifications, except chironomids, were verified by $\mathrm{Dr}$. George Roemhild, Montana State University. Chironomids were identified by Mr. Daniel McGuire, Montana State University.

Zooplankton

Zooplankton samples were collected with a one ft diameter Wisconsin-type net $3.3 \mathrm{ft}$ long with 0.006 inch mesh. A detachable plankton bucket was secured to the net to allow for removal of the sample. Samples were collected in backwater pools and main channel areas and the sampling procedure varied depending upon the area where the collection was made.

The pool areas were sampled with 25 foot horizontal tows, and main channel areas sampled by positioning the net in the river current for 15 seconds. Flow velocities at the mouth of net were determined with a Price AA current meter. Sampling in the main channel was brief because of the problems associated with heavy turbidities, consequently, two samples were usually taken in these areas to compensate for the short sampling duration. The samples were transferred to collecting jars and preserved with five percent formaldehyde.

In the laboratory, samples were diluted, agitated to attain a homogenous suspension and subsamples then withdrawn using a $2 \mathrm{ml}$ Hensen-Stempel pipette. Three 2-ml samples were counted for each sample using a modified Ward plankton counter (Ward 1955). Counts and identifications were made using a dissecting microscope at $30 \mathrm{X}$ total magnification. Taxonomic keys by Edmondson (1959) and Pennak (1953) were used to identify the zooplankters, which were usually determined to genus.

Larva1 Fish

Larval fish were sampled with a $1.6 \mathrm{ft}$ diameter by $6 \mathrm{ft}$ long Nitex plankton net $(0.030$ inch mesh). A detachable plankton bucket was fastened to the net to allow for removal of the sample. Nets were towed from the bow of a boat, one on each side, for periods of 10 to 20 minutes. During 1979 and 1980 the volume of water filtered was determined with a Price AA current meter positioned near the center of the net orifice. Since the sampling was designed for survey investigations, it was felt that volume measurements during 1981 and 1982 were not warranted. 
Field samples were preserved in 10 percent formaldehyde solution to which the stain, Phloxine $B$, had been added to stain the fish larvae thereby making them more visible. Larval fish were identified using taxonomic keys by Hogue et a1. (197.6) and May and Gasaway (1967).

\section{Fish Eggs}

Fish eggs were collected using an egg basket described by Priegal (1969). The basket consists of a metal framework covered with small mesh nylon cloth. A length of wood handle is attached to the metal frame for holding the basket in position. The riverbottom substrate was agitated upstream of the basket using a wide-toothed garden rake to free eggs from the riverbottom and allow them to be washed into the basket.

Gravel bars and channel borders where known concentrations of sport fish were observed were sampled randomly at various depths up to $3.5 \mathrm{ft}$. The samples were sorted at the site and the eggs collected were measured and identified. Stizostedion sp. eggs collected from the river bottom were distinguished from those of other species by the small size (less than $2 \mathrm{~mm}$ ) as described Scott and Crossman (1973). Other early spawners, which include the white sucker, longnose sucker, shorthead redhorse and northern pike have considerably larger eggs, or do not spawn on gravel.

Adult and Juvenile Fish

The lower Missouri River is a large river and in order to accurately access the fish populations several sampling methods were necessary to accomplish the intended objectives. The following fishery sampling gear and methods were used during the study.

\section{Gil1 Nets}

Gill nets were successfully fished in areas with little or no current. Most were set in backwaters. Nets set in significant current became fouled with drifting filamentous algae and caught no fish. Nets used were $125 \mathrm{x} 6$ feet with graduated mesh size from $3 / 4$ to 2 -inch square mesh. Gill net catch rates were expressed as number of fish caught per overnight set. Floating gill nets of 4 and 5 inches square mesh, 100 feet long and 6 feet deep were drifted downstream in areas of paddlefish concentration.

\section{Baited Hoop Nets}

Baited hoop nets were set to capture channel catfish. The nets used are described in detail by Berg (1981). Basically, they consisted of four wooden hoops of 2.5 feet diameter, covered with 1.25 -inch square tarred nylon mesh. Each net had two throats and was anchored by 70 pounds of weight. A perforated rubber bait bag was attached to the bottom of the upstream hoop inside the net and filled with one to two pounds of rotten cheese. A rope with a float was attached to the downstream hoop to mark the net's location. Nets were set in a variety of water depths and current velocities to determine the type of physical habitat yielding the largest catches. Hoop net catch rates were expressed as number of fish trapped per overnight set. 
Frame trap nets were fished at various locations to determine their utility for Eish sampling. Nets consisted of two rectangular frames of lightweight conduit 4-feet high and 6.5-feet wide. Behind these were three 4-foot diameter wood hoops. Frames and hoops were covered with one-inch square mesh tarred nylon netting. A 4-feet high and 50-feet long lead was attached to the front hoop. This also had one-inch square mesh.

Nets were set in areas lacking current with the lead placed upstream or cownstream. The lead was sufficiently weighted so that both trap and lead sank in water deeper than the net.

\section{Seines}

Young-of-the-year (YOY) fish were sampled with a $100 \mathrm{x} 10 \mathrm{ft}, 0.25$ inch beach seine. The seine was operated by two persons and worked in as many different habitats as the current and bottom features allowed. Fish collected were identified, and associated habitat type was recorded. All comparisons between study areas or habitat types for fish sampled by seining were based on catch per unit effort. A unit of effort was accomplished by dragging the seine 15-30 yds through an area.

\section{Electrofishing Apparatus}

The electrofishing system used was described by Peterman (1978). The electrofishing apparatus was mounted on a 14-foot fiberglass boat powered by a 25-horsepower outboard motor. Power was supplied by a 3500 watt AC generator. The alternating current was delivered to a Coffelt Model VVP-10 rectifying unit which changes the alternating current to pulsed or continuous direct current. The positive electrode consisted of two circular hoops with 12- to 16-inch stainless steel "droppers" fastened on each hoop. These electrodes were supported by fiberglass booms and were positioned about 6 feet in front of the boat. The negative electrodes were 2 to 4 feet lengths of flexible steel conduit suspended from the side of the boat. The unit was typically operated at 7-12 amps, 125-175 volts, 50\% pulse width and a pulse frequency of 50-100 pulses per second. Electrofishing catch rates were expressed as number of fish sampled per hour.

In 1979, paddlefish were captured and counted during electrofishing runs in which other species were also collected, weighed, measured and tagged. During the following years, separate counting runs were made for paddlefish so that electrofishing could be done exclusively in the habitat usually favored by this species. Separate electrofishing runs were also made to capture paddlefish for length and weight measurements and tagging.

\section{Fish Sample Processing and Tagging}

Fish captured by various methods were weighed to the nearest 0.01 pound if the weighed less than 5 pounds. Fish weighing over 5 pounds or more were weighed to the nearest 0.1 pound except paddlefish which were weighed to the nearest pound. Only total length was measured. Fish were measured to the 
nearest 0.1 inch if less than 3 feet total length, or to the nearest inch if over 3 feet.

Sauger, walleye, northern pike and trout were tagged with individually numbered Floy "T-tags" inserted with a tagging gun. Tags were placed just under the dorsal fin. Floy "cinch-up" tags were used for tagging channel catfish, shovelnose sturgeon and burbot. The tag was placed under the posterior part of the dorsal fin on sturgeon and burbot, and under the adipose fin on channel rarfish. A 0.5 inch, individually numbered metal band was clamped to the lower jaw of paddlefish.

\section{Fish Population Estimates}

Because of the large size of the Missouri River and the difficulty of sampling substantial numbers of fish, a multiple census technique was used to mark and recapture enough fish to obtain population estimates. A modified Schnabel census method (Ricker 1975) was used to estimate the population.

$$
\begin{aligned}
& N=\sum B_{t}+\sum\left(m_{t} c_{t+1}\right) \\
& \sum r_{t}
\end{aligned}
$$

Where: $\mathrm{N} \quad$ population estimate

$$
\begin{aligned}
& \mathrm{m}_{\mathrm{t}}=\text { number of marked fish in sample after run } \mathrm{t} \text { (initial marking run) } \\
& \mathrm{C}_{\mathrm{t}+1}=\text { number of fish in sample after run } \mathrm{t}+1 \text { (lst recap run) } \\
& \mathrm{r}_{\mathrm{t}+1}=\text { number of marked fish recaptured after run } \mathrm{t}+1 \\
& \mathrm{~B}_{\mathrm{t}}=\text { number of fish removed prior to lst recapture run }
\end{aligned}
$$

With this methodology fish were marked and recaptured concurrently. Eight to ten electrofishing trips were made through each river section. Tagging or partial fin clips were used for future recognition.

\section{Age and Growth}

Most fish were aged from plastic scale impressions made from field collected fish scales. Shovelnose sturgeon were aged from sectioned pectoral fin rays. The process involved cutting a 0.02 -inch section about 0.4 inches from the base of the articulation using a dremel saw arranged similar to that described by Witt (1961). These sections were immersed in a five percent solution of hydrochloric acid for partial decalcification. The sections were washed in tap water and placed in glycerin between two microscope slides. Annuli appeared as narrow, translucent single or banded lines, similar to that reported by Roussow (1957) and Cuerrier (1951). Scale and spine samples were projected at $66 \mathrm{X}$ on a Northwest NMI 90 microfiche reader. Calculations of length at previous annuli for sauger, only, were made using a modified version of FIRE I (Hesse 1977), a fisheries statistic program.

Burbot were aged from the large otolith by a procedure similar to that described by Clemens (1950). The otolith was removed in the field immediately after killing the fish and placed in a three percent solution of trisodium 


\section{Food Habits}

Food habits were determined for adult shovelnose sturgeon, burbot and sauger. To study the food habits of shovelnose sturgeon, some burbot and YOY sauger, the entire stomach was collected and stored in 10 percent solution of formaldehyde. For sauger and burbot the stomach contents were collected by massaging the stomach with a slow pulsating pressure, causing the fish to regurgitate the contents. Stomach contents were identified in the laboratory. For larger burbot and sauger, which usually contained only one or a few large food items, identification of stomach contents was usually made in the field.

\section{Instream Flow Assessment}

To evaluate instream flows necessary for maintenance of important fish habitat areas in the Missouri River, the wetted perimeter (WETP) hydraulic simulation computer program was employed. The WETP computer program develops a stage-discharge relationship using field measurements taken at three different river flows. This program was not only used to determine wetted perimeter values at varying flows, but also was used to predict river stage height at various flows. River stage height was an important consideration for this study because both rearing and spawning sites for sauger depended on proper water levels. This program is described in detail by Nelson (1984). Using standard surveying techniques, water surface elevations at three discharges were measured with a level and rod. Channel profiles were measured using a range finder and fathometer in conjunction with the level and rod. 
The 183-mile reach of the Missouri River covered by this study is still in a semi-natural state, although flows are completely regulated by Fort Peck Reservoir (Figure 1). The dam, completed in 1937, is the uppermost dam of the six mainstem impoundments on the Missouri River. Flood control, navigation and hydropower are its chief purposes, however, the Water Resources Development Act of 1986, Section 861 has made a provision that another recognized purpose of the Fort Peck project is to provide recreation. Releases to the river are from the hypolimnion, 185.5 feet below the surface of the reservoir at full pool. The 185 megawatt hydropower unit is presently operated as a combined baseload and peaking plant, with the amount of peaking depending on water availability and electrical power marketing. The operation of Fort Peck Dam restructures the normal seasonal flow pattern of the river by storing the high spring run-off flows and augmenting summer and winter flows. Normal, naturally occurring, biological and hydrological features which depend upon the seasonal high flow period have been affected by these altered flow patterns. Montana Fish, Wildlife and Parks has rated the entire lower Missouri River as value Class I, the highest value fishery resource. This reach is valued at the highest degree because of the presence of a viable paddlefish population, known occurrence of pallid sturgeon, sicklefin chub and shortnose gar three other fish "species of special concern" (Holton 1980) and good populations of sauger and shovelnose sturgeon.

The river immediately below the dam is clear and cold, very much unlike the warm and turbid middle Missouri River which flows into Fort Peck Reservoir 134 miles upstream. The Milk and Poplar rivers, two of the larger tributary streams entering the Missouri downstream of the dam, contribute to restoring some of the prairie river characteristics by increasing both water temperatures and turbidities to more natural levels.

There is not any appreciable amount of artificial channel stabilization in this reach and the river is free to meander over wide limits. Off-channel riverine features are fairly prevalent except in a 10-mile section immediately below the dam where bank erosion is excessive.

The river's course in the study area has largely been determined by past continental glaciation. Generally, the topography on the north side varies from rolling hills to flat plains, contrasting with the south side which is bordered by rough badlands. The river floodplain upstream of Brockton is relatively wide, averaging 4 miles, and is a result of the valley being underlain with weak Bearpaw shale. Downstream of Brockton the floodplain narrows noticeably, resulting from continental glaciation forcing the river south into the more structured Fort Union formation (Swenson 1955). Below Culbertson the valley narrows into a 15-mile canyon averaging 1 mile wide. Here the colorful badlands flank both sides of the river, towering nearly 500 feet above the Missouri.

Eight study sections were established on the mainstem Missouri in the study area (Figure 2 and 3). All these sections except Fort Peck Dam were combined into three reaches to facilitate data interpretation. Table 1 describes the locations, lengths and gradients of each section.

The Fort Peck Dam section is a 10.7-mile reach that has been substantially altered by the operation and construction of the dam. There is a paucity of 


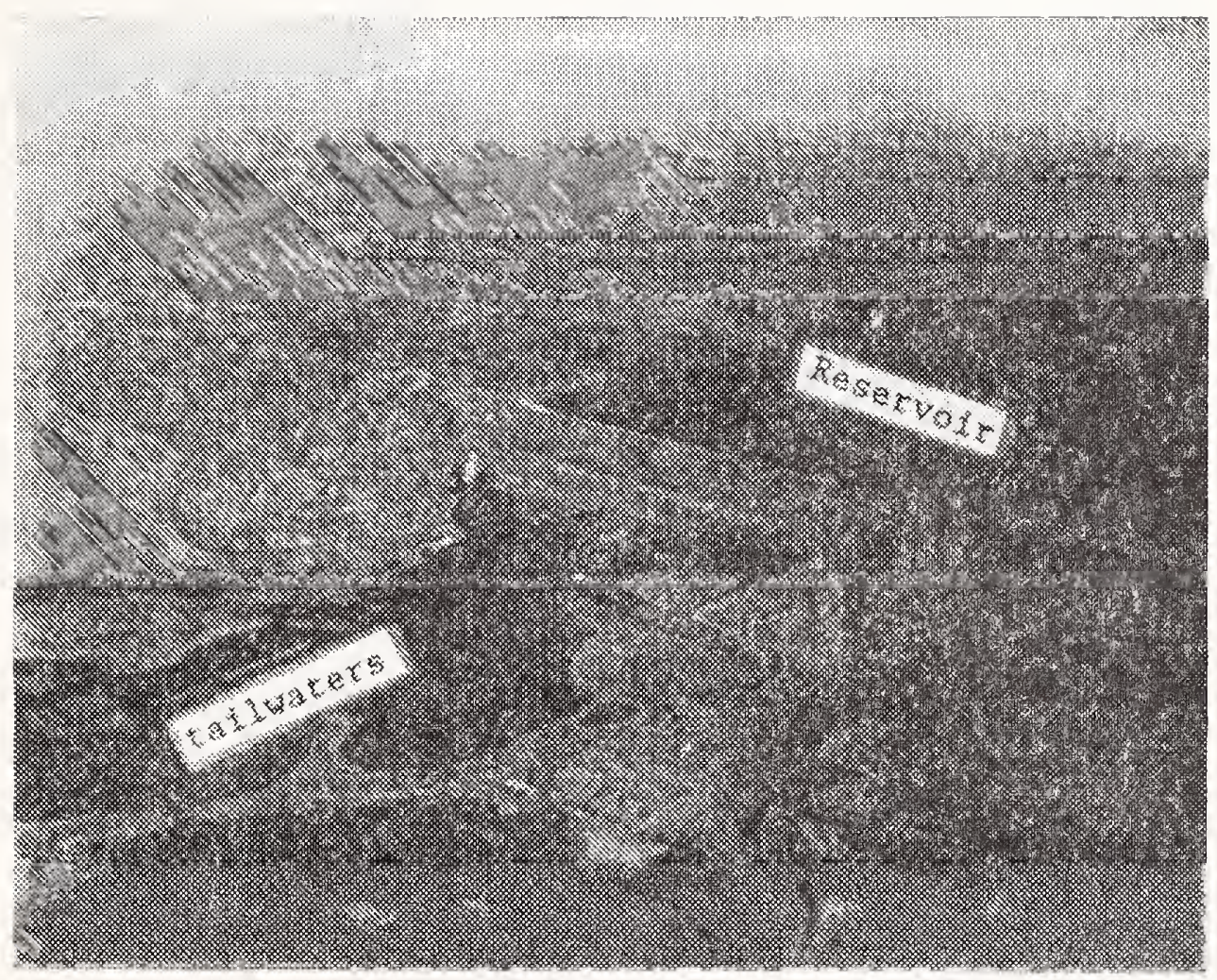

Figure 1. Fort Peck Dam completed in 1936 impounds about 19 million acre-feet of water and completely regulates flows in the lower Missouri River. 


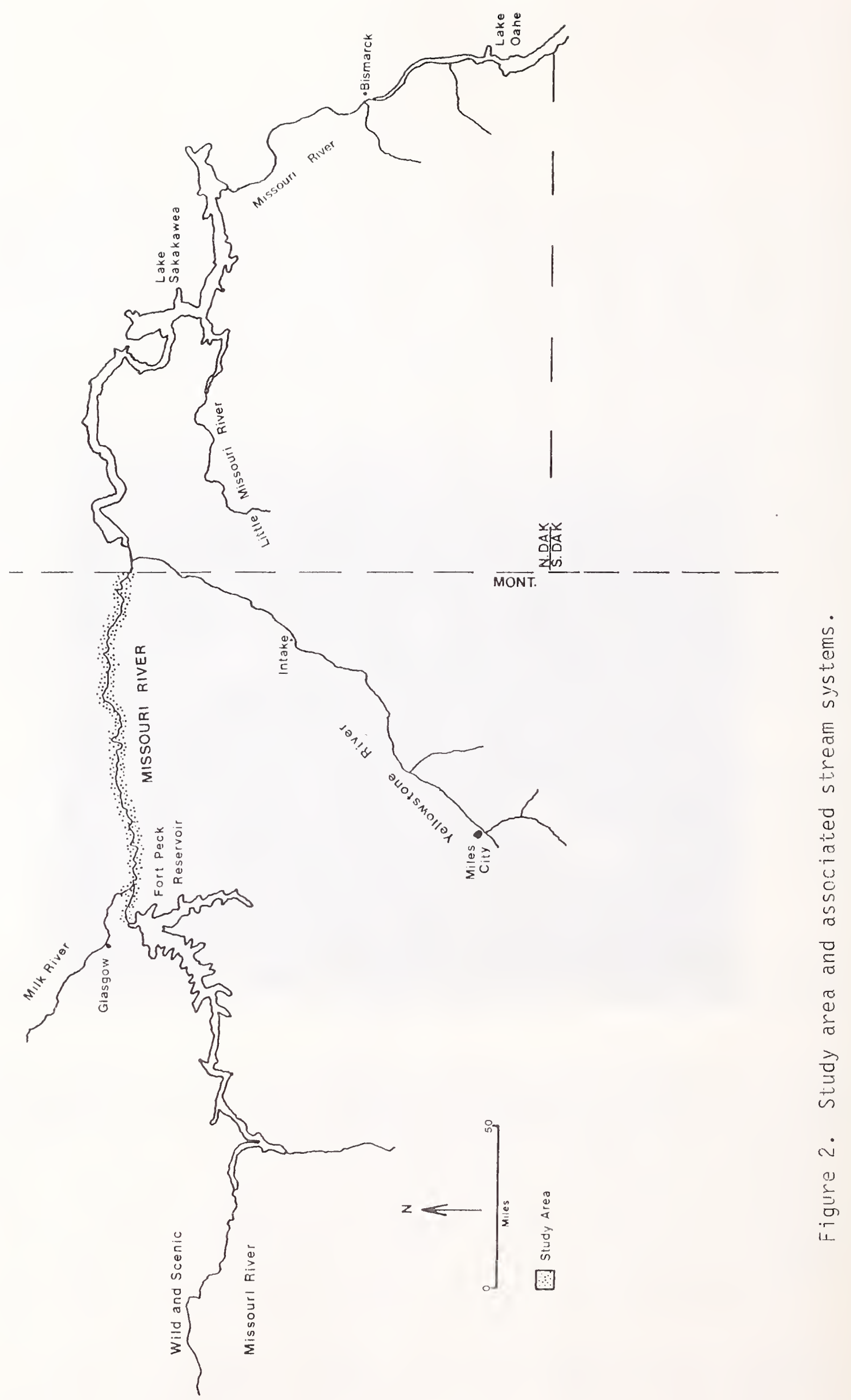




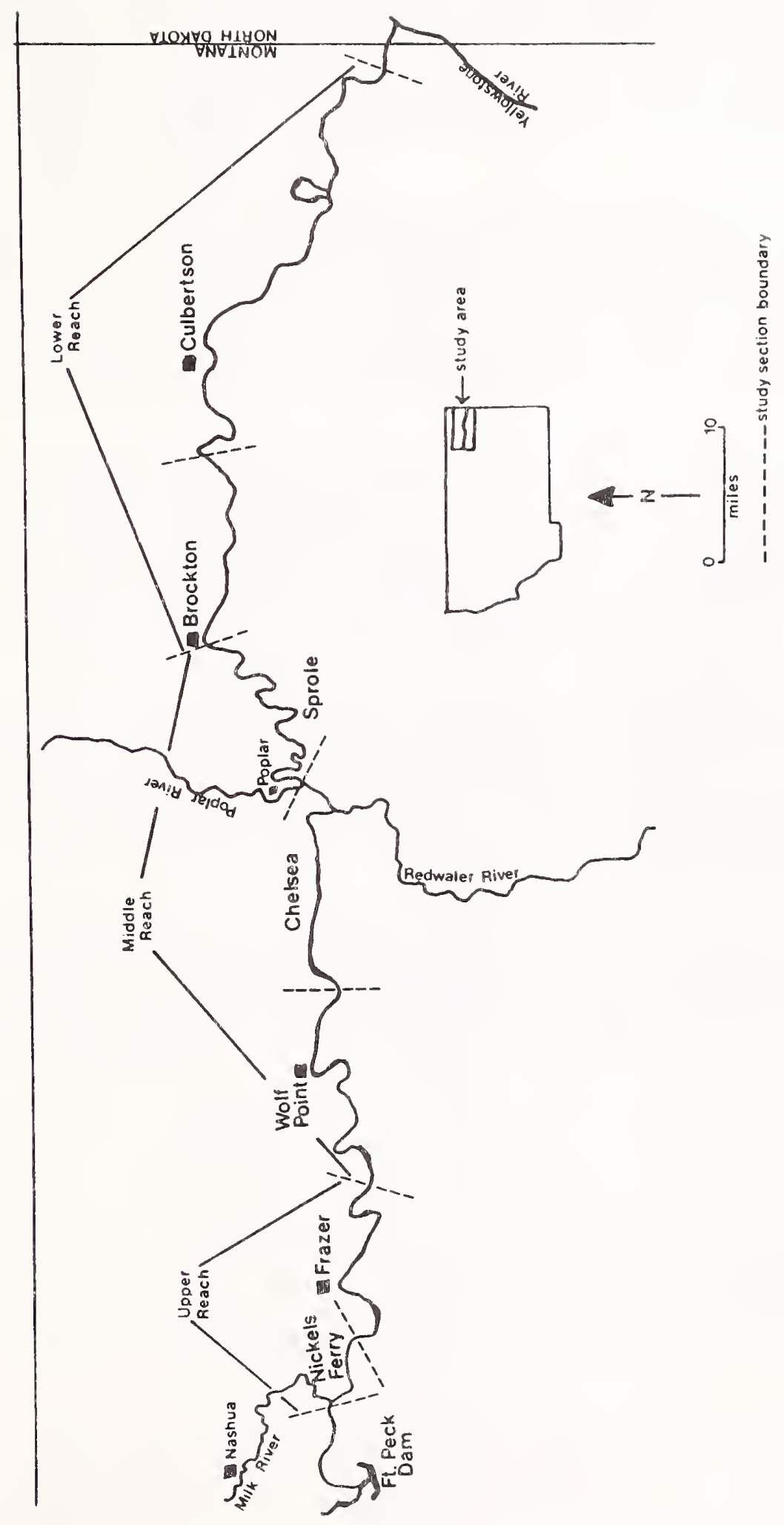

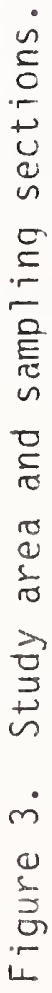


Table 1. Study section locations and gradients of the lower Missouri River from Fort Peck Dam to near the state border.

\begin{tabular}{|c|c|c|c|c|}
\hline $\begin{array}{l}\text { STUDY } \\
\text { SECTJON }\end{array}$ & $\begin{array}{l}\text { SITES WITHIN } \\
\text { SECTION }\end{array}$ & $\begin{array}{l}\text { RIVER } \\
\text { MILE }\end{array}$ & $\begin{array}{l}\text { LENGTH }(\mathrm{mi}) \\
\text { OF } \\
\text { STUDY SECTION }\end{array}$ & $\begin{array}{l}\text { Average } \\
\text { GRADIENT } \\
\text { (FT/MI) }\end{array}$ \\
\hline Fort Peck Dam & $\begin{array}{l}\text { Fort Peck Dam } \\
\text { Upper Dredge Cuts } \\
\text { Nelson Dredge Cuts } \\
\text { USGS Gage House } \\
\text { Spil1way } \\
\text { Milk River }\end{array}$ & $\begin{array}{r}.0 \\
1.6 \\
6.2 \\
8.6 \\
9.5 \\
10.7\end{array}$ & 10.7 & 0.9 \\
\hline $\begin{array}{l}\text { Nickels } \\
\text { Ferry }\end{array}$ & $\begin{array}{l}\text { Milk River } \\
\text { Wiota Pump }\end{array}$ & $\begin{array}{l}10.7 \\
27.3\end{array}$ & 16.6 & 0.6 \\
\hline Frazer & $\begin{array}{l}\text { Wiota Pump } \\
\text { Prairie Elk } \mathrm{Cr} \text {. }\end{array}$ & $\begin{array}{l}27.3 \\
49.5\end{array}$ & 22.2 & 1.4 \\
\hline Wolf Point & $\begin{array}{l}\text { Prairie E1k Cr. } \\
\text { Wolf Point } \\
\text { Highway } 13 \mathrm{Bdg} \text {. }\end{array}$ & $\begin{array}{l}49.5 \\
64.7 \\
70.2\end{array}$ & 20.7 & 0.7 \\
\hline Chelsea & $\begin{array}{l}\text { Highway } 13 \text { Bdg. } \\
\text { Chelsea Slough } \\
\text { Redwater River } \\
\text { Poplar River }\end{array}$ & $\begin{array}{l}70.2 \\
75.5 \\
85.7 \\
86.8\end{array}$ & 16.6 & 1.5 \\
\hline Sprole & $\begin{array}{l}\text { Poplar River } \\
\text { Sprole Bridge } \\
\text { Brockton }\end{array}$ & $\begin{array}{r}86.8 \\
101.9 \\
116.9\end{array}$ & 30.1 & 0.8 \\
\hline Brockton & $\begin{array}{l}\text { Brockton } \\
\text { Big Muddy Cr. }\end{array}$ & $\begin{array}{l}116.9 \\
141.2\end{array}$ & 24.3 & 0.7 \\
\hline Culbertson & $\begin{array}{l}\text { Big Muddy Cr. } \\
\text { Culbertson } \\
\text { Highway } 16 \text { Brdg. } \\
\text { Nohly Bridge }\end{array}$ & $\begin{array}{l}141.2 \\
149.3 \\
150.8 \\
182.6\end{array}$ & 41.2 & 0.8 \\
\hline
\end{tabular}

$303 / 8.1$ 
instream and bank cover. The clear water discharges from the reservoir are erosive and, inspite of the low gradient, are responsible for maintaining the gravelly substrate found throughout the area. Other significant features in the section are the two-mile-long side channel 2 miles below the dam, the 660-acre upper dredge cut and the 200-acre Nelson dredge cut ponds located 1.6 and 6.2 miles downstream from the dam. The dredge cuts, artifacts from the dam construction, are lake-type habitats and their water levels are affected by the flow in the river.

Nickels Ferry and Frazer study sections constitute about 40 miles of river and are collectively referred to as the upper reach of the study area. The upper end begins at the confluence of the Milk River, which has a major influence on the Missouri River downstream. Average stream gradients range from $0.6-1.4 \mathrm{ft} / \mathrm{mi}$, yet, inspite of these lower gradients there are numerous gravelly riffle areas.

The middle reach of the river consists of Wolf Point, Chelsea and Sprole sections and is 68 miles long. The river in this section appears to regain a more natural appearance, shifting from an erosional to a more depositional nature. River turbidities increase in this reach and sand bars are more common, coinciding with the general loss of gravelly riffles. A few old oxbow channels are evident in the large flood plain of cottonwoods and willows.

The 66 miles of the Brockton and Culbertson sections, the lower reach, completes the length of the study area. A recently-formed oxbow lake is still active during high water years and huge shifting sand bars are common. About 4 miles below the end of the study area, the Yellowstone River enters with the Missouri which flows about 5 more miles until it enters Lake Sakakawea Reservoir.

A longitudinal profile of the lower Missouri River, as well as those from the Missouri and Yellowstone rivers are presented in Figure 4. A comparison indicates the considerable difference in gradient between the lower Missouri and the other two stream reaches. 


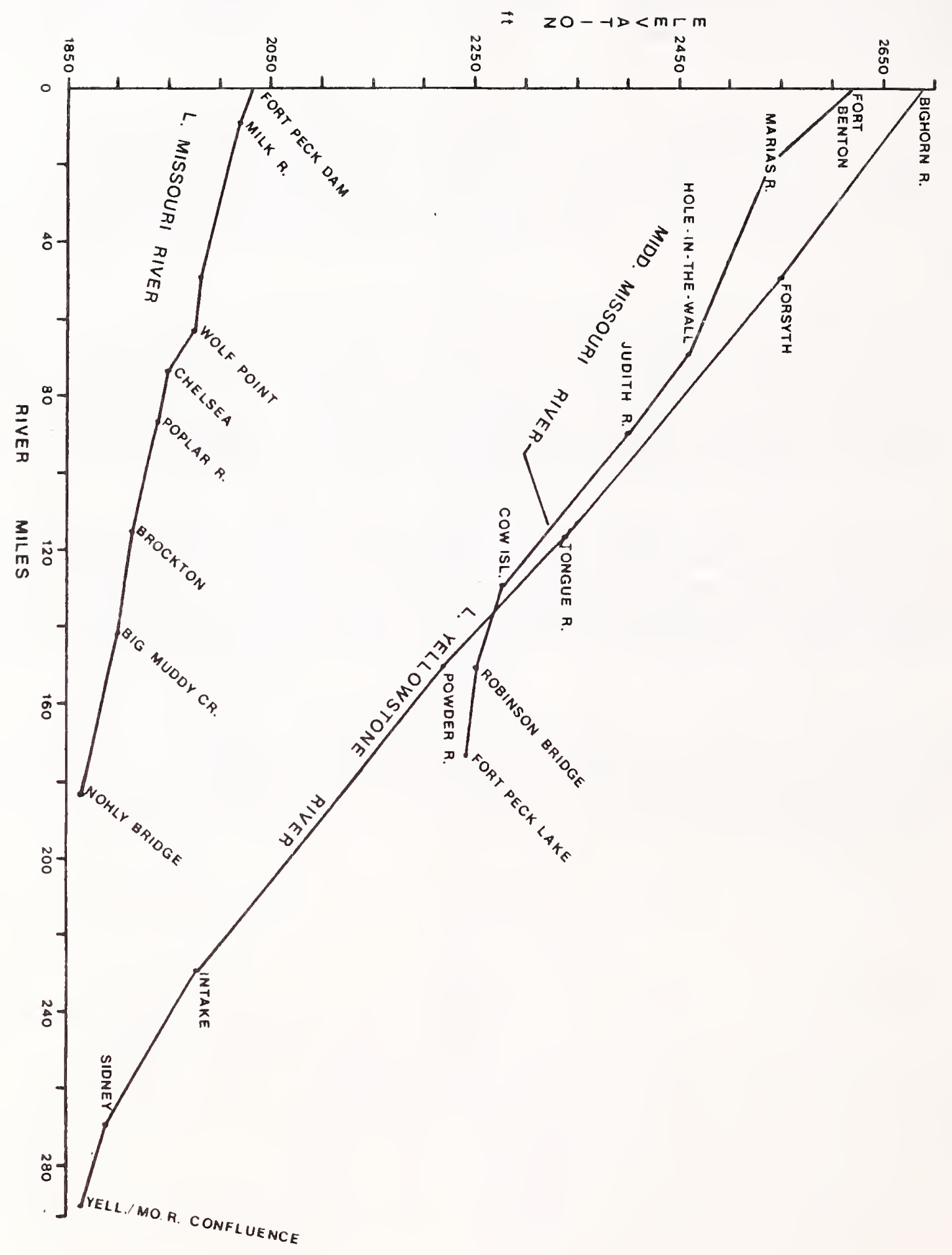

Figure 4. Longitudinal profile of the lower Missouri River stream gradient in comparison to the middle Missouri and Yellowstone Rivers. 
Physical and chemical features of the river

Basic knowledge of the physical and chemical environments of the Missouri River and its major tributary streams is essential for a better understanding of the aquatic ecology. Physical and chemical water analyses offers a more complete understanding of the ecosystem components and can often suggest explanations concerning the distribution and abundance of the aquatic organisins. The following data is a summary of information largely collected by the U.S. Geological Survey (USGS) and used in this report for descriptive background purposes.

\section{Annual flow patterns}

Flow patterns during this study varied significantly between years. Table 2 depicts the seasonal patterns for the Missouri (at Wolf Point) and Milk (at Nashua) rivers. The Missouri's flow pattern is typical of a river controlled by a large dam. Generally, the lower flows were recorded in the spring and higher flows occurred later in the fall and winter. Water run-off in the drainage was substantially above normal during 1979 and 1982. Highest monthly flows occurred during the spring months for both these years. Fluctuation in water releases from the dam due to the hydroelectric peaking operation are common, and sudden changes up to 12,000 cfs (from 3,000 to $15,000 \mathrm{cfs}$ ) in one hour occur sporadically (Frazer 1985). These fluctuations are dampened at downstream points as illustrated in Table 3 .

The Milk River exhibited below normal run-off during 1980, 1981, 1983 and 1984 (Table 2). Like the Missouri, the years 1979 and 1982 were above normal in run-off. The Milk River exhibits a natural run-off pattern and the two impoundments on that stream have minor affects on the spring flow regime during normal water years.

The Milk River is the largest of the tributary streams in the study area. It has an average annual discharge of 694 cfs. Comparatively, the Poplar and Redwater rivers (the second and third largest rivers) have average annual discharges of 134 and $48 \mathrm{cfs}$, respectively. (USGS 1982). Spring-time peak flows in the Missouri River are stored in Fort Peck Reservoir. As a result, the Milk River discharge is often a significant portion of the Missouri River's flow during the spring. Median Milk River flows during April through June average $10.3 \%$ that of the Missouri (USGS 1984).

The smaller tributary streams in the study area can, at times, discharge large quantities of water during the spring. Table 4 lists the high flows recorded for these streams during two of the wettest years for the study period. The June maximum flow illustrates the effects of springtime precipitation on stream flows. It is evident that these tributary streams have a significant effect on the Missouri River flow during certain periods.

Temperatures

The entire length of the Missouri River from Fort Peck Dam to the North Dakota border is affected by the discharge of relatively cold water from Fort Peck Reservolr. Monthly average water temperatures below the dam reach a 


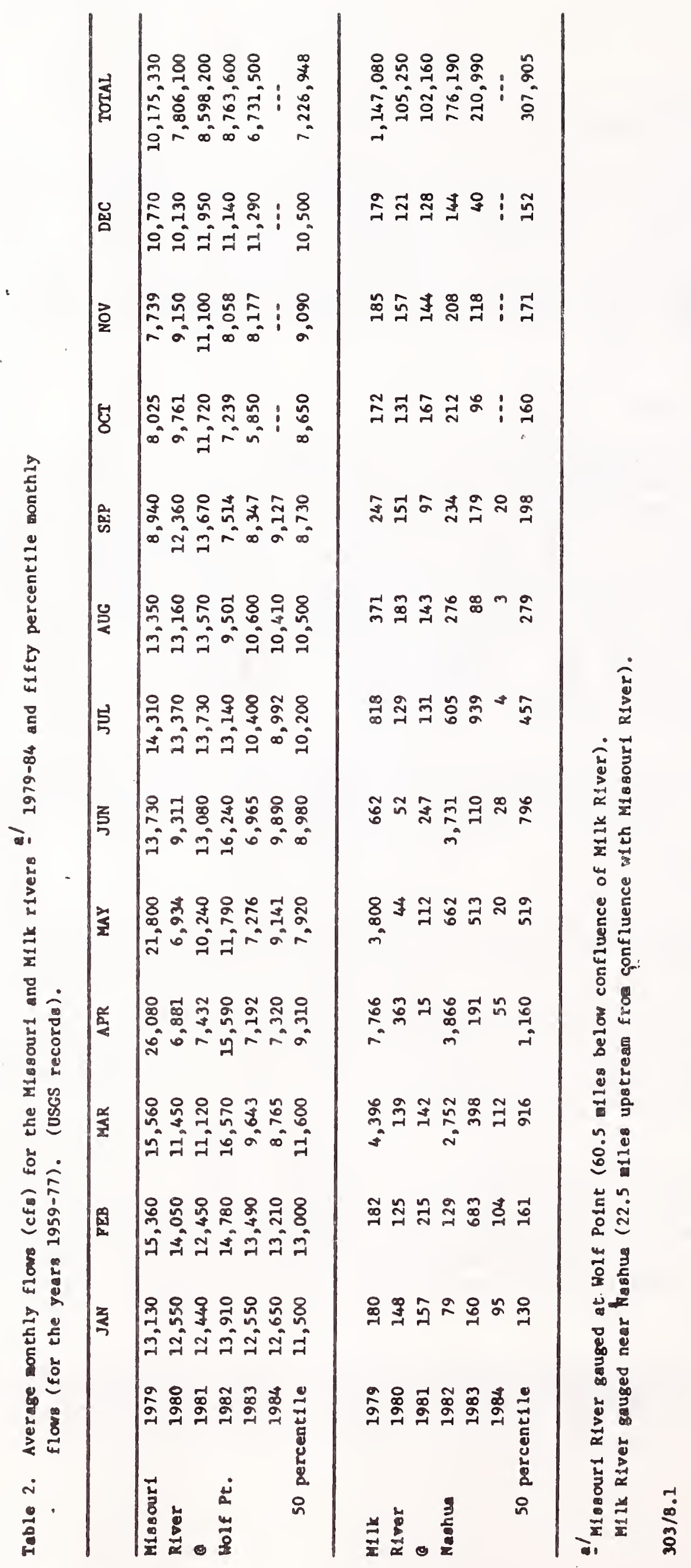


Table 3. Comparisons of daily river stage fluctuations between three USGS stream gauging stations on the lower Missouri River during a nine day period in August, 1985. (Range values are in parentheses). (USGS unpub1. data). (Note; stream transit times were applied for analysis).

\begin{tabular}{lcc}
\hline $\begin{array}{c}\text { Stations } \\
\text { Fort Peck Dam } \\
(\text { RM-7) }\end{array}$ & $\begin{array}{c}\text { Average Fluctuations } \\
\text { (feet) }\end{array}$ & $\begin{array}{c}\text { Average Flow } \\
\text { (cfs) }\end{array}$ \\
$\begin{array}{c}0.94 \\
\text { Wolf Point } \\
(\text { RM-70) }\end{array}$ & $(0.84-1.06)$ a / & 11,278 \\
$\begin{array}{l}\text { Cubertson } \\
(\text { RM-151) }\end{array}$ & 0.51 & $(10,800-11,800)$ b/ \\
& $(0.36-0.69)$ & 10,656 \\
& 0.37 & $(10,000-11,200)$ \\
\hline
\end{tabular}

$\frac{a}{b} /$ Range of daily fluctuation values for the nine example days.

$\underline{b} /$ Range of average daily flows during the example period.

$303 / 8.1$ 
Table 4. June maximum and annual maximum flows (cfs) of major tributary streams in the lower Missouri River basin. Data is for the two highest surface run-off years during the study period. (USGS 1979 and 1982).

STREAM

Prairie Elk Cr.

(near mouth)

Wolf Creek

(near mouth)

Redwater River

(31 miles above mouth)

Poplar River (at Poplar 11 miles above mouth)

Big Muddy Creek (at Antelope 111.5 miles above mouth)

\begin{tabular}{ll}
\multicolumn{2}{c}{1979} \\
\hline JUNE & ANNUAL MAXIMUM \\
MAXIMUM & AND DATE \\
\hline
\end{tabular}

4.5

996 - Apr 9

$-$

76

$8,230-\operatorname{Apr} 10$

43

3,000 - Feb 23

164

$5,800-\operatorname{Apr} 11$

1,090

$12,700-\operatorname{Apr} 16$

516

$2,740-$ Apr 20

340

1982

JUNE ANNUAL MAXIMUM
AND DATE

21

1,300 - Feb 23

26

1,020-Mar 28

3

3


maximum of $54 \mathrm{~F}$ in late summer and early fall (Table 5). Temperature records from a continuous recorder located near Wolf Point recorded maximum instantaneous daily temperatures of on $1 \mathrm{y} 65,66,66$ and $67 \mathrm{~F}$ for the years 1980, 1982,1983 and 1984, respectively (USGS). For these years the greatest monthly average temperature was $62.6 \mathrm{~F}$ (Appendix Tables 1-4). No temperature data are available before construction of Fort Peck Dam, but an examination of temperature data for the Missouri River near the headwaters of the reservoir and the Missouri River near Culbertson (151 river miles downstream from the dam) shows that river temperatures average $6.0 \mathrm{~F}$ colder at the downstream point (average of $67 \mathrm{~F}$ at Robinson Bridge vs average of $61 \mathrm{~F}$ at Culbertson) for the months of June through September. The average Missouri River temperatures for the same period below Fort Peck Dam and near Wolf Point was 52.5 and $58.8 \mathrm{~F}$, respectively. Without Fort Peck Dam, mean summer river temperatures near Culbertson should be similar to those recorded above the reservoir. It was evident that the Missouri River fails to completely equilibrate with ambient summer air temperatures through the 151 river miles from Fort Peck Dam to Culbertson.

The Milk River enters the Missouri 10 river miles downstream from Fort Peck Dam. It is somewhat warmer summer-time temperatures than the Missouri River upstream from the reservoir (Table 5) and is considerably warmer than the Missouri below the dam. During the spring when the flow of the Milk is relatively large, the warm water of the Milk forms a plume and mixes slowly with the cold clear water of the Missouri River. This results in a "two rivers" situation downstream from the Milk's confluence, with a warm turbid "river" on the north side of the channel and a cold clear "river" on the south side. Instantaneous temperatures taken on May 22, 1979 illustrate this occurrence. Two miles downstream from the confluence the water temperature was $56 \mathrm{~F}$ near the north bank (Milk River side) and $38 \mathrm{~F}$ near the south bank. The warming effects caused by the Milk River probably persist for at least 10 miles below the confluence as evidenced by the persistence of the Milk's turbid plume. This can have a major influence on the river fishery.

\section{Turbidities}

Fort Peck Dam greatly reduces the turbidity in the Missouri River (Table 6). Turbidities average in the single digits below the dam and the spring peak turbidities are eliminated. Unlike temperature, turbidities in the downstream areas probably return to normal values. The Milk River has average turbidities greater than at either locations indicated for the Missouri River (Table 6). Like it did for temperatures, the Milk River similarly creates a unique turbidity situation in the confluence area. When Milk River flows are 100 cfs or greater, a noticeable turbid plume on the north bank exists for about 10 miles downstream. The extent of the plume depends upon the river's flows. This situation has a major influence on the river fishery. Excessive erosion of the river channel banks also has a major influence on increasing the river turbidities.

Water chemistry

Basic water chemistry parameters for the Missouri, Milk and Poplar rivers are presented in Table 7. Data from the 1982 water year (a more typical run-off year) is given as an indication of the water quality of these rivers. The Missouri is characterized as a calcium bicarbonate type stream in contrast to 


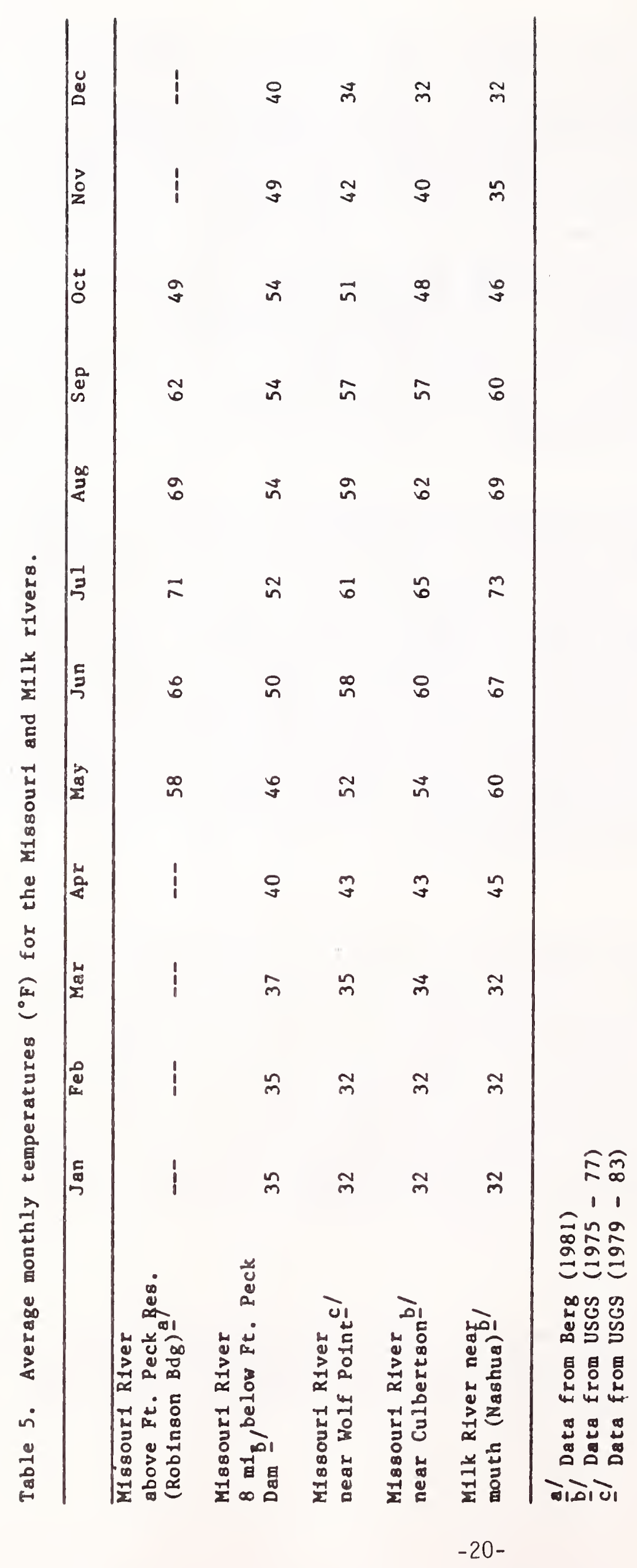




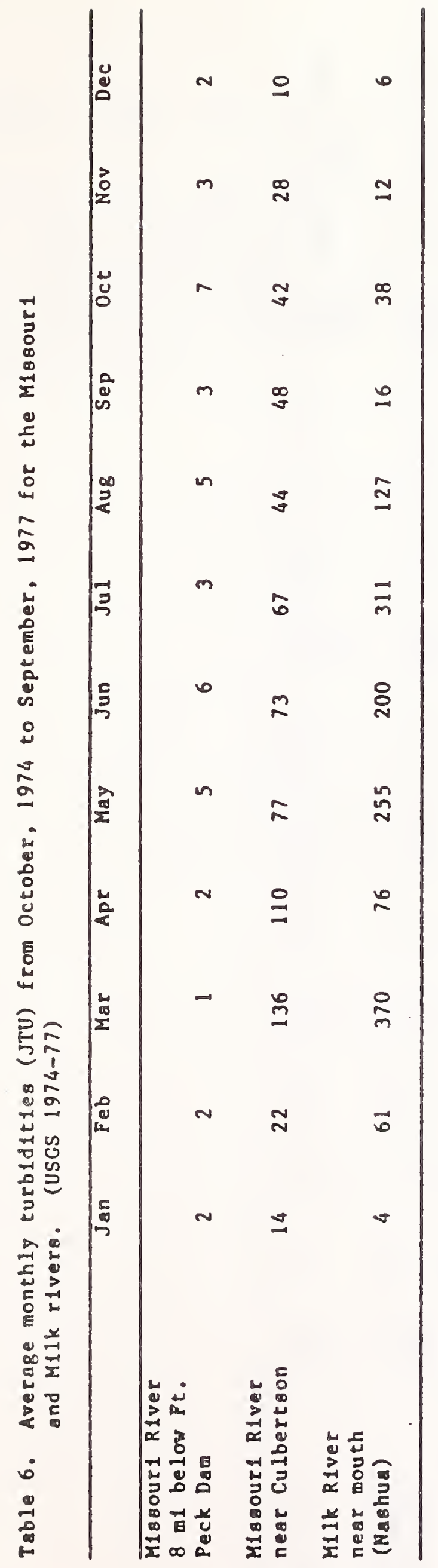




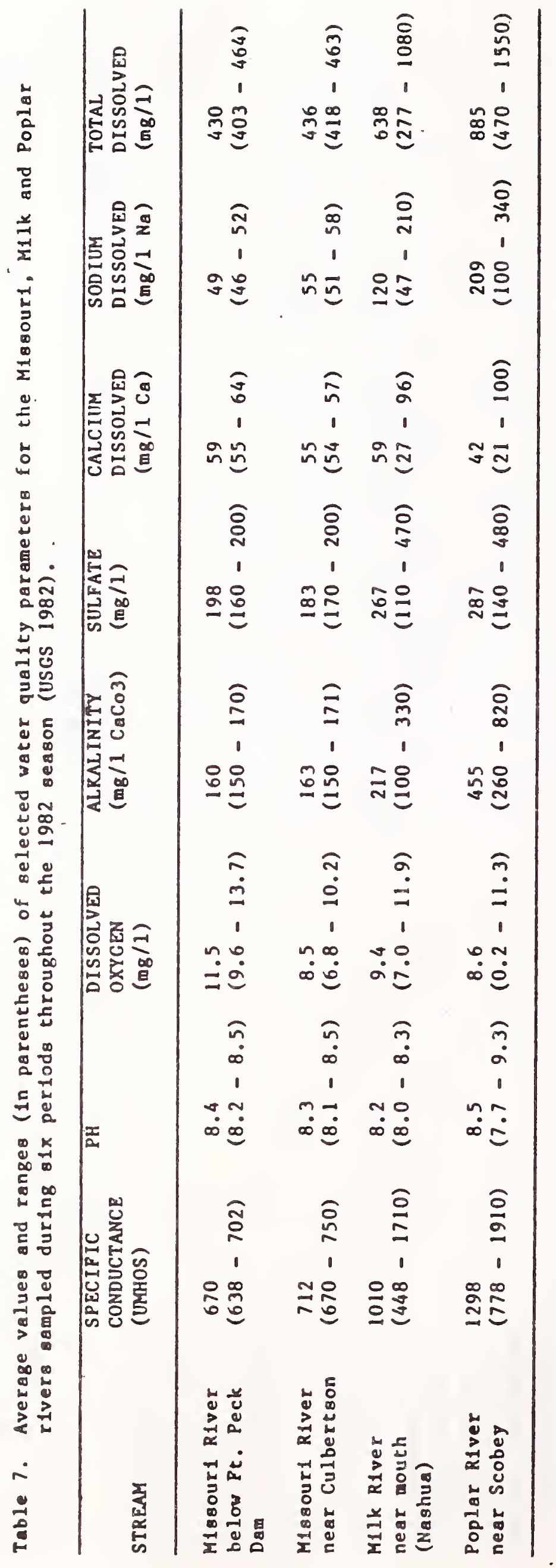


the Milk and Poplar rivers which are sodium bicarbonate type streams. The latter two rivers also exhibited much higher total dissolved solids.

Dissolved oxygen (DO) values for the rivers tested (except the Poplar) always remained within a range favorable for all life stages of the various fish species present. Highest values were recorded consistently in the Missouri near Fort Peck Dam. This was most likely related to the cold water releases from the dam and the moderate amount of riffle areas which help to aerate the water. The low $D O$ value of $0.2 \mathrm{mg} / 1$ in the Poplar River was recorded January 16 at our flow was estimated flow of $0.5 \mathrm{cfs}$. 
An investigation of the macroinvertebrate communities was conducted for a more comprehensive understanding of the river's aquatic ecosystem. General inventory information is important for describing distribution and abundance of macroinvertebrate species. A description of the macroinvertebrate communities also provides baseline information for evaluating existing river conditions and crables comparisons in later years. Knowledge of the macroinvertebrate communities also provides insight into the food web. Food habit studies have shown the importance of macroinvertebrates for such fish as shoveinose sturgeon, channel catfish, burbot and goldeye (Elser et al. 1977 and Gardner and Berg 1982).

Aquatic macroinvertebrate sampling was conducted at five sites on the lower Missouri River from March 24, 1981 through June 28, 1982. The sites were located at the Fort Peck Dam tailwaters area, near the Wiota Pumping Station, and near the Highway \#13, Highway \#16 and Nohly Bridge sites. Gravelly riffles were uncommon below Highway 非13, however, suitable sections of gravelly riffles were located for sampling at the lower sites.

Traveling kick samples were taken at all sites four different times; once each during spring, summer and fall of 1981 and again in the spring of 1982. Macroinvertebrate drift samples were also collected in conjunction with larval fish sampling during the spring of 1981-82. The drift nets were "fished" for 10 minutes. Results from the drift samples were not reported here because samples collected considerably lower total numbers and varieties of macroinvertebrates. Also, there were not any additional taxa collected in the drift which were not already collected in the kick samples.

\section{Ordinal composition}

A total of 5,312 aquatic macroinvertebrates, representing 12 orders and at least 26 families, was collected during the study. The number of macroinvertebrates collected per traveling kick sample ranged from 29 to 1986 (Appendix Tables 5-9). At the lower three sampling sites, Ephemeroperta, Trichoptera, Plecoptera and Diptera comprised an average of 55.6, 18.4, 15.6 and 7.7 percent of macroinvertebrates collected, respectively (Table 8). At the tailwaters site, about 2 miles below Fort Peck Dam, the ordinal composition was strikingly different from the downstream sites. Here, the orders Diptera, Ephemeroptera and Trichoptera comprised an average of $83.8,7.0$ and 1.0 percent of the macroinvertebrates collected, respectively. Wiota Pump Station, the sampling site located between the previously mentioned sites, had an ordinal composition intermediate between those two extremes. Community diversity exhibited a trend of less subordinal taxa numbers at the tailwaters site (average of 4.7) compared to greater subordinal taxa numbers (average of 10.5) at a lower site, Highway \#16 (Table 9). Total number of subordinal taxa for each site exhibited this same pattern. The differences were largely because of the greater Ephemeroptera and Trichoptera diversities at the downstream sites. Table 10 illustrates the distribution and relative abundance of macroinvertebrates collected at each sampling site.

Plecoptera (Stoneflies). The numerical percentage of stoneflies, averaging samples from all sampling dates, ranged from 0 at the tailwaters site to $29.2 \%$ at Nohly Bridge. Average numbers of subordinal taxa ranged from 0 at the 


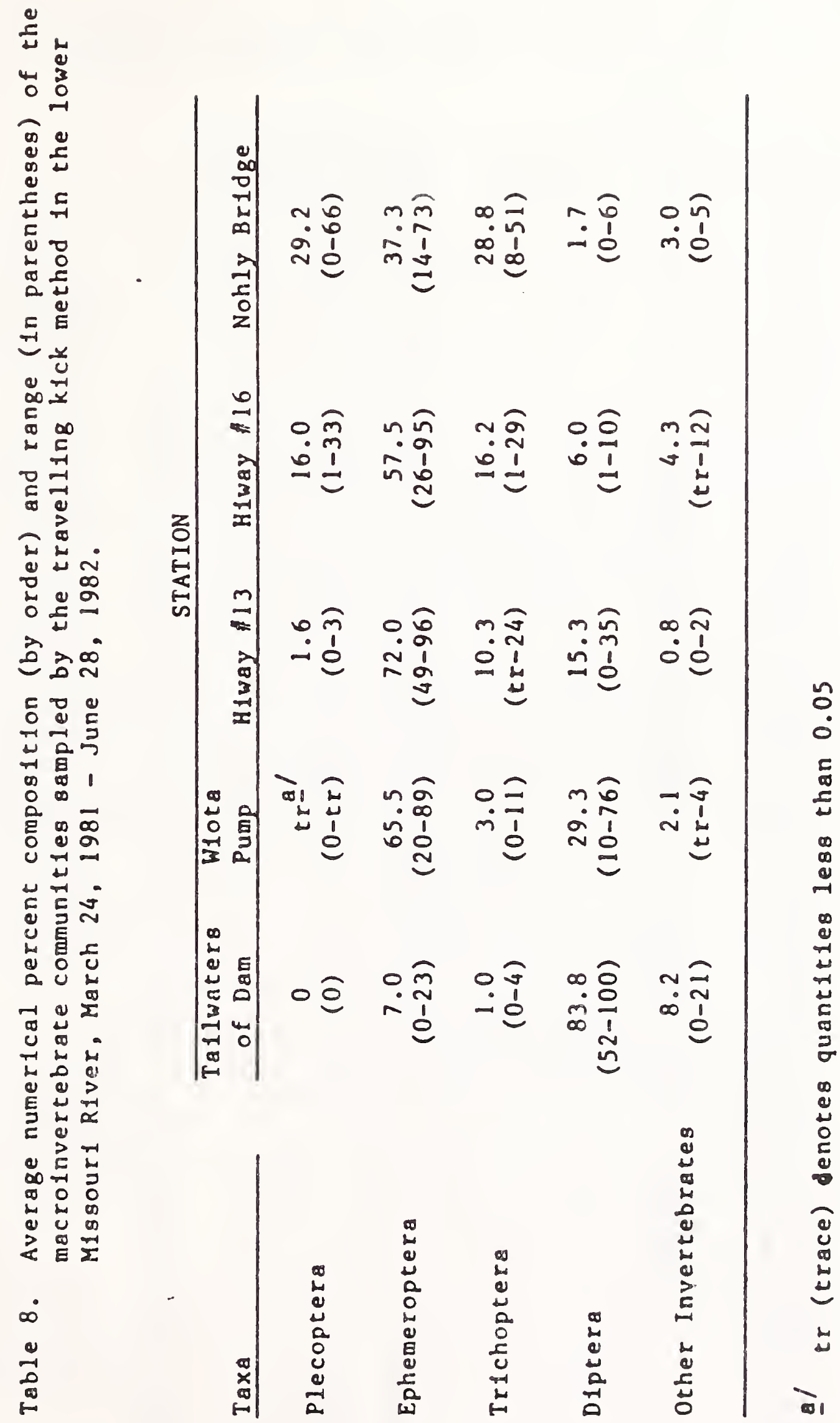




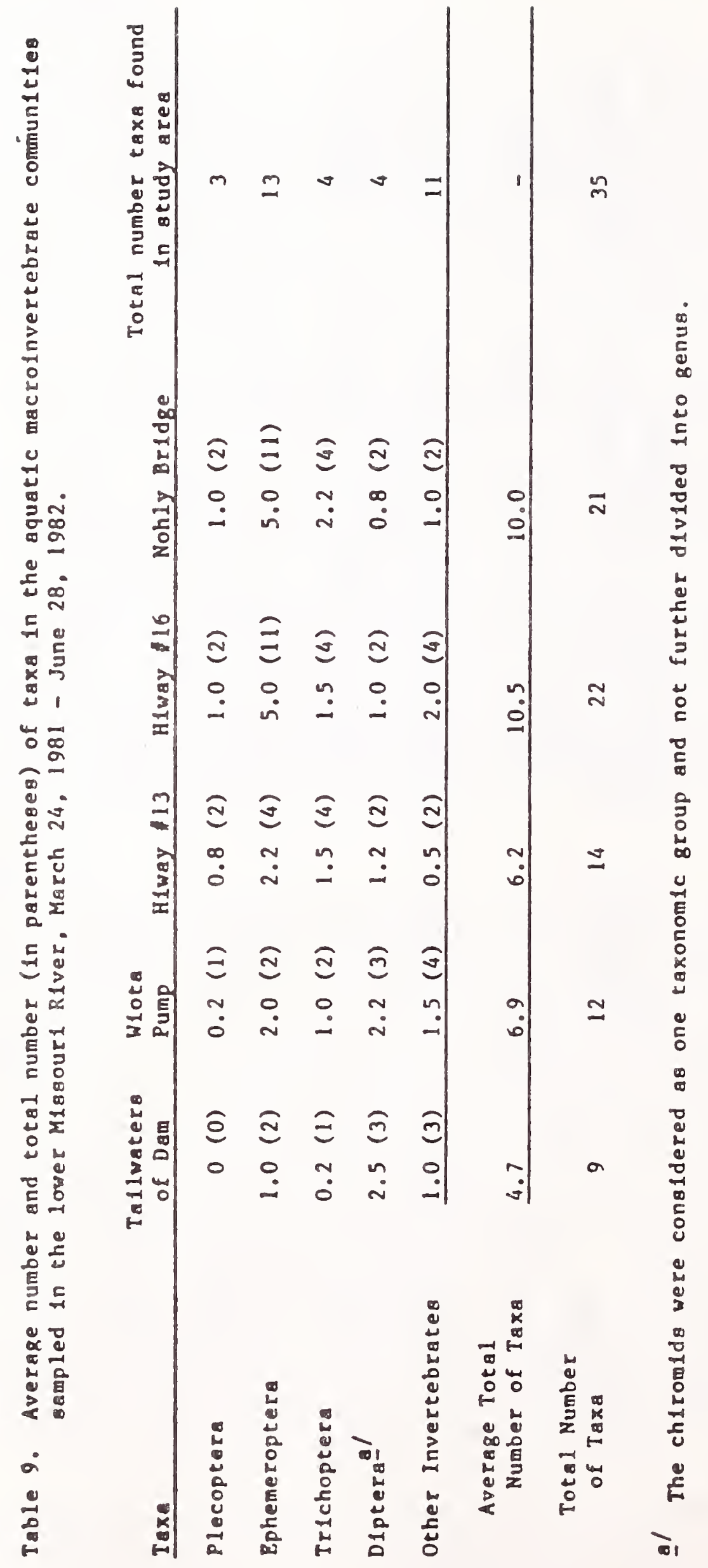


Tahle 10. Longltudinal distribution and relative abundance of aquatic macroinvertebratea in the lower Missour1 River, March 24, 1981 - June 28, 1982.

Taxa

\begin{tabular}{cllll}
\hline $\begin{array}{c}\text { Tallwatera } \\
\text { of Dam }\end{array}$ & $\begin{array}{l}\text { Wlota } \\
\text { Pump }\end{array}$ & H1way $\# 13$ & H1way $\# 16 \quad$ Nohly Bridge \\
\hline
\end{tabular}

Plecoptera

Perlod1dae

Isogenus

Isogeno1des

Isoperla

$\mathbf{R}$

R

$\mathrm{R}$ - $/$

Ephemeroptera

Siphlonuridae

Analetris

Ametropus

Isonych1a

S1phlonurus

Baetidae

Baetis

Heptagen 11dae

Heptagen1a

Stenonems

Ephemerel11die

Ephemereila

Caenldae

I

I

C

$\mathbf{R}$

I

I

(1)

C

C

Caen18

Brachycercus

Leptophleb11dae

Travere 11 a

Ephemer1dae

Hexagen 1 a

Polym1tarcyldae

Ephoron

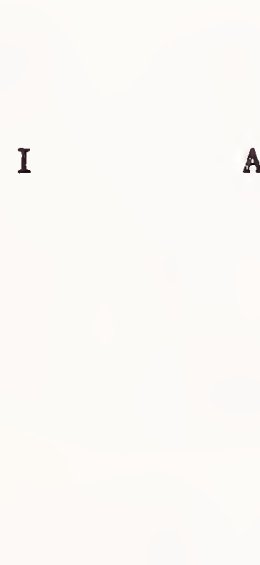

Trichoptera

Polycentropod1dae

Neurecl1psis

Hydropsych1dae

Cheumatopsyche

Hydropsyche

Brachycentridae

Brachycentrus

R

A

R

R

A

C

C

C

C

A

$\begin{aligned} \text { C } & \text { C } \\ & \text { R }\end{aligned}$

A

A

A

C

$\mathbf{R}$

R

$\mathbf{R}$

R

C

I

R

$\mathbf{R}$

I

R

Diptera

S1mul11dae

S1mu 11 um

Muscidae

L1mnophora

Emp1d1dae

Ch1ronomidae

$\begin{array}{ll}\text { A } & \text { A } \\ \text { C } & \text { R } \\ \text { A } & \text { A }\end{array}$

R

R

$\mathbf{R}$

I

I

C

C

C

c

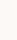

I

C

I

A

C

$\mathbf{R}$

$\mathbf{R}$

A C

C 
Table 10. (Cont.)

STATION

T\&xa

Phaenopsectra

Cricotopus

Orthocladius

Paraphaenocladius

Monodiames1a

Euklefferlella

Bri111a

Paracladoplema

Diamesta

Psectrocladius

Potthastia

Polypedilum

Dicrotendipes

Tanytarsus

Odonata

Gomphus

\begin{tabular}{cc}
\hline $\begin{array}{c}\text { Tallwaters } \\
\text { of Dam }\end{array}$ & $\begin{array}{c}\text { Winta } \\
\text { Pump }\end{array}$ \\
\hline b $/$ & $\star$ \\
$\star$ & $\star$ \\
$\star$ & \\
$\star$ & $\star$ \\
& \\
& \\
& $\star$ \\
& $\star$ \\
& $\star$ \\
& $\star$
\end{tabular}

SATION


tailwaters to 1.0 at the Highway 16 and Nohly Bridge sites. A total of three subordinal taxa was collected in the study area with the greatest diversity exhibited at Highway $\|_{13}$ and Nohly Bridge (Table 10). Isoperla was the most widely distributed genus and was commonly collected only at the lower three sites.

Ephemeroptera (Mayflies). Mayflies were the predominant macroinvertebrate taxa sampled in the study area. At all sites, except the uppermost tailwater site, they constituted the greatest average percent composition by order, ranging from $37.3 \%$ at Nohly Bridge to $72.0 \%$ at Highway 113 . Their diversity was the highest for all the orders with 13 genera collected in the study area. The average number of genera collected per sampling date ranged from 1.0 at the tailwaters to 5.0 at both the Highway 16 and Nohly Bridge sites.

Baetis and Ephemerella were collected at all sites. The burrowing and silt tolerant mayflies Analetris, Ametropus, Heptagina, Traverella, Hexagenia and Ephoron were chiefly sampled at the lower two sites where the river bottom was predominantly silt. Because of their habits, burrowing and sediment tolerant mayflies were difficult to sample, and their numerical importance in the study area was probably underestimated.

Trichoptera (Caddisflies). Caddisflies were also an important macroinvertebrate order. Overa11, they were the second most common order at the lower three sampling sites in terms of average composition and diversity. The numerical percentage of this order, averaging all sample dates, ranged from $1.0 \%$ at the tailwaters to $28.8 \%$ at Nohly Bridge. The average number of subordinal taxa ranged from 0.2 at the tailwaters to 2.2 at Nohly Bridge. Only four genera were sampled in the study area. Hydropsyche and Chematopsyche were regularly sampled at the lower three sites. Brachycentrus was sampled at all five sites, yet was considered common only at Highway \#13.

Diptera (Trueflies). The average numerical percent composition for Diptera displayed a predominance at the uppermost tailwater site, averaging $83.8 \%$, then diminishing in importance in a downstream direction, where the average was a mere $1.7 \%$ at Nohly Bridge. A wide variety of dipterans was collected, most of which were members of the family Chironomidae. This family was considered common at all sites except Nohly Bridge. Simulium, another taxon which was sampled in large numbers, was chiefly confined to the upper three sites. 


\section{DISCUSSION}

Two factors in the study area having the greatest influence on the distribution and abundance of the aquatic macroinvertebrates are the operation of Fort Peck Dam at the upper end of the study area and the general erosional aspect of the river.

Fort Peck Dam has altered the lower Missouri River by:

1) decreasing the natural turbidity, consequently causing the river to be more erosional despite its flat gradient

2) causing severe flow fluctuations

3) reducing the water temperatures (from pre-dam conditions)

The results from this study indicate these three major changes have affected the macroinvertebrate communities to a significant degree. It was apparent that both the ordinal composition and diversities were substantially different between the tailwater site and the two lower sites, Highway 非 16 and Nohly Bridge. The tailwater site exhibited a community composition dominated by dipterans, compared to more balanced communities of plecopterans, ephemeropterans and trichopterans at the lower two sites. At the tailwaters site, only 9 different subordinal taxa were collected compared to 20 at the lower two sites. The intermediate sites, Wiota Pump and Highway \#13 both displayed communities which indicated a change from the simplistic to the more complex and natural. Fort Peck Dam and its operations (fluctuating, cold clear water releases) can be isolated as the factor affecting the communities below, since balanced and healthy macroinvertebrate communities exist immediately above the impoundment (Berg 1981). Berg reported here that a total of 34 subordinal taxa were found, and plecopterans, ephemeropterans and trichopterans were well balanced. The response of the macroinvertebrate communities to the operation of Fort Peck Dam as reported here are similar to other investigations concerning regulated rivers (Lehmkuhl 1972 and Ward 1976).

The other major influence on the macroinvertebrate communities is the erosional nature of the river. The lower Missouri River, in general, is in a depositional state responding to the geology of the area. The gradient is flat, there are few gravelly riffles and most of the river bed is comprised of sand and silt. Substrate size and current velocities are major physical factors affecting the distribution and abundance of macroinvertebrates in undisturbed rivers (Hynes 1970). Substrate size will determine the type of cover and food available, thereby favoring one species and limiting another according to their requirements (Hynes 1970 and Merritt and Cummins 1978). The clear water releases from the reservoir have changed the river from a depositional to an erosional stream. This situation is maintained to some degree at least to the Highway 非13 site. There are several riffles with clean gravel in this reach which had a noticeable influence on the macroinvertebrate communities. In this reach most of the more common taxa were not silt tolerant forms, and the kick sample collections indicated that numbers of organisms were greater than in the downstream reach (grand total average of 336 vs 130 organisms per collection). Below the Highway 非 13 site the erosional influences of Fort Peck Dam are 
probably reduced to a minimum. In this lower reach 9 of the 13 mayfly genera are listed by Merritt and Cummins (1978) as being chiefly associated with depositional zones, or silt tolerant. One of these silt tolerant mayflies, Analetris, had never been found in Montana until this study reported its occurrence. Edmunds et al. (1976) reported occurrences of Analetris in larger prairie rivers of Wyoming, Utah and Saskatchewan. He goes on to state that in all three of these places the river habitat for this rare mayfly has either been lost or is in a precarious situation. Very little is known about the life cycle and specific habitat requirements of Analetris. It is imperative that the istribution and habitat requirements be determined for the population which exists in the state.

The abundance of benthic macroinvertebrates sampled in the lower sections of the study area is considered to be low compared to the populations found made in other large Montana prairie rivers (personal observation). This is understandable since river characteristics such as shifting sand substrate, excessive turbidities, siltation and fluctuating water levels are associated with low benthos production (Berner 1951). Other habitats of the macroinvertebrate communities could be associated with organic substrate such as the prevalent brush piles and cottonwood snags. This component could be categorized as the aufwuchs. An evaluation of the aufwuchs community was not made. Morris et al. (1968) found that aufwuch communities comprised a substantial portion of the overall standing crop of macroinvertebrates in the unchannelized Missouri River, Nebraska. 
Zooplankton could be an important trophic level in the Missouri River reaches described in this report. Cummins (1975) mentions that large turbid rivers with heavy sediment loads characteristically possess plankton communities. Other studies have reported that large mainstem reservoirs substantially increase the zooplankton concentrations in the receiving river below (Kallemeyn and Novotny 1977 and Repsys and Rogers 1982). With Fort Peck Reservoir being the "source" of river flow it is likely that zooplankton produced in the reservoir will sometimes be discharged into the river downstream.

Zooplankton samples were collected to determine trophic level significance in the river system. Samples were collected along the borders of the main channel and in off-channel pools. These off-channel pools, either abandoned channels or pools formed by lateral sand bars situated near the channel magins, were 20 to 180 feet wide, 100 to 600 feet long and with maximum depths between 3 and 8 feet. Collections were taken at sites within the upper, middle and lower reaches (72, 138 and 180 miles below Fort Peck Dam) on May 24, July 24 and October 10,1984 .

\section{Composition}

Cyclops and Daphnia spp. dominated the collections for both the main channel and off-channel pool sites comprising an average of $52.5 \%$ and $18.5 \%$ of the organisms sampled, respectively (Table 11 and Appendix Tables 10-12). Bosmina, a taxon uncommon in the Missouri River system above the study area (Frazer 1985), was collected in high densities on one occasion. Although the two types of sampling methods are not entirely comparable (horizontal tows vs. stationary river tows), gross density differences were apparent. Average combined total number of organisms per liter of water filtered in the main channel sites was less than 3 organisms, whereas, in the off-channel pool sites the highest density was nearly 26 organisms per liter.

The highest zooplankton densities at the main channel sites were regularly recorded at the upper reach station (Table 12). Middle and lower reach stations exhibited densities only about $25 \%$ that of the upper station. The reverse was the case for the off-channel pool sites. Here, the middle and lower stations had zooplankton densities 15 times that of the upper station. The high main channel zooplankton densities at the upper station were most likely the result of this station's proximity to Fort Peck Dam. Frazer (1985) attributed high densities of zooplankton in the Fort Peck Dam tailpool to large quantities of zooplankton being flushed from the reservoir during the spring turnover period.

A possible explanation for the greater zooplankton densities in the off-channel pool sites of the middle and lower reach stations may be related to the more stable flows experienced in these reaches further from the dam. Daily river fluctuations at the upper reach station were greater because of the proximity to the dam. This may have resulted in flushing of the off-channel pool sites in this area. 
:

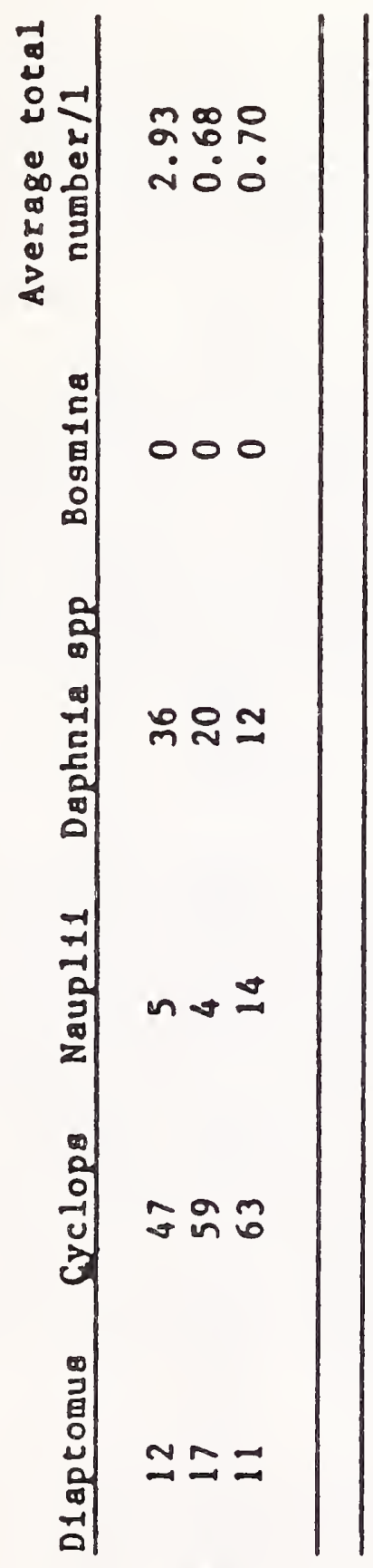

造范

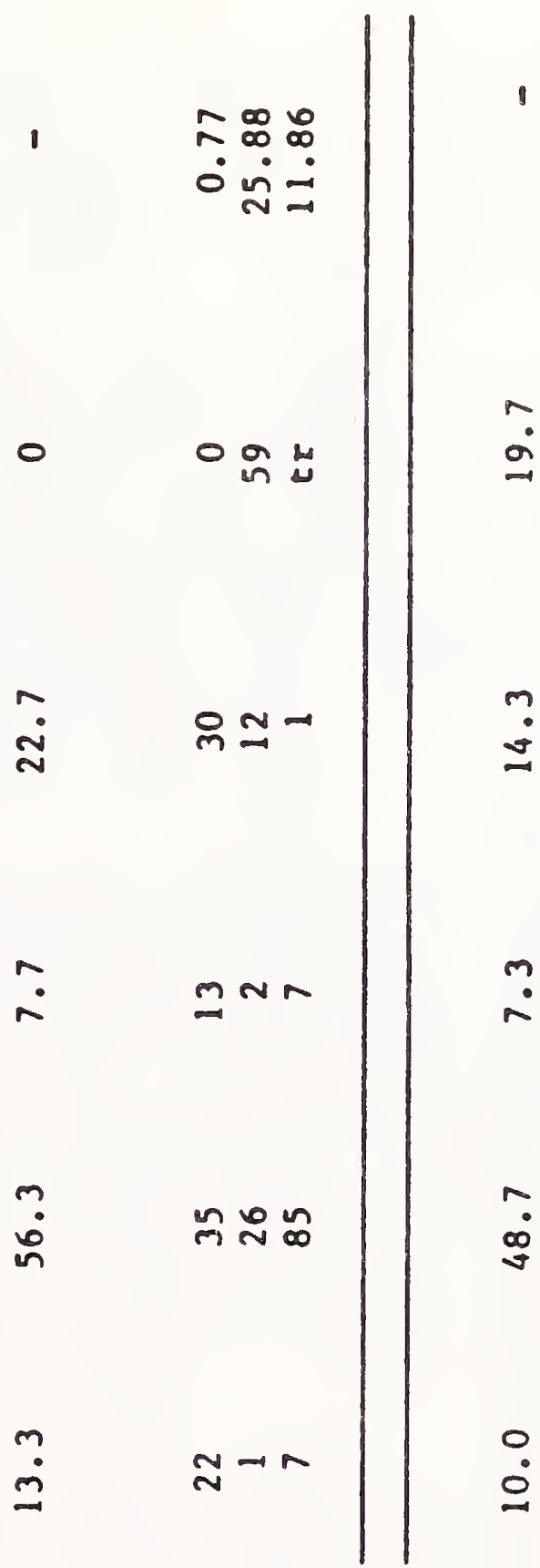

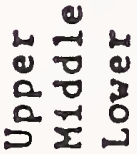
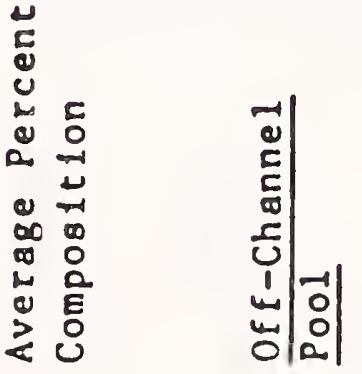

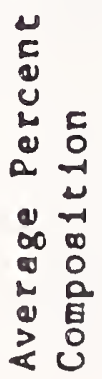




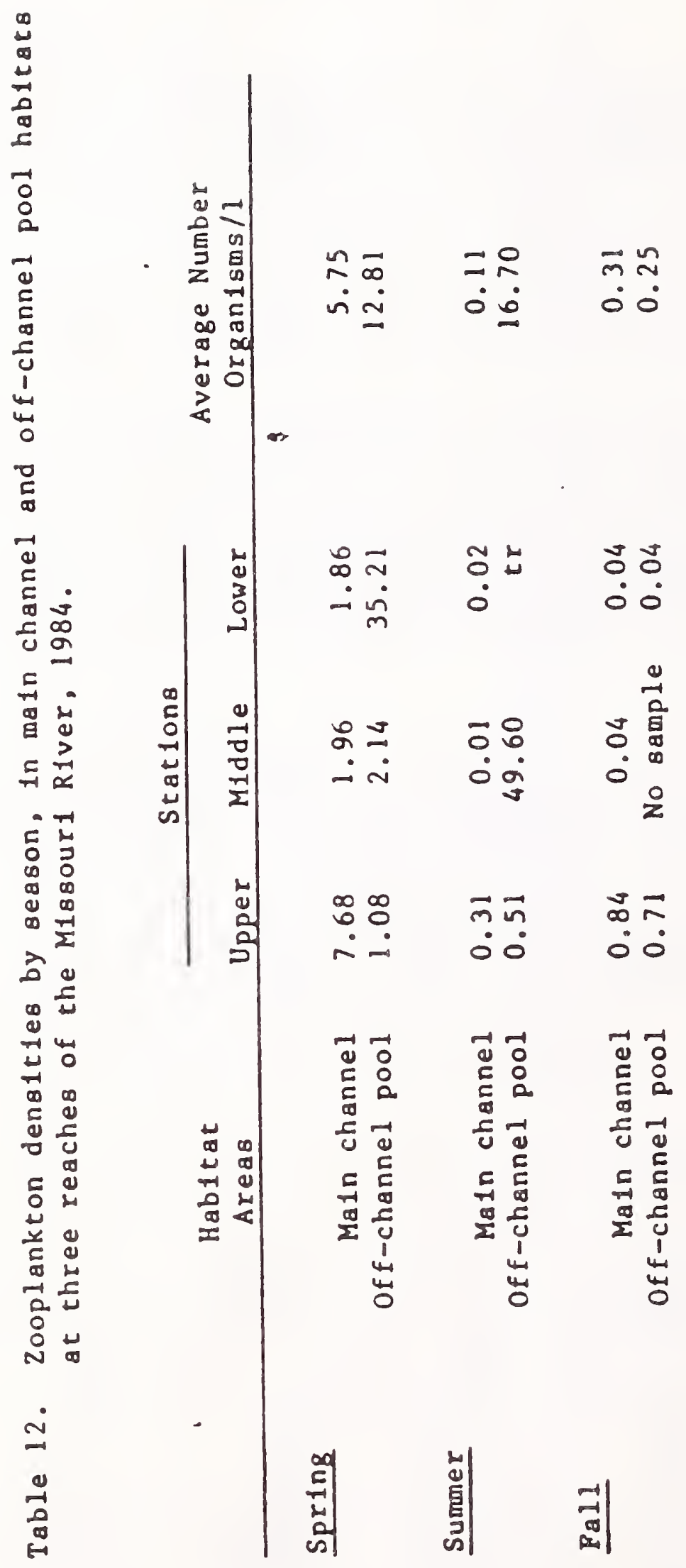


Seasonal abundance

There appeared to be seasonal differences in zooplankton densities. For the main channel sites, the greatest densities were sampled during the spring, where spring samples consisted of densities at least 9 times those of summer and fall samples (Table 13). At the off-channel pool sites both spring and summer collections exhibited high zooplankton densities, although this was not consistent at all stations.

Table 13 is a very general comparison between zooplankton populations in the associated Missouri River system. There are some similarities and differences between these sites. Comparisons indicate that, during the spring and most likely the fall, the reservoir was probably the main source of zooplankton to the river system. However, during the summer the off-channel pool sites were the only areas in the river where there were fair concentrations of zooplankton. Summer zooplankton production appears to be indigenous to the off-channel pool sites and not produced in the reservoir or tailwaters of Fort Peck.

\section{DISCUSSION}

Major taxa found in the river were similar to those found in Fort Peck Reservoir. Wiedenheft (1984) reported that Cyclops and Dapnia were the two most prevalent zooplankters; this was also the case for the taxa found in the river. Even though there were good densities of zooplankton in the reservoir and tailpool of the dam during October, there were perhaps only slight increases in plankton densities from the summertime low. These increases were noted only at the upper reach site. It was possible that fall zooplankton densities in the river could have been greater and that our sampling efforts missed the later peak. Repsys and Rogers (1982) described a bimodal peak of Missouri River zooplankton densities, one in spring and fall. These two seasonal peaks were associated with the spring and fall turnover periods of the large mainstem impoundments. Peak river zooplankton densities occurred in late October and early November.

It appears that river production of zooplankton was chiefly limited to off-channel pool sites. The only significant numbers of the uncommon taxon, Bosmina, were collected here and this was the main habitat area where high densities of zooplankton were collected during the summer. Kallemeyn and Novotny (1977) reported that most zooplankton present in the Missouri River (in South Dakota and Nebraska) originated in the mainstem reservoirs. This was the case here, however, during the summer there were also substantial zooplankton densities in the off-channel pool habitats. 
단

प्रे

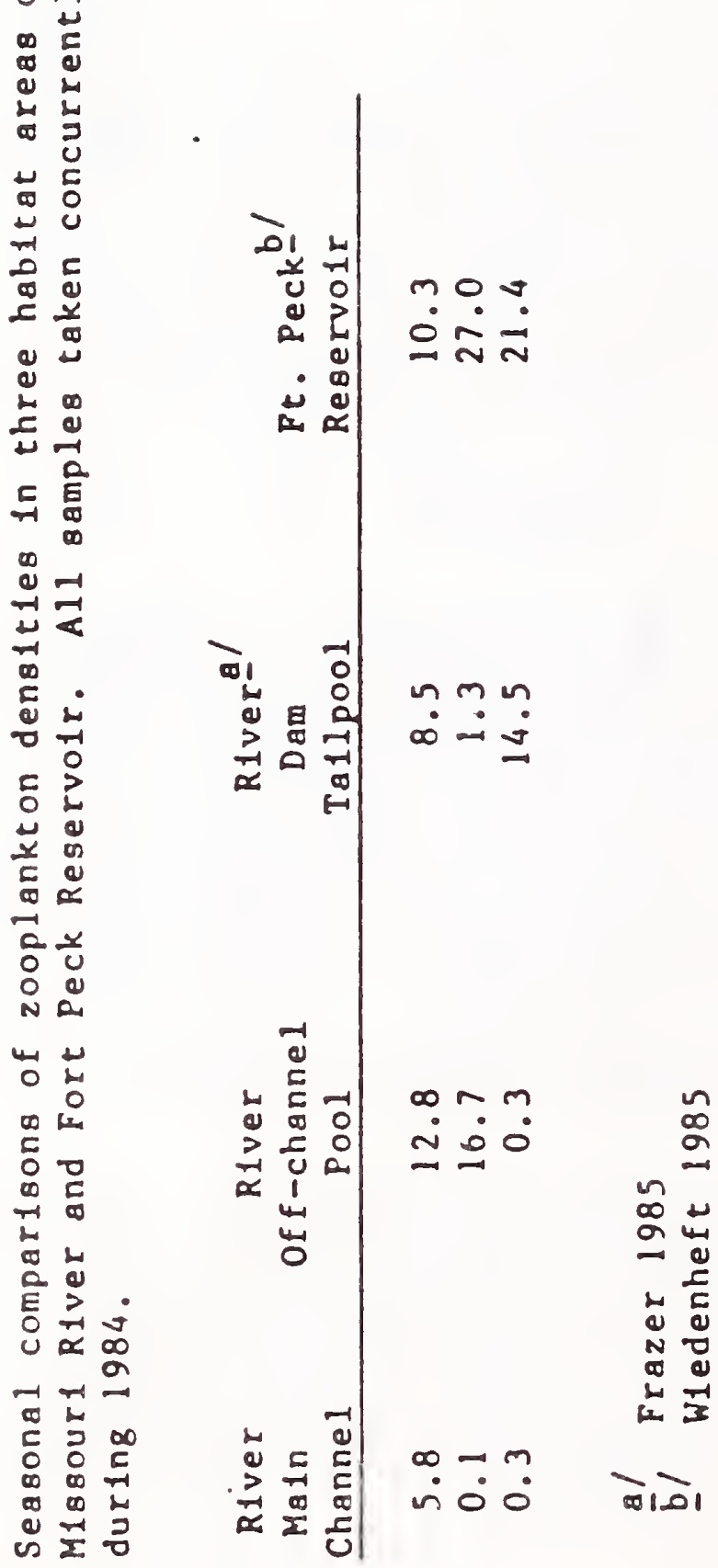

2
$\frac{1}{0}$

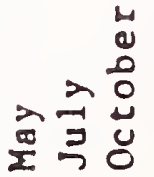


A study of the fish populations in the lower Missouri River and its major tributaries was conducted to determine the fisheries resources in this reach of river. Additionally, the basic habitat requirements, life cycles and important habitat areas for the river fisheries were also evaluated. A better understanding of this fishery will be valuable for making future management decisions.

\section{Species distribution}

Sampling of the fish fauna was accomplished throughout the study area from April 1979 through November 1984. A total of 14,706 fish representing 43 species, was sampled during the study period (Table 14). Of the 43 species, 20 were found to be widely distributed throughout the study area and 8 species were limited to the dredge ponds or tailwaters area. Eighteen species were considered as rare in occurrence. The pallid sturgeon, paddlefish, shortnose gar and sicklefin chub were the four fishes sampled in the study area which the MDFWP has listed as "species of special concern."

The Fort Peck section exhibited the best fish diversity containing 35 of the 43 species found in the entire study area (Table 14). This study section was comprised of both lake (dredge cuts) and river habitats. Because of this diversity of habitats; many different types of fish species were attracted to the area. Culbertson was the next diverse study section containing 30 of the 43 species. 
Table 14. Distribution and abundance of adult fish spectes found in the lower Missouri River.

Pallfd sturgeon
Shovelnose sturgeon
Paddlefish
Shortnose gar
Goldeye
Lake whitefish
Cisco
Chinook
Rainbow trout
Brown trout
Lake trout
Rainbow smelt
Northern pike
Carp
Northern redbelly dace
Flathead chub
Sicklefin chub
Lake chub
Emerald shiner
Northern spottall shiner
Western silvery minnow
Fathead minnow
Longnose dace
River carpsucker
Blue sucker
Smallmouth buffalo
Bigmouth buffalo
Shorthead redhorse
Longnose sucker
White sucker
Black bullhead
Channel catfish
Stonecat
Burbot
Brook stickleback
White bass
Smallmouth bass
White crapple
Yellow perch
Sauger
Walleye
Iowa darter
Freshwater drum

Fort Nickels Wolf

Peck Ferry Frazer Point Chelsea Sprole Brockton Culbertson

Pallid sturgeon

A

A

R

$R$

C

C

$\mathrm{R}$

L

C

A

R

R

R

R

C

L C

C

R

R

A

A

A

C

C

C

A

A

A

A

L L

C C

C

R

R

A $\quad$ C

R

R

L

C

C

C

$R$

C

C

c

C

C
R

R

c

C

C

A

$\begin{array}{ll}\text { C } & \text { C } \\ \text { C } & \text { C } \\ \text { A } & \text { A }\end{array}$

R

C

c

C A

A

C
C
C
C
C
C
R
C
R
C

C

C

C

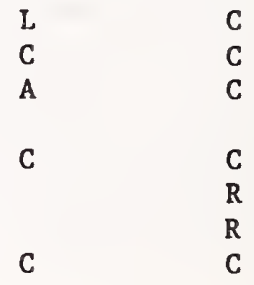

R

$\mathbf{R}$

$\begin{array}{ll}\mathbf{R} & \mathbf{R} \\ \mathrm{C} & \mathrm{A}\end{array}$

$\begin{array}{lll}\mathbf{R} & & \mathrm{R} \\ & \mathrm{R} & \mathrm{R} \\ \mathrm{R} & \mathrm{C} & \mathrm{R} \\ \mathrm{A} & \mathrm{C} & \mathrm{C} \\ \mathrm{C} & \mathrm{C} & \mathrm{C} \\ \mathrm{R} & \mathrm{R} & \mathrm{R}\end{array}$

$\begin{array}{ll}\mathrm{C} & \mathrm{C} \\ \mathrm{C} & \mathrm{C} \\ \mathrm{C} & \mathrm{C} \\ \mathrm{C} & \mathrm{C} \\ \mathrm{C} & \mathrm{C} \\ \mathrm{R} & \mathrm{C} \\ \mathrm{R} & \mathrm{R} \\ \mathrm{C} & \mathrm{C} \\ \mathrm{C} & \mathrm{C}\end{array}$

Total Number of Species

35

25

26

27

22

25

22

30

$303 / 8.1$

Subjective index of abundance:

$R=$ rare in numbers

$L=$ occurs in fair numbers but is limited in distribution

$C=$ common in numbers

$A=$ abundant in numbers 
Relative abundance

Catch rate summaries for electrofishing, gill net and baited hoop net surveys are presented in Tables 15, 16, and 17, respectively. The catch rate summaries provide an indication of species composition in each study section and allow for general comparisons between sections.

Both electrofishing (most effective in shallow water river conditions) and gill netting (most effective in deeper water pond conditions) surveys indicated ihat sauger was the most common sport fish species found in the lower Missouri River. Electrofishing results revealed that the greatest densities of sauger were found in the Missouri/Milk river confluence area of the Nickels Ferry section. Catch rates for sauger averaged about $8 \mathrm{fish}$ per hour. The average catch rate for sauger, all sections and years combined, was 4.3 fish per hour and was about seven times greater than the average catch rate for shovelnose sturgeon, the next most common sport fish in the study area. Shovelnose sturgeon, burbot, northern pike and walleye were the other common sport fish vith overall average catch rates of $0.6,0.6,0.4$ and 0.4 fish per hour, respectively. Gill net catch rates were relatively similar to that of electrofishing with an average combined sauger catch rate of $1.3 \mathrm{fish}$ per hour. Northern pike, shovelnose sturgeon and walleye followed with average catch rates of $1.2,0.9$ and 0.8 fish per hour.

Channel catfish is an important sport fish common to the Missouri River. For a deep river, like the Missouri in this study area, sampling for catfish with a boom electrofishing boat is ineffective and gill netting and seining are difficult because of the current. Good success fishing with baited hoop nets in large rivers has been reported by Berg (1981) and Helms (1974). For this study it was felt that hoop net sampling gave only moderate results and could very well have underestimated the catfish population. The hoop net method for sampling catfish sometimes is unpredictable and requires considerable knowledge and skill locating and setting the net. Channel catfish were sampled with baited hoop nets at six of the eight study sections. Three of the six study sections included tributary streams and nets were usually fished in these confluence areas. A total of 137 sampling days yielded 121 catfish (Table 17). The best catches were at Chelesa and Brockton, two of the three confluence areas. Catches averaged 1.6 catfish per net day. The catfish relative abundance results reported here were similar to those reported for upper areas of the middle Missouri River (Berg 1981).

The sampling for non-sport fish indicated that goldeye, carp, river carpsuckers and shorthead redhorse were the most common species found throughout the study area (Table 18). Both white and longnose suckers were distributed chiefly in the upper river segment. The limited electrofish sampling depicted the Nickels Ferry section as having the greatest numbers of non-sport fish except carp, which were most abundant in the Fort Peck section. 
Table 15. Catch rate sumary for sport fish species sampled by electrofishing on the lower Missouri River, expressed as number of fish sampled per electrofishing hour.

Ft. Nickels Wolf Total number Peck Ferry Frazer Polnt Chelsea Sprole Brockton Culbertson of fish

Shovelnose Sturgeon

1979

1980

1981

1982

1983

Ave.

Total hrs.

\begin{tabular}{|c|c|c|c|c|c|c|c|c|}
\hline$-\frac{a}{0}$ & 0.1 & 0.1 & 0.1 & 0 & 0.2 & 0 & 0.1 & 18 \\
\hline- & 2.2 & 0.9 & 1.4 & 0.1 & 0.2 & 0.1 & 0.1 & 114 \\
\hline 0 & 0.3 & 0.7 & 0.5 & 0.5 & 0.3 & 0.1 & 0.2 & 62 \\
\hline - & 12.6 & 0 & 0 & 1.51 & 0.8 & 0.1 & 0.2 & 143 \\
\hline 0.5 & 0.7 & 0 & 0.6 & - & 0 & - & 0 & 21 \\
\hline 0.2 & 3.2 & 0.3 & 0.5 & 0.5 & 0.3 & 0.1 & 0.1 & \\
\hline 35.4 & 83.3 & 88.1 & 71.2 & 118.6 & 94.9 & 58.8 & 231.2 & 781.5 \\
\hline
\end{tabular}

Northern P1ke

1979

1980

1981

1982

1983

Ave.

Total hrs.

\begin{tabular}{rrrrrrrrr}
- & 0.6 & 0.3 & 0.2 & 0.8 & 0.6 & 0.1 & 0.2 & 44 \\
- & 0 & 0.1 & 0.6 & 0.6 & 0.4 & 1.0 & 0.3 & 79 \\
0 & 0 & 0.5 & 0.3 & 1.4 & 0.5 & 0.4 & 0.5 & 101 \\
- & 1.0 & 0.8 & 0.3 & 0.9 & 0.9 & 0.6 & 1.1 & 173 \\
0.1 & 0 & 0 & 0.4 & - & 0.2 & - & 0.4 & 6 \\
\hline tr & 0.3 & 0.3 & 0.4 & 0.9 & 0.5 & 0.5 & 0.5 & \\
35.4 & 83.3 & 88.1 & 71.2 & 118.6 & 94.9 & 58.8 & 231.2 & 781.5
\end{tabular}

Burbot

1979
1980
1981
1982
1983

1983

Total hrs.

\begin{tabular}{rrrrrrrrr}
- & 0.2 & 0.2 & 0.1 & 0.1 & 0.1 & 0.3 & 0.2 & 29 \\
- & 0 & 0.1 & 0 & 0.1 & 0.2 & 0.2 & 0.4 & 36 \\
0 & 0.1 & 0.8 & 0.4 & 1.3 & 0.9 & 1.9 & 1.7 & 194 \\
- & 1.3 & 2.8 & 2.2 & 0.8 & 1.1 & 1.4 & 1.9 & 268 \\
0.2 & 0 & 0.2 & 0 & - & 0 & - & 0 & 6 \\
\hline 0.1 & 0.3 & 1.0 & 0.5 & 0.6 & 0.5 & 0.9 & 0.8 & \\
35.4 & 83.3 & 88.1 & 71.2 & 118.6 & 94.9 & 58.8 & 231.2 & 781.5
\end{tabular}

Sauger

\begin{tabular}{|c|c|c|c|c|c|c|c|c|c|}
\hline 1979 & - & 7.5 & 2.2 & 3.2 & 1.7 & 5.2 & 2.1 & 3.6 & 616 \\
\hline 1980 & - & 0.6 & 1.3 & 1.1 & 2.2 & 1.8 & 4.5 & 3.7 & 463 \\
\hline 1981 & 0 & 2.0 & 4.8 & 3.0 & 5.1 & 5.8 & 7.6 & 5.3 & 1095 \\
\hline 1982 & - & 26.3 & 3.2 & 15.0 & 3.9 & 15.1 & 5.2 & 5.3 & 1308 \\
\hline 1983 & 0.63 & 2.7 & 1.3 & 3.5 & - & 2.0 & - & 5.4 & 130 \\
\hline Ave. & 0.3 & 7.8 & 2.6 & 5.2 & 3.2 & 6.0 & 4.8 & 4.7 & \\
\hline Total hrs. & 35.4 & 83.3 & 88.1 & 71.2 & 118.6 & 94.9 & 58.8 & 231.2 & 781.5 \\
\hline
\end{tabular}

Halleye

\begin{tabular}{|c|c|c|c|c|c|c|c|c|c|}
\hline 1979 & - & 0.2 & 0.1 & 0.2 & 0.1 & 0.1 & 0.1 & 0.4 & 17 \\
\hline 1980 & - & 0 & 0.2 & 0.2 & 0.1 & 0.3 & 0.7 & 0.5 & 59 \\
\hline 1981 & 0 & 0.3 & 0.4 & 0.1 & 0.5 & 0.5 & 0.6 & 0.5 & 88 \\
\hline 1982 & - & 0.6 & 0.8 & 0.2 & 0.2 & 2.3 & 0.8 & 0.7 & 110 \\
\hline 1983 & 0.83 & 0.1 & 0 & 0.2 & - & 0 & - & 0.3 & 26 \\
\hline Ave. & 0.4 & 0.2 & 0.3 & 0.2 & 0.2 & 0.6 & 0.5 & 0.5 & \\
\hline Total hrs. & 35.4 & 83.3 & 88.1 & 71.2 & 118.6 & 94.9 & 58.8 & 231.2 & \\
\hline
\end{tabular}

b/ hyphen indicates no sampling effort at station for this period tr Indicates catch rate 18 less than 0.05 


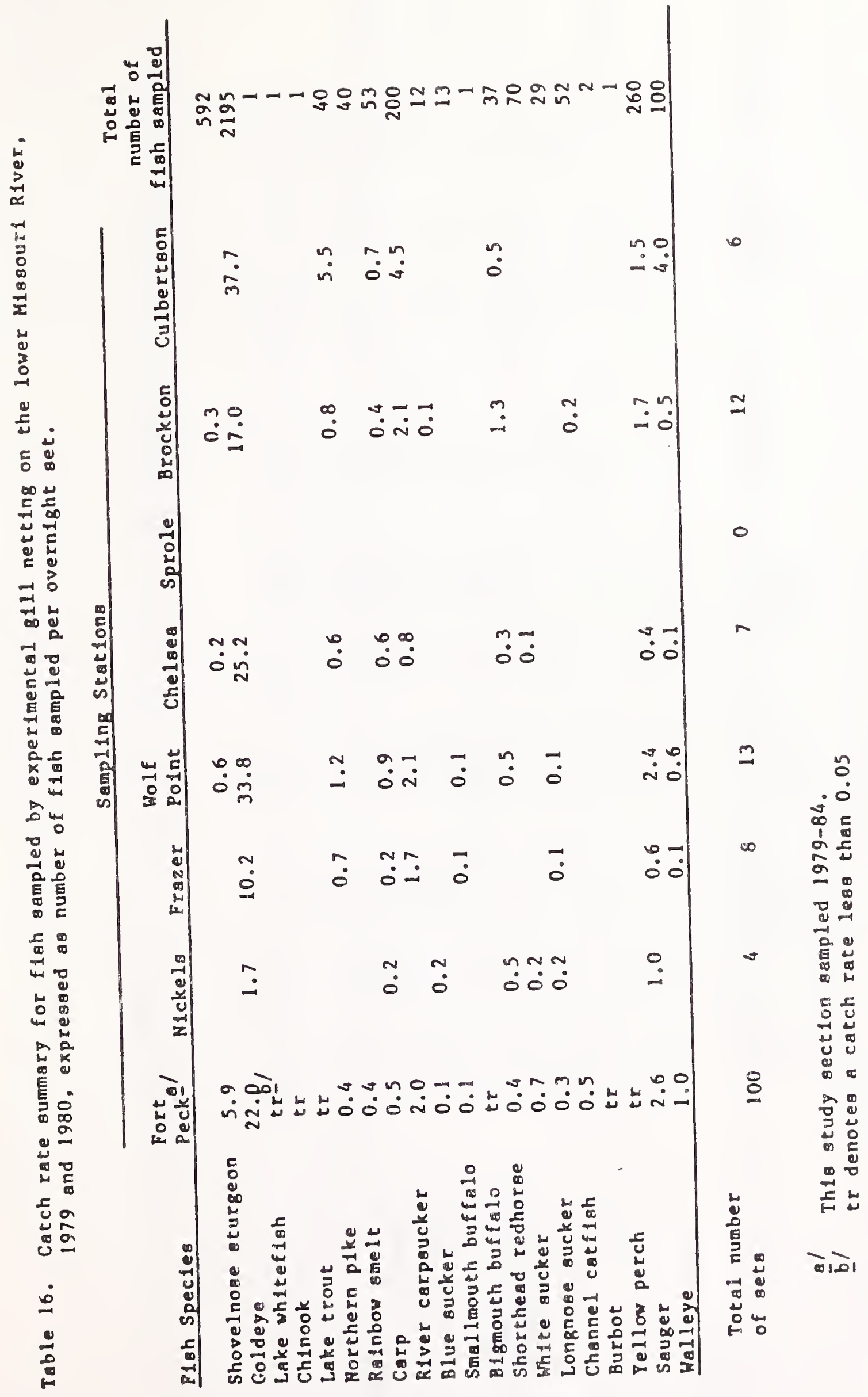




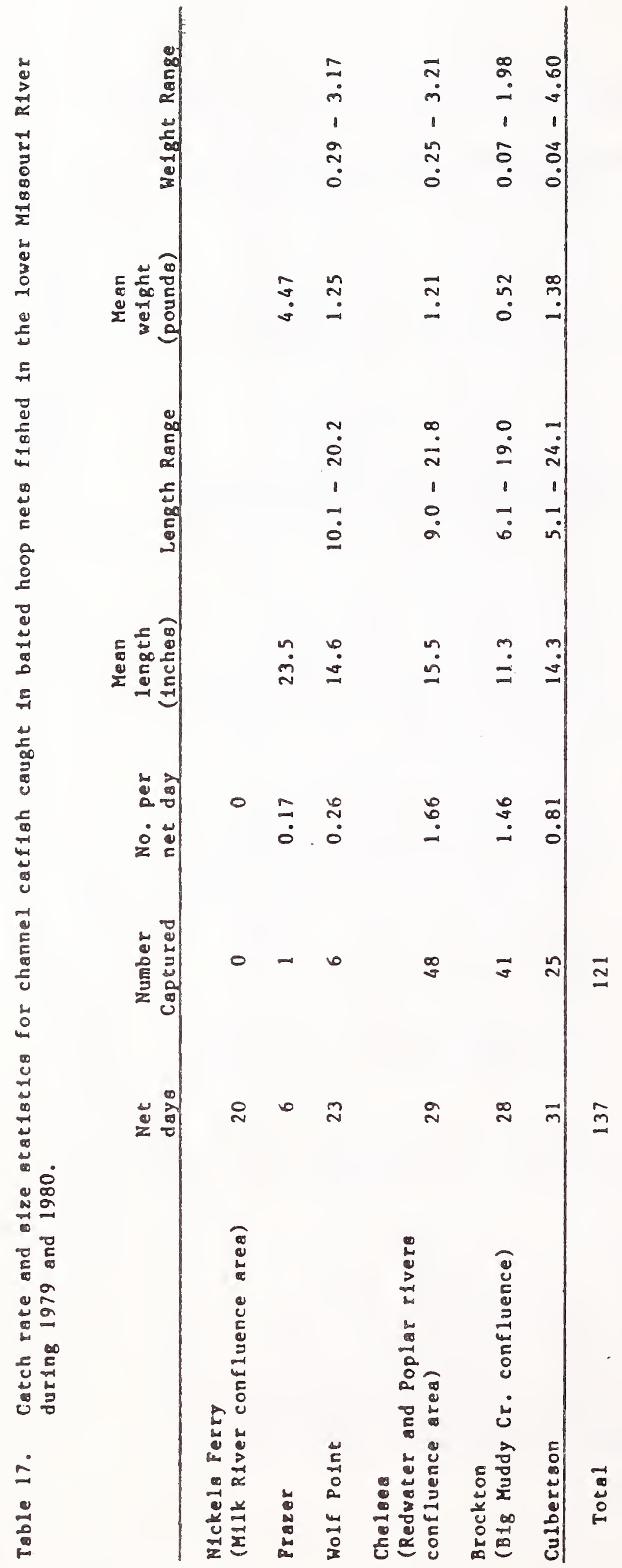




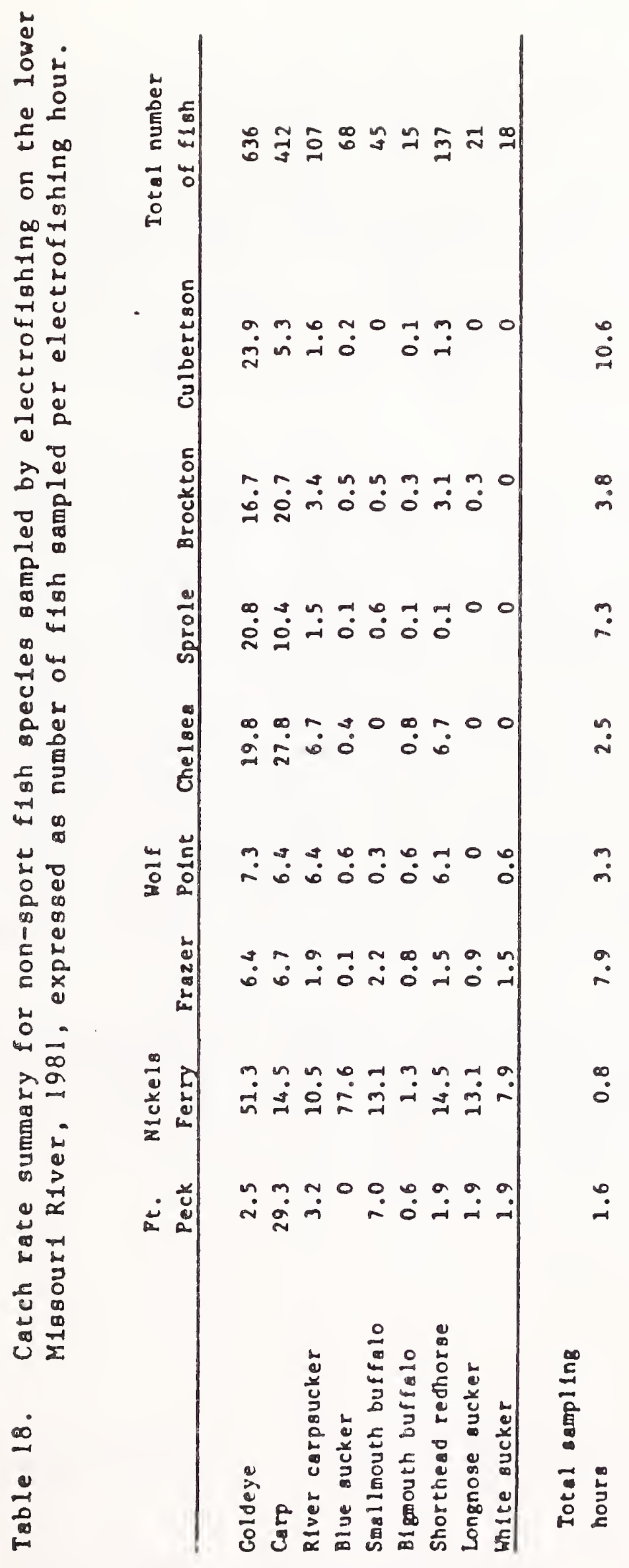


Appendix Tables 13-28 list the total catches and size statistics for each study section sampled by both electrofishing and gill netting. There appeared to be a pattern related to longitudinal distribution and sizes of fish, as indicated by electrofishing surveys. The shovelnose sturgeon, goldeye, carp river carpsuckers and shorthead redhorse exemplified this pattern consisting of larger average size fish in the upper sections, decreasing to smaller average size fish in a downstream direction (Figure 5). Berg (1981) also reported a similar pattern for the shovelnose sturgeon, channel catfish, burbot, sauger, goldeye and carp. He attributed this to the combination of upstream migration of mature adults associated with spawning and the downstream drift of larval fish where some of these species rear in favorable habitat areas of the lower reaches.

Considering both average length and weight for the composite of all the five common sport fish and then ranking them according to sizes, the average sizes found in the Fort Peck section ranked the highest, followed by Brockton and Nickels Ferry sections. The locations where the best average and maximum weights of these sport fish occurred are listed in Table 19. These sizes, with the exception of the sturgeon, were considered indicative of an exceptional quality for river sport fisheries. The northern pike, burbot and sauger exhibited larger best average and maximum weights in the lower Missouri than that reported by Berg (1981) for the middle Missouri River. Conversely, shovelnose sturgeon were considerably smaller in the lower Missouri (best average weights were 2.50 vs 6.67 lbs.) and walleye, although probably less numerous in the middle Missouri, were slightly larger here compared to the lower Missouri's population. The channel catfish size statistics are given in Table 17. Catfish found in the study area appear to be small. A comparison with the sizes found throughout the middle Missouri River indicate that both average lengths ( 15.3 vs 13.8 inches) and weights ( 1.47 vs 1.04 lbs.) are greater in the middle Missouri River.

Paddlefish sampled in the study area appeared to be smaller than other populations in the state (Table 20). However, these comparisons may not be entirely valid, since Berg's and Stewart's statistics were gathered from fish harvested by fishermen who were most likely selective of larger fish. Electrofish sampling for paddlefish tends to be selective for smaller, easier captured fish. 

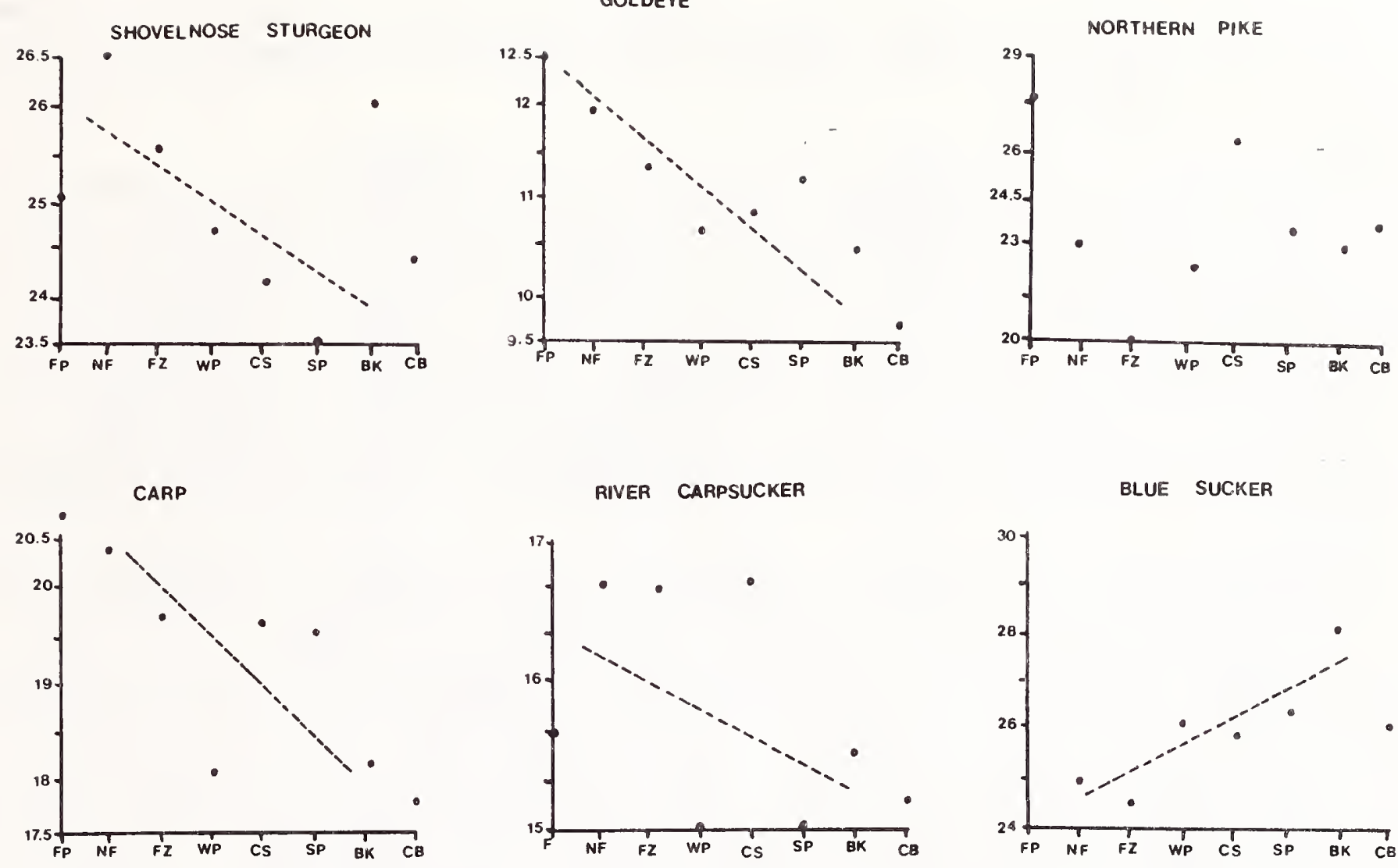

RIVER CARPSUCKER

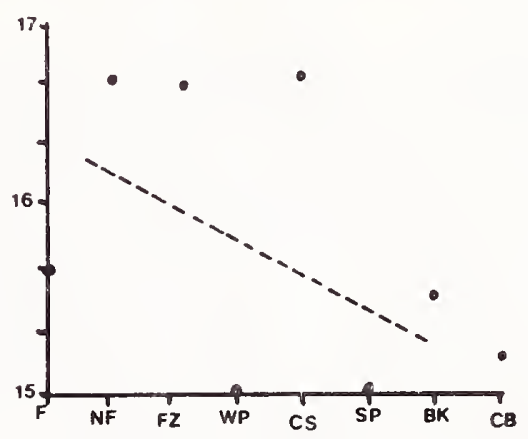

BIGMOUTH BUFFALO

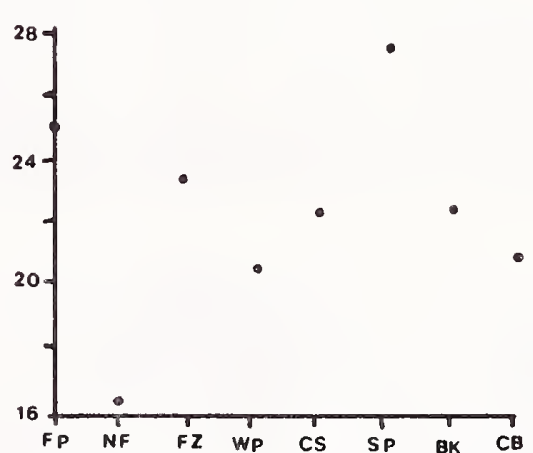

SAUGER

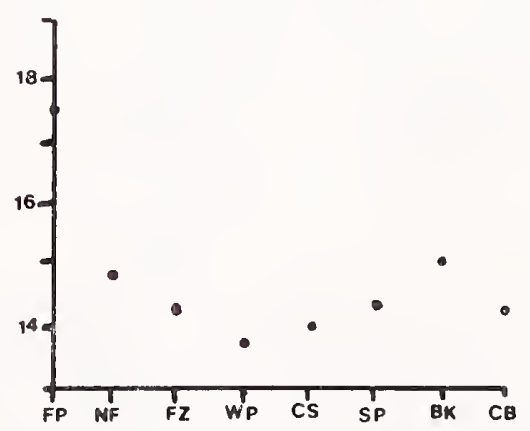

BLUE SUCKER
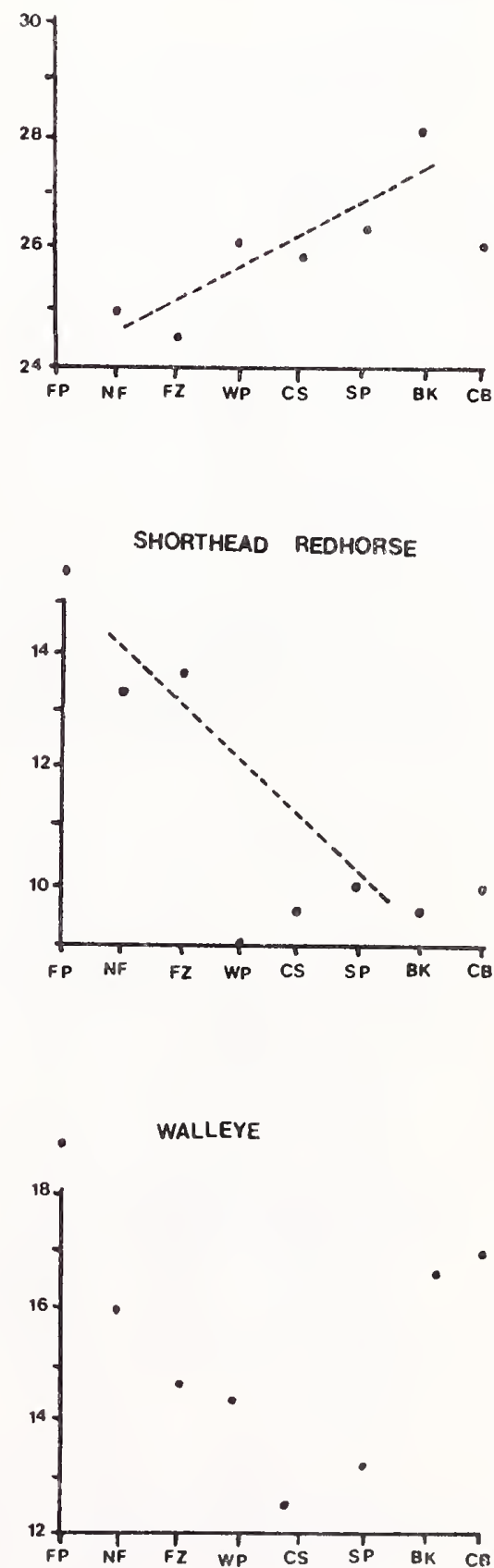

Figure 5. Relationship between average length (inches) of fish and study locations in the Missouri River. 
Table 19. Greatest average we1ghts, maximum welghts and locations of the five most coumon sport flsh sampled by electroflshing in the lower Missourl River, 1979-83.

\begin{tabular}{lllcl} 
& $\begin{array}{c}\text { Best } \\
\text { Ave Wt. } \\
(1 \mathrm{~b} .)\end{array}$ & Location & $\begin{array}{c}\text { Maximum } \\
\text { Wt. } \\
(1 \mathrm{~b} .)\end{array}$ & Location \\
\cline { 2 - 5 } & 2.50 & N1ckels Ferry & 6.50 & N1ckels Ferry \\
Shovelnose sturgeon & 5.55 & Chelsea & 21.5 & Culbertson \\
Northern ptke & 3.26 & Wolf Polnt & 13.1 & Wolf Point \\
Burbot & 1.61 & Ft. Peck & 6.7 & N1ckels Ferry \\
Sauger & 2.50 & Ft. Peck & 10.2 & Culbert8on \\
Walleye & & &
\end{tabular}

Table 20. Sizes of paddlef1sh sampled by electroflshing in the study area during 1979-81 compared to other major Montana paddleftsh populations.

\begin{tabular}{|c|c|c|c|c|c|}
\hline Location & $\begin{array}{l}\text { No. } \\
\text { F1sh }\end{array}$ & $\begin{array}{c}\text { Average } \\
\text { Total Length } \\
\text { (1nches) }\end{array}$ & $\begin{array}{l}\text { Length } \\
\text { Range }\end{array}$ & $\begin{array}{l}\text { Average } \\
\text { We1ght } \\
\text { (pounds) }\end{array}$ & $\begin{array}{l}\text { We1ght } \\
\text { Range }\end{array}$ \\
\hline $\begin{array}{l}\text { Missour1 River belo } \\
\text { Ft. Peck Dam } \\
\text { (Present Study) }\end{array}$ & 151 & 57.2 & $(43-69)$ & 36.8 & $(16-76)$ \\
\hline $\begin{array}{l}\text { Mlssourt Rlver abov } \\
\text { Ft. Peck Reservolr } \\
\text { (Berg-1981) }\end{array}$ & 231 & 60.1 & $(46-74)$ & 55.0 & $(10-111)$ \\
\hline $\begin{array}{l}\text { Yellowstone Rlver a } \\
\text { Intake } \\
\quad(\text { Stewart - 1984) }\end{array}$ & 1400 & 63.7 & - & 50.2 & - \\
\hline $\begin{array}{l}\text { Missour1 River at } \\
\text { Dredge Cuts } \\
\quad \text { (Frazer - 1986) }\end{array}$ & 375 & 51.4 & $(31-66)$ & 25.9 & $(5-72)$ \\
\hline
\end{tabular}


Population estimates were made in three river sections in summer and fall 1982. Estimates were attempted for all of the sport fish but sufficient recaptures were obtained only for sauger. Goldeye and shorthead redhorse populations were also estimated. Numbers and sizes of fish captured during population estimates are shown in Table 21. All sauger captured were weighed and measured, but only a sample of the goldeye and redhorse were retained for weighing and measuring. Only sauger numbers were estimated in the section downstream from the Milk River. No attempt was made to estimate numbers of other species at that location. Average sizes of the species shown in Table 21 are typical of the study area.

Sauger population estimates and corresponding confidence intervals are shown in Table 22. Reliability of the estimates is largely dependent on the number of recaptures and on marked fish staying in the section while electrofishing runs are being made. The reliability of the sauger estimate below the Milk River is considered high because (1) sauger movement was minimal during the estimate period, (2) recaptures are relatively high, and (3) the estimate was made over a short period of time. The other sauger estimates are considered to have low reliability because of significant sauger movement and the low number of recaptures. One sauger marked in the section below the Highway \#13 Bridge was caught by an angler near Fort Peck Dam several days after electrofishing runs were completed. Movement of marked fish out of the section before electrofishing runs were completed would cause the estimate to be biased upward. Reliability of the goldeye estimates is considered high because goldeye were thought to be nonmigratory at the time of the estimates and the number of recaptures was high. Reliability of the redhorse estimates is considered somewhat lower only because of the fewer numbers of recaptures (Table 23).

The highest of the Missouri River sauger population estimates, 2,028 per mile, was found just below the Milk River (Table 22). Almost all of the sauger were located along the north bank in the warm, turbid plume resulting from the inflow of the Milk River. Few sauger were present downstream from the lower end of this section where the Milk River and Missouri River water become mixed. The number of sauger present at the time of the estimate was a temporary concentration not present during spring electrofishing and was probably dispersed by late summer. The sauger in this section were even more concentrated than the number indicates, because almost all of the sauger were located along the north bank. Sauger estimates for the lower two sections (Table 22) are only suggestive of absolute numbers present because of movement, few recaptures, and wide confidence intervals. The actual numbers are probably lower than the estimates because of movement of marked sauger out of the section.

Goldeye estimates were approximately 2,000 fish per mile in both the Highway 非 13 Bridge and Highway 非16 Bridge sections (Table 23). This number is probably a typical density for goldeye in the Missouri River because goldeye catch rates during electrofishing runs for the estimate were similar to goldeye catch rates noted in other parts of the study area. 


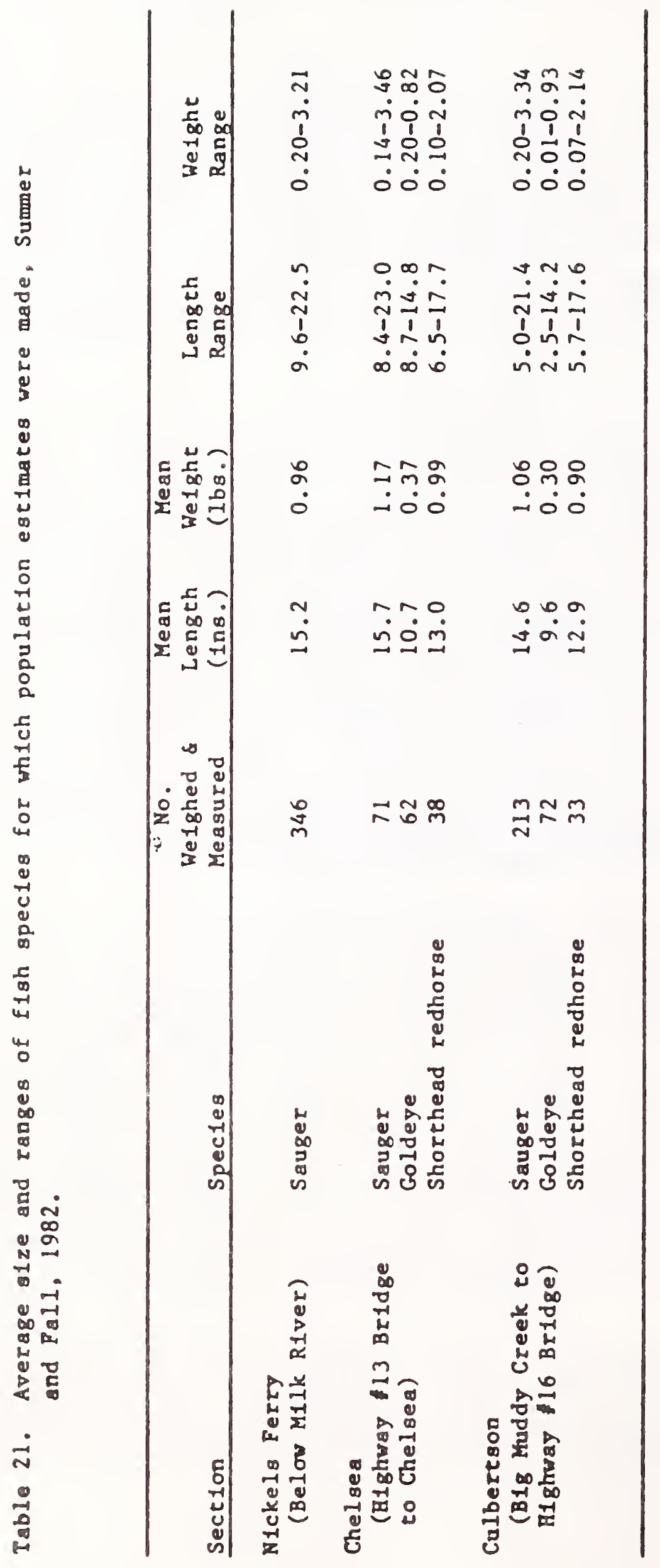




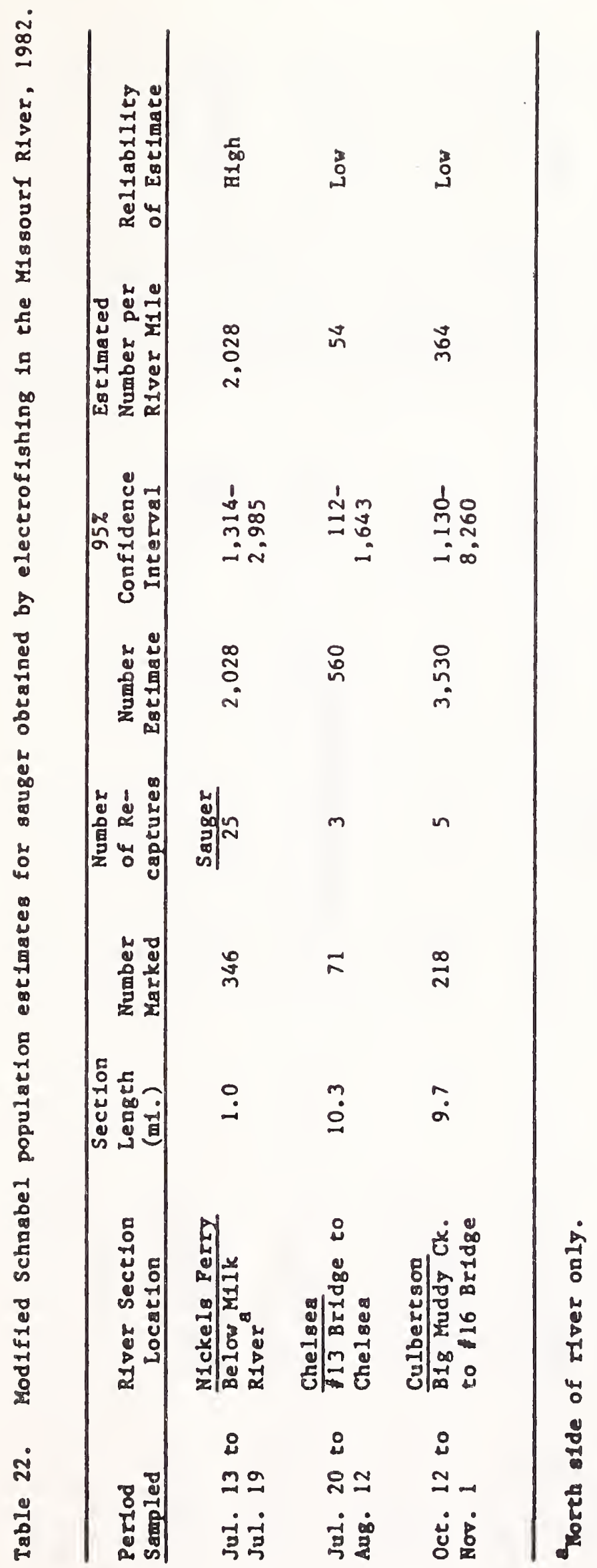




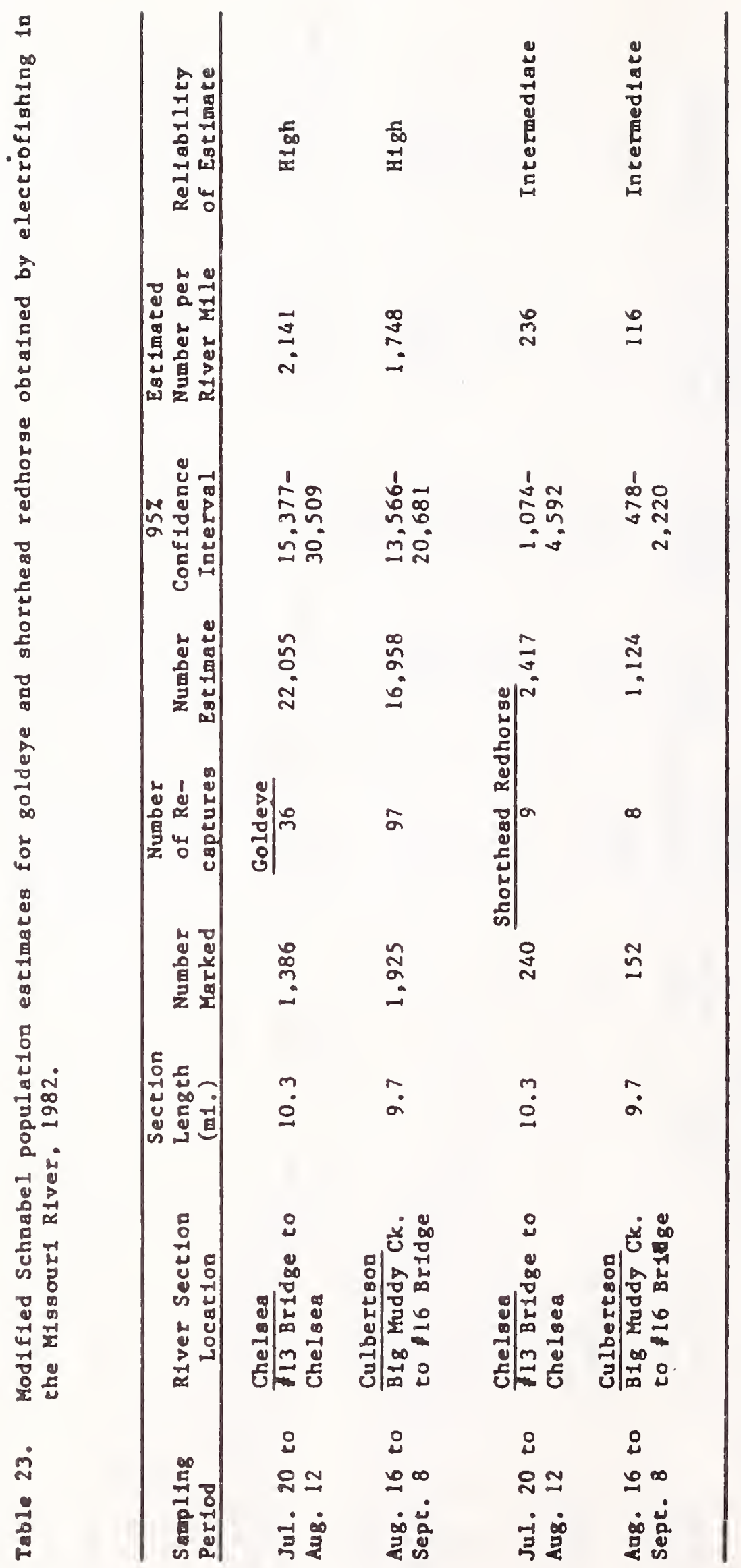


Shorthead redhorse estimates were approximately 6 to 12 percent of the estimates for goldeye. River carpsuckers and smallmouth buffalo are probably present in densities similar to that of redhorse. Since all three of these species were sampled with similar relative abundances.

No estimate was made for burbot because no recaptures were made for this species during electrofishing recapture runs. However, it can reasonably inferred that high numbers of burbot are present because 67 were marked during the summer and 63 during the fall estimate periods between Big Muddy Creek and the Highway 非16 Bridge. The numbers marked were apparently very small compared to the population size because no marked burbot were caught during subsequent electrofishing runs. 


\section{Reproduction}

Eggs

Various locations where concentrations of spawning sport fish had been noted were sampled for icubating eggs. Most of this effort was directed towards paddlefish and sauger/walleye since these were the three species for which reasonable ideas of their spawning locations were known.

Paddlefish. Sampling for paddlefish eggs was conducted during 1982 and limited to the Milk River and Milk/Missouri River confluence area. Only one paddlefish egg was collected and it was taken on June 21 from the Milk River at a gravel riffle approximately 2.5 miles upstream from the mouth. This egg hatched as it was being picked from the net with forceps. The larvae was easily identified as a paddlefish.

Sauger/Walleye. Sampling for Stizostedion sp. eggs was done at 17 locations--two on tributaries and 15 on the Missouri River. No sampling was done in the Poplar River where spawning by walleye is already well documented (Stewart 1979). No attempt was made to distinguish walleye from sauger eggs because there is considerable overlap in the egg diameter range for the two species. The 16 locations were sampled for eggs because of gravel-rock substrate at the reef sites and, in most cases, the presence of spawners.

Stizostedion sp. eggs were found at eight of the 17 locations sampled (Table 24). Eggs may have been present at some of the locations where none were found. The large angular substrate at some locations prevented substrate agitation and made egg collection less likely. Walleye/sauger eggs were found throughout the Missouri River and also collected in the Milk River, but not in Big Muddy Creek. Five of the seven locations where eggs were found are located downstream from the town of Brockton indicating the spawning preference for this reach.

\section{Larval fish}

Larval fish were sampled in eight study sections on the mainstem of the Missouri River and one site near the mouths on each of the four major tributary streams. Samples were collected between 1979-1982, usually during May through June. This larval fish survey was conducted to determine timing location and incubation success of spawning fish.

\section{Composition}

Missouri River. A total of 3,124 larvae were collected in 339 samples (Appendix Tables 29-36). Only 177 of the 3,124 larvae were of sport fish species. The majority of these larval sport fish were comprised of Stizostedion sp. (167), the remainder were paddlefish (9) and burbot (1). Catostominae (shorthead redhorse, longnose and white suckers) were the most common subordinal taxon averaging $38 \%$ of the larvae at all sections for the four years (Table 25). Ictiobinae (river carpsucker and buffalo) and Cyprinidae (minnows) were the next common larval taxa sampled in the river averaging $26.6 \%$ and $19.6 \%$ of the composition, respectively. Stizostedion larvae (most likely sauger) were 
Table 24. Occurrence of Stizostedion sp. eggs sampled in the study sections, May, 1982.

\begin{tabular}{|c|c|c|c|c|c|c|c|c|c|}
\hline $\begin{array}{c}\text { Ft. Peck } \\
\text { Dam }\end{array}$ & $\begin{array}{l}\text { Nickels } \\
\text { Ferry }\end{array}$ & Frazer & $\begin{array}{l}\text { Wolf } \\
\text { Point }\end{array}$ & Chelsea & Sprole & Brockton & $\begin{array}{c}\begin{array}{c}\text { Culbert- } \\
\text { son }\end{array} \\
\end{array}$ & $\begin{array}{l}\text { Milk } \\
\text { River }\end{array}$ & $\begin{array}{l}\text { Big } \\
\text { Muddy } \\
\text { Creek }\end{array}$ \\
\hline$\star a^{\prime}$ & 0 & & * & 0 & 0 & $\begin{array}{l}\star \\
\star \\
0\end{array}$ & $\begin{array}{l}\text { * } \\
\text { * } \\
\text { * } \\
0 \\
0 \\
0\end{array}$ & * & 0 \\
\hline
\end{tabular}

* eggs found

0 eggs not found

af this location was only sampled during 1983

Note: Each entry represents a different location where'a search was made for fish eggs.

Table 25. Average percent composition of fish larvae collected in the lower Missouri River, 1979-1982.

\begin{tabular}{|c|c|c|c|c|c|c|c|c|}
\hline Taxa & $\begin{array}{l}\text { Ft. } \\
\text { Peck }\end{array}$ & $\begin{array}{l}\text { Nickels } \\
\text { Ferry }\end{array}$ & Frazer & $\begin{array}{l}\text { Wolf } \\
\text { Point }\end{array}$ & Chelsea & Sprole & Brockton & Culbertson \\
\hline Paddlef1sh & & $t r^{a /}$ & & & $\mathrm{tr}-\mathrm{b} /$ & & $\operatorname{tr}$ & $\operatorname{tr}$ \\
\hline Goldeye & & $\operatorname{tr}$ & & 10 & tr & 10 & 14 & 10 \\
\hline Cyprinidae & & 21 & 36 & 26 & 34 & 13 & 13 & 14 \\
\hline Catostominge & 100 & 37 & 19 & 40 & 20 & 43 & 30 & 15 \\
\hline Ictiobinae- & & 34 & 26 & 24 & 45 & 24 & 36 & 24 \\
\hline Burbot & & & & & & & & 7 \\
\hline Yellow perch & & $\operatorname{tr}$ & & & & & & \\
\hline Stizostedion & & 1 & & & $\operatorname{tr}$ & 10 & 7 & 29 \\
\hline Iowa darter & & & & & & & tr & tr \\
\hline Freshwater drum & & 7 & 20 & & & & & \\
\hline Number of samples & 21 & 31 & 33 & 44 & 32 & 49 & 55 & 84 \\
\hline Total number of larvae & 11 & 1055 & 149 & 130 & 164 & 317 & 463 & 835 \\
\hline $\begin{array}{l}\text { Average number of larvae } \\
\text { per sample }\end{array}$ & 1.3 & 31.3 & 6.4 & 3.1 & 3.2 & 5.6 & 6.4 & 6.6 \\
\hline
\end{tabular}

a/ tr (trace) denotes composition less than $0.5 \%$

b/ questionable identification

c/ Includes shorthead redhorse and white and longnose suckers

d includes river carpsucker and buffalo 
collected in fair numbers at the lower three stations where good numbers of incubating eggs and sauger in spawning condition were observed during 1982. Nine Stizostedion larvae were collected from sites above Highway 非 3 Bridge, including the Milk River. This indicates that some walleye/sauger spawning does occur in the upper reaches of the study area.

A total of nine paddlefish larvae were collected in the river samples. They were collected below the Milk River confluence in the Nickels Ferry section and in the Chelsea, Brockton and Culbertson sections. It is believed that most of the paddlefish spawning was in the upper reaches of the river (i.e. Milk/Missouri River confluence area) or in the Milk River and, therefore, the larvae collected in the lower river sections most likely originated upriver.

Tributary streams. A total of 5,526 larval fish were collected in 77 samples from tributary streams of the Missouri River (Table 26). Appendix Tables 37-40 list the numerical values for collections in these streams during 1979-82. The streams sampled were the Milk, Redwater and Poplar rivers and Big Muddy Creek, the major tributaries of the Missouri.

Similar to the Missouri River, Cyprinidae Catostominae and Ictiobinae were major taxa noted at all tributaries. Yellow perch were common in both the Poplar River and Big Muddy Creek but were rare or absent in the drift samples from the Missouri and Milk rivers. Stizostedion was collected at three of the four tributaries and in lower numbers. Paddlefish larvae were found only in the Milk River.

Seasonal abundance

The greater abundance of larval fish in the Missouri River generally occurred during the month of June for all years except 1979 (Figures 6 and 7). During 1979 the timing of larval fish abundance for the Missouri River was considerably early, yet, for the tributary streams peak larval abundances were later than normal. No explanation can be offered for this departure from 1980-82 seasonal pattern of larval abundance. The average time peak larval abundance occurred was mid-June for both the Missouri River and tributary streams. Species composition, timing of spring run-off, and water temperature conditions undoubtedly influence when peak larval abundances will occur within seasonal limits.

\section{Relative abundance}

The abundance of larval fish in the Missouri River samples appeared to be relatively low. A comparison of total number of larvae collected per sample indicates that, on the average, the tributary stream catches were nearly 6 times greater than the larval fish catches for the Missouri River (Tables 25 and 26). During 1979 the quantities of water filtered for the larval fish samples were metered and the results confirmed the differences in larval densities between the mainstem and tributaries (Tables 27 and 28). Here average larval densities for the tributary streams were nearly 20 times greater than densities found in the Missouri. The best larval fish densities in the Missouri were at the Nickels Ferry Section. The most likely reason for this occurrence is probably related to the contribution of larvae from the Milk River. Considering the physical conditions (i.e. water temperatures and turbidities) in the Milk/Missouri confluence area it is also likely that this area is more favorable 

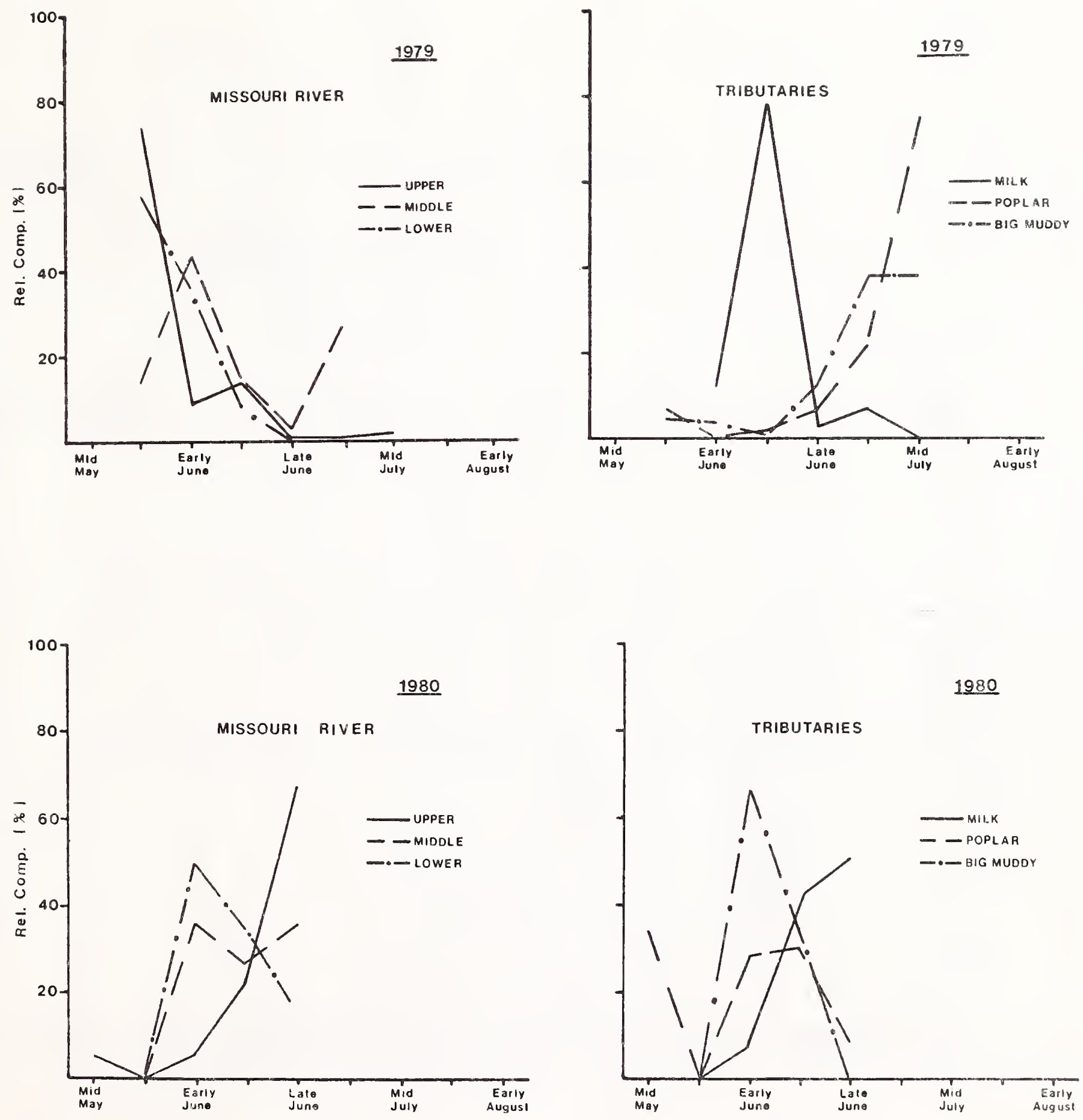

Figure 6. Relative percent composition of larval fish numbers collected in the Missouri River at three reaches and in three tributary streams, 1979 and 1980. 

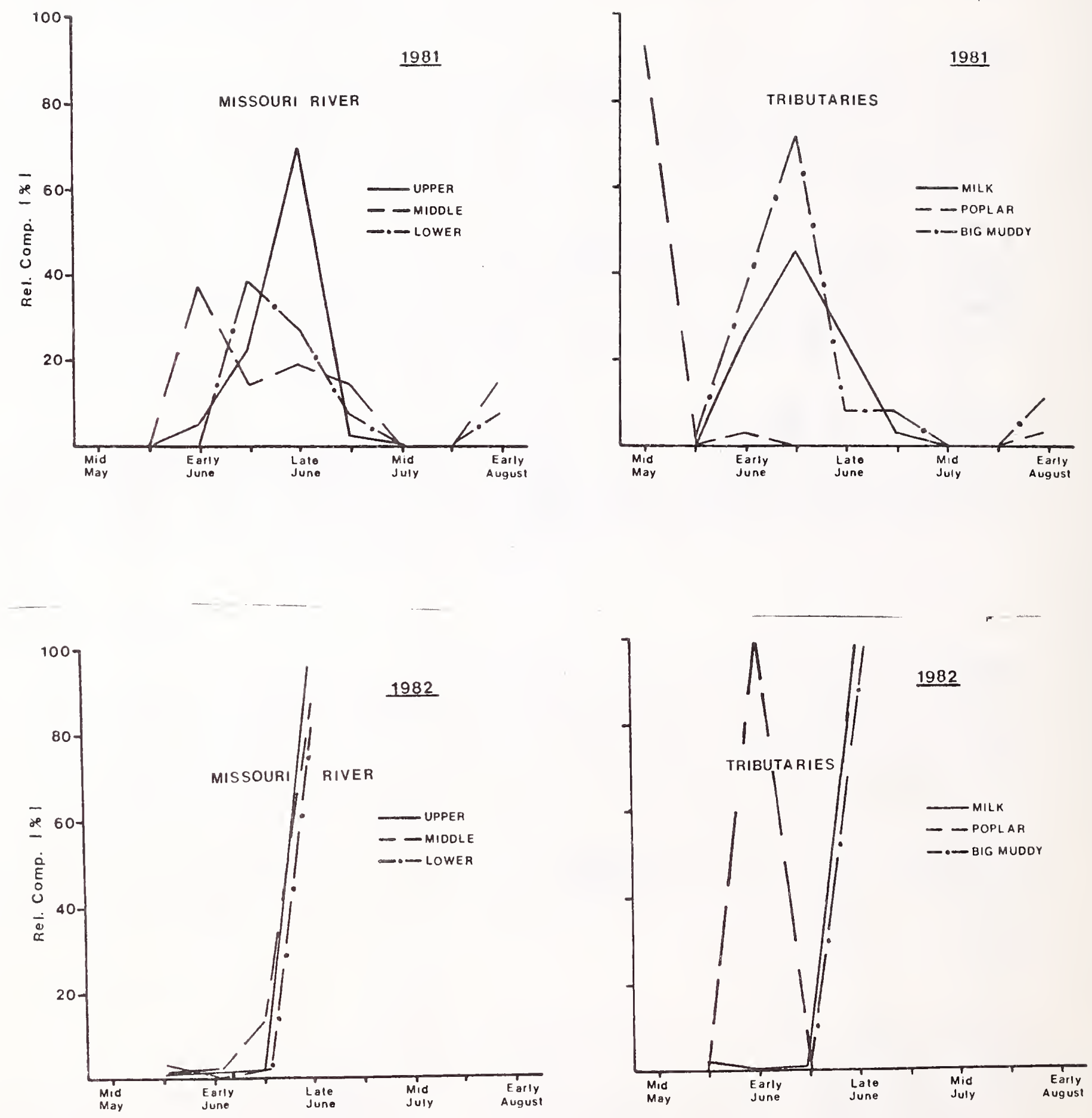

Figure 7. Relative percent composition of larval fish numbers collected in the Missouri River at three reaches and in three tributary streams, 1981 and 1982. 
岁

$\pm$

골

음

는.

다

워ํ

过

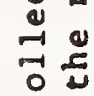

㟧

2 政

㟧

$\rightarrow$

कำ

竝

뜽 응

동

-1

-1

응

웅

䓀

단

to

ฆ

$\begin{array}{ll}0 \\ 0 \\ 0 & 0 \\ 0 & 0 \\ 0 & 0\end{array}$

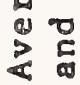

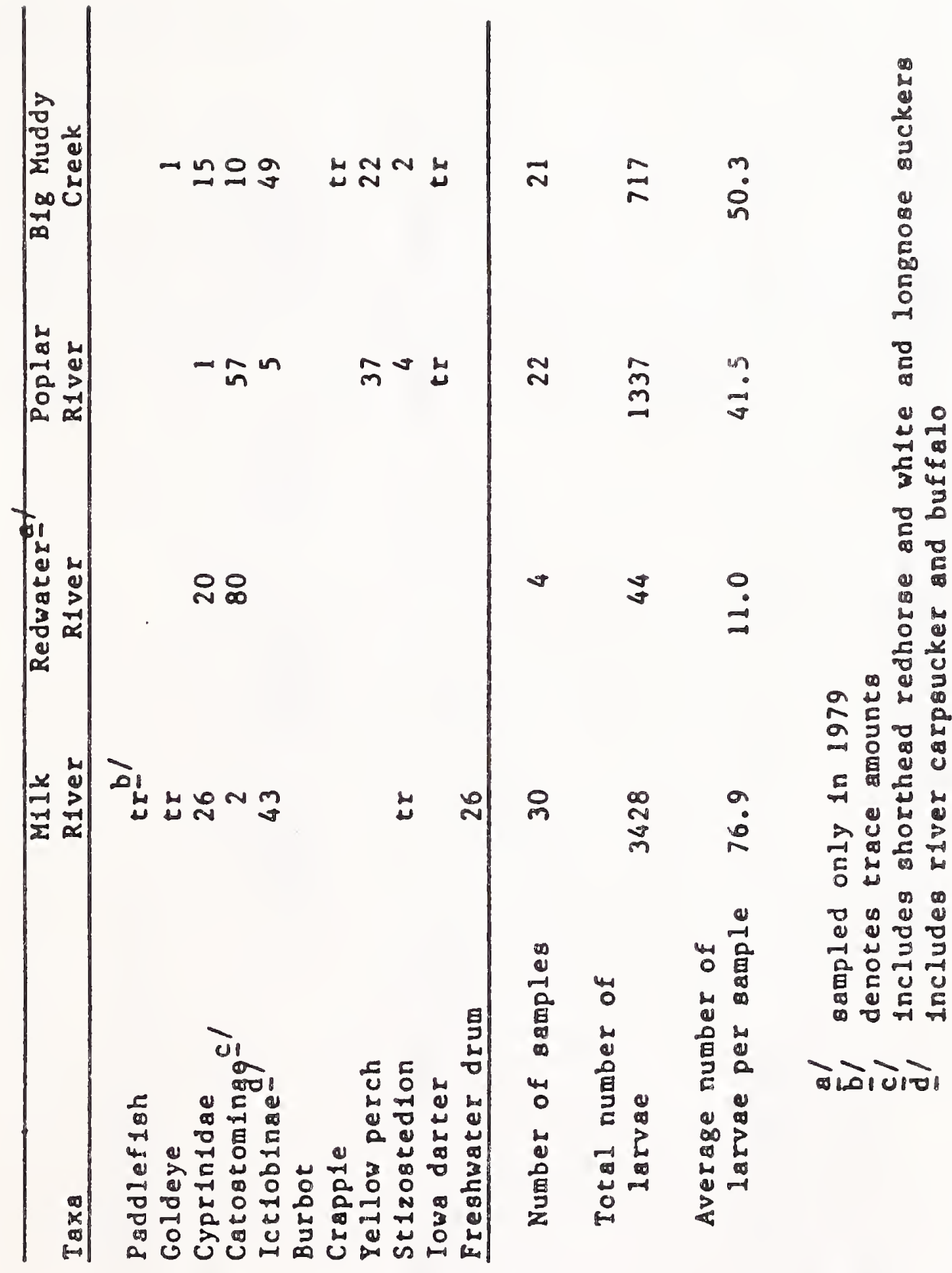




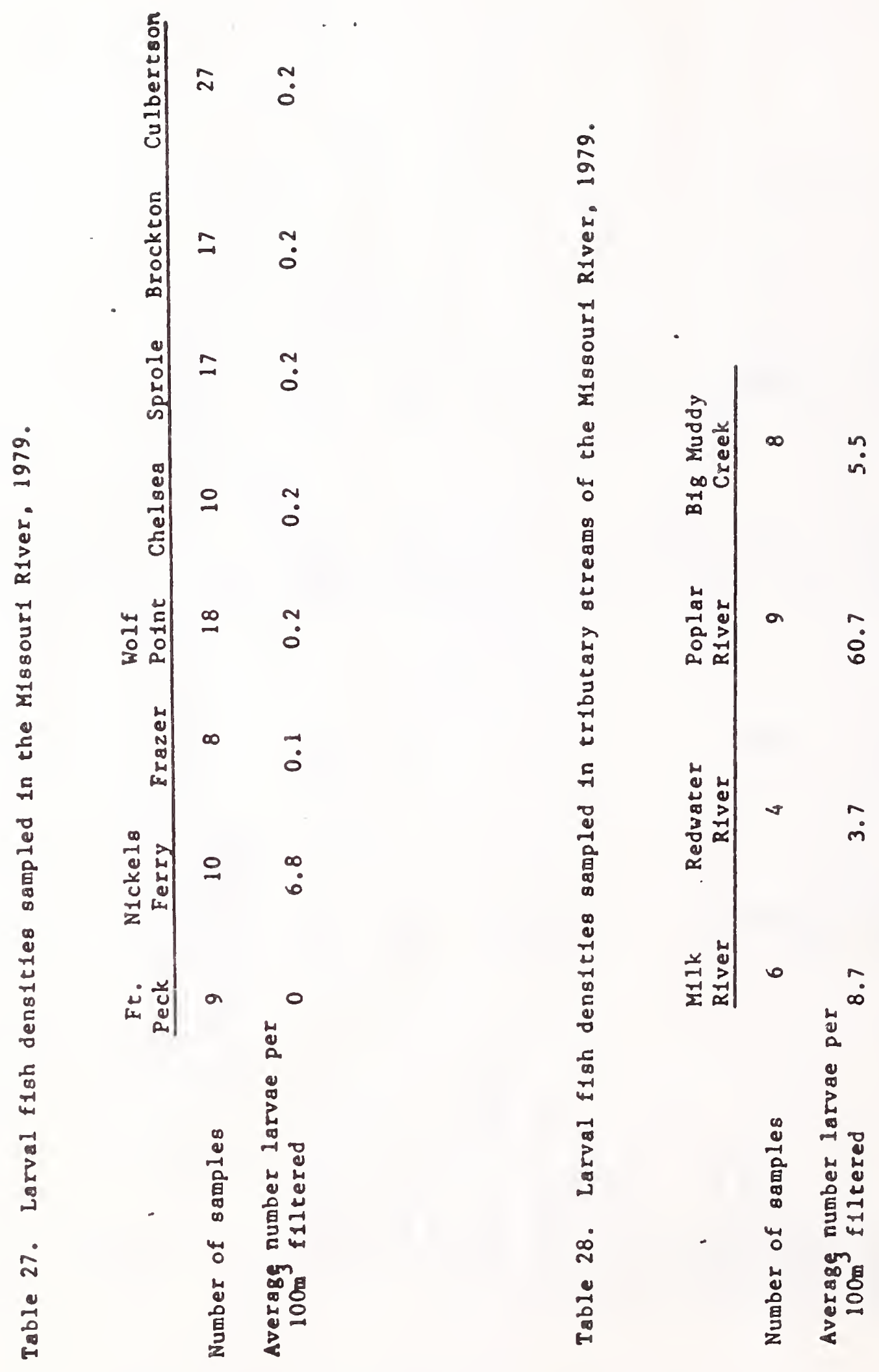


for larval fish production. The Milk and Poplar rivers both appeared to have

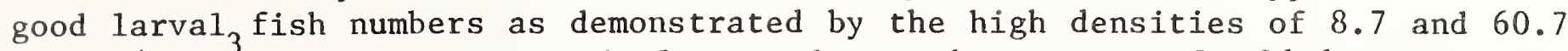
larvae/100m water, respectively, and catch rates of 96.6 and 71.5 larvae/sample, respectively. Larval fish densities found in the middle Missouri River were nearly 20 times greater than that found in this study (Berg 1981).

The annual abundance of larval fish between years appeared to be generally influenced by "spring" run-off conditions. Figure 8 indicates this trend for the river and partially for the Milk River. River larval densities differed between years corresponding to the spring flow conditions. When the Missouri iiver May/June flow at Culbertson during 1982 was relatively high (15,000 cfs) larval fish densities correspondingly were high. During low spring flow conditions such as experienced in 1980, low densities of larval fish were sampled. It should also be noted that larval fish densities in the river may have also been influenced by the tributaries' spring flows. The years 1979, 1982 and perhaps 1981 exhibited good spring-time tributary flows. These were the three years when larval fish densities in the river were the greatest. As previously mentioned the tributary streams of the Missouri River are not only important in themselves as spawning streams, but they also have a substantial influence on the mainstem by increasing turbidities, temperatures and flow - all of which are important for improving spawning conditions. 


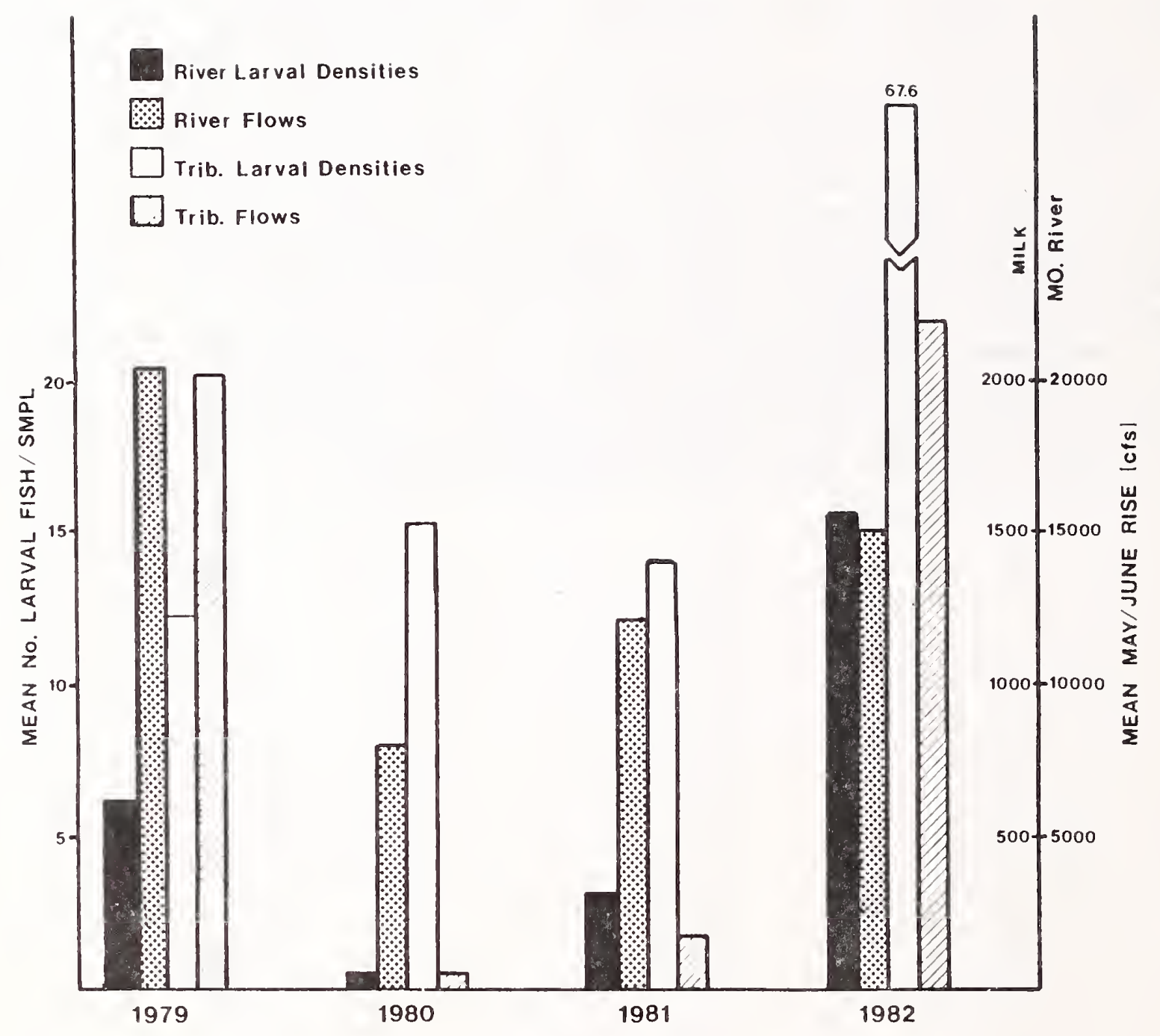

Figure 8. Comparison between flows in the Missouri River and a tributary (Milk River) stream, and larval fish catches. 
Paddlefish. The paddlefish is native to eastern Montana and is found in both the Yellowstone and Missouri river drainages. These paddlefish populations are largely residents of Fort Peck Reservoir and Lake Sakakawea, two large mainstem impoundments located on the Missouri River. A portion of the fish migrate out of the reservoirs and up the Missouri and Yellowstone rivers during the spring time, where they spawn in shallow gravelly areas. Destruction of spawning areas, blockage of migration movements by dams and dewatering of streams are some of the major environmental impacts which have affected paddlefish numbers in the past and threaten this species existence in the future (Carlson and Bonislawsky 1981). The paddlefish in Montana is listed as a "species of special concern" - Class A, the highest rating. Several other states recognize the sensitive status of the paddlefish and officially consider this species as rare or endangered (Miller 1972). Montana, however has some of the best paddlefish populations left in the Missouri River system.

Paddlefish were found in the study area in both the dredge cuts and in the river. Paddlefish in the dredge cuts have received considerable study. A population estimate made by Needham (1979) indicated the presence of over 3,000 paddlefish in the 684 acre Fort Peck upper dredge cuts during the summer, 1978. There is evidence to indicate that a portion of the paddlefish population in the dredge cuts is partially sedentary, remaining here several years (Frazer 1985). Frazer also reported that a significant interchange of fish between the lower Yellowstone River and the dredge cuts occurs as demonstrated by tagged fish recaptured from these locations.

The annual migration of paddlefish from Lake Sakakawea into the Missouri River was studied during 1979-82 and 1984. The objectives were to monitor the paddlefish movements in the river by defining timing and extent of river use. Location of spawning areas and relative abundance were also investigated. The migration was monitored by sampling with a boom mounted electrofishing boat using similar techniques as described by Berg (1981). The sampling plan was to determine the presence, numbers and locations of paddlefish. Therefore, only 150 of the 1826 fish observed during the four years of major study were measured and tagged. The numbers of fish counted were the results of sampling a limited area, representing only an index of their relative abundance and obviously not a complete census of paddlefish densities. Results of the counts for each section and time of year are given in Appendix Tables 41-46.

There were noticeable differences of paddlefish distributions in the study area between years (Figure 9). A good paddlefish run, with fish distributed well into the upper sections of the study area, was observed during 1982. Poor paddlefish runs and limited distributions were noted during 1980 and 1984. (The paddlefish population was not monitored during the spring of 1983). For these low water years average number of fish per trip was depressed in most sections and very few fish were found in upper river areas. The year 1981 exhibited a paddlefish run intermediate between the previously mentioned extremes. The results of the 1979 run were not entirely comparable with the other years because sampling efficiency during this year was lower due to inexperience. However, the strong showing of paddlefish numbers in the Nickels Ferry section during 1979 indicates there most likely was a good paddlefish run that year. 


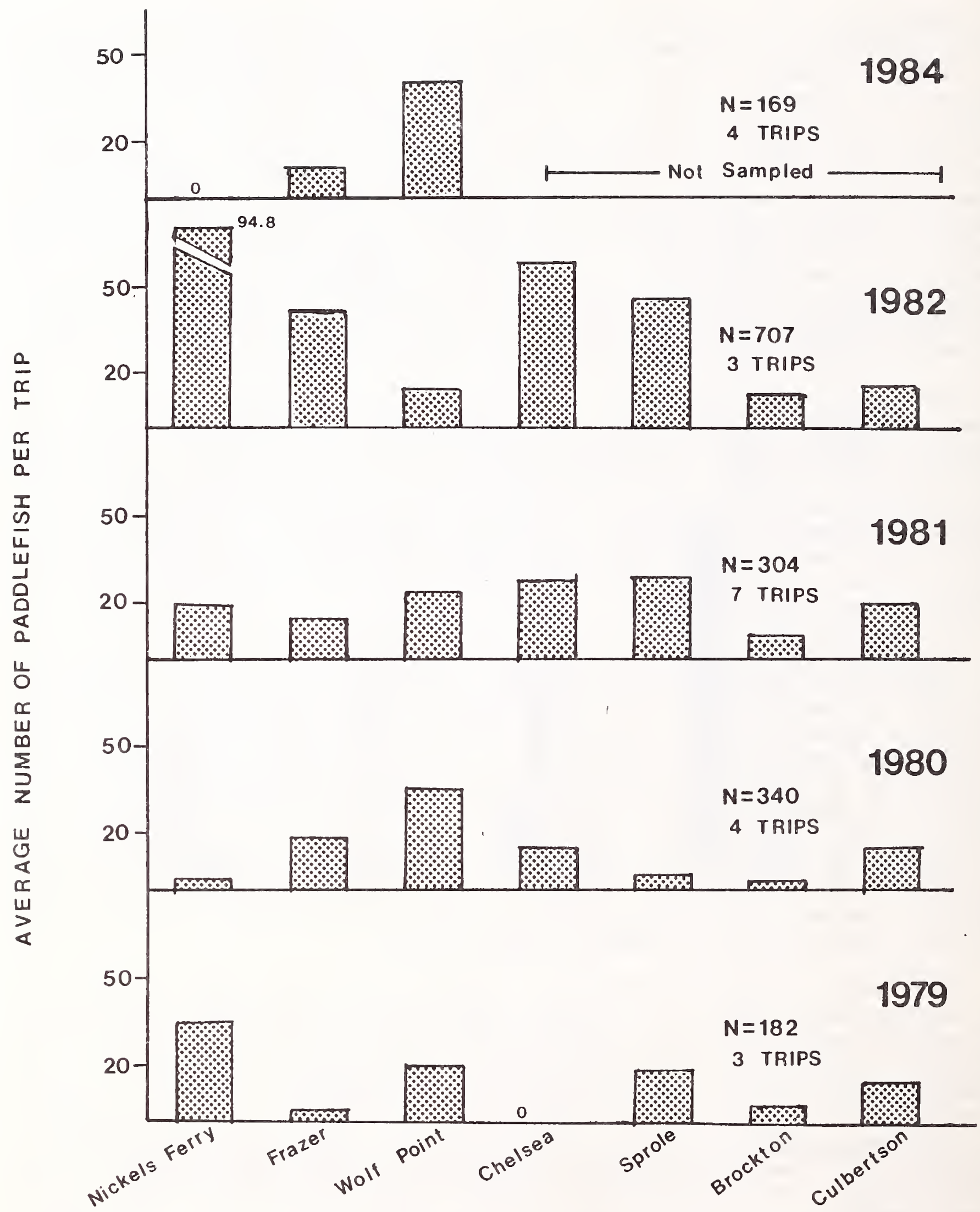

Figure 9. Number of paddlefish counted in each study section by electrofishing in the Missouri River, April-June. ( $N$ =the total number of paddlefish counted for a given year). 
Paddlefish usually require a substantial rise in river flow during the spring to trigger the spawning run (Purkett 1963, Berg 1981, Gardner and Berg 1982 and Rehwinke1 1978). This appeared to be the case for the lower Missouri River paddlefish, however, it was most likely to a lesser degree. Figure 9 shows average counts in the Nickels Ferry section, (a major spawning area) exceeded 60 fish per trip during the high water years of 1979 and 1982. Low spring counts, averaging less than 2 paddlefish per trip, were experienced during the poor water years of 1980 and 1984. Average monthly flows recorded at the Wolf Point USGS gauging station and the Milk River station near its mouth during 1979-1984 are presented in Table 29. Spring flows (May and June) were the greatest in 1979 and 1982 and least 1980 and 1984. Corresponding1y, the Milk River exhibited the greatest and least spring flows during the same years. Relating the strength of paddlefish run with river flow conditions indicates that the paddlefish were responding to the magnitude of flow in the Missouri River. It appears that both the Missouri and Milk rivers' spring flows are important to attract paddlefish up from the middle river areas into upper areas where their major spawning sites are located. The Milk River may play a greater role in attracting paddlefish up into their major spawning area. Usually, good spring flows in the Milk River drainage are accompanied by moderately high releases from Fort Peck Dam, so it is difficult to identify which river has the most influence on the paddlefish spawning run. Observations and data collected here suggest that good spring flows in the Milk River are essential for paddlefish migrations and greater discharges from Fort Peck dam cannot replace the lack of adequate spring runoff from the Milk. This was based on the following:

(1) Comparing the spring flows experienced in 1980 and 1981 and the paddlefish runs; it appeared that a better spring flow in the Milk during 1981 was the factor which was responsible for the better paddlefish run that year compared to 1980. The Milk River 1980 May and June average flows were $70 \%$ less than during 1981. This is compared to the Missouri's which only had a difference of $30 \%$ between these years, thus isolating the flow in the Milk River as the major influencing variable (Table 29).

(2) The literature suggests that paddlefish prefer warm turbid water (Purkett 1963 and Rehwinkel 1978). Upstream of the spawning area the Missouri is cold and clear, whereas, the Milk is warm and turbid (see previous section). The Milk River appears to be more attractive for paddlefish. When electrofishing the Missouri River in this area the paddlefish are all usually observed in the warm turbid plume below the Milk River.

It is also important that releases from Fort Peck Dam are not abnormally low. The volume of water supplied by the reservoir enhances the flow conditions in the river which are critical for maintaining the paddlefish spawning run.

Paddlefish most likely live in the Missouri River year-around, with largest numbers of them occurring during the spawning season, late spring and summer. They were noted in the river at the earliest beginning of the field season, April 1 and on the later field season date of October 15, 1980. Figure 10 shows the seasonal distribution and abundance of paddlefish during the spring. Only 1981 data was used because it was the most complete, paddlefish movements were monitored more intensely that year and the migratory run, although just fair, had a timing which was judged to be representative of normal years. It is obvious from Figure 10 that the abundance of paddlefish within the reaches 
Table 29. Average monthly flows in the Missourl River (at Wolf Point) and Milk R1ver (near mouth) and condition of paddlef1sh spawning run, 1979-84.

\begin{tabular}{|c|c|c|c|c|}
\hline \multirow[t]{2}{*}{. } & & \multicolumn{2}{|c|}{$\begin{array}{l}\text { Average Monthly } \\
\text { Flow (cfs) }\end{array}$} & $\begin{array}{l}\text { Condition of } \\
\text { Paddlefish Run }\end{array}$ \\
\hline & & May & June & \\
\hline 1979 & $\begin{array}{l}\text { Missour1 R. } \\
\text { M1lk R. }\end{array}$ & $\begin{array}{r}21,800 \\
3,800\end{array}$ & $\begin{array}{r}13,730 \\
662\end{array}$ & good \\
\hline 1980 & $\begin{array}{l}\text { M1ssour1 R. } \\
\text { M1lk R. }\end{array}$ & $\begin{array}{r}6,934 \\
44\end{array}$ & $\begin{array}{r}9,311 \\
52\end{array}$ & poor \\
\hline 1981 & $\begin{array}{l}\text { Missour1 R. } \\
\text { M1lk R. }\end{array}$ & $\begin{array}{r}10,240 \\
112\end{array}$ & $\begin{array}{r}13,080 \\
247\end{array}$ & falr \\
\hline 1982 & $\begin{array}{l}\text { Missour1 R. } \\
\text { Milk R. }\end{array}$ & $\begin{array}{r}11.790 \\
662\end{array}$ & $\begin{array}{r}16,240 \\
3,731\end{array}$ & very good \\
\hline 1983 & $\begin{array}{l}\text { M1ssour1 R. } \\
\text { M1lk R. }\end{array}$ & $\begin{array}{r}7,276 \\
513\end{array}$ & $\begin{array}{r}6.965 \\
110\end{array}$ & not sampled \\
\hline 1984 & $\begin{array}{l}\text { M1ssour1 R. } \\
\text { M11k R. }\end{array}$ & $\begin{array}{r}9,141 \\
20\end{array}$ & $\begin{array}{r}9,890 \\
28\end{array}$ & poor \\
\hline
\end{tabular}




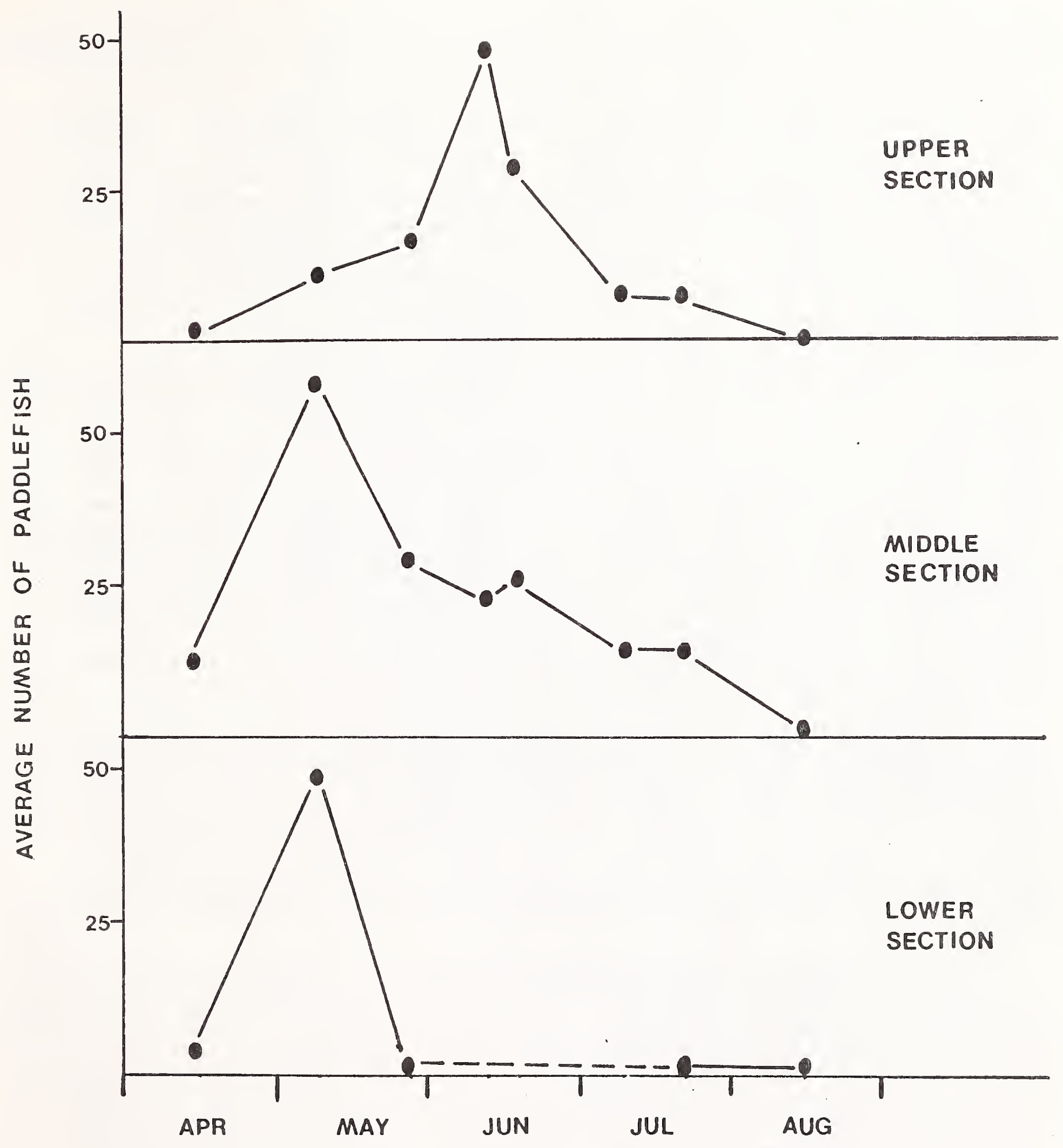

Figure 10. Seasonal distribution and abundance of paddlefish in three reaches of the Missouri River, 1981. 
shifts substantially from April through July, indicating significant spawning movement patterns. Concentrations of paddlefish were first noted during late April in both the lower river reach (where they quickly migrated through) and in the middle river reach where they staged for a considerable amount of time. When the environmental conditions were met; $60 \mathrm{~F}$ water temperature, increased water turbidities, proper photo period duration and a high river flow (usually late May through June) (Purkett 1963), a large increase in paddlefish numbers were observed in the upper river sections for at least a month. These observations suggest that, under normal spring-time water conditions, paddlefish will migrate out of Lake Sakakawea Reservoir, move through the lower river reach, at least 100 miles, into the middle river reach, where they stage. If the Milk and Missouri rivers are of an adequate flow, the fish will further migrate up into the upper river reach or up the Milk River to spawn.

The paddlefish migration pattern observed here was different than other migration patterns reported elsewhere. Most investigators report that paddlefish do not leave a reservoir situation and migrate up river significantly until a major rise in the river flow occurs (Rehwinkel 1978 and Berg, 1981). The paddlefish studied here apparently did not require a major rise in river flow to migrate out of Lake Sakakawea Reservoir up into their staging areas. However, high spring flows, especially in the Milk River, appear to be essential for attracting paddlefish up into their major spawning grounds. Another paddlefish run which also originates from Lake Sakakawea Reservoir but ascends the Yellowstone River apparently do not move into the Yellowstone until river flows are of a great enough magnitude (Stewart 1985). The depressed paddlefish run observed in the Yellowstone during 1985 was attributed to the exceptionally low spring runoff flows and exemplifies the need for good spring flows.

Paddlefish also ascend the Milk River and spawn on the flooded gravel bars. Several paddlefish larvae were sampled in the Milk near its mouth and 110 miles upstream during good run-off years (Needham 1979 and 1983). An adult paddlefish tagged in the dredge cuts during 1978 was found dead one year later in the Milk River 65 miles above the mouth apparently stranded during receeding flows (Needham, personal communication). These findings indicate that paddlefish spawn within a 117-mile reach of the lower Milk. A 50-foot-high-dam located on the river blocks further upstream paddlefish migration and spawning in this system.

There are possibilities that paddlefish spawning may occur in other areas of the Missouri River besides the Nickels Ferry section. Spring run-off conditions in the Milk River were extremely low during 1984. Consequently, paddlefish were not observed at their major spawning areas of the Milk River and Milk/Missouri confluence areas. However, after a heavy rainstorm substantial numbers of paddlefish were found concentrated below the mouths of small intermittent tributary streams. These streams were discharging a significant volume of warm turbid water into the Missouri and paddlefish were orientated in the warm turbid plume of the stream. These concentrations of paddlefish could have been spawning. Two of the streams where this was noted was Prairie Elk Creek, situated between the Frazer and Wolf Point sections, and Sand Creek, located in the Wolf Point Section. USGS stream discharge records have shown that several tributary streams in the lower Missouri drainage including Prairie E1k Creek discharge large volumes of water after heavy precipitation in the drainage (Refer to previous section). Desirable conditions for paddlefish 
spawning could be provided by these tributary streams under the right circumstances.

Sauger. Sauger spawning in the study area was largely confined to the Milk/Missouri River confluence area, several isolated sites below the Highway \#13 Bridge to Nohly Bridge and the Milk River. Concentrations of sauger in spawning condition were noted in these areas during the spring. Sauger appeared to use the Milk/Missouri confluence area for spawning during times when the Milk River had an ample enough discharge to create a turbid warmwater plume into the Missouri. This area affected by the plume extended at least five miles below the mouth of the Milk River. The reach of the Missouri River which sauger used for spawning was determined to be from Highway 非13 Bridge to Nohly Bridge, but limited to about 14 gravelly or rocky reef areas varying in length from 200-600 yards and often not extending the full width of the river. During the spawning period in May, few sauger of any kind could be found at any location except near these rocky and gravelly areas of the river.

Table 30 is a review of the larval Stizostedion sp. catches. Most of these larvae were probably sauger and not walleye because sauger was the most common sport fish found throughout the study area. The locations where larval Stizostedion sp. were sampled coincided with the locations where concentrations of adult sauger were sampled in the spring time. This table also indicates that the major sauger spawning occurs from the Sprole Section and downstream, corroborating with the locations where most of the spawning adults were sampled.

The magnitude of the sauger spawning run was much greater in 1982 than during 1980 or 1981. Catch rates were over 12 times greater in 1982 compared to the previous two years (Table 31). During 1982 spring runoff was above average and the sauger responded to these favorable conditions. Spring runoff conditions were poor in 1980 and, correspondingly, numbers of sauger in the river were low. Spring runoff conditions during 1981 were again below normal. Very little sampling effort was directed at monitoring the sauger run that year and the extent of run was undetermined.

The sauger spawning period in the Missouri River, as depicted by the presence of ripe females, extended from late April through late May, the last sampling date. It was possible that sauger were also spawning in early June, since a few ripe females were still noted during late May. Sampling of the sauger spawning run was not conducted during June. Figure 11 shows the peak of spawning occurred during mid to late May. This was the period when the greatest numbers of ripe and spent females were noted. The Milk River appeared to have the same sauger spawning period, however, peak spawning most likely occurred in early May (Figure 12). These observations of spawning condition of sauger in the Milk River were similar to those reported by Haddix and Estes (1976) for the Yellowstone River, Elser et al. (1977) for the Tongue, Berg (1981) for the Marias River and Gardner and Berg (1982) for the middle Missouri River. Peak sauger spawning in the lower Missouri River occurs about 15 days later than for most sauger rivers in the state. This is most likely due to the cooler water temperature conditions here resulting from coldwater releases from Fort peck Dam.

Rainbow trout. A rainbow trout spawning run within the tailwater of Fort Peck Dam has developed over the past 10 years. This run was observed the first year this study was in progress (1979). The spawning population was monitored during 

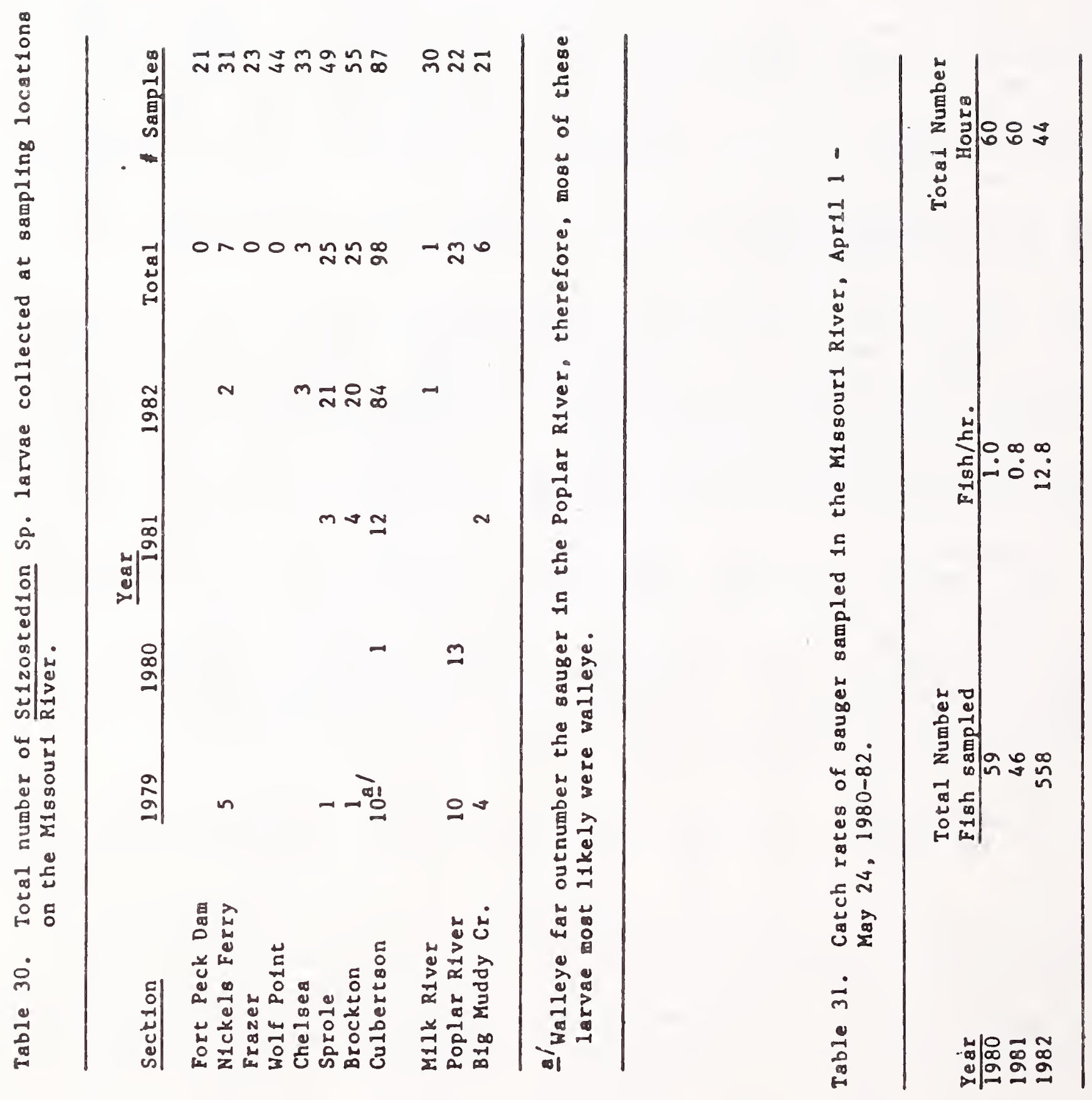


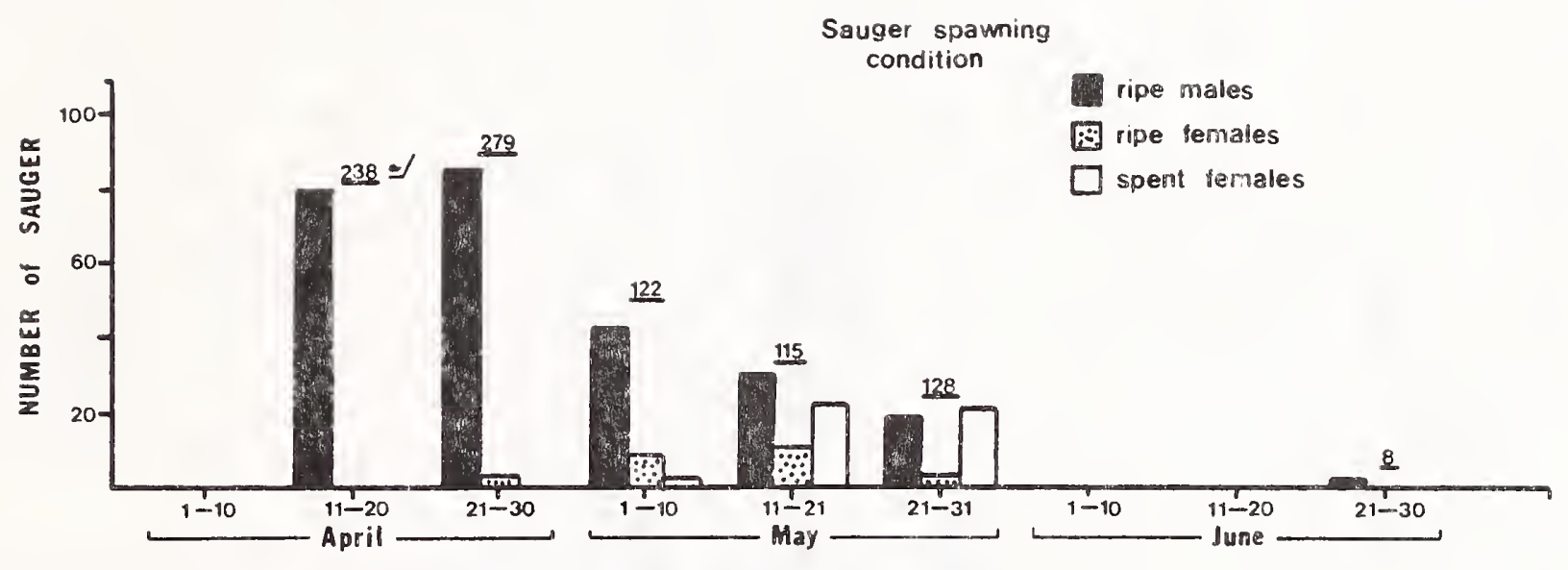

Figure 11. Spawning condition of sauger sampled in the lower Missouri River during the Spring, 1979 and 1982.

a/ denotes total numbers of sauger examined for spawning condition, including fish determined in non-spawning condition. 


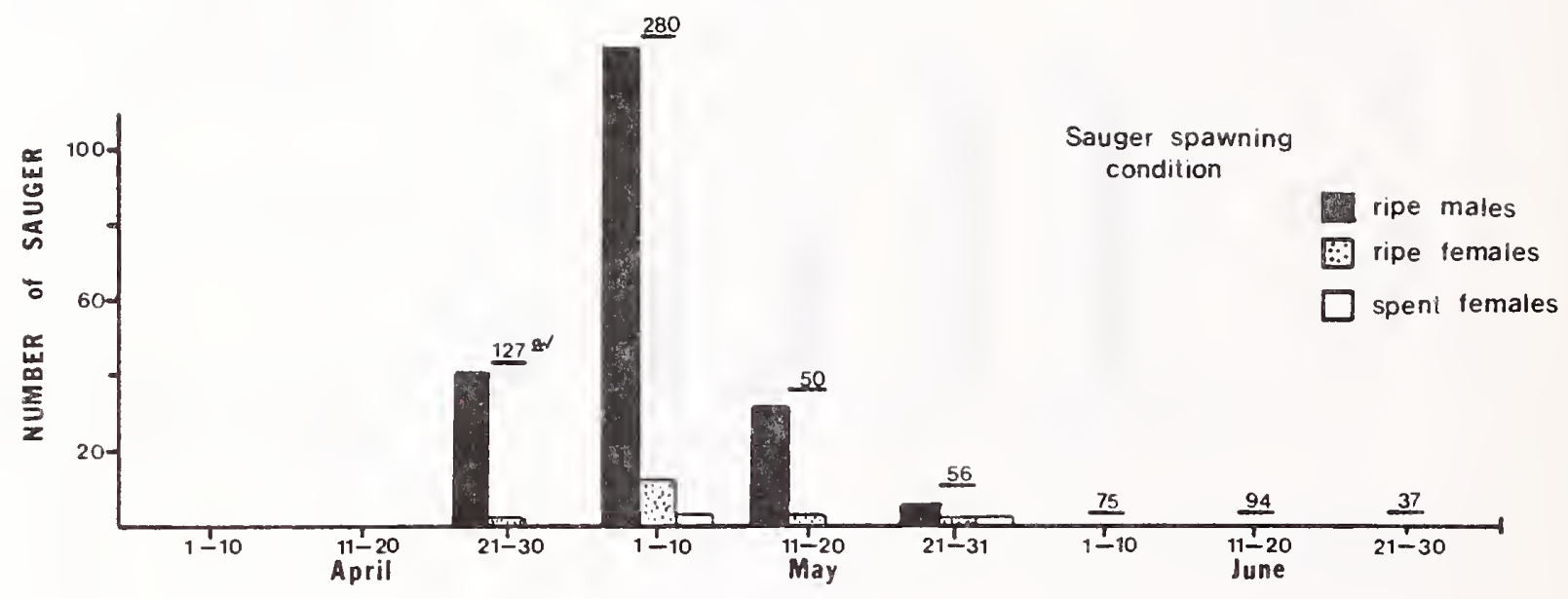

Figure 12. Spawning condition of sauger sampled in the Milk River near its confluence with the Missouri River during Spring, 1979-82 and 1984.

a/ denotes number of sauger examined for spawning condition including fish determined in non-spawning condition. 
1980 and 1981 and a total of 72 fish were captured and measured. Average size was large, with lengths and weights of 21.9 inches and 3.87 pounds. The spawning population was believed to be small as witnessed by the number of tagged fish recaptured ( 7.2 to 27.3 percent) for the period 1980-83 (Frazer 1985).

Most spawning occurred in a well developed side channel a few miles below Ft. Peck Dam, although a few redds and trout in spawning condition were noted in the main channel as far as 6 miles downstream of the dam. The majority of rainbow trout spawning occurred in late April through May during the 1983 and 1984 seasons (Frazer 1985). Water temperatures were monitored in the side channel during 1983 and it appeared that the majority of spawning occurred after maximum temperatures surpassed $50 \mathrm{~F}$. Minimum and maximum temperatures monitored during the spawning season averaged $45 \mathrm{~F}$ and $51 \mathrm{~F}$ (Appendix Table 47). It should be noted that water temperatures in the main channel probably were cooler during this period. This occurrence was most likely related to the difference in water exchange rate between the two river areas. A more detailed description of rainbow trout life history in the downstream area has been reported by Frazer (1985).

Other sport fish. Walleye and northern pike were two other sport fish which were found in spawning condition in the study area. Walleye spawners were usually associated with sauger in gravelly areas but in fewer numbers. Fair concentrations of spawners were noted in the Brockton and Culbertson sections. In addition to these areas there was a significant concentration of spawning walleye located in a riffle area within the Fort Peck Dam section. The spawners here, as elsewhere, were large averaging 19.5 inches and 2.80 pounds (Stewart 1983 and Gardner 1984). The walleye spawning run most likely originates from Lake Sakakawea Reservoir (Refer to fish movement section). Walleye from Lake Sakakawea also run up the Yellowstone River where large spawning concentrations occur in the spring (Phil Stewart, personal communication).

Greater average sizes and catch rates of walleye in the spring compared to other seasons would indicate a spawning run moving into the study area. This was evident during most years with 1982 (a year when monitoring was most comprehensive) used as an example (Table 32). Walleye sampled in the study area during the spring averaged 19.4 inches and nearly 3 pounds compared to the smaller sizes noted during the summer which averaged 17.2 inches and 2.27 pounds. This size difference was attributed to the seasonal presence of large spawning walleye. A comparison of walleye catch rates for spring versus summer was 1.3 and $0.3 \mathrm{fish}$ per hour, respectively. The difference in catch rates was believed to be attributed to the influx of migratory spawners.

The walleye spawning run in the study area appeared to be smaller than that reported for the lower Yellowstone River. Catch rates of walleye in spawning areas of the Missouri River were about 10 fish per hour compared to the Yellowstone at Intake where catches are reported to be about 20-80 fish per hour (Phil Stewart, personal communication). The spawning period for walleye in the Missouri River extended from late April through early May, similar to that for the lower Yellowstone run.

Northern pike in spawning condition were found mostly in the Missouri River from the Wolf Point section and downriver through the study area. They were also sampled in the dredge ponds and tributary streams. Pflieger (1975) 
describes pike spawning habitat as occurring in marshes or shallow water margins. Eggs are broadcast over submerged vegetation and are adhesive (Frost and Kipling 1967). Several of the pike spawners sampled in the study area were found near backwaters, channel margins, or tributary embayments which contained submerged vegetation. Most of the northern pike spawners probably were residents of the study area. Fish movement data does not indicate increased movements during the spawning season (refer to movement section). Average sizes of pike in the spring were 24.2 inches and 4.20 pounds, similar to the summer averages of 26.3 and 4.04 pounds (Table 32). Catch rates were also similar. These facts imply there were few if any, migratory spawners moving into the area, along with an increase in numbers associated with a run up the river. The spawning period for northern pike in the Missouri extended from early April through mid-May.

Conclusive evidence of shovelnose sturgeon spawning in the lower Missouri River was not documented during this study, however some shovelnose sturgeon must be able to reproduce in the lower Missouri River study area. The shovelnose sturgeon spawning period in the Missouri River above Fort Peck Dam was reported to range between late may and early July (Gardner and Berg 1982). During the period of this study there was no indication of spawning activities by shovelnose sturgeon. Brown (1971) reports that shovelnose sturgeon spawn at water temperatures between $60 \mathrm{~F}$ and $70 \mathrm{~F}$. Missouri River water temperatures during the spawning season were barely approaching the low 60 's and could be a factor affecting initiation of spawning. However, there are limited areas below tributary streams where warm-water mixing zones most likely provide spawning temperature criteria. Below the confluence of the Milk River would be the most likely area, although the other larger and some small tributary streams could provide substantial warm-water plumes. Evidence of shovelnose reproduction is the obvious abundance of the species at apparently stable levels. Examinations of 24 female sturgeon revealed seven which contained mature eggs (Table 33). Also, aging of sturgeon spines showned characteristic annuli belt patterns which several investigators attribute to being the result of slower growth during periods of gonadal development (Roussow 1957).

It did not appear that shovelnose sturgeon migrated up into the larger tributary streams in the study area. Surveys of the lower Milk and Poplar rivers indicated that few, if any, sturgeon use these tributaries during their spawning season. Successful shovelnose sturgeon spawning has been reported in major tributary streams of the middle Missouri and Yellowstone rivers of Montana (Berg 1981 and Stewart personal communication).

Very little information was gathered concerning the spawning habits of pallid sturgeon, channel catfish, burbot and smallmouth bass because of their low population numbers or the difficulty of monitoring them during their spawning stage.

Sportfish Rearing

All seven study sections were sampled in an effort to define important rearing areas used by sportfish species. Peripheral habitats and main channel areas were seined and electrofished to determine their presence. Results of survey sampling indicated that young-of-the-year (YOY) sauger was the most abundant sportfish rearing in the study area. A moderate seining effort recovered 63 sauger and 7 walleye. Electrofishing collected a few more YOY of 
Table 32. Average $81 z e s$ and catch rates of walleye and northern plke sampled by electrofishing in the Missourt River during 1982.

\begin{tabular}{|c|c|c|c|c|}
\hline WALLEYE & & & & \\
\hline & AVERAGE & AVERAGE & & TOTAL \\
\hline • & LENGTH & WEIGHT & CPUE & NUMBER \\
\hline Spring & 19.4 & 2.92 & 1.3 & 61 \\
\hline Sumber & 17.2 & 2.27 & 0.3 & 47 \\
\hline \multicolumn{5}{|c|}{ NORTHERN PIRE } \\
\hline & AVERAGE & AVERAGE & & TOTAL \\
\hline & LENGTH & WEIGHT & CPUE & NUMBER \\
\hline Spring & 24.2 & 4.20 & 1.3 & 69 \\
\hline Summer & 26.3 & 4.04 & 0.8 & 109 \\
\hline
\end{tabular}


Table 33. Gonad cond1tion of shovelnose sturgeon in the M1ssour1 River, 1982. as determined by interal examination.

\begin{tabular}{|c|c|c|c|c|c|}
\hline \multirow[b]{3}{*}{ Locacion } & \multirow{3}{*}{$\begin{array}{c}\text { Number } \\
\text { Plsh Exanined }\end{array}$} & \multicolumn{2}{|c|}{$-\infty-$ Females- } & \multicolumn{2}{|c|}{$-\infty-$ Males- } \\
\hline & & Mature & Irmature & Mature & Imonature \\
\hline & & Egg8 & E8g8 & & \\
\hline N1ckels Perry & 15 & 1 & 11 & & 3 \\
\hline Wolf Polnt & 4 & 4 & 0 & & 0 \\
\hline Chelsea & 2 & 0 & 1 & & 1 \\
\hline Brockton & 1 & 1 & 0 & & 0 \\
\hline Culbertson & 2 & 1 & 1 & & 0 \\
\hline
\end{tabular}


these two species plus a few YOY northern pike and burbot. No YOY shovelnose sturgeon, paddlefish, channel catfish and smallmouth bass were sampled.

Most of the YOY sauger were sampled in the lower $80 \mathrm{miles}$ of the study area between the confluence of the Poplar River and North Dakota border (Table 34). Within this reach catch rates of YOY sauger averaged 1.5 fish per seine haul. An average catch rate of 1.5 YOY sauger per seine haul was reported for the middle Missouri River 275 miles upstream (Garder and Berg 1982). Young-of-the-year sauger were usually sampled in substantial numbers in calm water areas such as off-channel pools protected by lateral sand bars as depicted 1n Figure 13. Pools with depths less than 1.5 feet in depth usually did not contain YOY sauger. Other areas which were not as protected and having a noticeable river current, did not appear to be favorable rearing habitat. Preferred sauger rearing habitat found in this study differed from that reported as ideal rearing habitat for the middle Missouri River (Gardner and Berg 1982). Side channel pools were preferred in the middle Missouri. This type of habitat was not prevalent in the study area. It is apparent that both types of habitat are structurally similar (i.e. both in calm river areas and separated from the main channel) and therefore serve the same function.

Movements of fish as indicated by tag returns

An understanding of fish movement patterns is an essential consideration for comprehending the fisheries dynamics in the lower Missouri River. A tagging study was the principal method for evaluating the movement patterns of several sport fish in the study area. Tagging studies can provide information about (1) stock identification to determine the home location for spawning fish; (2) migrations, including the path and distance of migration, rate of movement and homing tendencies of a species; (3) behavior, including factors that limit abundance, such as habitat selection and intra-and interspecies interactions, or other factors, such as being attracted to vulnerable forage organisms; and (4) mortality rates, such as the effects of natural and fishing mortality on a population (Wydoski and Emery 1983).

A total of 6,462 fish of 8 species were marked with individually numbered tags during the period July 1979 through May, 1984. Most of these fish were tagged in the mainstem of the Missouri and lower Milk rivers. The species tagged included 150 paddlefish, 338 shovelnose sturgeon, 210 rainbow trout, 496 northern pike, 155 channel catfish, 193 burbot, 4530 sauger and 390 walleye. More tagged walleye were recovered relative to the total marked than any other sport fish. Their tag recovery percentage was $17 \%$ followed by rainbow trout (16\%), northern pike ( $11 \%)$, sauger ( $8 \%)$, channel catfish (6\%), burbot (6\%), paddlefish (3\%) and shovelnose sturgeon (trace amounts). The recaptures of these tagged fish provided insight on fish movement patterns in the lower Missouri River system.

Sauger. Sauger appeared to be a highly mobile fish within the Missouri River and associated water system. Nearly $50 \%$ of the recaptured sauger moved over distances greater than 10 miles. One sauger travelled 420 miles over a 628-day period. Another sauger covered a similar distance in 121 days. This distance represented the maximum mileage which is physically possible since barriers (dams) prevent further migration. Tagging data also indicate that sauger caught in the Missouri River not only move lengthy distances but they also travel throughout the 150-mile long Lake Sakakawea Reservoir and the lower 


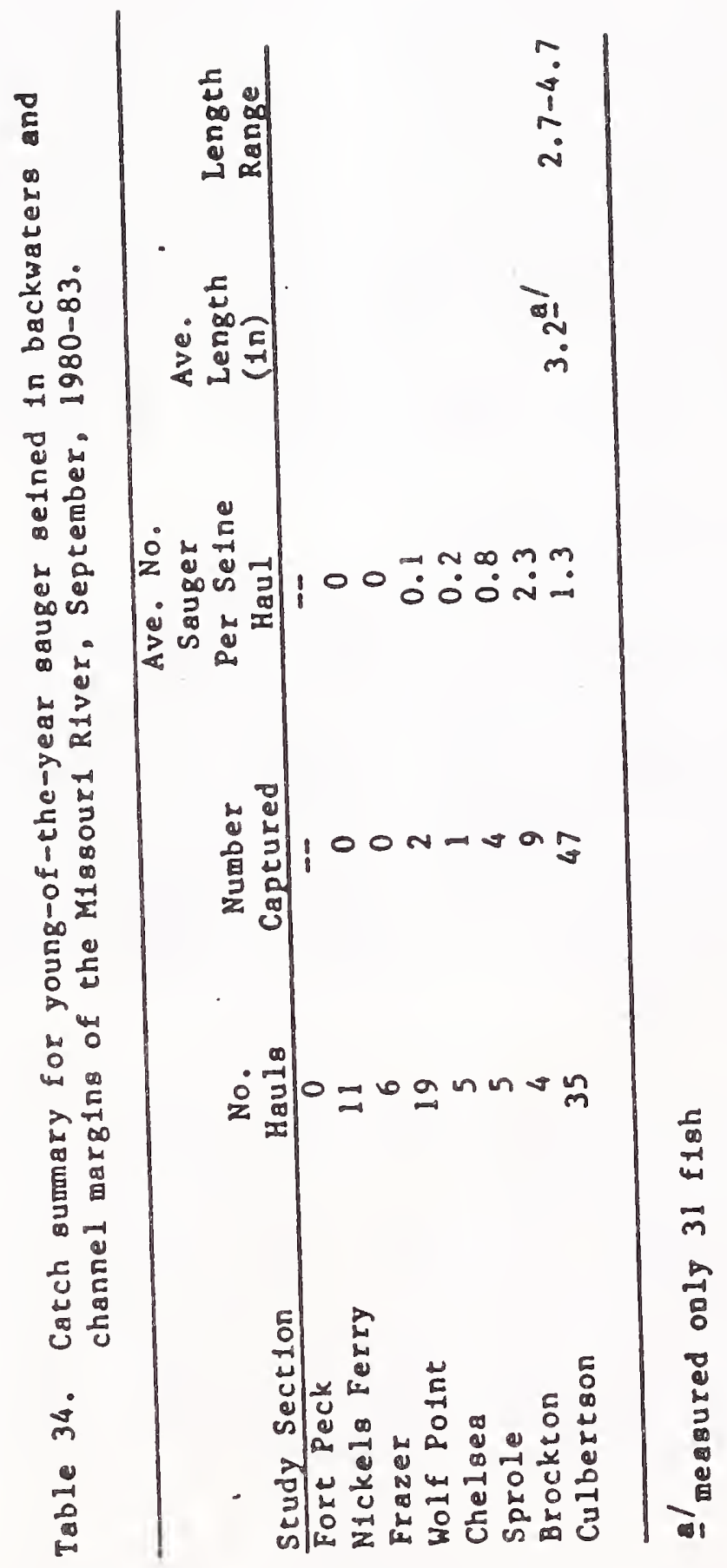




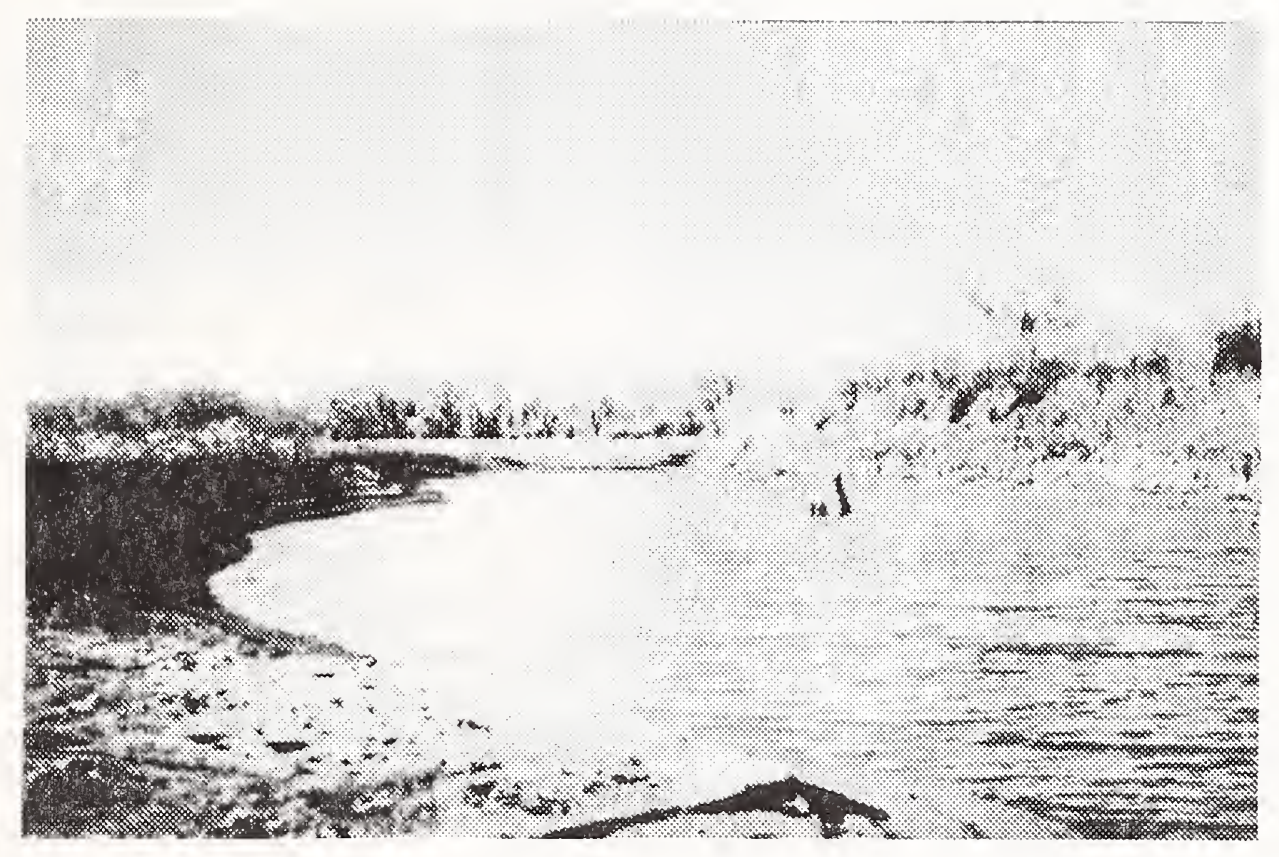

Figure 13. Young-of-the-year sauger were iypically found in these types of off-channel areas. 
Yellowstone River. Sauger in river environments commonly move long distances. Berg (1981) reported that $46 \%$ of the sauger tagged in the middle Missouri River, Montana moved 10 miles or more with maximum recorded movements of 184 miles. other researchers have described similar wide-ranging sauger movements. (Graham and Penkal 1978; Posewitz 1963 and Morris 1965). There were five movement patterns which dominated all other possibilities. These patterns basically involved the river and Lake Sakakawea or the attration to the Milk/Missouri River confluence area. The five movement patterns reported below represented $68 \%$ of all the recaptured tagged sauger (Table 35 ).

1. Sauger movement within the upper river reach was the most common pattern, represented by $26 \%$ of all the recovered tags. This would imply that sauger were mostly sedentary and did not move extensively. However, this is believed not to be the case. By examining the season when fish were tagged and recovered it was evident that $75 \%$ were tagged and/or recovered during the spring to the mid-summer periods (Appendix Table 48). Very few sauger were either tagged or recovered in this reach during the late summer-fall period because few sauger remained in the area. A complete description of this movement pattern, therefore, could not be based on tag recoveries alone. Electrofishing results revealed that significant concentrations of sauger usually occur in the upper river reach (mostly downstream of the Milk River confluence) during spring to mid-summer. The sauger are attracted to this area because of the warm turbid plume of the Milk River which apparently is favored for spawning and foraging activities. Usually the effects of the Milk River plume are substantially reduced by the late summer because of reduced flows. Responding to the loss of these favorable conditions, the concentration of sauger disperse. In summary it appears, that under normal conditions, sauger gather in the Milk/Missouri River confluence area during the spring when the Milk River plume begins. Sauger concentrations remain until the plume ceases (usually about 4 months) and at that time the concentration disperses.

2. Sauger movement from the upper river upstream to the Fort Peck tailwaters was indicated by $8 \%$ of all the recovered sauger tags. This upstream movement usually involved a distance of 5 to $10 \mathrm{miles.} \mathrm{About} 70 \%$ were tagged during the spring in the upper river reach and nearly $80 \%$ of these were recovered during the fall in the tailwaters area, clearly illustrating this movement both in time and space. A most likely reason for this pattern would be that the sauger move into the upper river (chiefly in the Milk/Missouri River confluence area) during the spring to spawn and forage until late summer and fall when the Milk River reaches a low flow (with no turbid plume). This low flow triggers the sauger to disperse and a good majority of them move upstream into the tailwaters area of Fort Peck Dam.

3. Sauger movement within the lower river reach was indicated by $14 \%$ of al1 the recovered sauger tags. There did not appear to be any noticeable seasonal pattern between tagging and tag recovery, indicating that a group of fish maintained their presence throughout the sampling period.

4. Sauger movement between upper/middle reach (combined) and Lake Sakakawea was indicated by $9 \%$ of all the recovered sauger tags. This movement pattern was variable between years and most likely related to river flow conditions and spawning and foraging activities. It was noted that no fish which were tagged during 1979 and 1980 exhibited this movement 
Iable 35. Percentage of recaptured tagged flsh whlch exhlbited a designated movewent pattern in the lower Missourl River dralnage, 1979-1984.

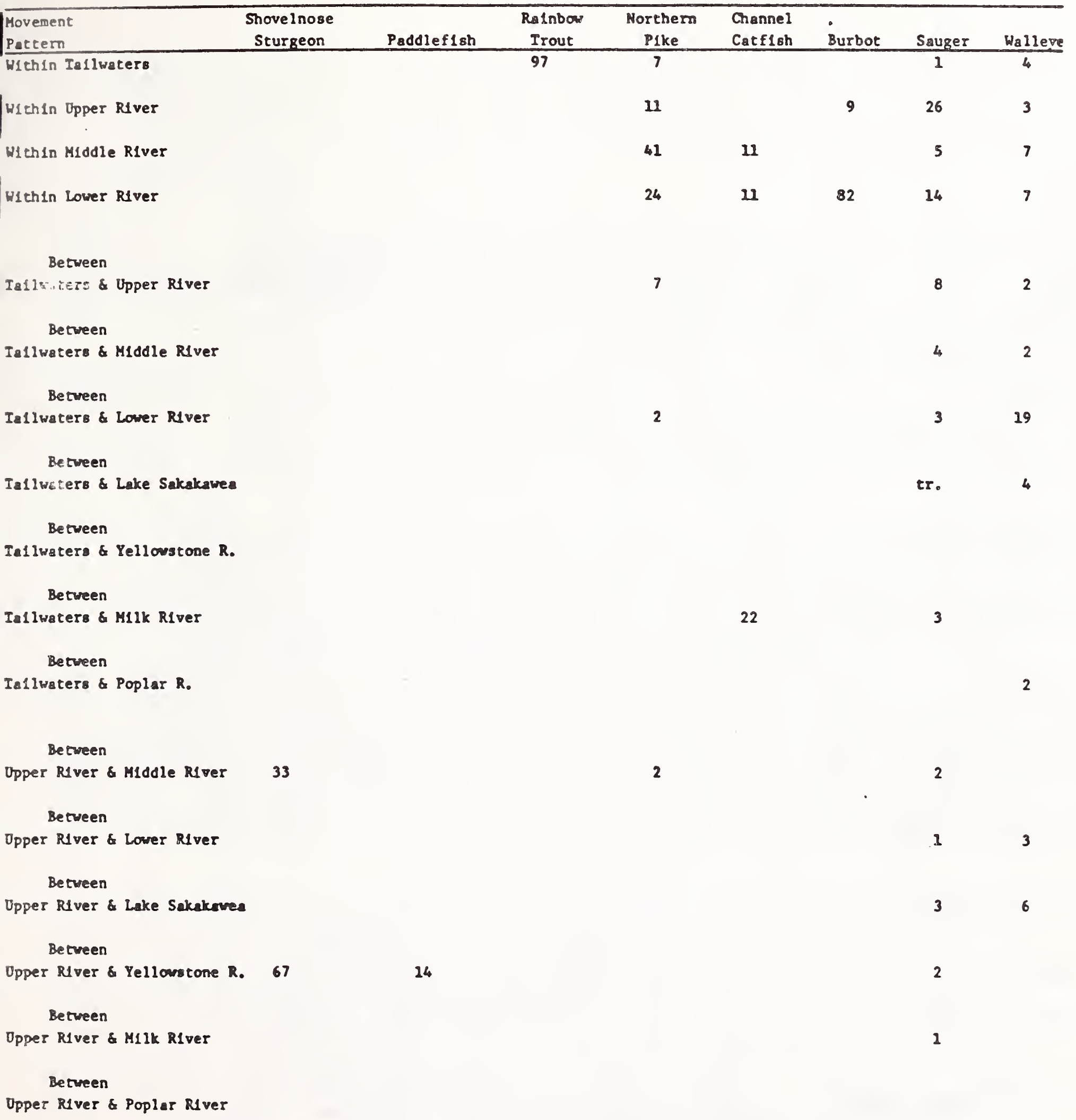


Table 35. (Cont.)

\begin{tabular}{|c|c|c|c|c|c|c|c|}
\hline Shovelnose & & RaInbow & Northern & Channel & & & \\
\hline Sturgeon & Paddlef1sh & Irout & Plke & Catf18h & Burbot & Sauger & Wallere \\
\hline Becween & & & & & $\cdot$ & & \\
\hline Middle RIver \& Lower RIver & 14 & & & & & 4 & 6 \\
\hline \multicolumn{8}{|l|}{ Between } \\
\hline M1ddle RIver \& Lake Sakakawea & & 3 & 2 & 11 & & 6 & 5 \\
\hline \multicolumn{8}{|l|}{ Between } \\
\hline Middle RIver \& Yellourone RIver & 43 & & & & & tr. & \\
\hline \multicolumn{8}{|l|}{ Between } \\
\hline Mlddle Rlver \& MIlk River & & & 2 & & & & \\
\hline \multicolumn{8}{|l|}{ Between } \\
\hline Middle RIver \& Poplar RIver & & & 2 & & 9 & tr. & \\
\hline \multicolumn{8}{|l|}{ Between } \\
\hline Lower River \& Lake Sakakswea & & & & & & 11 & 19 \\
\hline \multicolumn{8}{|l|}{ Between } \\
\hline Lower Rlver \& Yellowstone River & 29 & & & 34 & & 2 & 3 \\
\hline \multicolumn{8}{|l|}{ Bectreen } \\
\hline \multicolumn{8}{|l|}{ Lower River \& Hilk River } \\
\hline \multicolumn{8}{|l|}{ Between } \\
\hline Lower River \& Poplar RIver & & & $\cdot$ & & & 1 & 3 \\
\hline Within Milk River & & & & 11 & & 3 & 2 \\
\hline Hithin Poplar River & & & & & & er & \\
\hline
\end{tabular}

Between

Poplar River Lake Sakakawea

Ex. 3

Munber tagsed

Number Ings Recovered

138

210

33

155

193

4530

393

3

- Iags frow the Yellowstone River were not Included. 
pattern. Only fish tagged in 1981 and 1982 exhibited this movement. Moreover, all 1981 tagged fish which were later recovered in Lake Sakakawea had been tagged in the river only during the fall. Conversely, $75 \%$ of the 1982 tagged fish which were later recaptured in Lake Sakakawea were tagged in the spring. A probable explanation for these variable movement patterns are as follows:

- During years with good spring run-off conditions (1982) sauger will migrate out of Lake Sakakawea to spawn in the upper and middle reaches of the study area.

- During years with poor spring run-off conditions (years 1980-81) Lake Sakakawea sauger will not migrate up the Missouri to spawn.

- A factor such as the large migration of rainbow smelt can entice sauger to leave Lake Sakakawea following the smelt migration in spite of low spring flows. This foraging run was observed during 1980 and 1981. (Refer to forage fish section).

5. Sauger movement between the lower river reach and Lake Sakakawea was indicated by $11 \%$ of all the recovered tags. None of these fish were tagged in Lake Sakakawea. There was no evident seasonality to the time when recovered fish were tagged. Fish were tagged both in the spring, while in spawning condition as well as in the summer and fall. It was evident that this movement pattern occurs not only during the spring spawning season but also during the other seasons.

Movement of sauger throughout the Missouri River was fairly important. Sauger were never tagged in Lake Sakakawea, and therefore, a coinplete understanding of this movement pattern and its significance cannot be entirely evaluated. The majority (93\%) of tagged fish which were recaptured in Lake Sakakawea were taken in the upper third of the reservoir. Graham and Penkal (1978) reported similar findings for the lower Yellowstone River sauger.

Sauger use of the tributary streams, as depicted by tagging information, indicated there was not appreciable amounts of interchange. Movement between the Milk River and Missouri River was indicated by only four percent of the total recaptures. The majority of these fish moved from, or to, nearby areas such as the tailwaters or upper Missouri River reach. A general tendency was noted for sauger tagged in the Milk River to remain there. About half of the fish tagged or recaptured in the Milk remained there throughout their exposure period. There did not appear to be any seasonality to these movements. Berg (1981) found considerable interchange of sauger between the middle Missouri River and a major tributary. There were only a couple of examples of interchange between the Poplar and Missouri rivers. Sauger interchange between the Missouri and Yellowstone rivers appeared to be low, representing about $4 \%$, however, very few sauger were being tagged or monitored concurrently in the Yellowstone. Therefore, the significance of the sauger interchange between the Missouri and Yellowstone rivers could not be evaluated.

Walleye. Like the sauger, movements of walleye were also extensive. Over $75 \%$ of the tagged walleye moved distances greater than 10 miles. One walleye travelled 350 miles over a 825-day period. Tag recovery information indicated that walleye not only move throughout the entire study area but also through 
other major connecting systems including Lake Sakakawea and the lower Yellowstone River. Extensive migratory movements have been well documented for walleye in the Yellowstone River. Graham and Penkal (1978) have reported a large number of walleye originating in Lake Sakakawea migrate 75 miles up the Yellowstone River to spawn.

Four major movement patterns were detected from the tag recovery data. These were represented by $69 \%$ of all the recovered tags.

1. Walleye tagged and recovered within the middle and lower reach of river represented a common movement pattern amounting to $20 \%$ of al1 the walleye tag recoveries. By examining the season when fish were tagged and recovered, it was evident that the relationship between times of tagging and recovery was not governed by any particular season. A total of $57 \%$ of the walleye were tagged in the spring, but only $14 \%$ of the tag recoveries also occurred during the spring. This suggests that a group of walleye remain in this area throughout the sampling period being exposed to tagging and recovery operations during all seasons. No evident trend for a particular time period was evident.

2. Walleye movements from the lower river reach upstream to the tailwaters of Fort Peck Dam were indicated by $19 \%$ of all the recovered walleye tags. Most of the fish were tagged during the fall but tag recoveries in the tailwaters area were made during any season. All years were represented and no obvious trend between years was noted. No explanation for this movement pattern could be determined.

3. Walleye movement between the lower river reach and Lake Sakakawea was indicated by $19 \%$ of the recovered tagged walleye. Since no walleye were tagged in Lake Sakakawea all movement was indicated as being from the river downstream into the reservoir. Seventy-five percent of the walleye exhibiting this pattern were tagged in the spring indicating a spring migratory run out of the reservoir. Many of the fish tagged during this season were in spawning condition and most likely spawned in this reach of Missouri River.

4. Walleye movement between the upper and middle river reaches and Lake Sakakawea was indicated by $11 \%$ of the total number of tagged walleye recovered. Like the pattern detailed in (2), this pattern did not appear to be related to a single phase of the walleye life cycle. The fish which exhibited this movement were apparently vulnerable to tagging during most seasons. A total of $43 \%$ and $57 \%$ were tagged during the spring and fall seasons, respectively. This sort of movement pattern indicates that walleye move up into the river from the reservoir during the spring and maintain their presence through the fall, returning to the reservoir at some time later. Another possibility could be that there is back and forth movement between the river and reservoir within a given season.

Another walleye movement pattern which appeared to be of less significance was between the Fort Peck tailwaters and Lake Sakakawea. This pattern most likely was of greater importance than indicated since, walleye in the tailwaters area were rarely tagged until 1983 when a major spawning area was discovered. A 
total of 39 fish were tagged during 1983 and 1984 in the tailwaters area and six tag recoveries were reported. Three of these walleye were recovered seven miles upstream immediately below Fort Peck Dam and the other three were recovered in Lake Sakakawea. This demonstrates that although these fish spawned in the same area, they most likely did not return to the same location. This could indicate that there may be some switching of residence periodically between the river and reservoir. Movement of walleye between Lake Sakakawea and varlous locations upstream in the Missouri was a common and important pattern. Walleye were never tagged in Lake Sakakawea during this study, and therefore a complete understanding of this movement pattern and its implications cannot entirely be evaluated. It was interesting to note that only about one third of the Missouri River tagged fish recaptured in lake Sakakawea were from the upper third of the reservoir, indicating that a good portion of these tagged walleye dispersed throughout the reservoir. This is contrary to the movement of sauger in this study where most were recaptured in the upper third of the reservoir. Also, Graham and Penkal (1978) reported that walleye which were previously tagged in the lower Yellowstone River usually were recovered in the upper end of the reservoir.

Walleye use of the Missouri River tributaries was limited. There was no record of tagged walleye moving between the Milk and Missouri rivers. There was some interchange between the Poplar River and Missouri. This amount, if Lake Sakakawea recordings are considered, was represented by $5 \%$ of all the recovered walleye tags. Walleye is one of the most dominant sport fish in the Poplar River (Stewart, 1977).

Other sportfish - Movement distances of northern pike were restricted, with only $17 \%$ of the recaptured pike moving more than 10 miles. The longest distance travelled was 51 miles up the Missouri and 117 miles up the Milk River, for a total of 166 miles in a 275-day period. The majority of pike recaptures (83\%) were from the river sectlons in which they were originally tagged, indicating that northern pike in the Missouri River are sedentary for the most part.

The burbot displayed similar movement patterns to those of the northern pike. Only 9\% of the recaptured burbot moved distances greater than 10 miles. The longest distance traveled was only 12 miles.

Movements of rainbow trout appeared to be restricted to the 10 miles of the cold clear tailwaters below Fort Peck Dam. One exception to this was one rainbow trout which was tagged in the middle reach of the Missouri and later recaptured in Lake Sakakawea. Rainbows were tagged and recaptured primaxily during the spring, however, a number of them were also handled during the fall. Rainbow trout appear to be residents of the Fort Peck tailwaters area.

Limited numbers of shovelnose sturgeon, paddlefish and channel catfish were tagged and recaptured. However, from the movements of recaptured tagged fish it. was apparent that these three species were highly mobile and traveled not only throughout the Missouri River but also the Yellowstone and Milk rivers and Lake Sakakawea Reservoir. All three recaptured shovelnose sturgeon moved distances greater than 10 miles. Two sturgeon which were tagged in the Yellowstone River traveled distances of 260 miles or more down the Yellowstone River and up the Missouri River to the upper river reach. Tagged paddlefish exhibited similar movement patterns between both rivers. Although these movements resembled the sturgeon's, the paddlefish were believed to spend a considerable amount of time 
in Lake Sakakawea, whereas, the shovelnose sturgeon were believed to reside exclusively in the rivers. Paddlefish interchange between the Missouri and Yellowstone rivers is substantial. Needham (1985) reported that from a total of 102 recaptured paddlefish which were tagged in dredge cuts complex (Fort Peck tailwaters area) $55.9 \%$ were recaptured in the dredge cuts and $44.1 \%$ were recaptured in the Yellowstone River. Frazer (1985) reported that at least 32 paddlefish tagged in the Yellowstone River at Intake were eventually recaptured in the dredge cut complex. Tagging information from six years of study in the Missouri River shows that paddlefish tagged in the Yellowstone were recovered in the Missouri's lower river reach, and fish tagged in the upper and middle Missouri reaches were recaptured at Intake on the Yellowstone River. This interchange between systems represents lengthly travel distances. Total distances traveled by tagged paddlefish between the release and recapture sites ranged from 72 - 244 miles.

Only nine tagged channel catfish were recaptured so information on movement patterns are limited. Most of the catfish moved more than 10 miles with total distances ranging between 0-160 miles. Interchange was noted between the Missouri and Yellowstone rivers and Milk River and tailwaters area (dredge cuts complex).

Age and growth studies

The evaluation of fish populations in the Missouri River included age and growth studies for descriptive and comparative purposes. Growth rates of a population are indicative of environmental quality and reflect the fisheries potential of an aquatic system. Knowledge of fish sizes at a given year and age structure are important considerations for appropriate management of river fisheries.

Shovelnose sturgeon. A total of 77 shovelnose sturgeon pectoral spines were collected, however, only 56 of these could be used in the sturgeon aging analyses. Cross sections of the spines were difficult to age because of the longevity of the species (20-30 yrs.) and because the numerous annuli were crowded on the narrow (0.07-0.16 inches diameter) pectoral spine cross sections. A sample of these cross sections was aged by four individuals to insure the precision of the assigned ages. Only those spines with determined ages within five years agreement were used. Assigned ages, as determined by the four individuals, were usually within two years agreement.

Annuli were read according to the technique used by Cuerrier (1951). Under transmitted light the narrow clear bands were considered annuli. Annuli belt patterns were characteristic of most sturgeon spines. Zweiacker (1967) and Berg (1981) identified similar annuli belt patterns on shovelnose sturgeon pectoral rays from the Missouri River. Roussow (1957) found annuli belts on pectoral fin ray sections of lake sturgeon. These researchers attributed the belts of annuli to slower growth during periods of gonadal development.

Assigned ages ranged from seven to 33 years (Table 36). An average age of these 56 samples was not determined because the samples were not taken randomly, but were collected selectively to insure that all sturgeon sizes and ages were represented. The observed growth rates from sturgeon between the ages of 7 and 30 years averaged 0.25 inches and 0.09 pounds of growth per year. This was considered to be a slow growth rate for shovelnose sturgeon compared to the 
Table 36. Age-frequency of shovelnose sturgeon collected from the lower Missouri River during 1983 and 1984 with average lengths and weights and their standard deviations.

\begin{tabular}{|c|c|c|c|c|c|c|}
\hline Âge & $\begin{array}{l}\text { Number } \\
\text { of fish }\end{array}$ & $\begin{array}{l}\text { Avg. Total } \\
\text { length } \\
\text { (in.) }\end{array}$ & $\begin{array}{l}\text { Avg. Fork } \\
\text { length } \\
\text { (in.) }\end{array}$ & $\begin{array}{c}\text { Standard } \\
\text { deviation } \\
\text { (total length) }\end{array}$ & $\begin{array}{c}\text { Avg. Weight } \\
\left(1 b_{0}\right)\end{array}$ & $\begin{array}{l}\text { Standard } \\
\text { deviation } \\
\text { (weight) }\end{array}$ \\
\hline 7 & 2 & 21.5 & 18.6 & 0.35 & 0.85 & 0.35 \\
\hline 8 & 2 & 23.0 & 20.2 & 0.78 & 1.18 & 0.03 \\
\hline 9 & 1 & 22.9 & 20.1 & ---- & 1.48 & --- \\
\hline 10 & 0 & --- & --- & ---- & -- & $-\cdots$ \\
\hline 11 & 4 & 24.8 & 22.1 & 1.03 & 1.78 & 0.41 \\
\hline 12 & 6 & 24.6 & 21.9 & 1.72 & 1.72 & 0.40 \\
\hline 13 & 1 & 23.6 & 20.8 & --- & 1.58 & $-\cdots$ \\
\hline 14 & 3 & 24.9 & 22.2 & 1.53 & 2.00 & 0.41 \\
\hline 15 & 2 & 24.7 & 22.0 & 1.70 & 1.85 & 0.49 \\
\hline 16 & 3 & 25.6 & 23.0 & 1.71 & 2.02 & 0.43 \\
\hline 17 & 4 & 26.7 & 24.1 & 1.20 & 2.54 & 0.52 \\
\hline 18 & 2 & 28.0 & 25.5 & 0.57 & 2.40 & 0.42 \\
\hline 19 & 3 & 27.3 & 24.8 & 3.03 & 2.70 & 1.07 \\
\hline 20 & 1 & 25.7 & 23.1 & ---- & 1.98 & ---- \\
\hline 21 & 2 & 29.4 & 27.0 & 1.66 & 2.94 & 0.19 \\
\hline 22 & 4 & 27.5 & 25.0 & 1.23 & 2.52 & 0.23 \\
\hline 23 & 3 & 28.5 & 26.1 & 1.53 & 2.82 & 0.67 \\
\hline 24 & 3 & 28.8 & 26.4 & 1.04 & 3.13 & 0.35 \\
\hline 25 & 2 & 29.4 & 27.0 & 1.70 & 3.14 & 0.56 \\
\hline 26 & 0 & ---- & ---- & ---- & $-\infty$ & ---- \\
\hline 27 & 1 & 31.3 & 28.8 & ---- & 4.48 & --- \\
\hline 28 & 2 & 27.7 & 25.2 & 2.12 & 2.45 & 0.47 \\
\hline 29 & 2 & 28.5 & 26.1 & 2.12 & 2.91 & 0.78 \\
\hline 30 & 2 & 28.6 & 26.2 & 0.71 & 2.90 & 0.70 \\
\hline 31 & 0 & ---- & ---- & ---- & $-\infty$ & --- \\
\hline 32 & 0 & ---- & $-\cdots$ & ---- & $-\cdots$ & ---- \\
\hline 33 & 1 & 28.2 & 25.7 & ---- & 2.81 & ---- \\
\hline
\end{tabular}


upstream population of the middle Missouri River which Berg (1981) reported as exhibiting an average growth rate of 0.72 inches and 0.31 pounds per year.

Sizes of sturgeon observed in the study area were intermediate for their age group between a population 250 miles upstream and one nearly 1,000 miles downstream (Table 37). It is apparent that the sturgeon population of the middle Missouri River consists of larger fish than was found in the study area. Shovelnose sturgeon in the middle Missouri averaged 4.8 inches longer and 2.24 pounds heavier for given ages than the sturgeon of the lower Missouri. However, the shovelnose sizes of the Missouri River, South Dakota were considerably smaller than those residing in the study area.

The 487 shovelnose sturgeon sampled by electrofishing and gill netting is thought to be representative of the sturgeon population's age and size distribution for fish greater than 15 inches. The age/length relationship (Table 36) and length frequency relationship (Figure 14) were used to approximate a general age structure of the shovelnose population. Length groups 21 (20.6-21.5 inches) through 25 inches dominated the shovelnose population comprising $81 \%$ of the sample. These groups were represented by ages 11-28 years. Other investigations have also reported older age-structured populations. Berg (1981) noted that 93\% of the sturgeon in the middle Missouri River, Montana were 15 years or older. Zweiacker (1967) found that $79 \%$ of the aged shovelnose sturgeon in the Missouri River, South Dakota were 13 years or older.

Sauger. A sample of 175 sauger collected in the Missouri river during the fal1 of 1979 were assigned ages ranging from $0+$ to $7+$ years (Table 38). Age classes $1+$ and $2+$ comprised $71 \%$ of the sample in spite of the generally poorer electrofishing efficiencies for the smaller fish.

Calculated lengths of sauger at annuli 1 through 8 are given in Table 39. The growth rate of sauger in the lower Missouri River was similar to the middle Missouri River (Table 39). Sauger in the study area exhibited slower growth rates for age classes 4 years and greater when compared to the lower Yellowstone River or Lake Sakakawea populations.

In a previous report Stewart (1982) noted that the average size of sauger in the lower Missouri River had increased greatly from 1979 to 1981. To ascertain the reasons for this change a comparison of sizes and age structures was made between fish collected in the fall of both years (Table 40). The comparison indicates that between 1979 and 1981 growth rates increased and the age structure shifted from a dominance of younger fish to a dominance of older fish. For ages 2+ through 6+ average lengths increased 1.6, 1.7, 2.1, 2.9, and 1.7 inches. Corresponding average weight increases were $0.16,0.26,0.59,0.81$, and 0.97 pounds. In 1979 age $2+$ was the modal year class, but by 1981 the modal year class had become age 4t. Only 16.8 percent of the sauger population was age 4t and older in 1979. By 1981, 59.3 percent was age 4t and older. The better growth rates, older age structure and age/length statistics for the suager sampled during 1981 indicates that these sauger most likely were from the lake Sakakawea population. Rainbow smelt are probably utilized by sauger in the upper portions of Lake Sakakawea where they are abundant. Large numbers of rainbow smelt have been present in the Missouri River only during their spring spawning runs in 1980 and 1981 and, most likely, the sauger followed the smelt upstream these years. 
Table 37. Observed growth of shovelnose sturgeon sampled in the lower Missouri River during 1983-84 compared to observed growth in other waters.

\begin{tabular}{|c|c|c|c|}
\hline Age & $\begin{array}{c}\text { Lower Missouri } \\
\text { River, MT } \\
\text { (present study) } \\
\text { Ave. Fork Length } \\
\text { (Inches) }\end{array}$ & $\begin{array}{l}\text { Middle Missouri } \\
\text { River, MT } \\
\text { (Berg 1981) } \\
\text { Ave. Fork Length } \\
\text { (Inches) }\end{array}$ & $\begin{array}{c}\text { Missouri River } \\
\text { S. Dakota } \\
\text { (Zweiacker 1967) } \\
\text { Ave. Fork Length } \\
\text { (Inches) }\end{array}$ \\
\hline 7 & 18.6 & -- & -- \\
\hline 8 & 20.2 & 22.8 & 19.5 \\
\hline 9 & 20.1 & 22.3 & 18.9 \\
\hline 10 & -- & 25.8 & 19.4 \\
\hline 11 & 22.1 & - & 19.6 \\
\hline 12 & 21.9 & - & 19.6 \\
\hline 13 & 20.8 & 27.0 & 19.9 \\
\hline 14 & 22.2 & 26.1 & 20.0 \\
\hline 15 & 22.0 & 26.9 & 19.4 \\
\hline 16 & 23.0 & 28.0 & 19.5 \\
\hline 17 & 24.1 & 27.6 & 19.7 \\
\hline 18 & 25.5 & 29.5 & 19.7 \\
\hline 19 & 24.8 & 29.5 & 20.0 \\
\hline 20 & 23.1 & 28.7 & 20.5 \\
\hline 21 & 27.0 & 30.0 & 20.2 \\
\hline 22 & 25.0 & 29.7 & 20.1 \\
\hline 23 & 26.1 & 29.9 & 19.9 \\
\hline 24 & 26.4 & 30.9 & 19.7 \\
\hline 25 & 27.0 & 32.0 & 20.6 \\
\hline 26 & - & 30.4 & - \\
\hline 27 & 28.8 & 31.1 & 19.5 \\
\hline 28 & 25.2 & 32.3 & \\
\hline 29 & 26.1 & 32.0 & \\
\hline 30 & 26.2 & 36.0 & \\
\hline 31 & - & 34.4 & \\
\hline 32 & -- & 35.5 & \\
\hline \multirow[t]{2}{*}{33} & 25.7 & 33.6 & \\
\hline & $\mathrm{N}=56$ & $\mathrm{~N}=122$ & $\mathrm{~N}=288$ \\
\hline
\end{tabular}

$303 / 8.1$ 


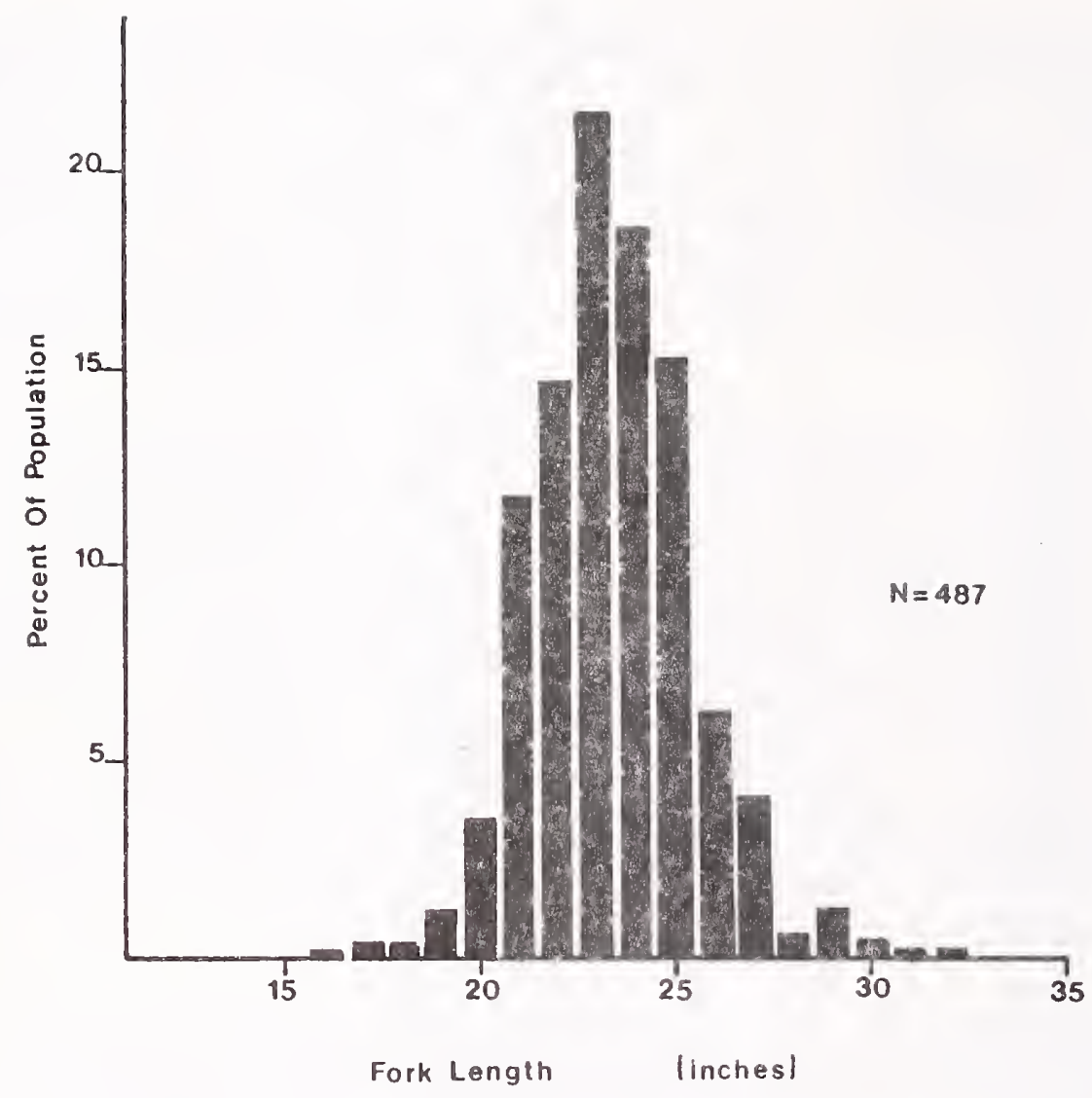

Figure 14. Length-frequency histogram for shovelnose sturgeon sampled in the Missouri River, 1979-1983. 


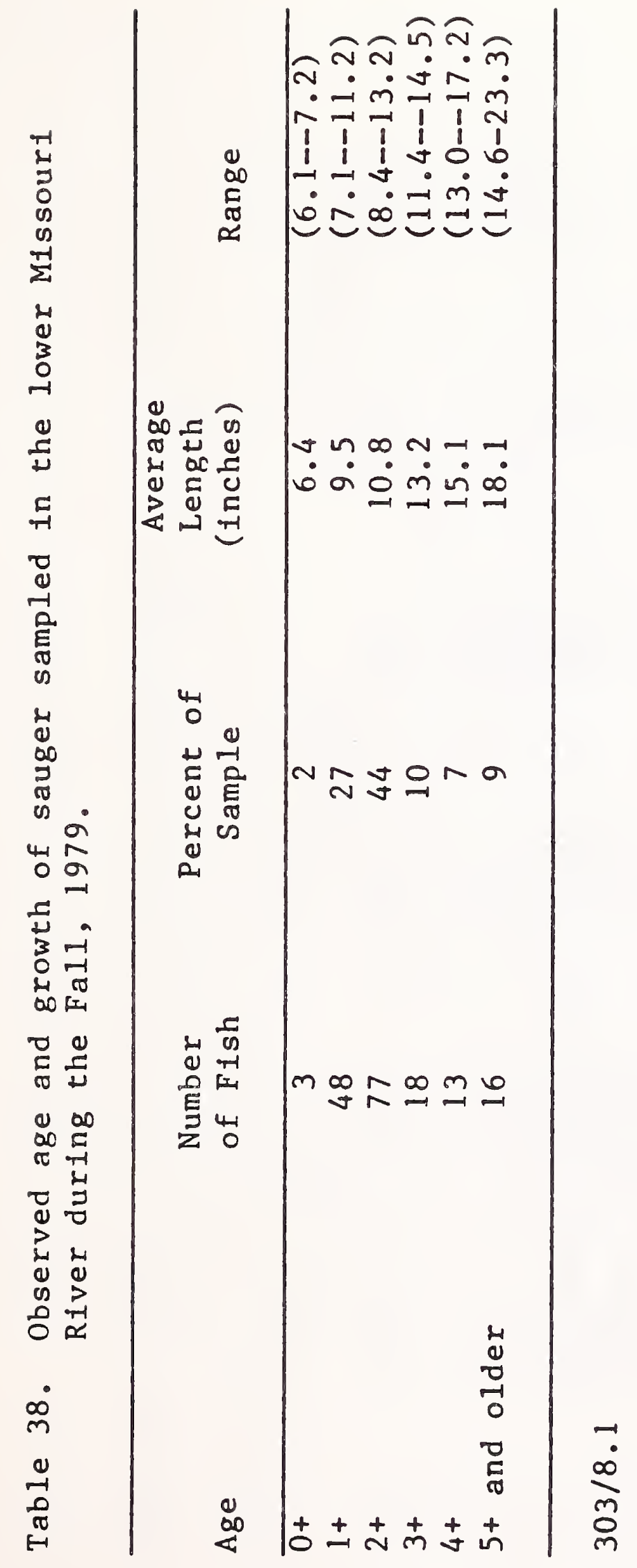




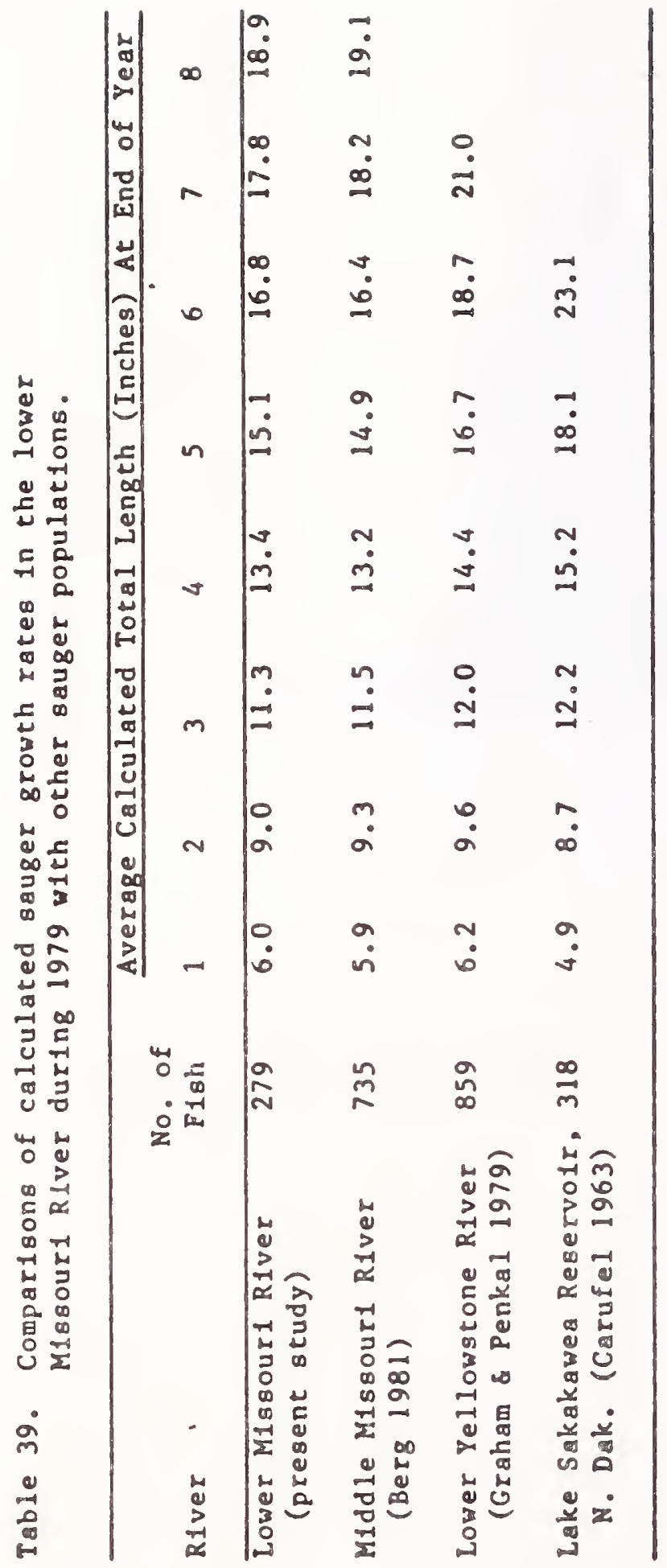




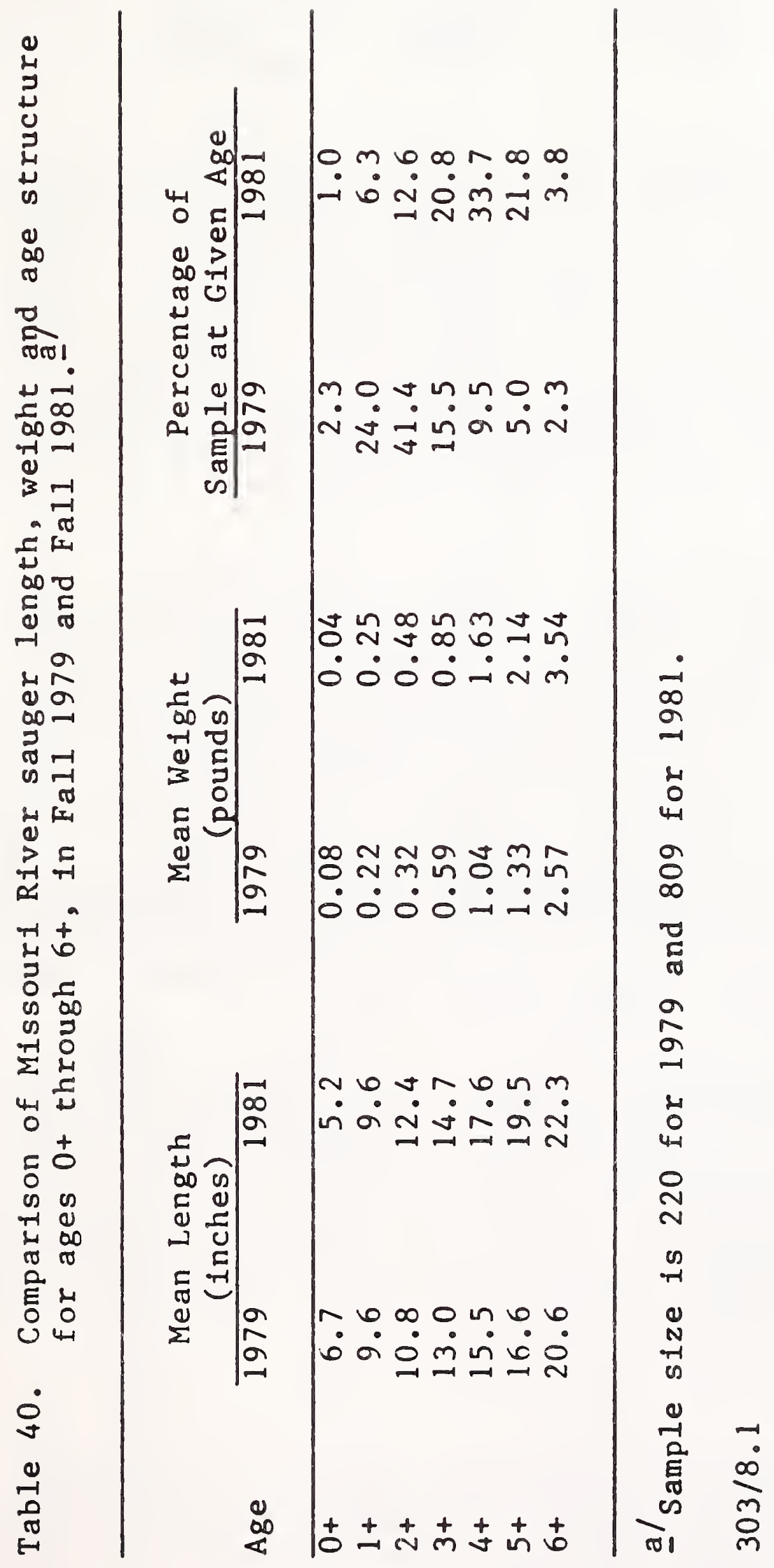


Other sportfish. Age and growth analysis of 76 northern pike determined from scales collected in 1982 is given in Table 41. Fish were assigned ages from $0+$ to $7+$. These fish appear to grow more rapidly than those reported by Brown (1971) for other locations in Montana. The maximum total length and weight in this sample was 42.5 inches and 21.5 pounds. Five fish weighed in excess of 10 pounds.

Age and size statistics for burbot are shown in Table 42. The sample size is small for some age groups but sufficient to indicate general growth for this species. Otoliths proved to be a good method for aging this species in the Missouri River. Only six of 121 otoliths could not be aged because of indistinct light and dark zones. There is a major increase in the annual length increment from age five to age six. This increase coincides with the age at which the diet changes from invertebrates to fish. The fish diet is probably responsible for the growth increase. Compared to growth data for burbot in other North American areas (Carlander 1969), Missouri River burbot tended to grow somewhat more slowly at younger ages, but more rapidly at older ages. Their weight at a given length is similar to North American averages given by Carlander (1969).

Nonsport fish. Age and growth analyses for an additional $11 \mathrm{fish}$ species are presented in Table 43. Sample sizes for the various species ranged from 308 for goldeye to 21 for white crappie. The smaller sample sizes are insufficient for indicating accurate annual growth increments, but still show the general growth rate status. Growth rates of the species listed in Table 43 were mostly similar to growth rates of these species at similar latitude in other states, using data from Brown (1971) and Carlander (1969) for comparison. Younger age classes for some species are absent or present only in low numbers in the study area. With the exception of several larval blue suckers sampled in spring, no blue suckers younger than age $6+$ have been sampled. The situation is similar for smallmouth buffalo and bigmouth buffalo except that significant numbers of these two species spend much of the first year of life in the Missouri River. These missing age groups probably remain in Lake Sakakawea, entering the Missouri River in increasing numbers at older age.

Berg (1981) also examined the age and growth characteristics of some non-sport fish found in the middle Missouri River. Comparisons between his and this study's findings for blue suckers and smallmouth and bigmouth buffalo indicate that both reaches of the Missouri have similar growth rates for the blue suckers and smallmouth buffalo; growth rates for bigmouth buffalo appear to be greater in the middle Missouri reach. There also are noticeable differences in age compositions between the two studies. All three species found in the lower Missouri River did not exhibit the older age groups (12-17 years) that were found in the middle Missouri River.

Forage fish populations.

The forage fish community of the Missouri River plays an important role in providing an adequate food base for piscivorous sport fish species such as sauger, northern pike, walleye, burbot, and channel catfish. The condition of the food base and habitat requirements for important forage species are important management concerns. Therefore, an evaluation of the forage fish 
Table 41. Age and growth of Missouri River northern pike collected in Summer and Fal1, 1982 .

\begin{tabular}{lcccrr}
\hline Age & $\begin{array}{l}\text { No. } \\
\text { of } \\
\text { Fish }\end{array}$ & $\begin{array}{l}\text { Mean } \\
\text { Length } \\
\text { (inches) }\end{array}$ & $\begin{array}{l}\text { Mean } \\
\text { Weight } \\
\text { (pounds) }\end{array}$ & $\begin{array}{l}\text { Length } \\
\text { Range } \\
\text { (inches) }\end{array}$ & \multicolumn{1}{l}{$\begin{array}{l}\text { Weight } \\
\text { Range } \\
\text { (pounds) }\end{array}$} \\
\hline $0+$ & 5 & 8.8 & 0.17 & $6.2-10.7$ & $0.04-0.30$ \\
$1+$ & 6 & 13.4 & 0.51 & $9.8-15.2$ & $0.18-0.74$ \\
$2+$ & 10 & 21.5 & 2.20 & $16.1-24.5$ & $0.78-3.06$ \\
$3+$ & 30 & 26.5 & 3.99 & $23.2-29.4$ & $2.06-5.44$ \\
$4+$ & 20 & 29.9 & 5.92 & $25.7-33.2$ & $3.42-8.10$ \\
$5+$ & 2 & 37.3 & 12.70 & $35.6-39.0$ & $11.40-14.00$ \\
$6+$ & 0 & -- & -- & -- & -- \\
$7+$ & 3 & 41.2 & 17.60 & $40.0-42.5$ & $12.80-21.50$
\end{tabular}

$303 / 8.1$

Table 42. Age and growth of 115 burbot collected from the Missouri River, Apri1 and May, 1982.

\begin{tabular}{|c|c|c|c|c|c|c|}
\hline Age & $\begin{array}{l}\text { No. } \\
\text { of } \\
\text { Fish }\end{array}$ & $\begin{array}{r}\text { Mean } \\
\text { Length } \\
\text { (inches) }\end{array}$ & $\begin{array}{r}\text { Mean } \\
\text { Weight } \\
\text { (pounds) }\end{array}$ & $\begin{array}{r}\text { Length } \\
\text { Range } \\
\text { (inches) }\end{array}$ & $\begin{array}{l}\text { Weight } \\
\text { Range } \\
\text { (pounds) }\end{array}$ & $\begin{array}{r}\text { Average } \\
\text { Annual } \\
\text { Length } \\
\text { Increment }\end{array}$ \\
\hline 1 & 1 & 6.3 & 0.04 & -- & -- & -- \\
\hline 2 & 16 & 8.8 & 0.16 & $6.8--10.5$ & $0.08-0.30$ & 2.5 \\
\hline 3 & 34 & 11.8 & 0.37 & $9.1-16.0$ & $0.17-0.96$ & 3.0 \\
\hline 4 & 21 & 13.7 & 0.59 & $10.8-18.1$ & $0.25-1.22$ & 1.9 \\
\hline 5 & 5 & 16.8 & 1.28 & $12.6-20.8$ & $0.40-2.71$ & 3.1 \\
\hline 6 & 14 & 23.2 & 3.34 & $16.5-28.0$ & $0.92-6.10$ & 6.4 \\
\hline 7 & 11 & 23.6 & 3.25 & $20.2-26.4$ & $1.68-5.10$ & 0.4 \\
\hline 8 & 6 & 28.4 & 5.36 & $22.6-33.0$ & $2.22-6.40$ & 5.2 \\
\hline 9 & 3 & 31.4 & 8.04 & $30.1-32.2$ & $5.80-10.30$ & 3.0 \\
\hline 10 & 0 & -- & -- & --- & -- & --- \\
\hline 11 & 3 & 32.1 & 8.64 & $28.4-35.6$ & $6.70-12.40$ & 0.3 \\
\hline 12 & 1 & 33.5 & 10.00 & --- & --- & 1.4 \\
\hline
\end{tabular}


Table 43. Age and growth and average length and weight for Missouri River non-sport fish species sampled in August, 1981.

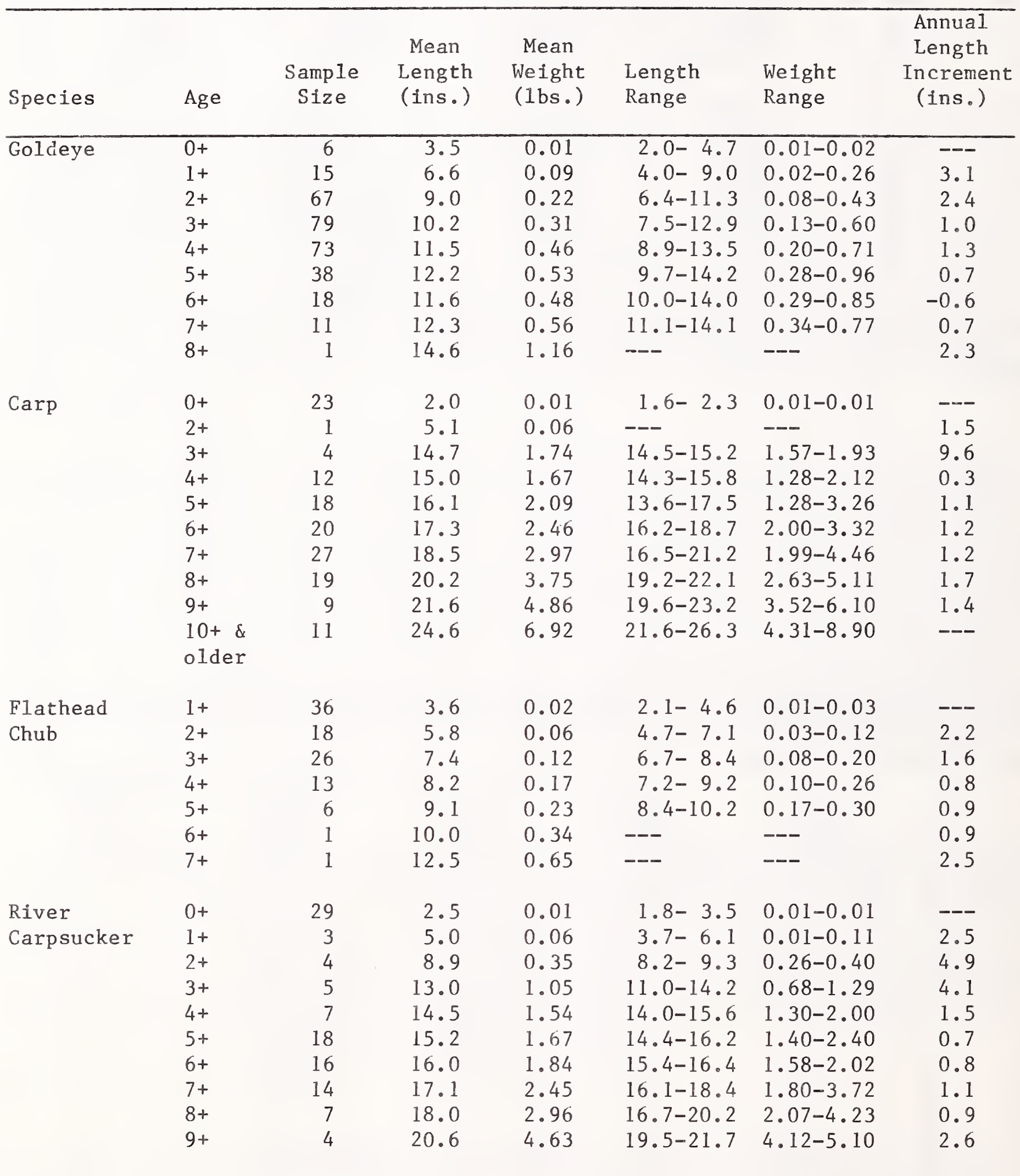


Table 43. (Cont.)

\begin{tabular}{|c|c|c|c|c|c|c|c|}
\hline Species & Age & $\begin{array}{c}\text { Sample } \\
\text { Size }\end{array}$ & $\begin{array}{l}\text { Mean } \\
\text { Length } \\
\text { (ins.) }\end{array}$ & $\begin{array}{c}\text { Mean } \\
\text { Weight } \\
\text { (1bs.) }\end{array}$ & $\begin{array}{l}\text { Length } \\
\text { Range }\end{array}$ & $\begin{array}{l}\text { Weight } \\
\text { Range }\end{array}$ & $\begin{array}{l}\text { Annual } \\
\text { Length } \\
\text { Increment } \\
\text { (ins.) }\end{array}$ \\
\hline Blue & $6+$ & 2 & 22.4 & 3.57 & $22.3-22.6$ & $3.50-3.64$ & $\overline{-m-1}$ \\
\hline \multirow[t]{6}{*}{ Sucker } & $7+$ & 7 & 23.6 & 4.12 & $22.9-24.5$ & $3.70-4.72$ & 0.8 \\
\hline & $8+$ & 19 & 25.0 & 4.82 & $22.7-28.8$ & $3.40-8.90$ & 1.4 \\
\hline & $9+$ & 15 & 25.1 & 4.80 & $23.4-27.9$ & $3.72-6.50$ & 0.1 \\
\hline & $10+$ & 9 & 26.0 & 5.52 & $23 \cdot 3-29 \cdot 3$ & $3.76-8.60$ & 0.9 \\
\hline & $11+$ & 4 & 25.5 & 5.71 & $24.2-26.8$ & $4.78-6.30$ & -0.5 \\
\hline & $12+$ & 1 & 26.5 & 5.90 & --- & $-\infty=-$ & 1.0 \\
\hline Smallmouth & $0+$ & 11 & 1.5 & 0.01 & $1.3-2.2$ & $0.01-0.01$ & $--\infty$ \\
\hline \multirow[t]{7}{*}{ Buffalo } & $4+$ & 2 & 15.6 & 2.08 & $15 \cdot 3-15.8$ & $2.01-2.16$ & $-\infty$ \\
\hline & $5+$ & 5 & 18.6 & 3.26 & $17.1-20.3$ & $2.33-4.55$ & 3.0 \\
\hline & $6+$ & 10 & 19.6 & 3.73 & $17.4-21.7$ & $2.88-4.94$ & 1.0 \\
\hline & $7+$ & 7 & 20.8 & 4.74 & $19.8-23.8$ & $3.89-7.20$ & 1.2 \\
\hline & $8+$ & 7 & 21.8 & 5.18 & $20.3-22.8$ & $4.14-6.00$ & 1.0 \\
\hline & $9+$ & 4 & 22.3 & 6.01 & $21.3-23.5$ & $4.83-7.70$ & 0.5 \\
\hline & $10+$ & 3 & 22.4 & 5.69 & $21.0-24.5$ & $4 \cdot 38-8 \cdot 10$ & 0.1 \\
\hline Bigmouth & $0+$ & 9 & 1.5 & 0.01 & $1.2-2.0$ & $0.01-0.01$ & $-\infty$ \\
\hline \multirow[t]{6}{*}{ Buffalo } & $4+$ & 1 & 16.5 & 2.40 & --- & --- & -- \\
\hline & $5+$ & 3 & 21.4 & 6.08 & $20.0-24.2$ & $4.46-8.60$ & 4.9 \\
\hline & $6+$ & 5 & 20.8 & 5.70 & $19.5-21.9$ & $5.11-7.00$ & -0.6 \\
\hline & $7+$ & 4 & 22.7 & 7.52 & $21.0-26.0$ & $5.70-11.60$ & 1.9 \\
\hline & $8+$ & 2 & 23.8 & 9.00 & $22 \cdot 6-25 \cdot 0$ & $7.30-10 \cdot 80$ & 1.1 \\
\hline & $9+$ & 2 & 25.8 & 10.25 & $25.0-26.6$ & $9.00-11.50$ & 2.0 \\
\hline Shorthead & $1+$ & 5 & 4.1 & 0.02 & $2.7-4.9$ & $0.01-0.04$ & -- \\
\hline \multirow[t]{9}{*}{ Redhorse } & $2+$ & 39 & 6.6 & 0.11 & $5.2-8.0$ & $0.06-0.18$ & 2.5 \\
\hline & $3+$ & 4 & 8.6 & 0.22 & $7.7-9.5$ & $0.15-0.30$ & 2.0 \\
\hline & $4+$ & 14 & 10.7 & 0.47 & $8.9-13.8$ & $0.27-1.10$ & 2.1 \\
\hline & $5+$ & 5 & 12.2 & 0.68 & $10.8-14.7$ & $0.45-1.03$ & 1.5 \\
\hline & $6+$ & 11 & 13.3 & 1.01 & $9.1-16.7$ & $0.27-2.21$ & 1.1 \\
\hline & $7+$ & 10 & 14.4 & 1.27 & $12.4-16: 7$ & $0.70-2.52$ & 1.1 \\
\hline & $8+$ & 10 & 15.0 & 1.32 & $12.7-17.1$ & $0.70-2.20$ & 0.6 \\
\hline & $9+$ & 9 & 16.1 & 1.70 & $14.7-18.1$ & $1.23-2.46$ & 1.1 \\
\hline & $\begin{array}{l}10+\& \\
\text { older }\end{array}$ & 6 & 16.8 & 1.93 & $15.5-18.1$ & $1.36-2.48$ & --- \\
\hline Longnose & $0+$ & 13 & 2.4 & 0.01 & $1.9-3.8$ & $0.01-0.02$ & --- \\
\hline \multirow{6}{*}{ Sucker } & $1+$ & 5 & 8.6 & 0.27 & $7.2-10.4$ & $0.15-0.50$ & 6.2 \\
\hline & $2+$ & 2 & 11.5 & 0.64 & $11.1-11.9$ & $0.60-0.67$ & 2.9 \\
\hline & $3+$ & 3 & 11.9 & 0.82 & $10.5-12.8$ & $0.41-1.30$ & 0.4 \\
\hline & $4+$ & 4 & 16.4 & 1.98 & $15.7-17.2$ & $1.70-2.11$ & 4.5 \\
\hline & $5+$ & 1 & 18.3 & 2.55 & --- & --- & 1.9 \\
\hline & $6+$ & 2 & 21.2 & 4.38 & $20.2-22.2$ & $3.48-5.28$ & 2.9 \\
\hline
\end{tabular}

$303 / 8.1$ 
Table 43. (Cont.)

\begin{tabular}{|c|c|c|c|c|c|c|c|}
\hline Species & Age & $\begin{array}{c}\text { Sample } \\
\text { Size }\end{array}$ & $\begin{array}{l}\text { Mean } \\
\text { Length } \\
\text { (ins.) }\end{array}$ & $\begin{array}{l}\text { Mean } \\
\text { Weight } \\
\text { (1bs.) }\end{array}$ & $\begin{array}{l}\text { Length } \\
\text { Range }\end{array}$ & $\begin{array}{l}\text { Weight } \\
\text { Range }\end{array}$ & $\begin{array}{l}\text { Annual } \\
\text { Length } \\
\text { Increment } \\
\text { (ins.) }\end{array}$ \\
\hline White & $0+$ & 33 & 2.2 & 0.01 & $1.2-3.4$ & $0.01-0.01$ & -- \\
\hline \multirow[t]{7}{*}{ Sucker } & $1+$ & 7 & 5.0 & 0.05 & $4.0-5.8$ & $0.02-0.07$ & 2.8 \\
\hline & $2+$ & 2 & 5.7 & 0.07 & $5.6-5.8$ & $0.07-0.07$ & 0.7 \\
\hline & $3+$ & 0 & --- & --- & --- & --- & --- \\
\hline & $4+$ & 2 & 13.1 & 1.16 & $13 \cdot 1-13 \cdot 2$ & $1.05-1.26$ & 3.7 \\
\hline & $5+$ & 3 & 14.5 & 1.36 & $13 \cdot 9-14.9$ & $1.09-1.75$ & 1.4 \\
\hline & $6+$ & 4 & 15.8 & 1.90 & $14.2-16.6$ & $1.27-2.18$ & 1.3 \\
\hline & $7+$ & 3 & 16.6 & 1.97 & $14 \cdot 5-18 \cdot 3$ & $1.30-2.80$ & 0.8 \\
\hline White & $0+$ & 5 & 2.0 & 0.01 & $1.6-2.3$ & $0.01-0.01$ & --- \\
\hline \multirow[t]{2}{*}{ Crappie } & $1+$ & 14 & 2.8 & 0.01 & $1.8-3.4$ & $0.01-0.01$ & 0.8 \\
\hline & $2+$ & 2 & 5.5 & 0.07 & $5.4-5.7$ & $0.07-0.08$ & 2.7 \\
\hline
\end{tabular}


populations is essential for a more complete understanding of the river sport fisheries.

This phase of the investigation was conducted to qualitatively describe the forage fish base. For purposes of this study, a forage fish was broadly defined as any fish utilized by another as a food source. This would include most age 0 fish, some juvenile fish, and nearly all adult minnows (cyprinids - carp excluded). Young-of-the-year (YOY) sport fish were not included.

There were 16 different species of forage fish collected in the study area (Table 44). Flathead chub, fathead minnow, shorthead redhorse, longnose and white suckers, white crappie and yellow perch were the most widely distributed species and were found at nearly all of the study sections. Species with limited distributions were the YOY goldeye and sicklefin chub (a Montana "Species of Special Concern") found only in the Culbertson section and the YOY bigmouth buffalo sampled only in the Frazer section. The Iowa darter was never sampled seining, and was only sampled on a couple of occasions by electrofishing in the Cubertson study section. This species may not be a resident of the Missouri River forage fish community; its presence may be the result of downstream drift from the Poplar River and Big Muddy Creek, where it was a fairly common forage fish (Stewart 1978).

Generally, the YOY and juvenile white sucker was the dominant forage species in the upper reach, YOY and juvenile white sucker, and YOY and juvenile white crappie predominated in the middle reach, and YOY and juvenile white crappie, alone, was the most common forage species in the lower reach.

The Frazer, Wolf Point, and Culbertson study sections displayed the most diverse forage fish populations, each containing at least 12 species (Table 44). The Frazer study section exhibited the best catch rates with at least 7.8 times those of the other sections. Major factors attributed to this large difference between the other sections was largely the results of high catches of river carpsuckers, smallmouth, and bigmouth buffalo and white suckers. The reason for the greater abundance of these four species in the Frazer section is unclear.

The Fort Peck Dam study section was found to have low numbers of forage fish (Frazer 1985). A total of 14 species was found in this section similar to that of the downstream sections. Western silvery minnow, spottail shiner and northern redbelly dace were three species of the total, which were found exclusively in the Fort Peck Dam section.

When compared with the middle Missouri River, the lower Missouri's forage fish populations were less diverse and most likely not as abundant. A total of 24 species were seined in the middle Missouri (Gardner and Berg 1982), eight more than were found in this study. The forage fish community in the lower Missouri does not appear to be balanced, but instead is dominated by white sucker and white crappie. Gardner and Berg (1982) found that three minnow and three sucker species dominated the forage fish community of the middle Missouri, indicating that several species, rather than just a couple comprised the bulk of the forage fish community. The lower Missouri River appears to have lower forage fish numbers than two comparable streams, the middle Missouri and lower Yellowstone rivers (personal observations). Gardner and Berg (1982) reported an overall catch rate of 77.3 forage fish per haul (50 ft. $x 4 \mathrm{ft}$. seine) in the 
Table 44. Longitudinal distribution and relative abundance (avg. number of fish per haul) of forage fish species seined in the lower Missouri River, 1980-81.

\begin{tabular}{|c|c|c|c|c|c|c|c|}
\hline \multirow[b]{2}{*}{ Fish Species } & \multicolumn{7}{|c|}{ STUDY SECTION } \\
\hline & $\begin{array}{c}\text { Nickels } \\
\text { Ferry }\end{array}$ & Frazer & $\begin{array}{l}\text { Wolf } \\
\text { Point }\end{array}$ & Chelsea & Sprole & Brockton & Culbertson \\
\hline Goldeye & & & & & & & 0.4 \\
\hline Carp & 14.1 & 10.7 & & & 0.2 & & 0.3 \\
\hline Flathead chub & 0.2 & & 1.2 & 1.8 & 1.0 & 0.5 & 1.2 \\
\hline Sicklefin chub & & & & & & & 0.4 \\
\hline Lake chub & 0.2 & 13.2 & 0.4 & & & & \\
\hline Emerald shiner & & 0.2 & 0.4 & 1.4 & & 1.8 & 0.4 \\
\hline Fathead minnow & 0.6 & 10.5 & 1.6 & 0.2 & 0.4 & & 0.1 \\
\hline River carpsucker & & 26.5 & 3.3 & 1.2 & & 1.5 & 1.2 \\
\hline Smallmouth buffalo & & 20.2 & 0.1 & & & & \\
\hline Bigmouth buffalo & & 22.5 & & & & & \\
\hline Shorthead redhorse & & 0.2 & 0.2 & 1.6 & 0.1 & 0.8 & 0.1 \\
\hline Longnose sucker & 2.2 & 8.0 & 1.1 & 0.8 & 2.2 & 1.2 & 0.1 \\
\hline White sucker & 6.5 & 54.0 & 8.4 & 0.2 & 4.4 & 0.2 & 0.6 \\
\hline White crappie & & 15.7 & 0.7 & 5.0 & 3.4 & 3.8 & 2.9 \\
\hline Yellow perch & 0.1 & 6.2 & 0.2 & 0.2 & 0.4 & 0.2 & 0.7 \\
\hline Freshwater drum & & 0.1 & 3.9 & & 0.4 & 1.2 & 0.4 \\
\hline
\end{tabular}

Average number of
fish per haul
23.9
$188 \quad 21.5$
12.4
12.5
11.2
8.8

Total number

of seine hauls

11

$6 \quad 12$

5

5

4

19

Overall average

number of fish

per haul

$\frac{278.3}{7}=39.75$

$303 / 8.1$ 
middle Missouri River. This was far greater than the 39.7 forage fish per haul (100 ft. x $10 \mathrm{ft}$. seine) determined for the lower Missouri River.

An explanation for the sparse forage fish populations in the lower Missouri compared to populations in the middle missouri and lower Yellowstone rivers is not clear-cut. It is evident from the data that best populations were found in the study sections with, at least, slight turbidities, warmer temperatures and hard substrate. Coincidently, these were the sites where the greatest number of macroinvertebrates were routinely sampled. These observations suggest that unstable channel substrate conditions (such as sand and silt) could be a major tactor limiting the abundance of forage fish in the lower half of the study area.

The rainbow smelt is a forage fish found in the study area which can have a major influence on the distribution and abundance of sauger and walleye in the river. The smelt was introduced into Lake Sakakawea Reservoir by the North Dakota Game and Fish Department in 1971 (Berard 1982). The first record of smelt in Montana was from the lower reach of the study area in October, 1979 when a few fish were observed while electrofishing. In the spring of 1980 a major migratory run of rainbow smelt was observed presumably originating from Lake Sakakawea. Smelt were first noted in the lower reach on April 17, 1980. Later in the spring the run had reached the Fort Peck Dam area. By mid-June they had left the Missouri River (excluding the tailwaters area of Fort Peck Dam). Numerous smelt numbers were encountered during electrofishing operations; several hundred could have been captured in one day.

Within the study area, smelt were commonly observed from Wolf Point downstream, but were uncommon in the river upstream from this point. They were quite uniform in size ranging between 6.1 and 7.2 inches. They were all aged at 2 years. About 30 smelt were examined for spawning condition and it was found that several males and a couple of females were ripe. No evidence of successful reproduction in the form of eggs, drifting larvae or collected YOY specimens was, found. Good catches of smelt were made in the dredge cuts/tailwaters area during August of that year indicating that a portion of the smelt remained here after the spring run. The smelt migratory run in 1981 did not appear to be of much significance. High numbers were observed only in the lower reach of the Missouri River with only a very few observed in upstream areas where they were noted during 1980. Smelt were found in the dredge cuts area in reduced numbers compared to 1980 levels (Figure 15). The occurrence of smelt in the study area during 1981 was also evident by the feeding activity of sauger. Sauger sampling in the Milk/Missouri River confluence area indicated intense feeding on smelt. Smelt were not found in the river during 1982 and only a slight run was observed in the lower reach of the study area during 1983. Their numbers in the dredge cuts declined to low levels during these years. Previous results from this report have depicted a close relationship between the exceptional numbers of sauger observed in the study area and the presence of smelt. Figure 15 clearly shows this relationship between sauger/walleye numbers in the dredge cuts and rainbow smelt abundance. This same relationship apparently existed at the Milk/Missouri River confluence area during 1980-81.

Rainbow smelt appeared to exhibit the same yearly abundance trends in the lower Yellowstone River as were observed in the Missouri River. Large numbers of smelt were present in the Yellowstone only during 1980. Electrofishing surveys in this area since this date have revealed few numbers of smelt 


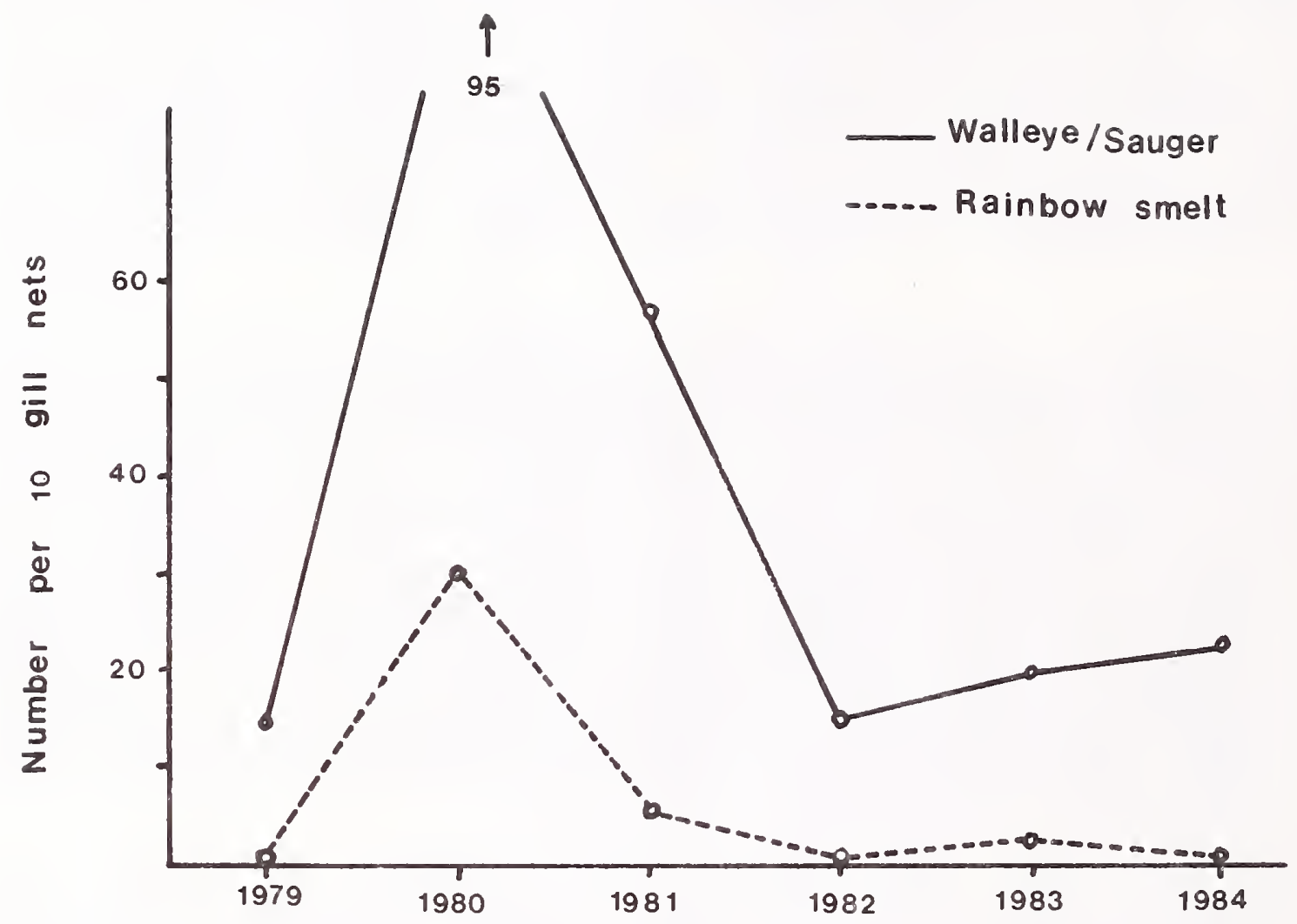

Figure 15. The relationship of sauger/walleye abundance in the Fort Peck dredge cuts/tailwater area to that of rainbow smelt abundance (Needham and Gilge 1985). 
(Stewart, personal communication). The reason for the significant migratory run up the Missouri and Yellowstone rivers during 1980 is unknown. The 1980 water year was characterized by abnormally low spring flows. Since then there has been one normal water year (1982) when spring flows were high, but smelt did not run during that year. It is apparent that smelt do not cue to high spring flows. It is possible that this run is a reflection of density levels in Lake Sakakawea, with migration occurring in the river during years when smelt are exceptionally abundant in the reservoir.

\section{Food habits analyses}

It is important that the food habits for the sport fishes in the study area be evaluated. Knowledge of the importance of various forage organisms in the diets of the sport fish will be valuable information for maintaining and improving the present fisheries and necessary for assessing impacts which might affect the food source. Sauger, burbot, shovelnose sturgeon, northern pike, and walleye stomach contents were examined during 1982. Data for the latter two species was not shown because of the small sample size. Sauger stomach contents were examined during spring, summer and fall; shovelnose sturgeon in the spring and summer; and burbot only in the spring.

Sauger. Food habits analyses for the 1,340 age $1+$ or older sauger examined were based on $59 \mathrm{fish}$ which had some food items present in their stomachs. A total of 54 organisms representing five orders of invertebrates and seven forage fish species were identified in the stomach contents (Table 45). For most of the stomach samples, unidentifiable fish items dominated the contents occurring in about 50 percent of the food-containing stomachs. In terms of bulk and numbers, fish species constituted a much greater portion of the sauger diet than aquatic invertebrates. The most important fish items were goldeye, flathead chub, and fathead minnow; species which inhabit shoal areas of the main channel and off-channel areas. It is interesting to note that the more abundant forage fish species (white suckers and white crappie) as enumerated by seining surveys, were rarely found in the sauger's diet.

Ninety-six percent of the sauger stomachs examined contained no food. This appeared to be an abnormally high percentage, since Gardner and Berg (1982) reported an empty stomach incidence of about 70 percent for the middle Missouri River sauger fishery and Elser et al. (1977) reported about a 60 percent incidence for the lower Yellowstone River sauger population. An explanation for these observed differences could be related to the sampling seasonality. During this study sauger food habit analysis was conducted spring summer and fall compared to the other two studies which conducted food habit analysis chiefly during the late summer and fall. Slower digestion rates and an increase in feeding during the later seasons could have attributed to the observed differences in the incidense of empty stomachs. Contents of 28 YOY sauger stomachs were examined in September 1982 (Table 46). In contrast to oldei. sauger no YOY stomachs were empty. Ninety-three percent contained copepods, and small crustaceans. Lesser percentages contained Ephemeroptera, Hydropsychidae, Chironomidae and fish larvae.

Burbot. A total of 99 burbot stomachs were examined for food items (Tables 47 and 48). This total was divided into fish smaller than 20 inches total length and fish larger than 20 inches total length because of obvious differences in diet between large and small burbot. Each of the two size 
Table 45. Stomach content results (number and percentages) for sauger age $1+$ and older sampled in Missouri River, 1982.

\begin{tabular}{|c|c|c|c|c|}
\hline & $\begin{array}{l}\text { Spring } \\
(n=576)\end{array}$ & $\begin{array}{l}\text { Summer } \\
(n=546)\end{array}$ & $\begin{array}{l}\text { Fal1 } \\
(n=218)\end{array}$ & $\begin{array}{l}\text { Composite } \\
(n=1340)\end{array}$ \\
\hline Invertebrates & & & & \\
\hline$\frac{\text { Orconectes }}{\text { (crayfish) }}$ & 0 & $1(0.2)$ & 0 & $1(0.1)$ \\
\hline $\begin{array}{l}\text { Ephemeroptera - } \\
\text { (nymphs) }\end{array}$ & 0 & $4(0.7)$ & 0 & $4(0.3)$ \\
\hline $\begin{array}{l}\text { Trichoptera - } \\
\text { (larvae) }\end{array}$ & $1(0.2)$ & 0 & 0 & $1(0.1)$ \\
\hline Heteroptera - & 0 & $1(0.2)$ & 0 & $1(0.1)$ \\
\hline $\begin{array}{l}\text { Diptera - } \\
\text { (1arvae) }\end{array}$ & 0 & 0 & $1(0.5)$ & $1(0.1)$ \\
\hline $\begin{array}{l}\text { Unidentifiable - } \\
\text { insects }\end{array}$ & 0 & 0 & $1(0.5)$ & $1(0.1)$ \\
\hline \multicolumn{5}{|l|}{ Fish } \\
\hline Goldeye - & 0 & $2(0.4)$ & $2(0.9)$ & $4(0.3)$ \\
\hline Flathead chub - & 0 & $5(0.9)$ & 0 & $5(0.4)$ \\
\hline Fathead minnow - & 0 & $1(0.2)$ & $3(1.4)$ & $4(0.3)$ \\
\hline White sucker - & 0 & $1(0.2)$ & 0 & $1(0.1)$ \\
\hline Black bullhead - & $1(0.2)$ & 0 & 0 & $1(0.1)$ \\
\hline Sauger - & 0 & 0 & $1(0.5)$ & $1(0.1)$ \\
\hline Freshwater drum - & 0 & $2(0.4)$ & 0 & $2(0.2)$ \\
\hline $\begin{array}{l}\text { Unidentifiable - } \\
\text { fish remains }\end{array}$ & $3(0.5)$ & $20(3.7)$ & $8(3.7)$ & $31(2.3)$ \\
\hline Stomach empty - & $571(99.1)$ & $512(93.8)$ & $198(90.8)$ & $1281(95.6)$ \\
\hline
\end{tabular}

Table 46. Stomach content results (number and percentages) for young-of-the-year sauger collected in the Missouri River, 1982.

\begin{tabular}{lccccc}
\hline Copepods & Ephemeroptera & Hydropsychidae & Chironomidae & $\begin{array}{l}\text { Larval } \\
\text { Fish }\end{array}$ & $\begin{array}{c}\text { Stomach } \\
\text { Empty }\end{array}$ \\
\hline $26(93)$ & $5(18)$ & $7(25)$ & $2(7)$ & $1(4)$ & $0(0)$ \\
\hline
\end{tabular}


Table 47. Stomach content results (number and percentages) for burbot less than 20 inches in total length sampled in Missouri River, Apri1 and May, 1982.

\begin{tabular}{|c|c|c|}
\hline Item & $\begin{array}{c}\text { Above Poplar River } \\
(\mathrm{N}=15)\end{array}$ & $\begin{array}{c}\text { Below Poplar River } \\
(\mathrm{N}=22)\end{array}$ \\
\hline Annelida & 0 & $6(21)$ \\
\hline Gammarus & $3(9)$ & 0 \\
\hline Urconectes & $1(3)$ & $6(21)$ \\
\hline Ephemeroptera nymphs & $20(61)$ & $11(38)$ \\
\hline Hydropsychidae larvae & $10(30)$ & 12 (41) \\
\hline Chironomidae larvae & $9(27)$ & $4(14)$ \\
\hline Simuliidae larvae & $16(48)$ & 0 \\
\hline Tipulidae larvae & 1 (3) & $2(7)$ \\
\hline Odonata nymphs & 0 & 1 (3) \\
\hline Unidentifiable insects & $1(1)$ & 0 \\
\hline Fathead minnow & 0 & $9(31)$ \\
\hline Emerald shiner & 0 & 1 (3) \\
\hline White crappie & 0 & $1(3)$ \\
\hline Goldeye & 0 & $1(3)$ \\
\hline Unidentifiable fish & $1(3)$ & $4(14)$ \\
\hline Frog & 0 & 1 (3) \\
\hline Stomach empty & $8(24)$ & 1 (3) \\
\hline
\end{tabular}

Table 48. Stomach content results (number and percentages) for burbot 20 inches or greater in total length sampled in Missouri River, April and May, 1982.

\begin{tabular}{lcc}
\hline Item & $\begin{array}{c}\text { Above Poplar River } \\
(\mathrm{N}=33)\end{array}$ & $\begin{array}{c}\text { Below Poplar River } \\
(\mathrm{N}=29)\end{array}$ \\
\hline $\begin{array}{l}\text { Hydropsychidae larvae } \\
\text { Orconectes }\end{array}$ & 0 & $1(5)$ \\
Goldeye & 0 & $6(27)$ \\
Burbot & 0 & $10(45)$ \\
Shorthead redhorse & $1(7)$ & $1(5)$ \\
Sauger & 0 & $1(5)$ \\
Unidentifiable fish & $1(7)$ & $1(5)$ \\
Stomach empty & 0 & $4(14)$ \\
\end{tabular}

$303 / 8.1$ 
classifications was further subdivided into fish sampled upstream and downstream from the Poplar River.

For burbot less than 20 inches total length, only 15 percent had empty stomachs. Invertebrates were the predominant food items at both upstream and downstream locations, with Ephemeroptera nymphs and Hydropschidae larvae being common food items. Simuliidae larvae were important food items only upstream from the Poplar River. Twenty-nine percent contained fish, but almost all of these were sampled downstream from the Poplar River. The fathead minnow was the most common fish food item found in their diet. There were often a large number of these in a single stomach. One 18.5-inch burbot contained 102 fathead minnows that were 1 to 2 inches long, plus a few other food items. For burbot larger than 20 inches, only 11 percent of the stomachs were empty and goldeye were the predominant food item. Sixty-two percent of burbot longer than 20 inches contained goldeye. Only larger goldeye were eaten; most of the goldeye in burbot stomachs were 10-14 inches 1ong. Only one burbot had eaten an insect larvae, but the crayfish, Orconectes, was common in burbot stomachs sampled downstream from the Poplar River. Other fish food items included other burbot, shorthead redhorse, and sauger.

Shovelnose sturgeon. Food habits analyses were completed for 26 adult shovelnose sturgeon collected by electrofishing throughout the study area. The sturgeon stomachs were collected during the spring and summer of 1982. Because of the lower numbers of samples, only general conclusions can be made.

Results of the shovelnose sturgeon food habits analyses are presented in Table 49. The diet was comprised of aquatic insects. Chironomids were the most frequent food item comprising the sturgeon's diet, and many times this item was the only taxa represented in the food contents. Members of the order Ephemeroptera and of the family Hydropsychidae (a trichopteran) were the other two taxa found in significant numbers in the sturgeon's diet. Modde and Schmulbach (1977), studying the food habits of shovelnose in the Missouri River, South Dakota, reported results similar to what was found for this study. They reported that chironomids were the chief food item found in the diets of shovelnose sturgeon during May through September. Ephemeropterans and hydropsychids were two other less important taxa found in the sturgeon's diets during this period. Food habits for sturgeon studied in the middle Missouri River were different than that found for this study. Gardner and Berg (1982) reported that the order Ephemeroptera was the most important food group for sturgeon in the middle Missouri River during the spring and summer periods. They also reported that hydropsychids and chironomids were important in the shovelnose diets during this period. Sixty percent of the stomachs collected during the summer were, or were nearly were empty indicating low foraging success. Modde and Schmulbach (1977) reported that shovelnose had less food contents in the stomach samples collected during May through September than for any other period. They attributed this occurrence of low food rations to factors associated with greater water releases from Gavins Point Dam. Gardner and Berg (1982) reported that the shovelnose in the middle Missouri River generally had full stomach contents throughout the three seasons they collected the samples.

Food habits analyses for sauger burbot and shovelnose sturgeon further identifies the habitat conditions that are necessary for maintaining healthy populations of these sport fish. Sauger food habit analysis underlines the 
Table 49. Stomach content results (number and percentages) for shovelnose sturgeon collected in the Missouri River, 1982.

Month

April-May

$\frac{\mathrm{Ju} 1 \mathrm{y}}{(\mathrm{N}=10)}$

Item

$(N=16)$

$9(90)$

9 (56)

2 (20)

$15(94)$

10 (100)

Hydropsychida

0

1 (6)

1 (6)

1 (10)

Corixidae

Muscidae

Simuliidae

4 (25)

0

Stomach nearly empty

25)

$6(60)$

a/ less than 20 organisms

$303 / 8.1$ 
importance of maintaining good flow conditions in the shoal habitat areas. These areas are also where the YOY sauger feed on ample supplies of zooplankton. Riffles are important food producing areas for insectivorous fish like burbot and shovelnose sturgeon. Adequate flows are essential for maintaining suitable aquatic insect production, the forage base for these fish.

\section{Tributary streams - fish populations}

The tributaries entering the Missouri River within the study area have an influence upon the physical, chemical, and biological characteristics of the mainstem (Figure 16). These tributaries augment the flow and increase turbidities and water temperatures of the mainstem. It has been noted in a previous section that significant changes in the fish communities occur in the mainstem, especially below the Milk River. Also, spawning migrations of important sport fish have been observed moving from the Missouri into the larger tributaries. The importance of major tributary streams to a larger river has also been reported by Berg (1981), Elser et al. (1977), and Rehwinkel et al. (1976).

An important feature provided by tributary streams, not discussed previously is cover habitat for both adult sport fish and forage fish. The calmer waters of tributary streams which have vegetated banks are ideal shelter areas and during low flow periods they resemble the highly productive mainstem backwaters habitat. Drewes and Gilge (1986) believed that most of the northern pike rearing areas in the middle Milk River, Montana were located in the lower most reaches and in the embayments of smaller tributary streams in this section of river. A comparison of electrofishing and gill netting results between tributary streams and nearby mainstem sections indicates that tributary streams probably have better sport fish numbers than the nearby Missouri River (Table 50). Electrofishing catch rates in the tributaries were usually better than those in the mainstem, averaging $9.0 \mathrm{fish}$ per hour in the tributaries compared to 7.3 fish per hour in the mainstem. Gill net catch rates followed the same trend with average catch rates of $9.7 \mathrm{fish}$ per hour in the tributaries compared to $1.8 \mathrm{fish}$ per hour in the mainstem sections.

Species composition - Milk River.

The Milk River is the largest tributary in the study area. Resident fish populations were surveyed, in the lower 60 miles of river. The river in this reach is about 100 feet wide, has a low gradient (averaging less than 0.5 foot per mile). Gravelly riffles are widely spaced at about 1 to 2 miles apart. The long pools are deep, with maximum depths of 6 to 8 feet during summer flow conditions.

Electrofishing for sport fish was confined to the lower five miles of river. Table 51 shows that in the Milk River there was an average catch rate of 10.2 sauger per hour, and probably having the best numbers of sauger of all the other tributaries. Other sport fish were found in low numbers. Length/weight data for each species is given in Appendix Table 49. Three sites on the lower Milk River were sampled with gill nets during the summer and fall. These sites are located 60,23 and 4 miles above the confluence with the Missouri River and are identified as the Glasgow, Nashua and confluence sites, respectively. The pools where the gill nets were set were at least six feet deep. A total of 1,104 fish representing 14 species were caught in the 16 gill net sets. Goldeye 


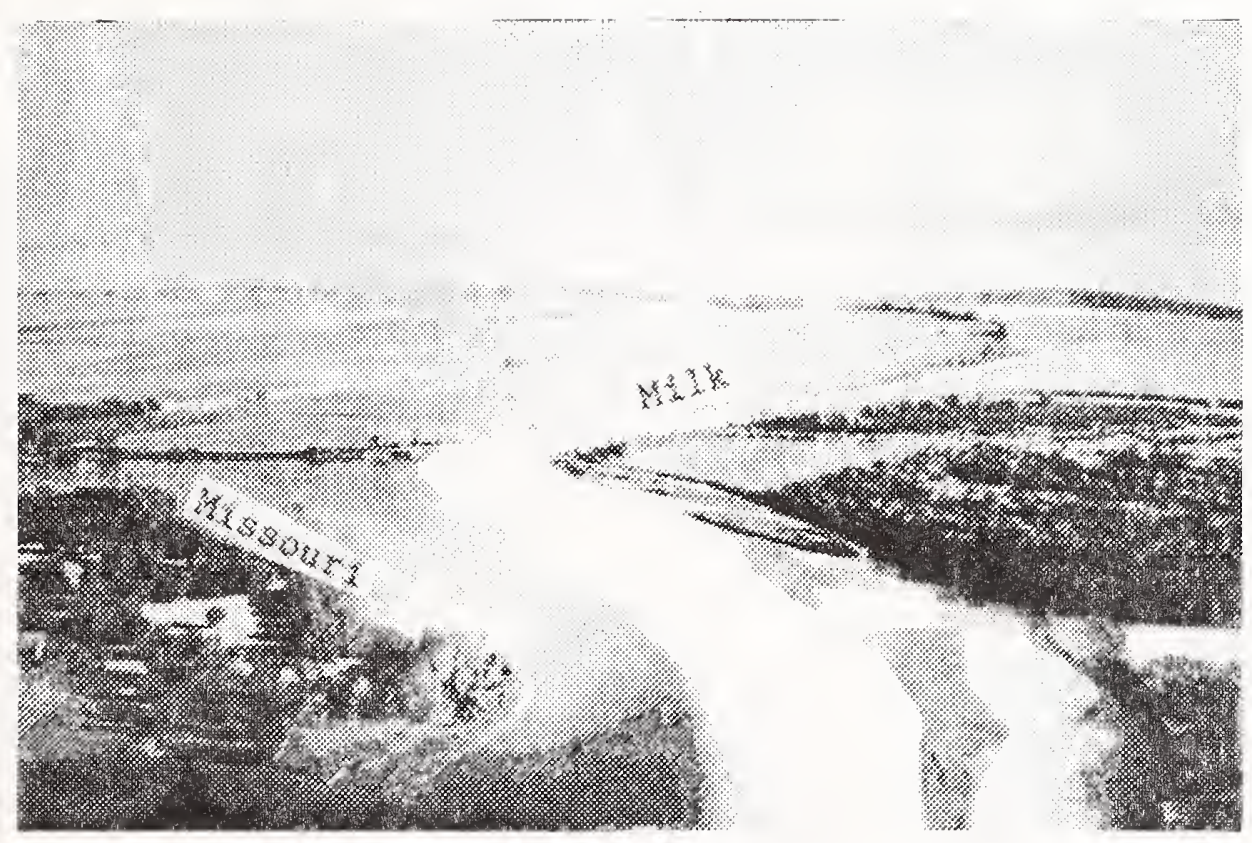

Figure 16. The Milk River restores some of the warmwater river characteristics of the Missouri and this confluence area was found to be one of the most important biological zones in the study area. 


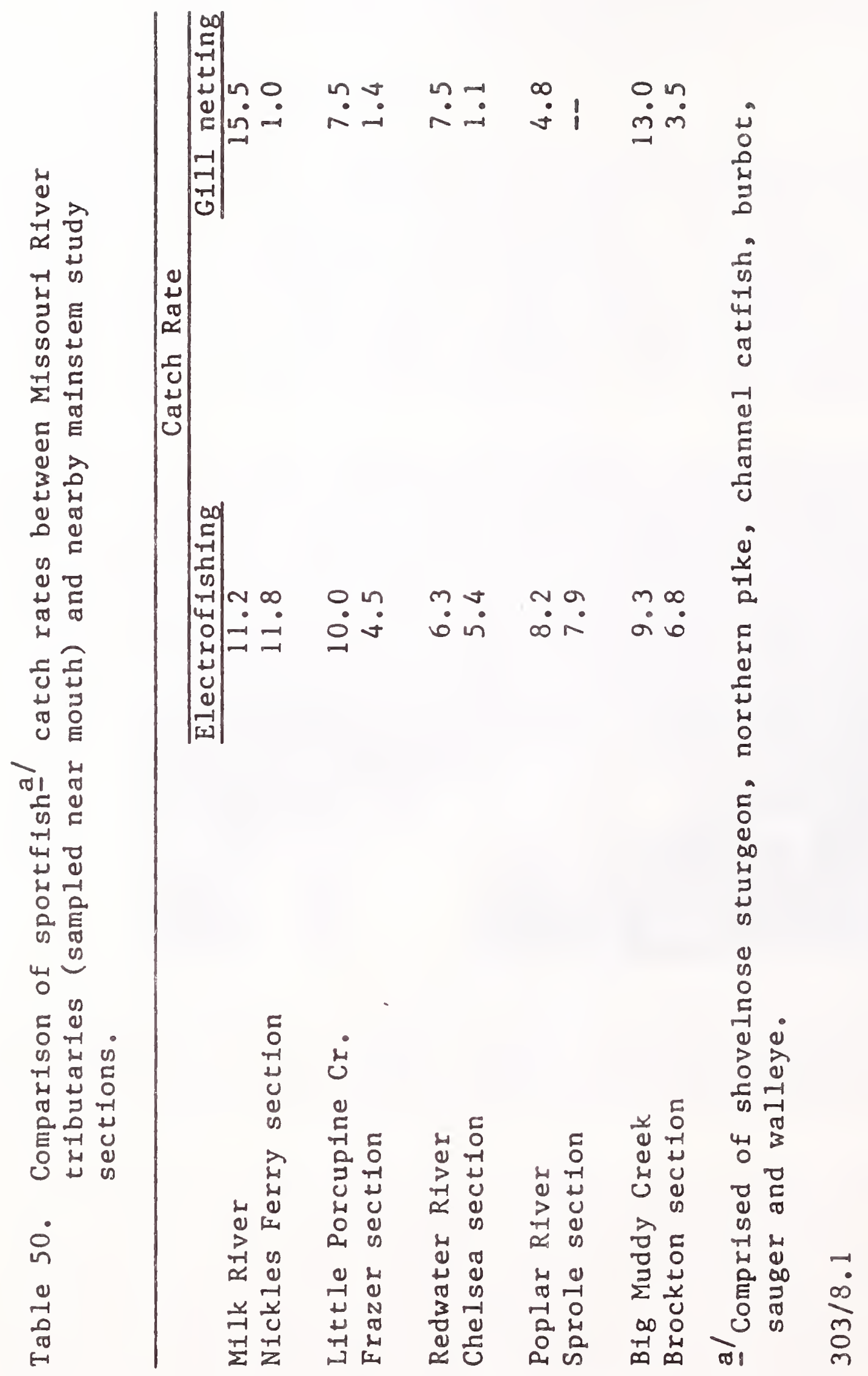




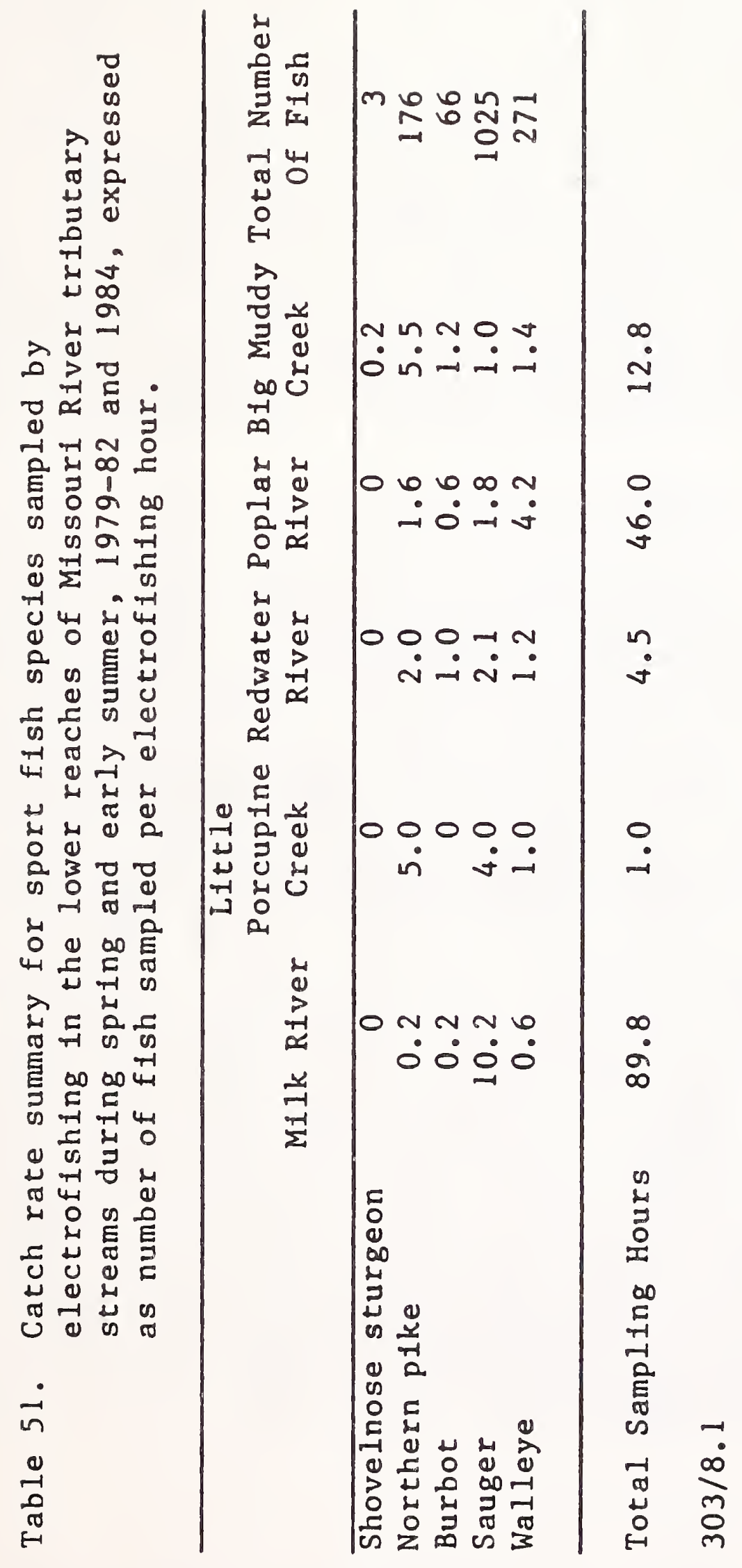


far outnumbered any other species caught having an average catch rate of 65.1 fish per net (Table 52). The average sizes of goldeye found at the Nashua and confluence sites are considered large for this species, with some specimens weighing well over a pound (Appendix Tables 50-52). Shorthead redhorse and river carpsucker were the other two predominant species. Sport fish were generally found in lower numbers, with catch rates between 0.2 and 12.0 fish per net. Sauger channel catfish and northern pike were the more common sport fish found, while walleye and shovelnose sturgeon were sampled less frequently. The sauger catch rate of 12.0 fish per net at the confluence site indicates that sauger numbers are most likely the greater at this site in the Milk River than at comparable locations in other tributary streams. It was interesting to note that very few white suckers and no longnose suckers were sampled. Good numbers and varieties of forage fish have been sampled in the past at the Nashua site (Needham 1978). Ten species of forage fish were collected averaging about 30 fish per net for a small $4 \mathrm{ft}$. X $25 \mathrm{ft}$. seine (Table 53). No young-of-the-year sport fish were noted.

Species Composition - Other tributaries.

The other lower reaches of Missouri River tributary streams included the Poplar and Redwater rivers and Little Porcupine and Big Muddy creeks. All of these streams are considerably smaller than the Milk River. Electrofishing surveys indicated that, in general, sport fish numbers were low. Catch rates for sauger in these tributaries ranged from 1.0-4.0 fish per hour (Table 51). Northern pike catch rates of about 5 fish per hour were recorded for the Little Porcupine and Big Muddy creeks. These relatively better pike catch rates in the smaller tributary streams are most likely the result of the heavily vegetated banks which were more prevalent in these streams. A catch rate of 4.2 walleye per hour noted in the Poplar River was considerably higher than that found for the other tributaries. This is because the Poplar was the only tributary stream of the Missouri known to have a resident walleye population (Stewart 1978).

An average of 175 fish representing 14 species was caught in the 12 gill net sets located in these smaller tributaries. Gill netting survey results of these four tributaries were similar to that reported for the Milk River (Table 52 and Appendix Tables 53-56). Goldeye dominated the catches comprising between 43 and 74 percent of the fish netted. The sampling of one shortnose gar in Little Porcupine Creek is of particular interest since this species is rare throughout the study area and in Montana. Brown (1971) reports that less than a dozen specimens have been taken in the last 20 years, all from the Missouri River dredge cuts below Fort Peck Dam. Because of its rarity in the state, this species is listed as a "Species of Special Concern," Class C in Montana. Most sport fish were found in low numbers with the exception of northern pike in Little Porcupine and Big Muddy creeks. Here catch rates of 3.7 fish per net in Big Muddy Creek and 5.0 pike per net in Little Porcupine Creek indicated that fair numbers of northern pike were present.

Instream flow assessment

Overview.

Maintenance of healthy and diverse fish populations in the lower Missouri River requires instream flows of a proper magnitude which will ensure that various fish species are able to successfully fulfill their essential life cycle 


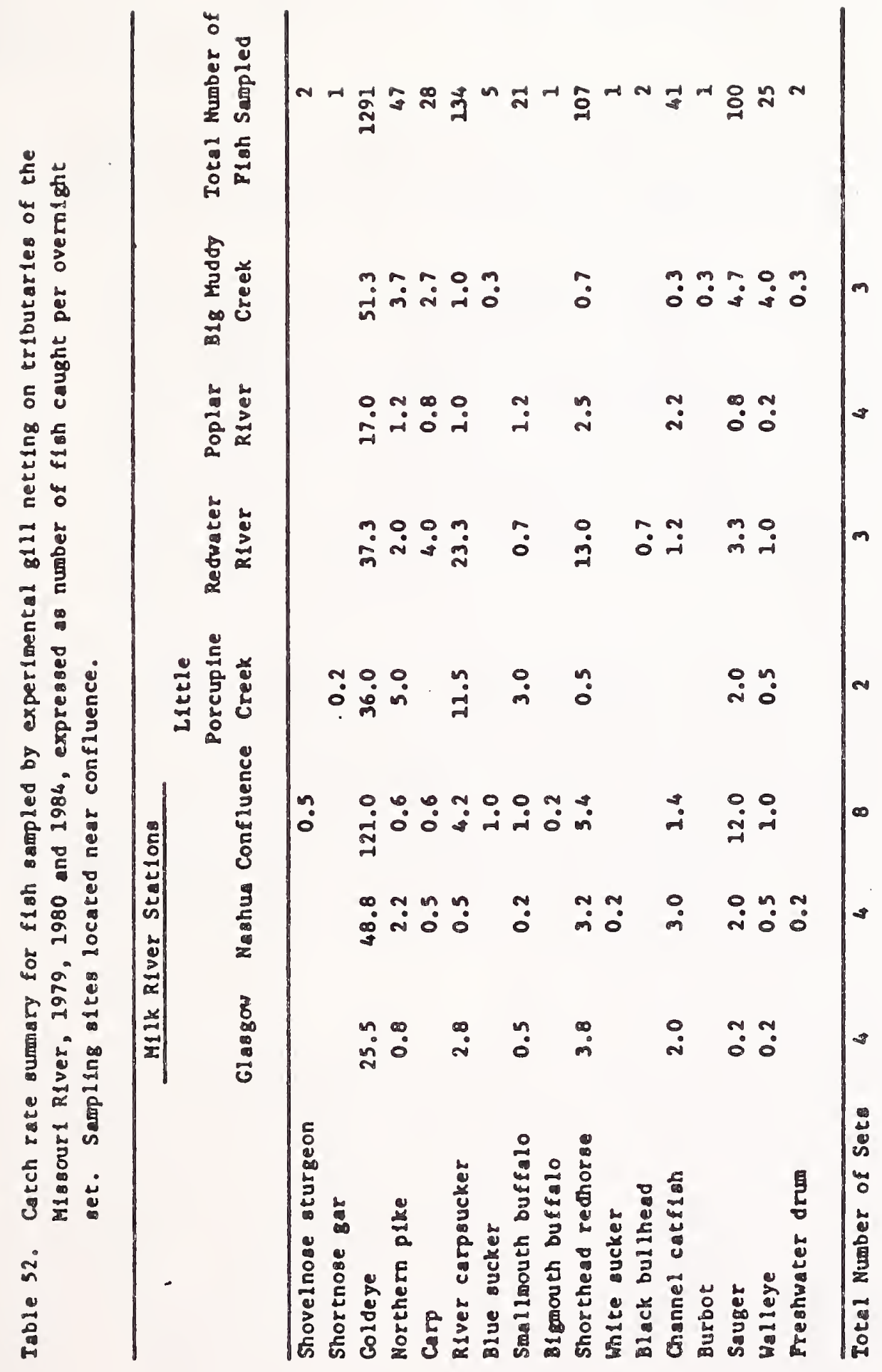




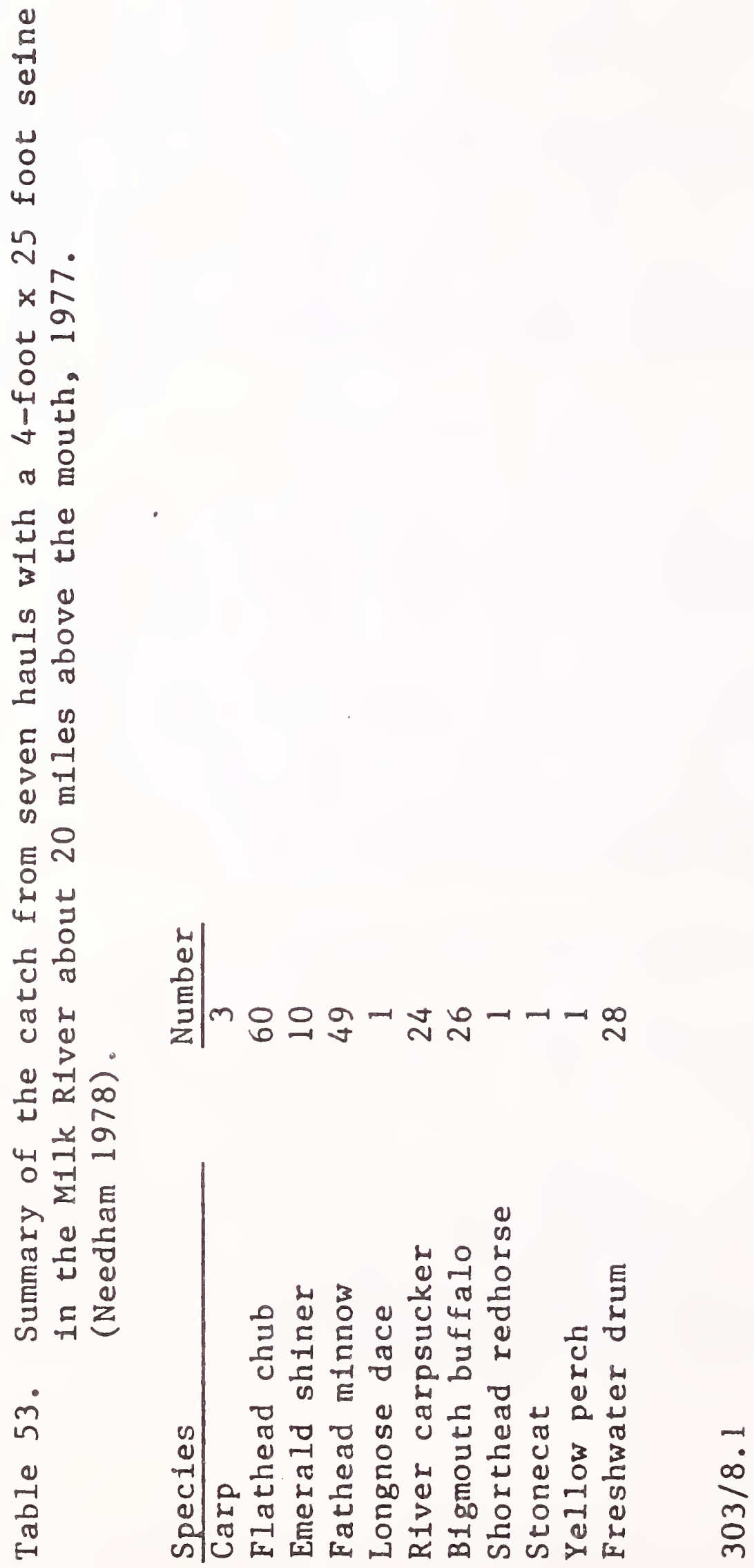


requirements. The river fish communities have evolved with the seasonal pattern of the flow conditions and their important habitat areas are also created and maintained by the river's hydrology. Substantial changes in the flow patterns could, therefore, seriously affect the distribution and abundance of many important sport fish in the river. It is important that instream flows necessary for triggering spawning migrations and habitat maintenance be identified and protected to prevent serious losses to the lower Missouri River fisheries resources.

An instream flow analysis was conducted in the study area. This analysis was concerned with identifying flows which would maintain important habitat areas that are vulnerable to dewatering. These critical habitat areas and their importance to the fishery are defined as follows:

(1) Off-channel pool areas used as rearing sites for YOY sauger, forage fish production, and sites for zooplankton production.

(2) Rocky reefs used intensively as spawning sites by sauger and walleye.

(3) Riffles and runs which are important habitat for fish food organisms (aquatic macroinvertebrates). Riffles are also the area of a stream most affected by flow reductions (Bovee 1974, Nelson 1977). Consequently, the maintenance of suitable riffle conditions should provide adequate shelter habitat conditions in pools and runs, areas normally inhabited by adult fish. These habitats are diagrammatically depicted in Figure 17.

Twenty-seven locations for cross-section profiles were selected. Nine were located at four off-channel pool sites, 6 cross sections at two sauger spawning/incubation sites, and the remaining 12 were situated at six different riffle sites. Three sets of river stage height and discharge data (a high, intermediate and low flow) were necessary for calibration of the WETP computer program. Since the Missouri River below Fort Peck Dam is entirely regulated, it was necessary that the Corps of Engineers maintain steady releases from the dam for 48 hours while water elevations were measured at each cross section site. The actual water releases used for calibration were 9,800, 7,200 and 4,400 cfs.

Sauger rearing pools.

Extensive seining surveys in the study area indicated that YOY sauger have a preference for off-channel pools. Other studies have also reported that YOY sauger prefer off-channel areas (Gardner and Berg 1982, Kallemeyn and Novotny 1977 and Kozel 1974). These pools are a unique feature found in the lower half of the study area and are most likely formed by lateral sand bars deposited near the channel margin or an abandoned channel (Figure 13). Approximate dimensions of these pools at normal summer flows range from 20 to 180 feet wide, 100 to 600 feet long, and with maximum depths between three and eight feet. While these pools were important sauger rearing habitat, better catches of forage fish also occurred in this habitat. In addition these areas were important for zooplankton production, a major food item for YOY sauger (Priegel 1969).

Four typical sauger-rearing pools were surveyed. At least two cross sections were established at each pool. The cross sections were usually located at the upper end and near the mouth of the pool. The criteria used to deternine the river flow that best maintains the pool habitat in a reasonable condition was determined to be the point where the profile of the pool cross section 


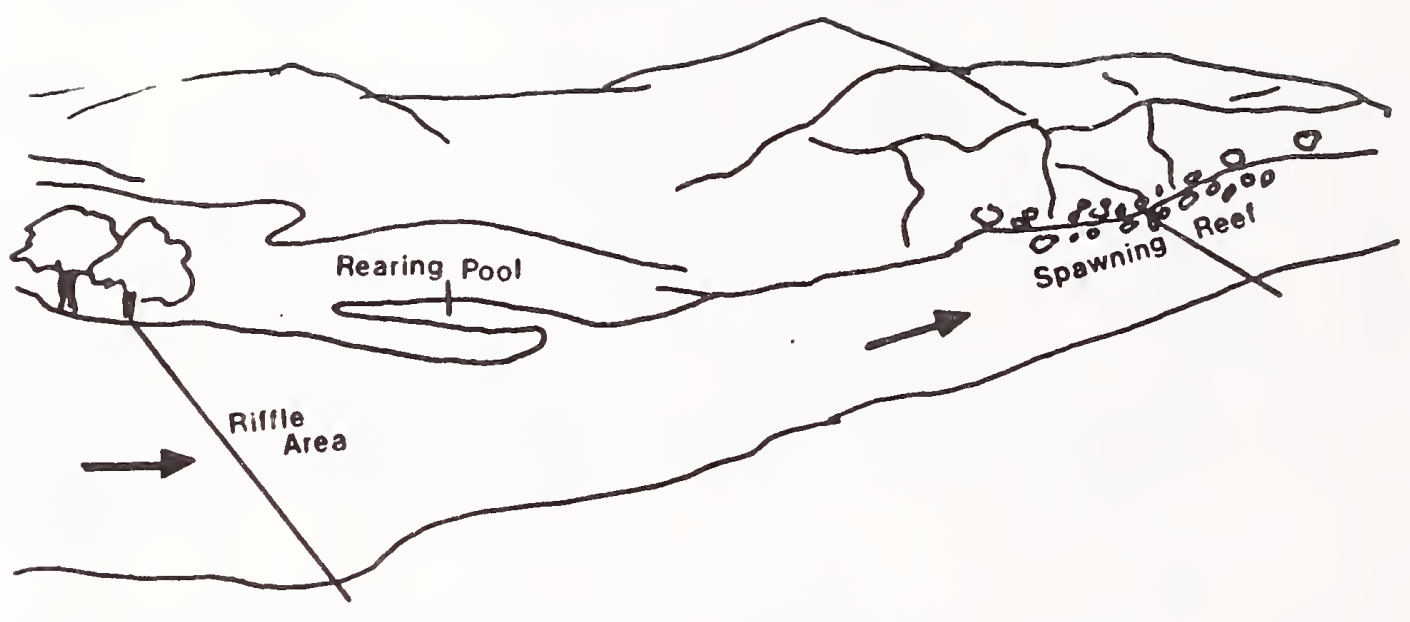

Figure 17. Diagrammatic representation of the habitat areas where instream flow analysis was performed 
changed sharply from more vertical sloping sides to gradual sloping sides. At this point losses of the pool width increase and there is a corresponding loss of pool size along with the preferred shoal areas. Basically, the size of the off-channel pool is a major factor which limits sauger rearing capacity. It is also important to maintain an adequate depth along with vegetated shoal areas for security habitat and food production. Figure 18 is an example of two cross sections from the same pool with the indicated river stage and flow which maintains that pool in a suitable condition. The river flow was determined from the WETP computer program which predicts the flow for a given river stage.

Results of the WETP analysis of the off-channel pools are given in Table 54. Curves for individual cross sections are given in Appendix Figures 1-4. The river flow which would maintain a reasonable water level at each off-chamnel pool cross section were determined. The predicted flows for the cross sections (usually two) in each side channel pool were averaged. this was done, rather than using the cross section with the highest flow, because it was felt that this method gave a flow which was a better representation of the side channel pool's conditions. Flows which would maintain these rearing pools in a suitable condition ranged from 5325 cfs at Culbertson section to 6,042 cfs (an average of 4,500 and $7,583 \mathrm{cfs}$ ) for the two rearing sites in the Brockton section. Therefore, instream flows at the Culbertson USGS gauging station, should be at least $6,042 \mathrm{cfs}$. The highest average instream flow value that maintained these rearing pools was chosen because this flow would fulfill the requirements for the monitored rearing pools in each study section. The rearing season for this study was not determined. Gardner and Berg (1982) recommended the rearing flows in the middle Missouri River be maintained from June 1-August 31. Until further evaluations are made concerning the sauger rearing period, instream flows for rearing in the lower Missouri should be provided from June 15-September 15. A fifteen day differential was added to the middle Missouri's period because of the 15-day spawning difference observed for the lower Missouri's sauger population. Summer water temperatures in the lower Missouri River were shown previously to be colder than temperatures in the middle Missouri, and therefore explains the difference in spawning time and, most likely, the rearing period.

Sauger and walleye spawning/incubation reefs

Major spawning/incubation areas used by sauger, and to a lesser extent, walleye, were located at rocky reef areas. There is considerable sauger spawning use in the reef areas. Electrofishing catch rates of adults during the spawning season averaged about $25 \mathrm{fish} / \mathrm{hr}$. compared to about $6 \mathrm{fish} / \mathrm{hr}$. during the summer and fall. Kick samples for incubating eggs yielded up to 20 eggs/sample, and later, larval fish tows at these sites captured upwards to 15 sauger larval for a 10-minute tow. The reefs where spawning activity was noted were associated with eroding cliffs of a hard sandstone formation which bordered the river and were limited to eight sites in the study area (Figure 19). Known spawning/incubation areas were confined to about five miles of river bank in the 184-mile study area. This was considered limiting and underscores the significance of maintaining adequate spawning flows in these important areas.

Two representative spawning/incubation reefs were studied and relationships between flow and spawning/incubation habitat conditions were investigated. The specific spawning/incubation areas were rocky substrate areas along the margins of the river channel. The width of these rocky areas did not extend indefinately across the channel, but were limited to the shoal areas of the 


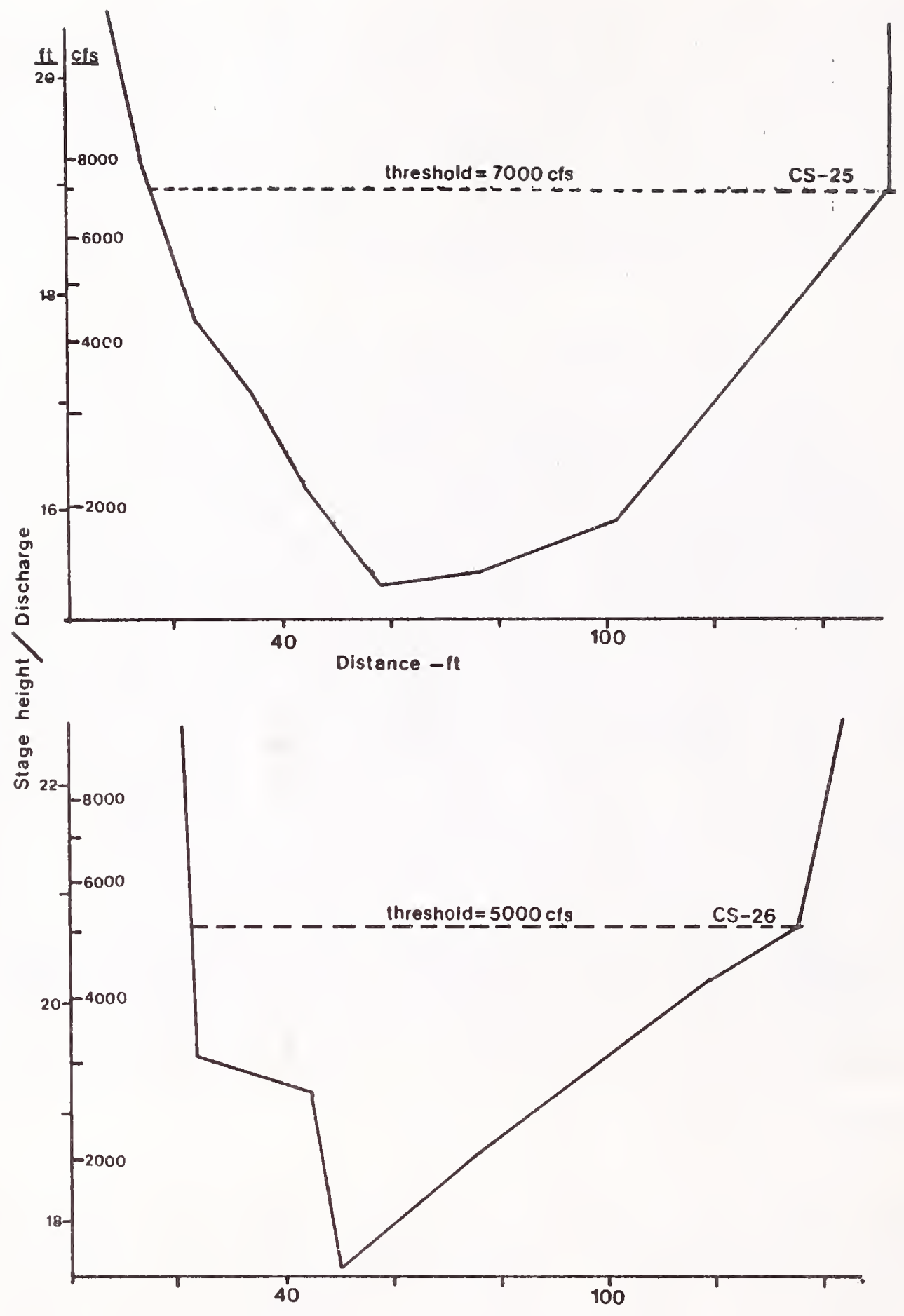

Figure 18. A representation of two cross section profiles of the same rearing pool showing river stage heights and flow which will maintain the pool in a suitable condition. 
Table 54. Predicted water elevations and corresponding flows at which four monitored pools are at suitable maintenance conditions.

\begin{tabular}{|c|c|c|c|c|}
\hline STUDY SECTION & $\begin{array}{l}\text { CROSS } \\
\text { SECTION \# }\end{array}$ & $\begin{array}{l}\text { RIVER STAGE ALLOWING } \\
\text { SUITABLE } \\
\text { POOL MAINTENANCE }\end{array}$ & & $\begin{array}{l}\text { FLOW } \\
(\mathrm{cfs})\end{array}$ \\
\hline $\begin{array}{l}\text { Sprole } \\
\text { (RM 93) }\end{array}$ & $\begin{array}{ll}25 & \text { (lower) } \\
26 & \text { (upper) }\end{array}$ & $\begin{array}{l}18.80 \mathrm{ft} . \\
20.65 \mathrm{ft} .\end{array}$ & Average = & $\begin{array}{l}7000 \\
\frac{5000}{6000}\end{array}$ \\
\hline $\begin{array}{l}\text { Brockton } \\
\text { (RM 125) }\end{array}$ & $\begin{array}{ll}27 & \text { (lower) } \\
28 & \text { (upper) }\end{array}$ & $\begin{array}{l}19.85 \mathrm{ft} . \\
21.60 \mathrm{ft} .\end{array}$ & Average $=$ & $\begin{array}{l}3500 \\
5500 \\
4500\end{array}$ \\
\hline $\begin{array}{l}\text { Brockton } \\
\text { (RM 139) }\end{array}$ & $\begin{array}{ll}34 & \text { (lower) } \\
35 \text { (middle) } \\
36 \text { (upper) }\end{array}$ & $\begin{array}{l}20.00 \mathrm{ft} . \\
29.90 \mathrm{ft} . \\
29.70 \mathrm{ft} .\end{array}$ & Average $=$ & $\begin{array}{l}9250 \\
7500 \\
6000 \\
7583\end{array}$ \\
\hline $\begin{array}{l}\text { Culbertson } \\
\text { (RM 179) }\end{array}$ & $\begin{array}{l}43 \text { (lower) } \\
44 \text { (upper) }\end{array}$ & $\begin{array}{l}18.30 \mathrm{ft} . \\
16.40 \mathrm{ft} .\end{array}$ & Average = & $\begin{array}{l}4850 \\
5800 \\
5325\end{array}$ \\
\hline
\end{tabular}

a/River miles from dam.

$303 / 8.1$ 


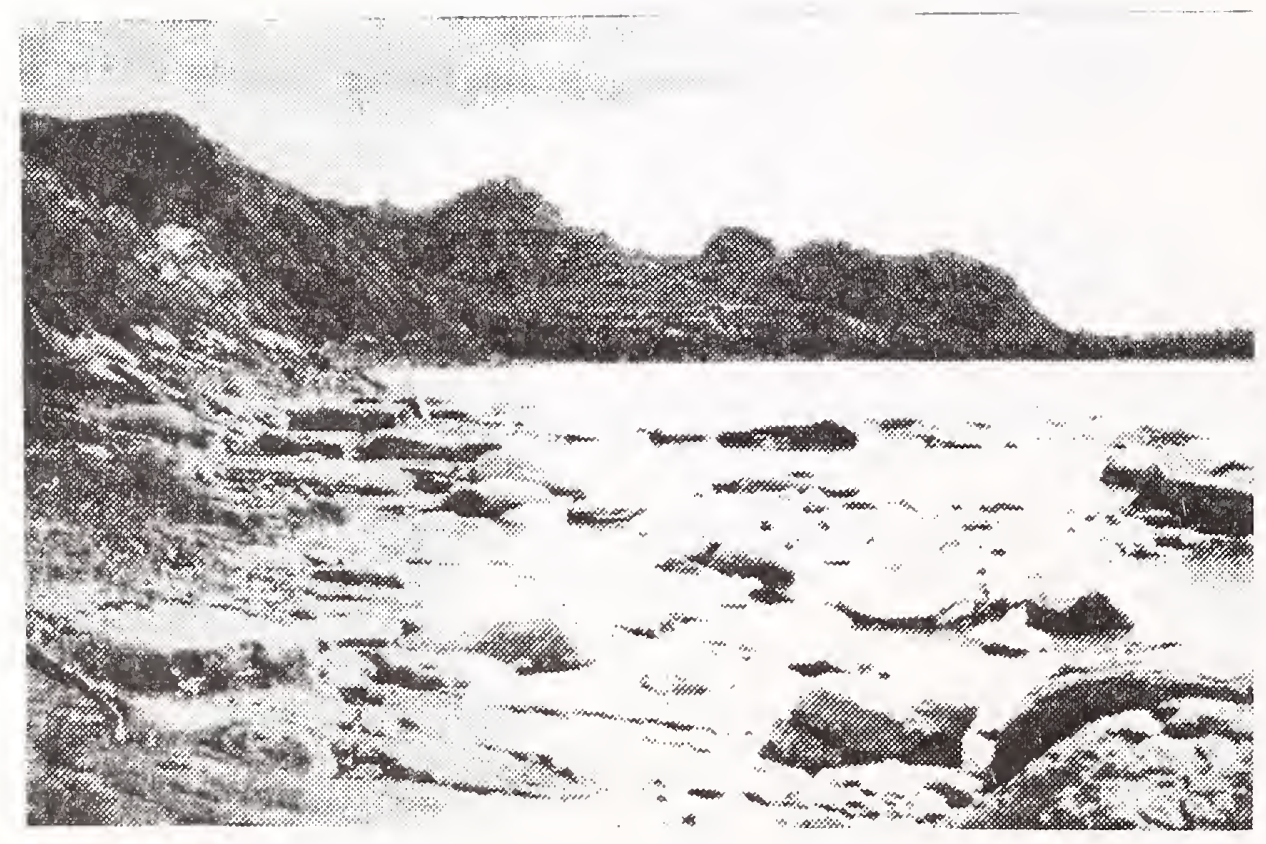

Figure 19. Sauger spawned in these types of reef areas. The photo was taken when the river was flowing about $7200 \mathrm{cfs}$. 
river channel. At each of the two sites three cross sections were located usually about equidistant from each other. The elevations of the lower (outer) border and higher (inner) border of the rocky substrate areas were determined for sites, usually 20 yds. above and below the cross section and at the cross section line. These three measurements were averaged and therefore described the rocky substrate area in the general vicinity of the cross section line. The surveyed measurements of the sauger spawning/incubation area were logged on the channel profile and stage/discharge modelling was performed to predict the river flow which would provide a 2 foot water depth at the lower border of the spawning area. A 2 foot depth criteria was selected as minimum spawning/incubation condition because sauger eggs were usually sampled at 2-3 foot water depth in the major spawning sites of the study area. Also, Scott and Crossman (1973) reports that sauger spawning occurs in water 2-12 feet deep.

Table 55 summarizes the results of the instream flow analysis for the spawning/incubation reefs. The flows which would maintain a two foot depth over the lower border of the reef varied in magnitude for the cross sections within a particular reef site. An average instream flow was determined from the three predicted flow values (one for each cross section) at each individual reef site. Flows which would provide adequate spawning/incubation conditions at the reef sites were 10,986 cfs at the Brockton reef and 11,497 cfs at the Culbertson reef. Instream flows during the sauger and walleye spawning/incubation season should be $11,497 \mathrm{cfs}$ at both the Wolf Point and Culbertson USGS gauging stations. The duration of these flows should be maintained during the spawning and incubation period, May 11 through June 30.

\section{Riffle maintenance flows}

Riffle habitats in the lower Missouri River are important for producing food organisms for sport $f i s h$ and are the principal habitat areas of certain unique fish found in the study area. Also, shallow riffles must be maintained allowing for fish passage throughout the ice-free season. If the flow through the riffle areas is low, passage by migratory fish, such as the paddlefish, could be hindered. All of the riffles throughout the study area were considered deep enough for paddlefish passage at normal base flows. However, one extensive riffle site located in the Frazer section could hinder paddlefish passage at lower flows. Flow recommendations for maintenance of riffles were determined using the wetted perimeter/inflection point method. Wetted perimeter is the distance along the bottom and sides of a channel cross section in contact with water. As the flow in the stream channel decreases, the wetted perimeter also decreases, but the rate of loss of wetted perimeter is not constant throughout the entire range of flows. There is a point, called an inflection point, on the curve of wetted perimeter versus flow, at which the rate of wetted perimeter loss is significantly changed. Above the inflection point, large changes in flow cause only very small changes in wetted perimeter. Below the inflection point, the river begins to recede from the riffle bottom, exposing the bottom at an accelerated rate. The flow recommendation was selected at the inflection point. Riffles are also the areas of a stream most affected by flow reductions (Bovee 1974, Nelson 1977). Consequently, the maintenance of riffles should ensure the maintenance of the pool areas. Six representative riffle sites were surveyed, with one to three cross sections located at each site. Table 56 gives the results of the wetted perimeter inflection point analyses. Results for individual cross sections are given in Append $1 x$ Figures 5-7. Inflection points occurred at flows ranging from 4,000 to $7,000 \mathrm{cfs}$. 


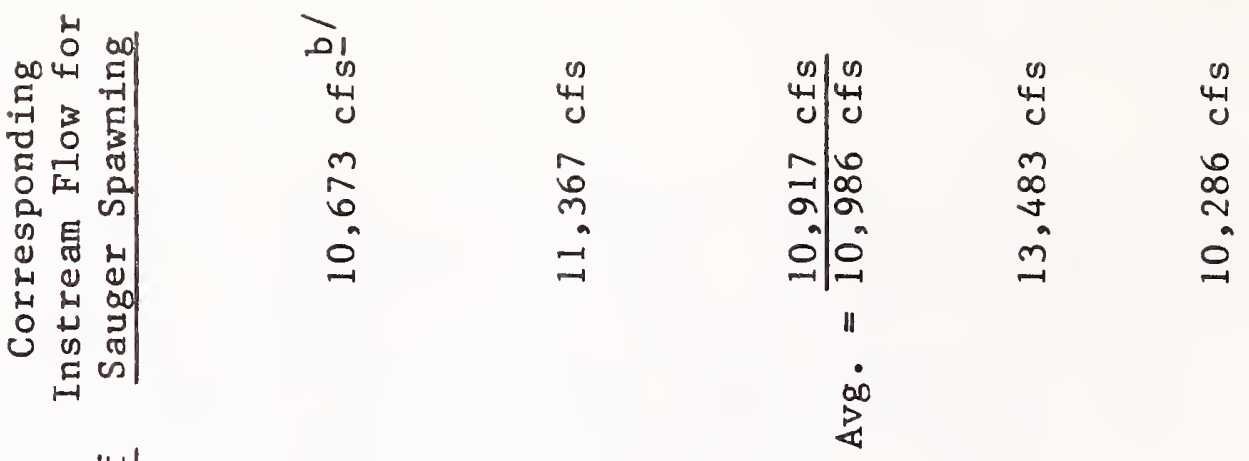

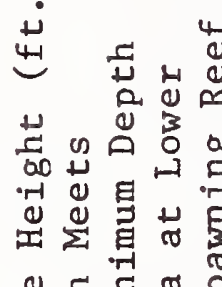

0 대

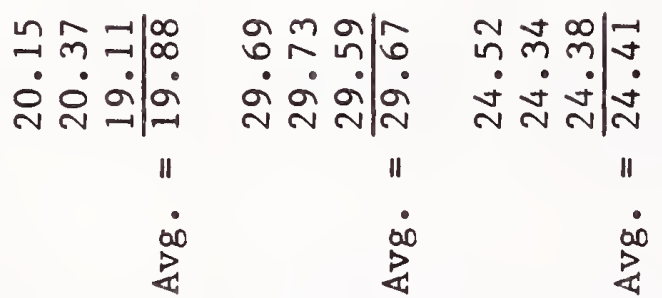

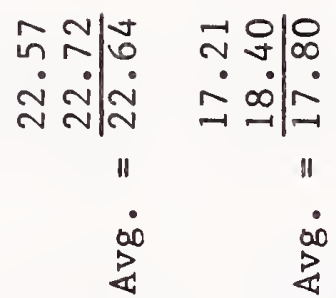

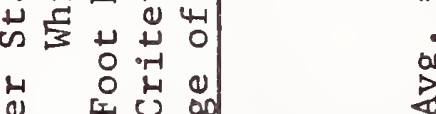

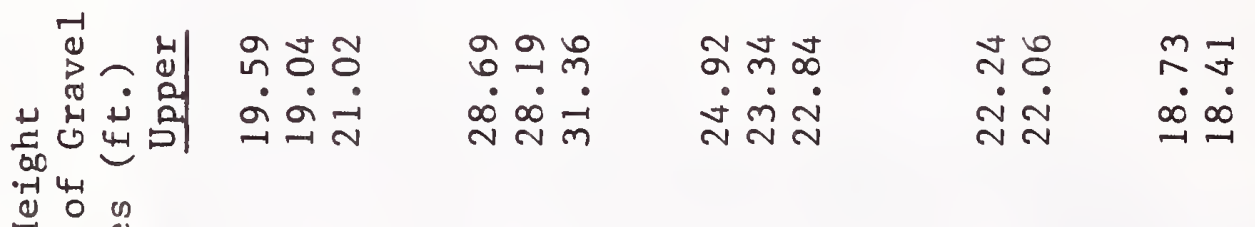

0

4

II

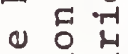

$\infty 0 \cdot-1$ क

i

至

nn $\Rightarrow$ on

bก

กิ $\stackrel{\infty}{m}$

กิก กับ

n

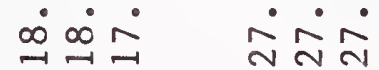

N

ㅇำ

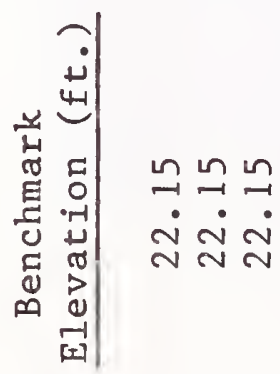

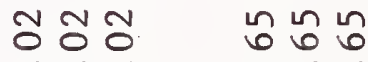

थून बू बू

inल

viv $\dot{\sim} \vec{v}$

c)

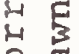

号

$\checkmark N$

范

त)

Е

$0_{01}^{\infty} \mathbb{E}$

¿ ब

(c)

o

苾㟧

욜

穴

in

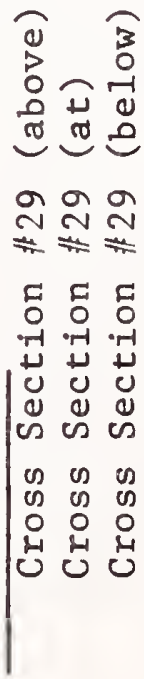

$\begin{array}{lll}0 & 3 \\ 0 & 0 \\ 0 & 0 & 0 \\ 0 & 0 & 0 \\ 0 & 0\end{array}$

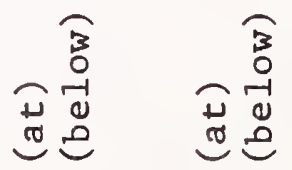

$\vec{m} \vec{m}$

man

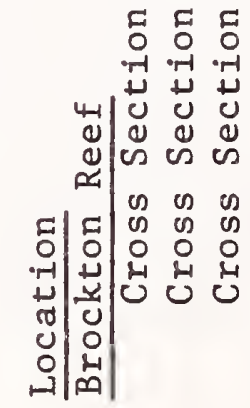

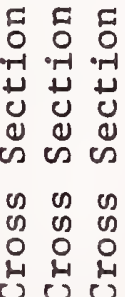

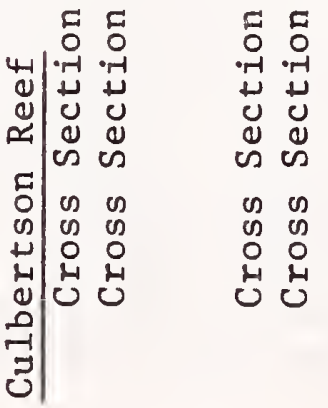




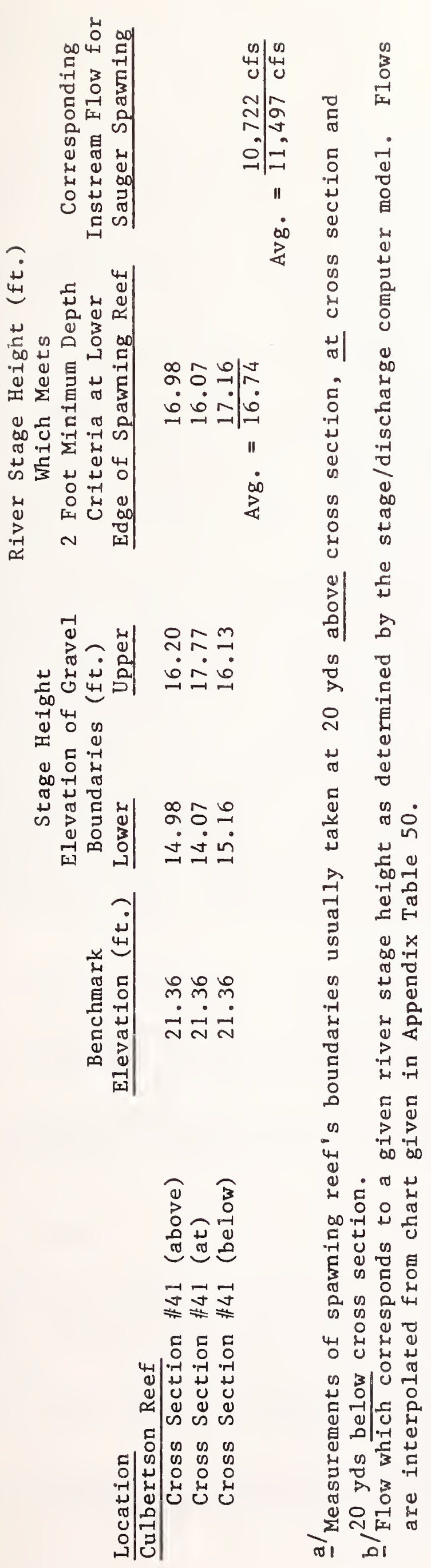




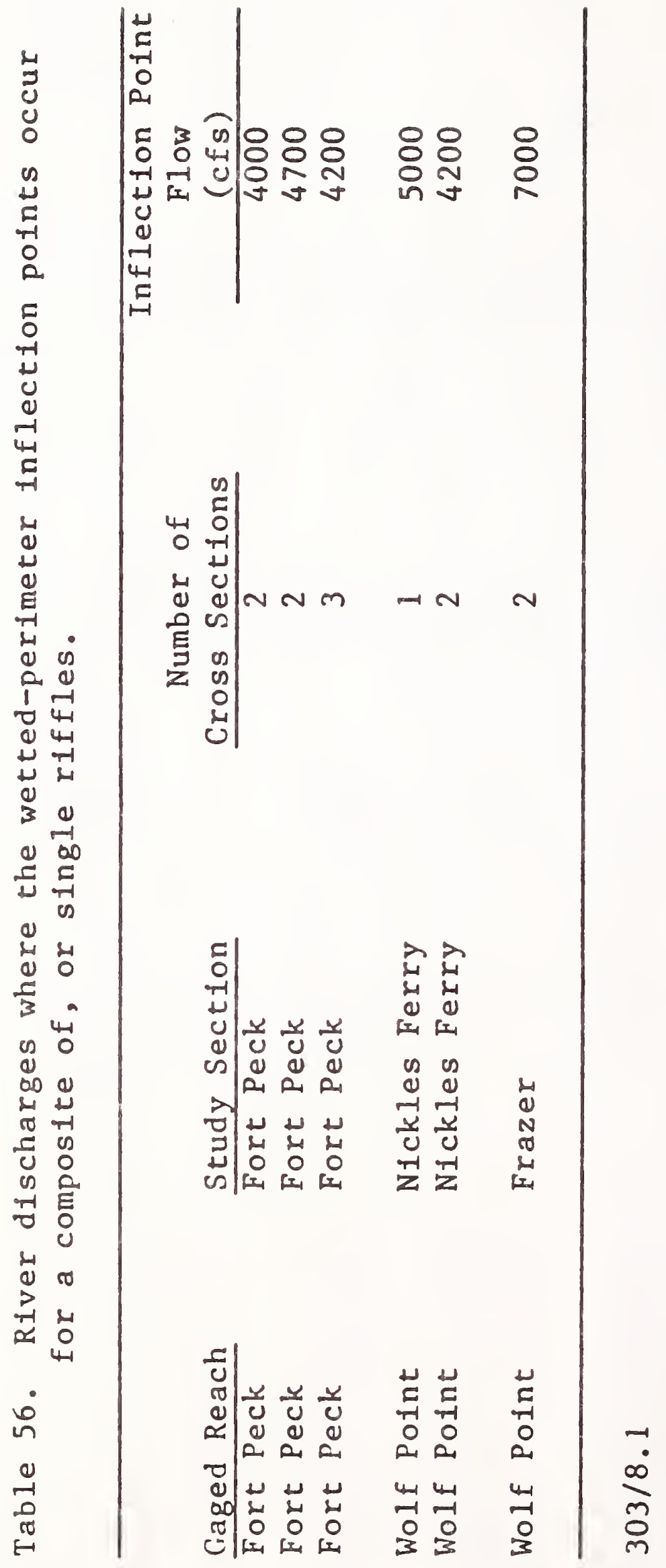


An instream flow of 7,000 cfs was recommended as the maintenance flow because it would protect all the surveyed riffles and, moreover, it would most likely provide maintenance flow requirements for the important sandy riffle areas in the lower reach of the study area. Four of these sandy riffle areas were surveyed and the WETP analysis was performed using the collected data (Appendix Figure 7). However, due to the shifting nature of the channel in these areas it was believed the accuracy of modelling these riffle cross sections were not as reliable as the other riffle sites located in the relatively stable gravelly areas. The analysis of these sandy riffle areas indicated that a flow of about $7,000 \mathrm{cfs}$ is required for riffle maintenance. These sandy riffle areas are unstable and therefore generally considered poor habitat for aquatic insect production (Hynes 1970). However, their value in this case is related to the habitat preference of these sites by the sicklefin chub and pallid sturgeon. Both of these rare fishes are listed in Montana as "Species of Special Concern" by the MDFWP. The pallid sturgeon has been classified as "threatened throughout its range" by the Endangered Species Committee of the American Fisheries Society (Deacon et al. 1979). Bailey and Cross (1954) have reported that pallid sturgeon and sicklefin chub both have. strikingly similar habitat preferences for riffly areas over firm sand. Therefore, the presence of one species would indicate suitable habitat for the other. Fair numbers of sicklefin chubs were sampled in these sandy riffle areas during the study period. A Pallid sturgeon has also been sampled in the study area, although not in these particular sites. As mentioned in a previous section a rare insect form, the large mayfly Analetris, was also sampled in these large sandy riffles. It's known distribution is severely limited and is considered by Edmunds et al. (1976) as being in an ecologically precarious situation. Considering the ecological status of these two fish and one aquatic insect species, all necessary precautions to protect and provide essential habitat should be afforded. An instream flow of 7000 cfs should be maintained in the Missouri River below the confluence with the Milk River throughout the year.

Recommended instream flow schedules

A general summary of the assessed instream flow recommendations for the lower Missouri River, and the USGS stream gauge of reference, are as follows:

From Fort Peck Dam to the confluence with the Milk River - - USGS gauge at Fort Peck

Habitat

Riffle Maintenance

Sauger Spawning/Incubation Reef

Sauger Rearing Pools
Recommended

Instream Flow

$7,000 \mathrm{cfs}$

$11,000 \mathrm{cfs}^{-}$

$6,042 \mathrm{cfs}$
Time Period

Year-long

May 11 - June 30

June 15 - Sept. 15

a/ Represents flow necessary to maintain minimum instream flow at Wolf Pt. gauged reach because of water accretions between gauges.

From the confluence with the Milk River to the confluence with the Poplar River -- USGS gauge at Wolf Point 
Riffle Maintenance 7,000 cfs

Year-long Sauger Spawning/Incubation Reef 11,497 cfs May 11 - June 30 6,042 cfs June 15 - Sept. 15 Sauger Rearing Pools

From the confluence with the Poplar River to the Montana/North Dakota border - USGS gauge at Culbertson

Recommended

Habitat

Riffle Maintenance

Sauger Spawning/Incubation Reef

Sauger Rearing Pools

\section{Instream Flow}

$7,000 \mathrm{cfs}$

$11,497 \mathrm{cfs}$

$6,042 \mathrm{cfs}$
Time Period

Year-long

May 11 - June 30

June 15 - Sept. 15

The recommended instream flows at each USGS gauging station are shown in hydrograph form in Figures 20-22. Some instream flow recommendations overlap during various time periods and in those situations the highest streamflow is recommended. With the exception of instream flows recommended for the sauger spawning/incubation period, most of the recommended instream flows were above the 70 percentile flow (Tables 57-59). A 70 percentile flow is a flow which is equal to or exceeded 7 out of 10 years (i.e. a flow that occurs commonly). The instream flow assessed for the sauger spawning/incubation reefs could possibly be in conflict with the newly-developed water level management plans for the Fort Peck Reservolr fisheries. Instream flow recommendations for the river system should be incorporated into the water management plan for the reservoir so that a plan will result which would integrate the water needs of both fisheries.

\section{Toxic residue in fish}

In Montana, pesticides and other harmful residue contamination of fish are becoming items of increasing concern. It is important to determine the current condition of residue contamination in the fishery resources for the protection of the public and as a general baseline for future comparisons. For this study, the rainbow trout and shovelnose sturgeon were selected for evaluation because of the trout's status as a sport fish and the sturgeon's high lipid content, which is the major storage area for these types of residues. The muscle tissue from each of 10 specimens was filleted, frozen, and later sent to Hazelton Raltech Laboratories for pesticides, $\mathrm{PCB}$ and mercury analyses.

None of the chemicals were present in concentrations to warrant concern at this time (Table 60). Only the shovelnose sturgeon samples exhibited some detectable residue concentrations; these being DDE and BHC. Mercury residue concentrations were also detectable only in the sturgeon samples, although at low levels. From past studies, it has been reported that endrin does not persist at high levels in fish tissues, while chlorinated hydrocarbosn, PCB's and mercury are long-lasting in the aquatic environment (Henderson et al. 1969 and Veithe 1975). 


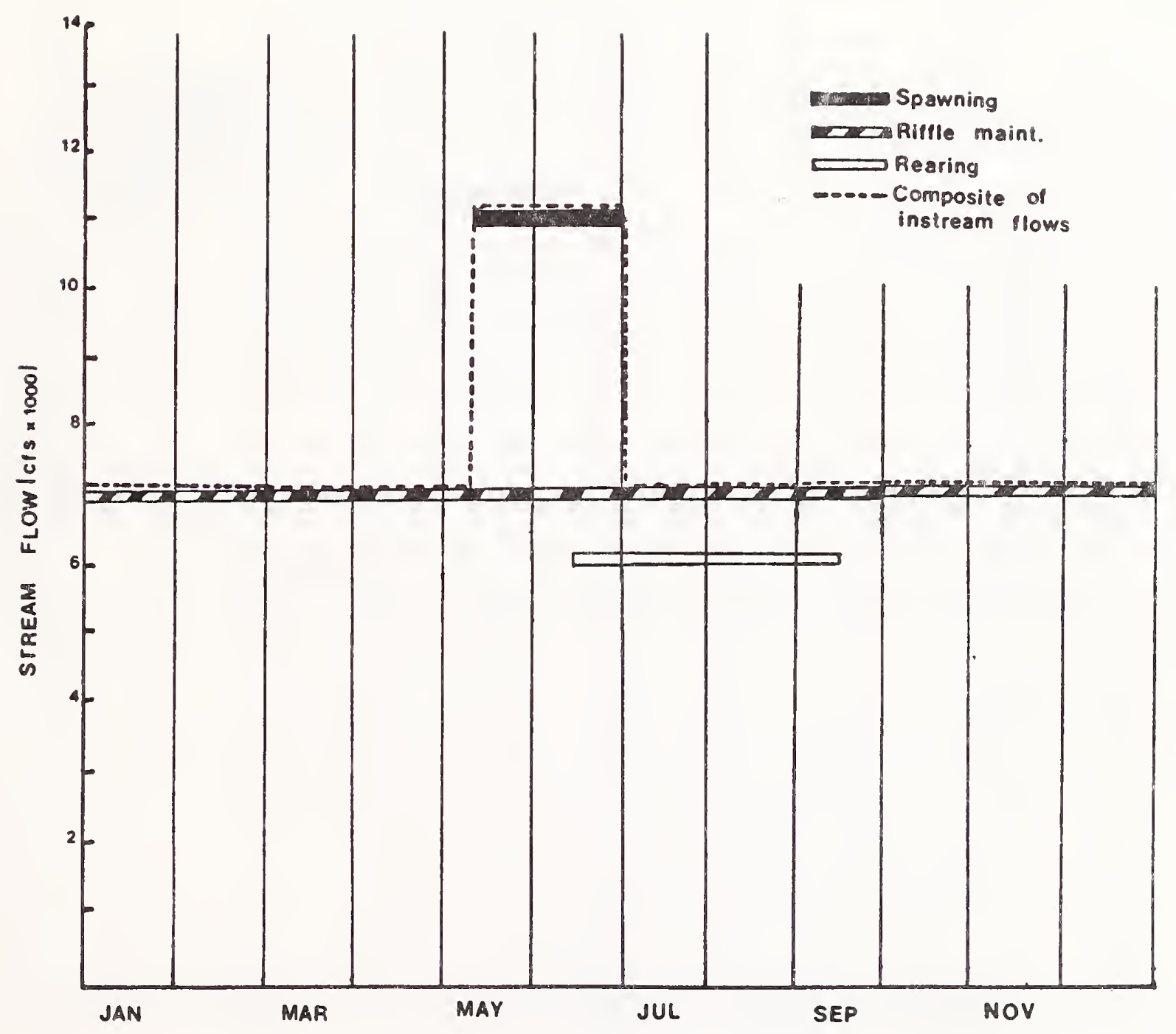

Figure 20. Hydrograph of all the recommended instream flows at the Fort Peck Dam USGS gauging station. 


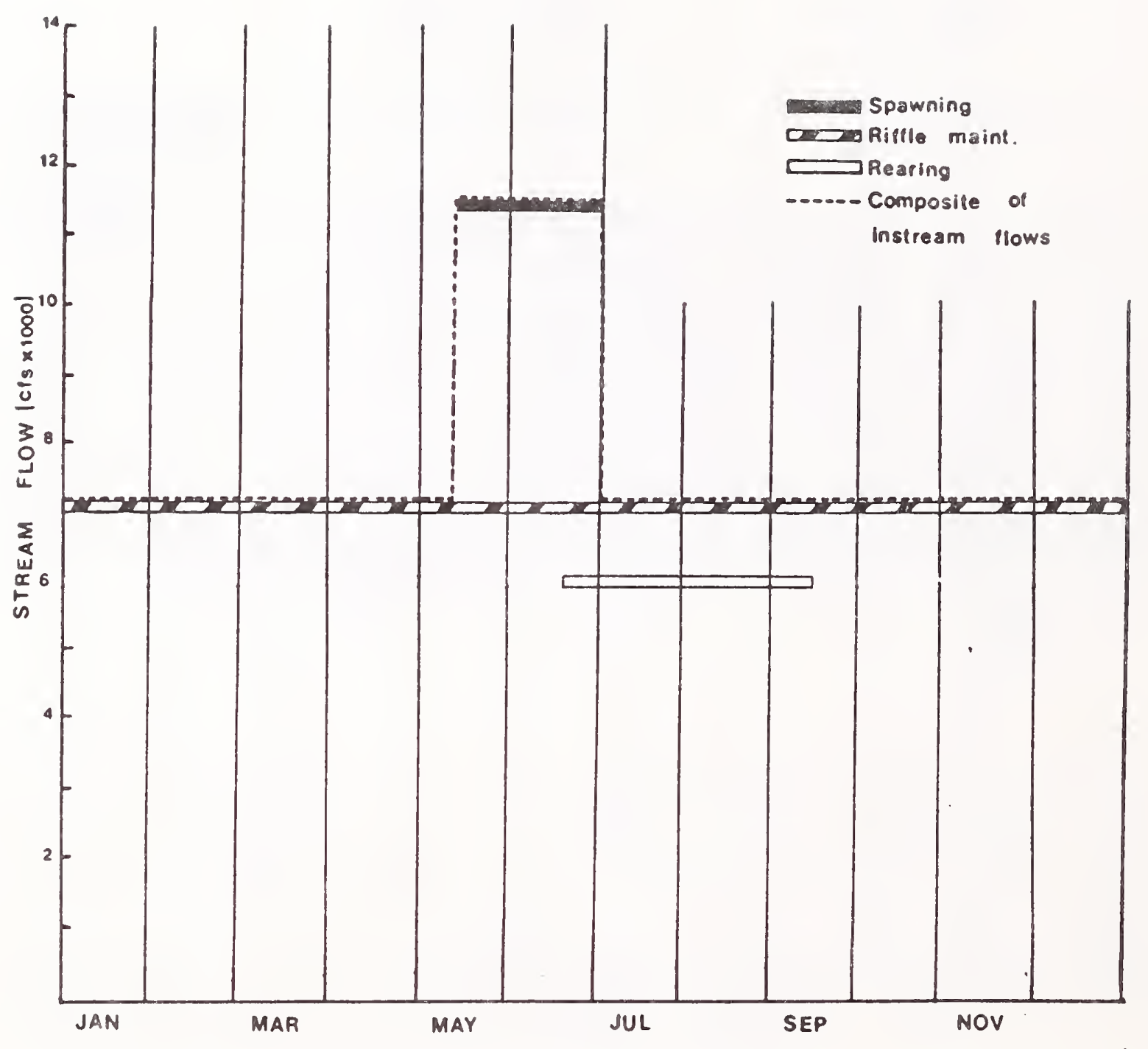

Figure 21. Hydrograph of all the recommended instream flows at the Wolf Point USGS gauging station. 


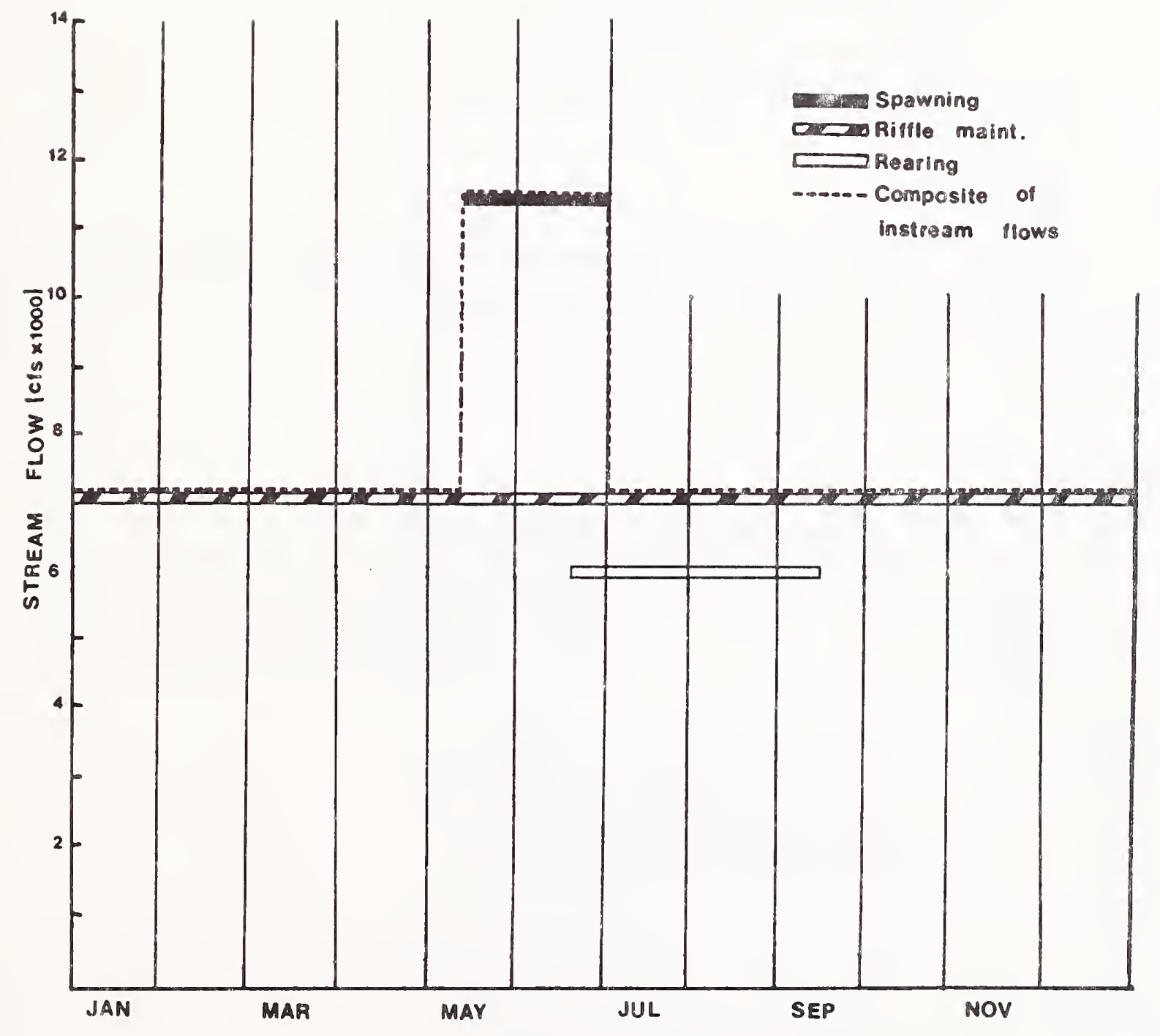

Figure 22. Hydrograph of all the recommended instream flows at the Culbertson USGS gauging station. 


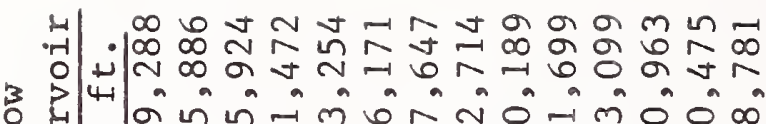
- d (1) मूय $\rightarrow-1<$

मू चै

范

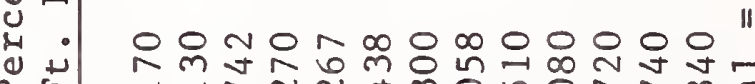

mi 引े 40

红 4

-

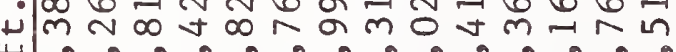
n 6 a mo un man un ànáa 嵌 틈 $\varangle$

H

$\rightarrow$ i in

ت্ৰ

$\exists$ 两

约 $=$ 合

क वे

茫落

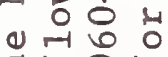

ट्या

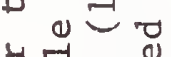

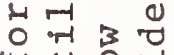

I

3 U

$-100$

政

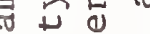

(1) 4 U क्ष

o 23

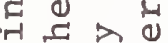

व

. 4 R है।

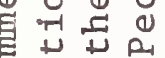

त

范

4 तथ

H. E E D

का 0 क क

(1) כए 2

-1 0 क

गु $00+\infty$

(2) U 000

U थ $F$

U 5 .

(1) E 20

E

$\infty 6 \infty N$ u v vorma $\infty m$ $\dot{0} \dot{0} \dot{\sim} \dot{\sim} \dot{0} \dot{0} \dot{0} \dot{0} \dot{\sim} \dot{ }$ नू बु

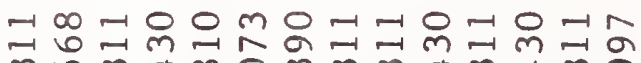

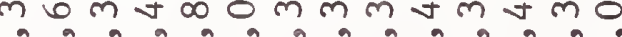
Oீ ชै

ㅇㅇㅇㅇㅇㅇㅇㅇㅇㅇㅇㅇㅇㅇㅠ

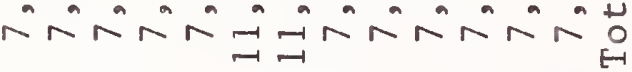

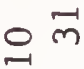

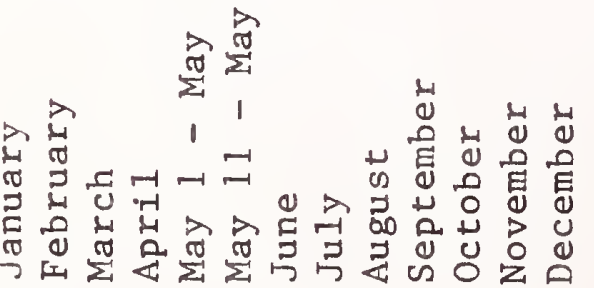

$\frac{i}{m}$ 


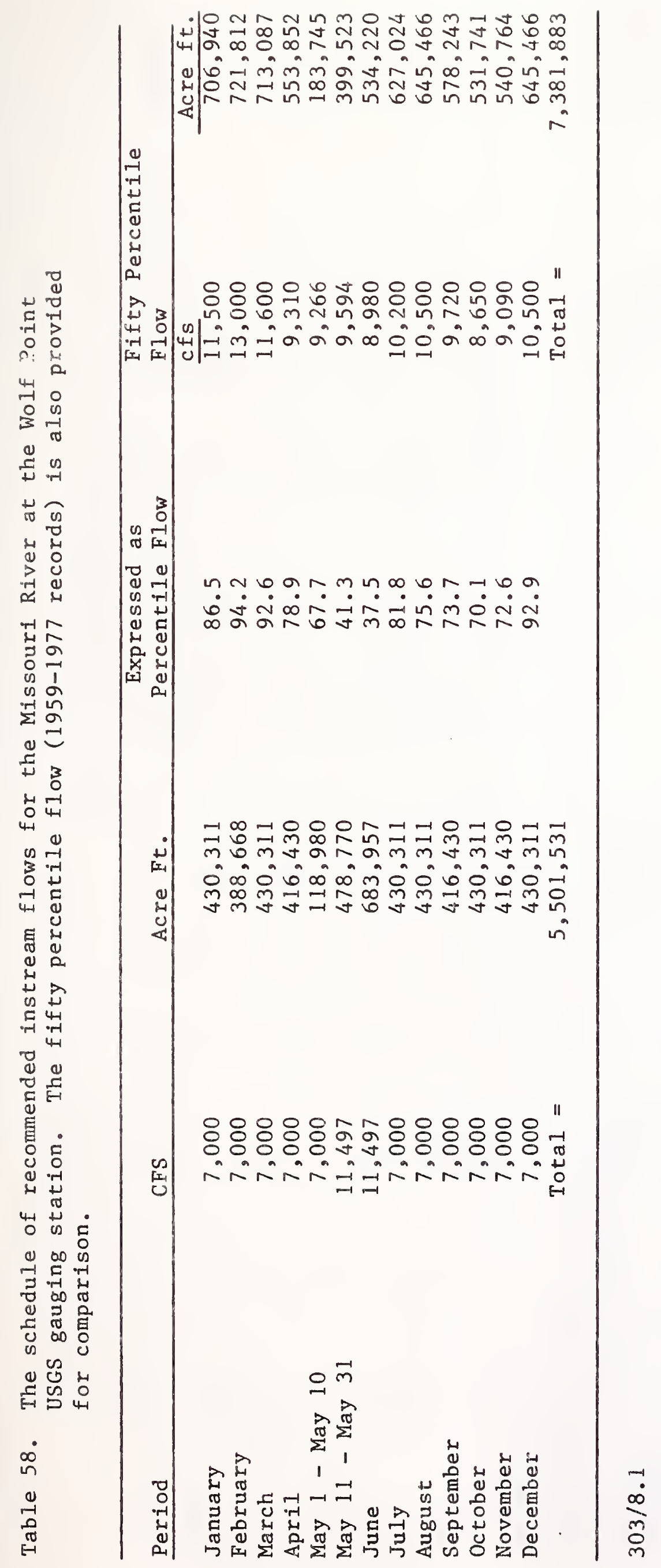




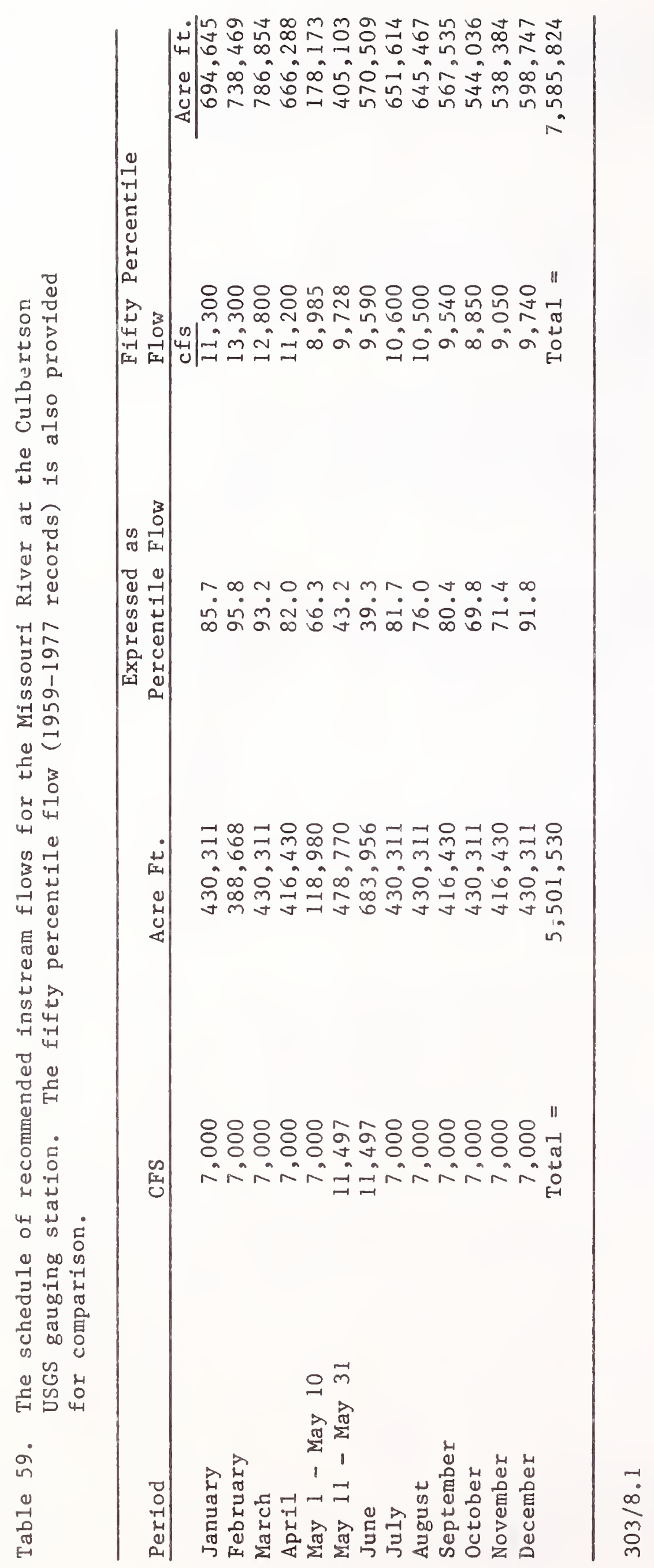




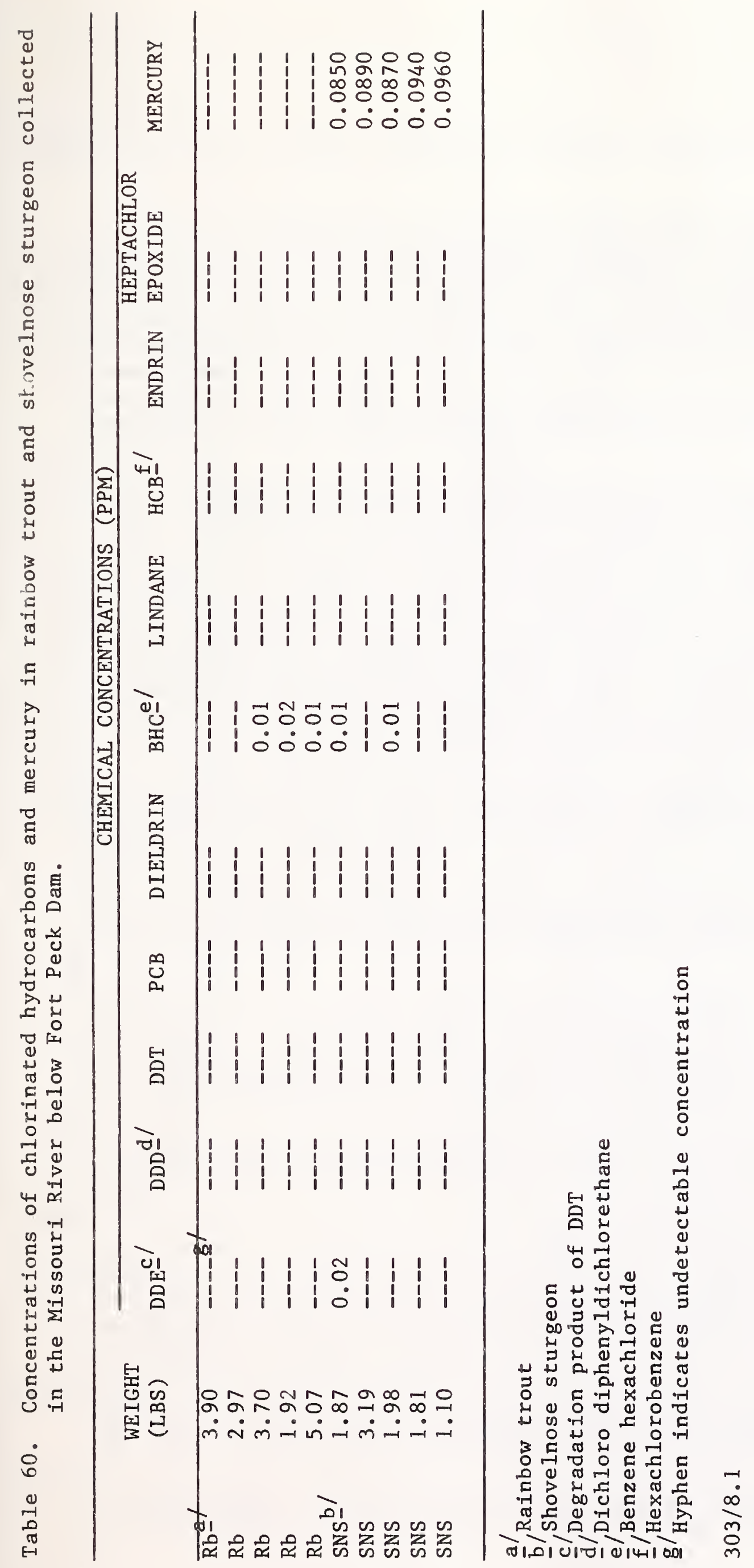


Sport fishing values

Present and future

The lower Missouri River fishery presently is lightly utilized by anglers. Reasons for the low amounts of fishing pressure relate to the considerable distances from population centers, the lower popularity of this type of fishery, and access difficulty associated with private ownership and general remoteness. Throughout the lower 175 miles of river there is only one recognized public access point, yet there are several state and federal river-front land parcels shich could provide public access if developed. State and federal recreational agencies responsible for public access should develop access sites at strategic locations along the river.

Based on this investigation of the lower Missouri River fishery, it was apparent that considerable warm water angling opportunities presently exist. Good populations of shovelnose sturgeon, paddlefish, northern pike, burbot, sauger and walleye have been noted in the study area. These sport fish were numerous at several locations during specific periods or throughout the entire season. Although paddlefish, most likely, have occurred in the study area for years, a snagging fishery has only recently become popular. The major portion of the pressure is confined to the Frazer section, but will likely expand to other locations with the discovery of the better paddlefish numbers upstream of Frazer and other in concentration areas downriver.

Other major recreation areas on the river are located in the tailpool and dredge cut areas immediately below Fort Peck Dam. The major fishery in this area is for sauger and walleye. Also, there is a trophy rainbow trout fishery here. Individuals average about 22 inches long and about four pounds, although the size of the population is thought to be small. Fishing pressure for these trout is seasonal, generally occurring during the spawning period of late March through mid-May.

An aggressive plan to develop a chinook salmon fishery in the tailwaters was initiated in 1983 with the introduction of 45,000 fingerlings. During 1984 and 1985, an additional 217,000 and 105,000 fingerlings were stocked, with continuation of the program planned in the future. It is expected that the young salmon will smolt in the tailwaters and move downstream 180 miles into Lake Sakakawea, returning to the Fort Peck tailwaters area to spawn three to four years later. Introductions of chinook salmon have been successful in the Missouri River below Garrison Dam and are providing a popular salmon fishery (Emil Berard; personal communication.).

The recent cisco ( $\mathrm{C}$. artedii) introductions into Fort Peck Reservoir could also enhance the tailwater fishery. Once the cisco establish in the reservoir it is likely that a considerable number will be lost through the dam, thereby constituting a new forage base for some of the tailwater sport fish species. The presence of an additional forage fish could enhance the numbers and sizes of favored sport fish. The influx of rainbow smelt (a forage fish) during 1980-81 had a dramatic effect, apparently attracting sauger and walleye into the tailwaters area, thereby enhancing the sport fishing. The presence of cisco in the tailwaters could attract sport fish and help maintain good populations in this area. Paddlefish are found in good numbers in the upper dredge cuts area of the river. An estimate of the population here was 3,406 paddlefish (5.2 
fish/acre) (Needham 1979). Fishing pressure on this population is very light, since the fish are chiefly harvested by archery methods.

The Milk/Missouri River confluence area also received noticeable fishing use. Most of the catches in this area were comprised of sauger. The turbid warm water discharge from the Milk River concentrates sauger in this area, thus attracting anglers. As more of the public becomes aware of the recreational fishing values that the lower Missourt has to offer, and as better access sites are developed, additional areas along the river will become important in providing angler recreation.

The effects of Fort Peck Dam has changed the once natural riter character, creating favorable cold water conditions for at least 50 miles below the dam. Because of habitat conditions, coldwater sport fish such as the trout, cannot exist within the entire reach. Clearly there appears to be an open space for a fish which could live in these open, coldwater conditions. The mountain whitefish native to the Missouri River 350 miles upstream could do well under these conditions. They have been successfully established below other dams located in prairie situations, such as Tiber Dam area (Gardner and Berg 1983). A mountain whitefish transplant should be considered in this reach if the recently established cisco do not fully inhabit the area within ten years. The mountain whitefish would have some sport value and might be utilized as a forage fish by the more popular sauger and walleye or northern pike. Commercial fish species such as goldeye and buffalo do not appear to be as abundant as that found in the middle Missouri River (Berg 1981) and lower Yellowstone River (Phil Stewart; personal communication). Therefore, commercial fishing in the lower Missouri River or its tributaries should not be permitted.

Fishing seasons and creel limits

The fishing season for major streams in the lower Missouri River drainage is essentially open the entire year. The daily and possession limits for fish in the study are:

Limft 1 .

Salmon and whitefish and all trout, except lake trout - ten (10) fish in any combination.

Limit 2 .

Lake trout - five (5) fish.

Limit 3.

Walleye and sauger - ten (10) fish in any combination.

Limit 4 .

Northern pike - five (5) fish, except Nelson Reservolr where there will be no number limit.

Limit 5.

Bass (largemouth and smallmouth) - ten (10) fish in any combination.

Limit 6 .

Paddlefish - one (1) fish daily and two (2) fish in possession. 
There is no number limit on catfish, burbot (1ing), sturgeon and nongame fish.

Fish Weight Limits (Sturgeon):

The maximum weight sturgeon which may be taken is 16 pounds. The weight limit was established for protection of the larger pallid sturgeon.

Special Regulations

Missouri River from Fort Peck Dam to Milk River:

Limit 1 - Rainbow trout - two (2) fish daily and in possession. Salmon, grayling, whitefish and all trout except rainbow trout and lake trout - ten (10) fish in any combination.

Limits 2 through 6 are the same as 1isted under Dally and Possession Limits for the rest of the fishing district.

There is no evidence that the fishing regulations outlined above have been detrimental to fish populations anywhere in the study area. Fishing pressure for most species (excluding rainbow trout) could probably be increased without harming the populations. Table 61 lists the harvest rates of the popular sport fish in the study area. These values were based on Appendix Tables 58-65. The rainbow trout and walleye had the greatest harvest rates of approximately five percent. The remaining six sport fish exhibited extremely low harvest rates of 2.8 percent or less.

Although overharvesting of the rainbow trout fishery does not appear to be a problem at this time, increased angling pressure in the future could threaten its quality. The Fort Peck Dam and Kootenai River populations probably are the only two fisheries in Montana where older-age, large-size fish dominate the populations. Management objectives for the Fort Peck Dam fishery should be to maintain the trophy-size rainbow trout. More restrictive angling regulations may be necessary to attain this objective as the fishery's popularity increases.

Potential and existing environmental problems

Fort Peck Dam and operations

Fort Peck Dam has and continues to have significant environmental impacts on the lower Missouri River. The loss of naturally occurring suspended sediment in the river along with the cold water releases from the hypolimnion of the reservoir has markedly reduced the warm water fish communities. Because of limited spawning, rearing and shelter habitats, a cold water fishery cannot become firmly established and replace the lost warm water fishery. Only a small cold water fishery presently exists and is confined chiefly to the tailwaters area. Basic habitat requirements are at least minimally fulfilled here. The clearwater releases accelerate erosion of the soft channel banks along with down-cutting of the channel bottom. The eroded banks provide little cover habitat and the down-cutting results in accelerated drainage of the important off-channel areas. 


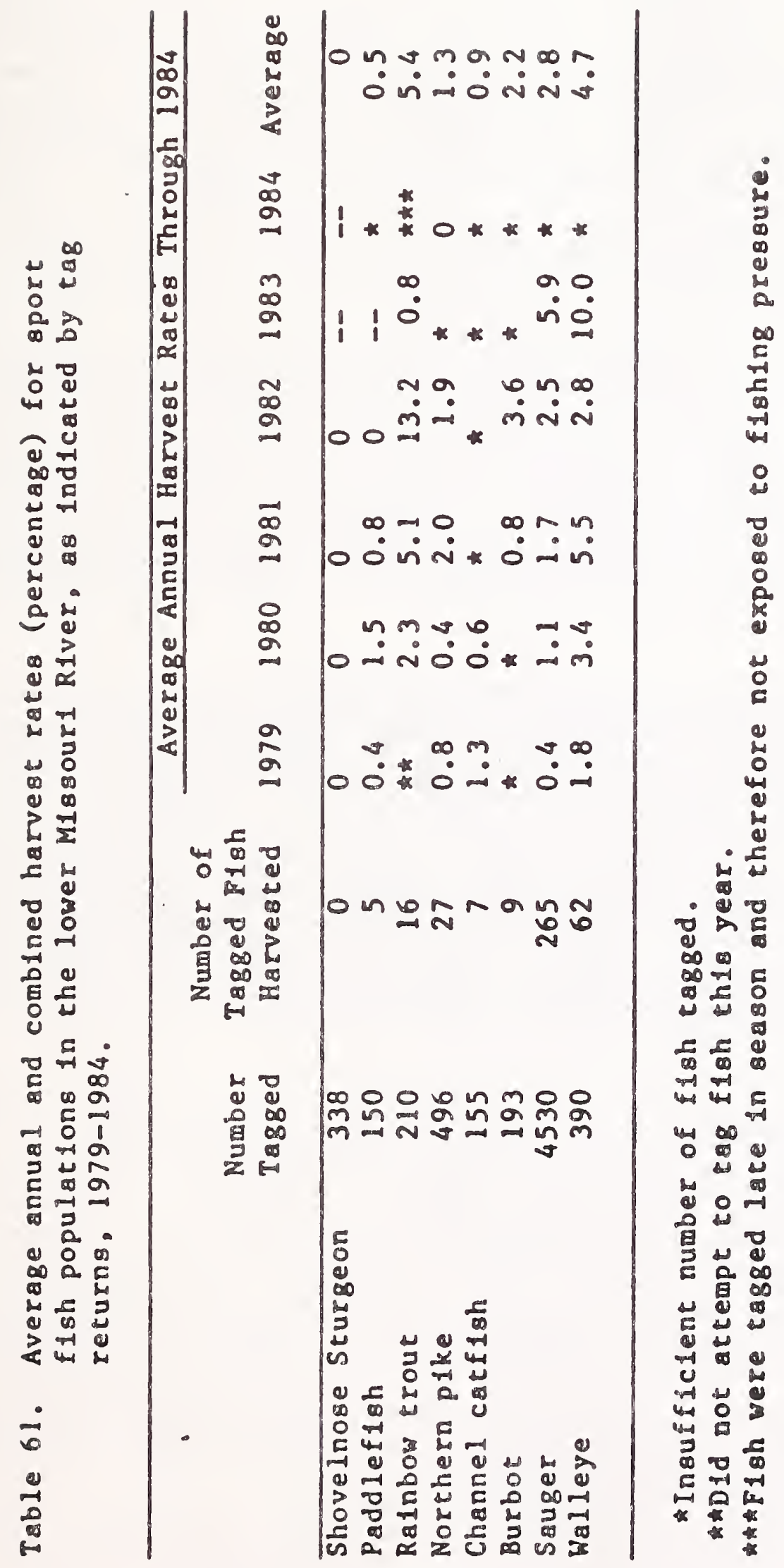


Fort Peck Dam has and continues to have significant environmental impacts on the lower Missouri River. The loss of naturally occurring suspended sediment in the river along with the cold water releases from the hypolimnion of the reservoir has markedly reduced the warm water fish communities. Because of limited spawning, rearing and shelter habitats, a cold water fishery cannot become firmly established and replace the lost warm water fishery. Only a small cold water fishery presently exists and is confined chiefly to the tailwaters area. Basic habitat requirements are at least minimally fulfilled here. The clearwater releases accelerate erosion of the soft channel banks along with Inwn-cutting of the channel bottom. The eroded banks provide little cover habitat and the down-cutting results in accelerated drainage of the important off-channel areas.

The present operations of Fort Peck Dam have substantial effects on the tailwaters fisheries. Sharp fluctuations resulting from peaking hydropower generation impacts the trout fishery and severely reduces the potential for forage fish production in the dredge cuts (Frazer 1985). Seasonal flow patterns are inverted to that of normal rivers. This usually results in low flows during the spring and higher flows occurring during the winter months. Flow patterns such as these negatively impact spring spawners such as sauger and sturgeon which depend upon a rise in the water level to provide the necessary spawning conditions or stimulus to trigger spawning migrations.

In 1977 the Army Corps of Engineers recommended that the Fort Peck Dam site should be studied for possible additional hydropower generation (U.S. Army Corps of Engineers 1977). This investigation recommended that two new 92.5 megawatt hydropower units be added to increase the output capacity of the dam from 165 to 350 megawatts. The project also called for the construction of a re-regulating dam eight miles downriver. The impacts of such a project on the existing tailwaters fishery would have been devastating. Frazer (1985) studied the fishery and reported the potential effects of this project. The project was eventually deactivated because of the state's concern for the environmental impacts on the fishery and the general decline in national energy needs (Mr. Steve Rothe, U.S. Army Corps Engineers; personal communication).

Water development projects

The potential water development projects presently planned do not appear to be of a size that would severely dewater the lower Missouri River. Present irrigation uses are light. Water withdrawals from the Missouri River for irrigation purposes (the major water user) during 1980 were about half of the amount used for irrigation on the Yellowstone River (Table 62). The Bureau of Indian Affairs, Frazer irrigation project, is the only major project in the area, withdrawing about 109,000 acre feet of water annually. There are several riverside portable pumps used by individual farmers, but these are generally small units with capacities less than 2 cfs. Proposed additional water withdrawals for irrigation amount to about 110,400 acre feet per year using seven pumping stations (Missouri River Basin Commission 1981). 
The present operations of Fort Peck Dam have substantial effects on the tailwaters fisheries. Sharp fluctuations resulting from peaking hydropower generation impacts the trout fishery and severely reduces the potential for forage fish production in the dredge cuts (Frazer 1985). Seasonal flow patterns are inverted to that of normal rivers. This usually results in low flows during the spring and higher flows occurring during the winter months. Flow patterns such as these negatively impact sprinô spawners such as sauger and sturgeon which depend upon a rise in the water level to provide the necessary spawning conditions or stimulus to trigger spawning migrations.

In 1977 the Army Corps of Engineers recommended that the Fort Peck Dam site should be studied for possible additional hydropower generation (U,S. Army Corps of Engineers 1977). This investigation recommended that two new 92.5 megawatt hydropower units be added to increase the output capacity of the dam from 165 to 350 megawatts. The project also called for the construction of a re-regulating dam eight miles downriver. The impacts of such a project on the existing tailwaters fishery would have been devastating. Frazer (1985) studied the fishery and reported the potential effects of this project. The project was eventually deactivated because of the state's concern for the environmental impacts on the fishery and the general decline in national energy needs (Mr. Steve Rothe, U.S. Army Corps Engineers; personal communication).

Water development projects

The potential water development projects presently planned do not appear to be of a size that would severely dewater the lower Missouri River. Present irrigation uses are light. Water withdrawals from the Missouri River for irrigation purposes (the major water user) during 1980 were about half of the amount used for irrigation on the Yellowstone River (Table 62). The Bureau of Indian Affairs, Frazer irrigation project, is the only major project in the area, withdrawing about 109,000 acre feet of water annully. There are severa1 riverside portable pumps used by individual farmers, but these are generally small units with capactities less than 2 cfs. Proposed additional water withdrawals for irrigation amount to about 110,400 acre feet per year using seven pumping stations (Missouri River Basin Commission 1981).

Table 62. Water use for irrigation in the lower Missouri and lower Yellowstone rivers during 1980. (Source - Dept. of Nat. Resc. and Consv. 1986)

$\begin{array}{cccc}\text { Miles } & \text { Lands Irrigated by } & \text { Surface Water } & \text { Surface Water } \\ \text { of River } & \text { Surface Water } & \text { Withdrawn } & \text { Consumed } \\ & (\text { acres }) & (\text { acre-ft.) } & (\text { acre-ft.) }\end{array}$

Lower

Missouri River

180

50,658

191,990

56,127

Lower

Yellowstone River

150

74,339

344,431

96,595

Coal development industries could be other potential users of Missouri River water. Thermoelectric power generation may again be promoted for fulfilling the nation's energy need. In 1971 the North Central Power Study (North Central Power Study Coordinating Committee, 1971) identified 42 potential 
power plant sites in the five states of the northern Great Plains region; 21 of them in Montana. These coal-fired plants would generate 200,000 megawatts of electricity and consume 3.4 million acre-feet of water per year. Missouri. River water could be a likely source for this potentially large water demand because most of the water in the Yellowstone River basin has already been allocated. A coal mine processing plant (Circle West) had been proposed to be constructed in the basin. This facility located in the vicinity of the study area would involve the manufacturing of ammonia methanol and synthetic diesel oil and would require about 67,000 acre-feet of water annually (Missouri River Basin Commission 1981). Because of changes in the nation's energy needs these projects are presently not as eminent as they once were.

The Fort Peck Indian Reservation Water Rights Compact was recently approved by the 1985 Montana Legislature. This compact gives the tribes the right to one million acre-feet of water annually. Surface water avallable for diversion by the tribes is primarily Fort Peck Reservoir. Other sources would be the lower Missouri River and tributary streams excluding, the Milk River. This water right is large, constituting about one-eighth of the Missouri River's average annual flow as gauged at Culbertson, Montana (USGS 1981). The implications of this water right on the lower Missouri River's aquatic resources cannot be ascertained, since the Fort Peck Indian Reservation has yet to develop water use plans.

\section{Fossil fuel development}

Petroleum exploration and development is a major activity in the lower Missouri River drainage. The lower reach of the study area is within the western edge of the Williston Basin, an area with large petroleum reserves. Along with the petroleum deposits are natural gas fields. These fossil fuels are presently being explored and developed. Only a few petroleum wells have been developed in the river floodplain. The majority are located in the uplands. There have not been any known petroleum or associated salt water brine spills in the floodplain within the study area. A few spills have occurred in the uplands near Culbertson, Montana and further downstream in the floodplains and uplands near Lake Sakakawea, North Dakota. Fortunately these spills have been small, consequently their effects on the aquatic fauna were not investigated. Development of petroleum reserves in the floodplain should proceed with extreme care and additional safeguards should be provided to prevent and contain the spills should they occur.

Associated with fossil fuel development are distribution and delivery pipelines which may require stream crossings. Presently, there is only one river channel crossing in the study area. Future crossings should be routed at existing utility crossings or in association with one of the four bridges. Pipeline crossings have usually been located at riffle areas which are a limited feature in the study area. Construction activities associated with crossings can disrupt the natural channel bottom. Fish habitat mitigation should be required with all pipeline crossings that involve trenching activities.

Streambank erosion

About 80 miles of the 184 miles of lower Missouri River is subject to extensive bank erosion because of the low quantity of suspended sediment loads from water discharged in water from Fort Peck Reservoir. Natural erosion occurs 
throughout the study area and adds sediment to the system. However, the resulting depostion does not offset erosion by the clearwater tailwaters for a distance of about 80 miles below the dam. Several important off-channel features are dependent upon natural fluvial erosion and therefore, all erosion should not be suppressed. An extensive bank stabilization program would most likely be detrimental for the lower Missouri River fisheries. Extensive channelized sections of the Missouri River in the state of Missouri have extremely reduced the fisheries resources (Funk and Robinson 1974). The losses, in part, consist of the reduction or complete loss of off-channel areas. If structures are installed to reduce bank erosion they should be designed to have the least possible impact on the aquatic environment. The important off-channel areas can be maintained if an amount of flow is directed to these lateral areas, and sediment is not allowed to accumulate here. Kallemeyn and Novotny (1977) evaluated bank erosion structures in the Missouri R., South Dakota and suggested modifications which could enhance or maintain habitat diversity for the fisheries resources.

\section{Management recommendations}

1. The Milk/Missouri River confluence area has been identified as an important habitat area for most major sport fish species found in the study area. Every effort must be made to protect this area from unnatural disturbances.

2. Operation of Fort Peck Dam should be modified to reduce daily fluctuations and provide a more natural seasonal flow pattern.

3. Future water demands could reduce the flows in the Missouri River. Instream flows should be reserved for maintenance of the existing river fisheries resources.

4. Development of irrigation along the Missouri River will likely increase. Structures associated with this development should be designed to have minimal impact on the fisheries. Water intake structures should not be located in ecologically sensitive aquatic areas. Evaluations should be made on a case-by-case basis. Diversion dams across the entire river channel should not be constructed.

5. Continued investigations and monitoring of the fish populations should be part of the regional fisheries plan. The paddlefish is listed as a "Species of Special Concern - Class A" in Montana, and few major self sustaining populations remain in the Missouri River Drainage, one of which is in the lower Missouri River, Montana. This local spawning population should be monitored occasionally for harvest rates. Paddlefish spawning areas in the Missouri and Milk rivers should be located. The status of the pallid sturgeon in the lower Misosuri is unknown. Very little information was collected about this unique species during the course of the study. Efforts should continue to try and determine it's status in the Missouri.

The Fort Peck Dam rainbow trout population should be monitored at least biennially. Population numbers, individual sizes, age structure and harvest rate should be of primary concern. The COE should continue to support the fishery habitat evaluation and improvement study which has been working towards these efforts since 1984. 
The sauger is probably the most abundant and desireable sport fish in the study area. Therefore, management efforts should be directed at maintaining and enhancing their abundance. More complete baseline information is needed for assessing the population dynamics in the system. Once a better data base is completed the sauger population should be routinely monitored to evaluate changes in fish abundance and their habitat.

6. The lower Missouri River is not a system in itself. The river fishery is integrated with both large mainstem reservoirs, Fort Peck and Lake Sakakawea fisheries'. Therefore, the river management plans should be developed with the two reservoir plans.

7. Access to the river is poor. In a 175-mile reach there is only one recognized public access site. There are presently no MDFWP access sites on the entire lower Missouri River. Along this reach there are 26 different riverfront land parcels 40 acres or greater in size owned by either the Bureau of Land Management or the State of Montana. Development of some of these sites or exchanged land parcels at strategic locations along the river for public river access sites is recommended. 


\section{LITERATURE CITED}

Bailey, R.M. and F.B. Cross. 1954. River sturgeons of the American genus Scaphirhynchus: Characters, distributions, and synonymy. Pap. Mich. Acad. Sci., Arts, and Letters. 39:169-208.

Baumann, R.W., A.R. Gaufin and R.F. Surdick. 1977. The stoneflies (Plecoptera) of the Rocky Mountains. Mem. Amer. Entom. Soc. No. 31. 200p.

Berard, E. 1982. Ecological investigations of the Missouri mainstem reservoirs in North Dakota. Fed. Aid to Fish and Wild1. Rest. Proj. No. F-2-R-28. N. Dak. Dept. Game and Fish. Bismarck. $44 \mathrm{p}$.

Berard, E. 1984. Fisheries Biologist. North Dakota Dept. Game and Fish. Personal communication.

Berg, R.K. 1981. Fish populations of the Wild and Scenic Missouri River, Montana. Fed. Aid to Fish and Wild1. Rest. Proj. FW-3-R. JobIa. Monta. Fish Wild1. and Parks. Helena. 242p.

Berner, L.M. 1951. Limnology of the lower Missouri River Eco1. 32:1-12.

Bovee, K.D. 1974. The determination, assessment and design of "instream value" studies for the Northern Great Plains region. Univ. of Mont. Final Rept. Contr. No. 68-01-2413, Envir. Prot. Agency. 204p.

Brown, C.J.D. 1971. Fishes of Montana. Big Sky Books, Mont. St. Univ., Bozeman. 207p.

Carlander, K.D. 1969. Handbook of freshwater fishery biology. Iowa St. Univ. Press, Ames. 752p.

Carlson, D.M. and P.S. Bonislawsky. 1981. The paddlefish (Polydon Spathula) fisheries of the midwestern United States. Fisheries $6(2) \overline{: 17-27}$.

Carufel, L.H. 1963. Life history of sauger in Garrison Reservoir. J. Wild1. Mgmt. $27(3): 450-456$.

Clemens, H.P. 1950. The growth of the burbot, Lota lota maculosa (LeSueur) in Lake Erie. Trans. Am. Fish. Soc. 79(2):163-173.

Cuerrier, J. 1951. The use of pectoral fin rays for determining age of sturgeon and other species of fish. Can. Fish. Cult. 11:10-17.

Cummins, K.W. 1975. Macroinvertebrates, p. 170-198. in B. Whitton (ed.) River ecology, Blackwe11 Sci, England 725p.

Deacon, J.E., G. Kobetich, J.D. Williams and S. Contreras. 1979. Fishes of North America endangered, threatened or of special concern. 1979. Fisheries $4: 29-44$. 
Drewes, H.G. and K. Gilge. 1986. Assessment of potential impacts associated with the Milk River Supply Project. Mont. Dept. Fish Wildl. and Parks. Helena. 68p.

Edmondson, W.T. (ed). 1959. Freshwater Biology (2nd ed.). John Wiley \& Sons, N.Y. $1248 p$.

Edmunds, G.F., Jr., S.L. Jensen, and L. Berner. 1976. The mayflies of North and Central America. Univ. Minnesota Press, Minneapolis 330p.

Elser, A.A., B. McFarland and D. Schwehr. 1977. The effect of altered streamflow on fish in the Yellowstone and Tongue rivers, Montana. Technical Rept. No. 8 Yellowstone Impact Study. Final rept. to the 01d West Reg. Comm. Mont. Dept. Nat. Res.\& Consv., Helena. 180p.

Frazer, K.J. 1985. Evaluation of the fishery in the Fort Peck tailwater/dredge cut area and assessment of potential impacts from increased hydropower production at Fort Peck Dam on this fishery. Mont. Dept. Fish Wildl. and Parks. Helena. 145p.

Frost, W.E. and C. Kipling. 1967. A study of reproduction, early life history, weight-length relationship and growth of pike, Esox lucius L., in Windermere. J. Anim. Eco1. 36:651-693.

Funk, J.L. and J.W. Robinson. 1974. Changes in the channel of the lower Missouri River and effects on fish and wildife. Aquatic series No. 11. Missouri Dept. of Consv. Jefferson City.

Gardner, W.M. 1984. Lower Missouri River basin investigations, planning and inventory, fisheries. Fed. Aid to Fish and WildI. Rest. Proj. FW-2-R-14. Mont. Dept. Fish Wildl. and Parks. Helena. 17p.

and R.K. Berg. 1982. An analysis of the instream flow requirements for selected fishes in the wild and scenic portion of the Missouri River. Mont. Dept. Fish Wild1. and Parks. Helena. 111p.

- 1983. Instream flow requirements for the Marias River fishery downstream from Tiber Dam. Mont. Dept. Fish Wildl. and Parks. Helena. 82 p.

Graham, P.J. and R.F. Penkal. 1978. Aquatic environmental analysis in the lower Yellowstone River. Mont. Dept. Fish and Game. Helena. 102p.

Haddix, M.H. and C.C. Estes. 1976. Lower Yellowstone River fishery study. Final Rept., Mont. Dept. Fish and Game. Helena. $81 \mathrm{p}$.

Helms, D.R. 1974. Age and growth of shovelnose sturgeon, Scaphirhynchus platorynchus, in the Mississippi River. Proc. Iowa Acad. Sci. 81:73-75.

Henderson, C., A. Inglis and W.L. Johnson. 1971. Organochlorine insecticide residues in fish - fall 1969. Pestic. Monit. J. 5:1-11. 
Hesse, L. 1977. Fire I, a computer program for the computation of fishery statistics. Nebraska Tech. Ser. No. 1. Neb. Game and Parks Comm. Proj. No. F-10-R 60p.

Hogue, J.J., R. Wallus and L.K. Kay. 1976. Preliminary guide to the identification of larval fishes in the Tennessee River. TVA, Norris, Tenn. $66 \mathrm{p}$.

Holton, G. 1980. The riddles of existence: Fishes of "Special Concern." Montana Outdoors $11(1): 2-6$.

Hynes, H.B.N. 1970. The ecology of running waters. Univ. of Toronto Press. $555 p$.

Kallemeyn, L.W. and J.F. Novotny. 1977. Fishes and food organisms in various habitats of the Missouri River in South Dakota, Nebraska and Iowa. U.S. Fish and Wild1. Ser., Office of Biol. Ser. 77/25. 100p.

Kozel, D.J. 1974. The utilization of select habitats by immature and adult fishes in the unchannelized Missouri river. MA Thesis, Univ, S. Dak., Vermillion. $74 \mathrm{p}$.

Lehmkuh1, D.M. 1972. Change in thermal regime as a cause of reduction of benthic fauna downstream of a reservoir. J. Fish. Res. Bd. Can. $29: 1329-1332$.

May, E.B. and C.R. Gasaway. 1967. A preliminary key to the identification of larval fishes of Oklahoma with particular reference to Canton Reservoir, including a selected bibliography. Okla. Fish. Res. Lab., Bull. 5, Contr. No. 164. Okla. Dept. Wildl. Cons., Norman. 42p.

Merritt, R.W. and K.W. Cummins. 1978. An introduction to the aquatic insects of North America. Kendall/Hunt Pub. Co., Dubuque, IA. $441 \mathrm{p}$.

Miller, R.R. 1972. Threatened freshwater fishes of the United States. Trans. Am. Fish. Soc. 101(2):239-2.52.

Missouri River Basin Commission. 1981. Upper Missouri River Basin Level B Study Report and Environmental impact Statement. Omaha, NB. 184p.

Modde, T. and J.C. Schmulbach. 1977. Food and feeding behavior of the shovelnose sturgeon, Scaphirhynchus platorynchus, in the unchannelized Missouri River, South Dakota. Trans. Am. Fish.Soc. 106(6):602-608.

Montana Department of Natural Resources and Conservation. 1986. Montana Water Use in 1980. Helena. 49p.

Morris, L.A. 1965. Sauger and walleye investigations in the Missouri River. Job Comp. Rept., Proj. No. F-4-R-10, Nebr. Game and Parks Comm. 7p.

, R.N. Langemeier, T.R. Russe11, and A. Witt, Jr. 1968. Effects of main stem impoundments and channelization upon the limnology of the Missouri River, Nebraska. Trans. Am. Fish. Soc. 97:380-388. 
Needham, R.G. 1978. Northeast Montana fisheries study, inventory and survey of waters of the project area. Job Prog. Rept., Fed. Aid to Fish and Wildl. Rest. Proj. No. F-11-R-25. Job Ia. Mont. Dept. Fish Wild1. and Parks. Helena. 20p.

1979. Northeast Montana fisheries study, paddlefish investigations. Job Prog. Rept., Fed. Aid to Fish and Wildl. Rest. Proj. No. F-11-R-26, JobIIa. Mont. Dept. Fish Wild. and Parks. Helena. 12p.

1983. Northeast Montana fisheries study, paddlefish investigations. Job Proj. Rept. Fed. Aid to Fish and Wildl. and Parks. Helena. 10p.

- 1984. Fisheries manager. Mont. Fish Wildl. and Parks. Personal communication.

and K. Gilge 1985. Northeast Montana fisheries study, inventory and survey of waters of the project area. Job. Prog. Rept., Fed. Aid to Fish and Wildl. Rest. Proj. No. F-11-R-32. Job Ia. Mont. Dept. Fish Wildl. and Parks. Helena. 25p.

Nelson, F.A. 1977. Beaverhead River and Clark Canyon Reservoir fishery study. Montana Dept. of Fish Wildl, and Parks. Helena. 118p.

1984. Guidelines for using the wetted perimeter (WETP) computer program of the Montana Department of Fish, Wildiife and Parks. Mont. Dept. Fish Wildl, and Parks. Bozeman. 58p.

Pennak, R.W. 1953. Freshwater invertebrates of the United States. The Ronald Press Co., NY 769p.

Peterman, L. 1978. Electrofishing large rivers - the Yellowstone experience. Presented at the Electrofishing Workshop, St. Paul Minnesota, 1978. Mont. Dept. Fish Wildl. and Parks. Miles City, Montana.

Pflieger, W.L. 1975. The fishes of Missouri. Missouri Dept. of Cons., Jefferson City. $343 p$.

Posewitz, J.A. 1963. Missouri River fish population study. Fed. Aid to fish and Wildl. Rest. Proj. No. F-11-R-10. Job III. Mont. Dept. Fish Wildl. and Parks. Helena. 9p.

Priegel, G.R. 1969. The lake Winnebago sauger. Wisc. Dept. Nat. Resc. Tech. Bul1. No. 43. $63 \mathrm{p}$.

Purkett, C.A. 1963. The paddlefish fishery of the Osage River and Lake of the Ozarks, Missouri. Trans. Am. Fish. Soc. 92(3):239-244.

Rehwinkel, B.J. 1978. The fishery for paddlefish at Intake, Montana during 1973 and 1974. Trans. Am. Fish. Soc. 107(2):263-268.

, M. Gorges and J. Wells. 1976. Powder River aquatic ecology project. Annual Rept. Mont. Dept. Fish Wildl. and Parks. Helena. 35p. 
Repsys, A.J. and G.D. Rogers. 1982. Zooplankton studies in the channelized Missouri River. p.125-146. In L.W. Hesse, G.L. Hergenrader, H.S. Lewis, S.D. Reetz and A.B. Schlesinger (ed.) The middle Missouri River. A collection of papers on the biology with special reference to power station effects. The Missouri River Study Group. Norfolk, NB. $301 \mathrm{p}$.

Ricker, W.E. 1975. Computation and interpretation of biological statistics of fish populations. Bull. Fish. Res. Bd. Can. Bull. 191. Ottawa. 382p.

Rothe, S. 1985. Biological assessment team. U.S. Army Corps Engineers. Personal communications.

Roussow, G. 1957. Some considerations concerning sturgeon spawning periodicity. J. Fish Res. Bd. Can. 14(4):553-572.

Scott, W.B. and E.J. Crossman. 1973. Freshwater Fishes of Canada. Bull. Fish. Res. Bd. Can. Bull.184. Ottawa. 966p.

Stewart, P.A. 1977. Lower Missouri River basin investigations, planning inventory, fisheries. Fed. Aid. Fish and Wild1. Rest. Proj. No. FW-2-R-6. Job Ib. Mont. Dept. Fish Wild1. and Parks. Helena. 40p.

- 1978. Lower Missouri River basin investigations, planning inventory, fisheries. Fed. Ald Fish and Wild1. Rest. Proj. No. FW-2-R-7. Job Ib. Mont. Dept. Fish Wildl, and Parks. Helena. 35p.

1979. Lower Missouri River basin investigations, planning inventory, fisheries. Fed. Ald Fish and W1ldl. Rest. Proj. No. FW-2-R-8 Job Ib. Mont. Dept. Fish Wildl. and Parks. Helena. 44p.

1982. Lower Missouri River basin investigations, planning inventory, fisheries. Fed. Ald Fish and Wild1. Rest. Proj. No. FW-2-R-11 Job I-b. Mont. Dept. Fish Wildl. and Parks. Helena. 39p.

1983. Lower Missouri River basin investigations, planning Inventory, fisheries. Fed. Ald Fish and Wild1. Rest. Proj. No. FW-2-R-12 Job I-b. Mont. Dept. Fish Wildl. and Parks. Helena. 44p.

1985a. Southeast Montana investigations, paddlefish Investigations. Fed. Ald Fish and Wildl. Rest. Proj. No. F-30-R-2l Job IIa. Mont. Fish Wildl. and Parks. Helena. 1lp.

1985b. Fisheries Manager. Mont. Fish. Wild1. and Parks. Personal communication.

Swenson, F.A. 1955. Geology and groundwater resources of the Missouri River valley in northeastern Montana. U.S. Geol. Surv. Water Supply Papers. W-1263.

U.S. Army Corps of Engineers, Missouri River Division. 1977. Missouri River South Dakota, Nebraska, North Dakota, Montana, Review Report for Water Resources Development, Vol. I. Omaha. 
USGS. 1974-1984. Water resources data for Montana. U.S. Dept. of Interior.

USGS. 1984. Flow duration hydrographs for Missour1 River at Fort Peck, Wolf Point and Culbertson, and Milk River at Nashua, MT, 19 year period between water years 1959-1977.

Veithe, G.D. 1975. Baseline concentrations of polychlorinated biphenyls and DDT in Lake Michigan fish, 1971. Pestic. Monit. J. 9:21-29.

Ward, J. 1955. A description of a new zooplankton counter. Quart. J. of Microscopical Sci. 96(3):371-373.

Ward, J.V. 1976. Comparative limnology of differently regulated sections of a Colorado mountain river. Arch. Hydrobiol. 78(3)319-342.

Wiedenheft, W.D. 1984. Establishment of aquatic baselines in large inland impoundments. Proj. No. 1-123-R. Mont. Dept. Fish Wild1. and Parks. Helena.

Witt, A. Jr. 1961. An improved instrument to section bones for age and growth determinations of fish. Prog. Fish. Cult. 23(2):94-96.

Wydoski, R. and L. Emery. 1983. Tagging and marking. Pages 215-238. in L. Nielsen and D.L. Johnson (ed.). Fisheries Techniques. American Fisheries Society. Bethesda. 468p.

Zweiacker, P.L. 1967. Aspectes of the life history of the shovelnose sturgeon, Scaphirhynchus platorynchus (Rafinesque), in the Missouri River. M.A. thesis, Univ. of S. Dak., Vermiliion. 46p.

$303 / 8$ 


\section{APPENDIX}

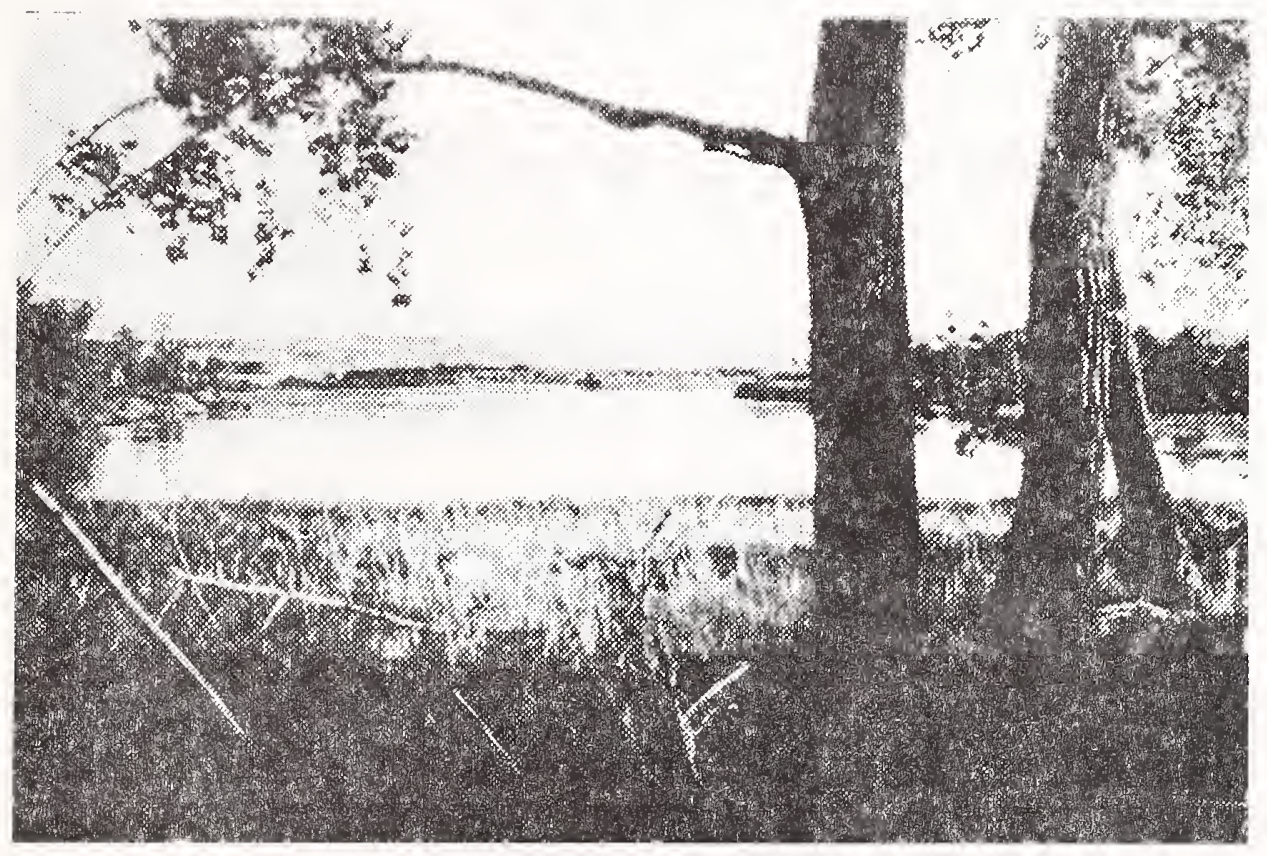




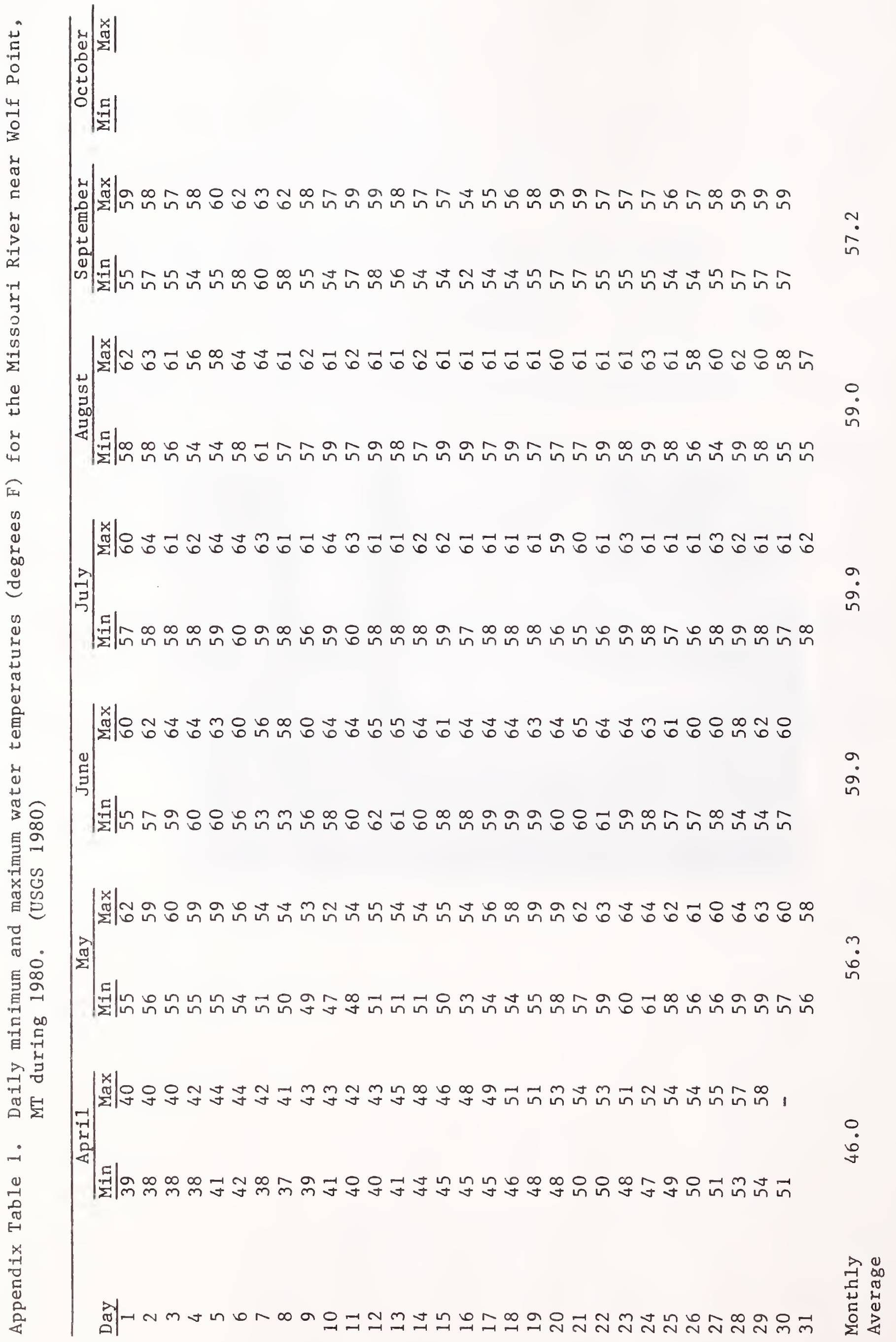




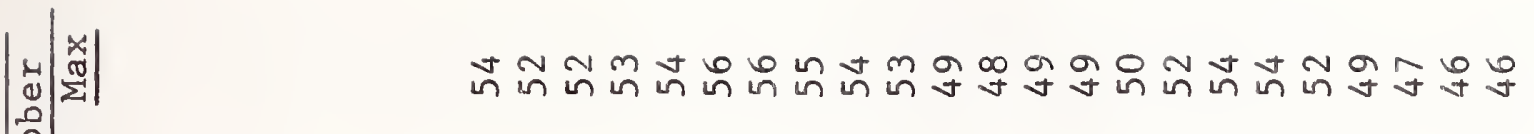

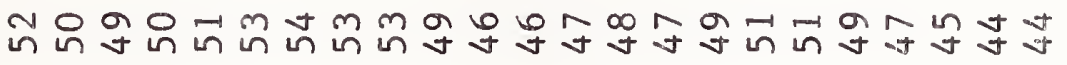

$\stackrel{\circ}{\circ}$

至|

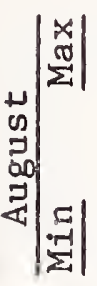

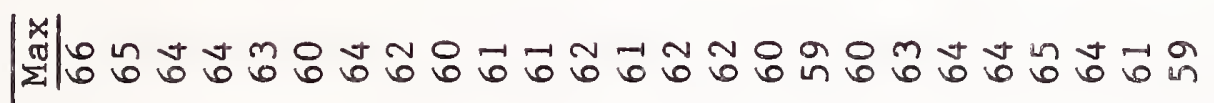

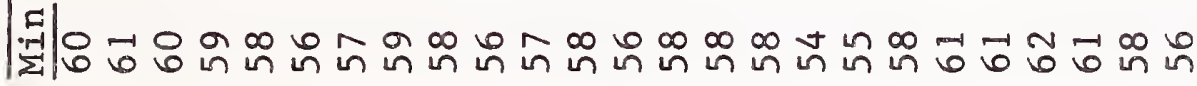

à

|

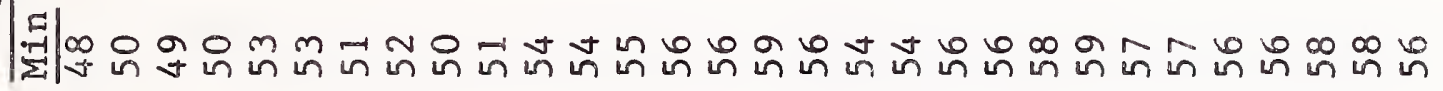

|

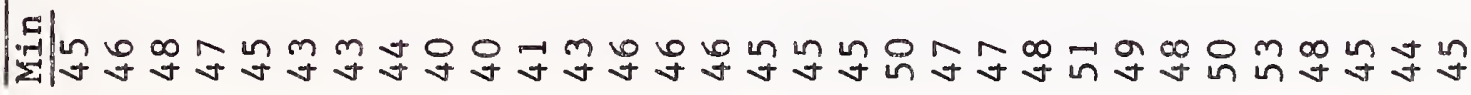

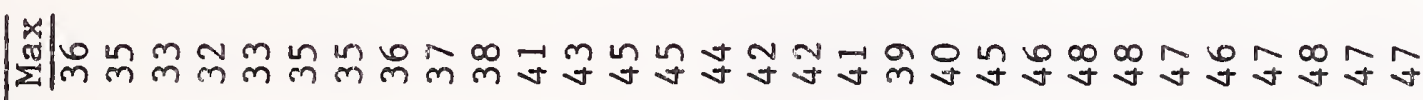

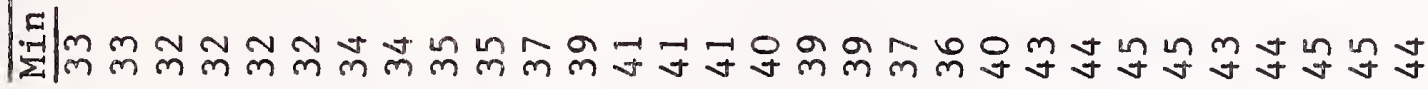

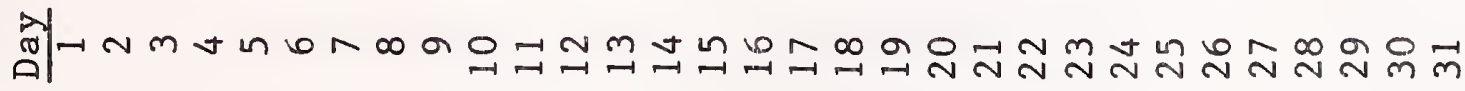




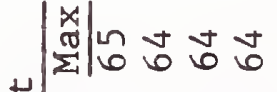

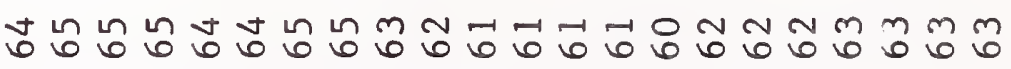

䠣

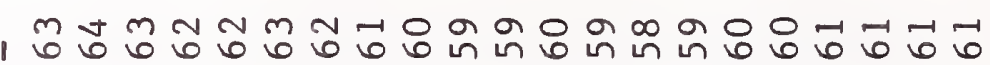

|

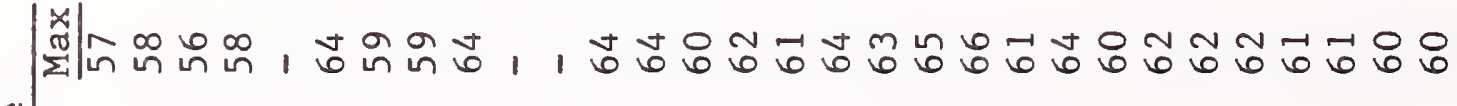

焉|تูง

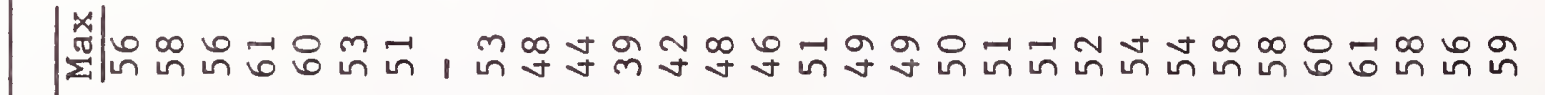

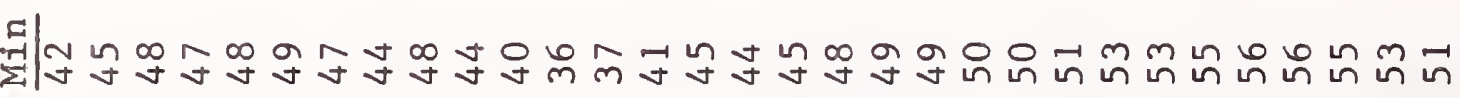

|

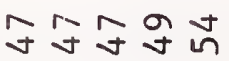

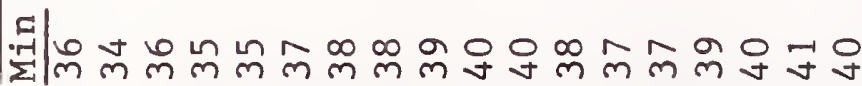

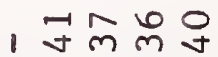




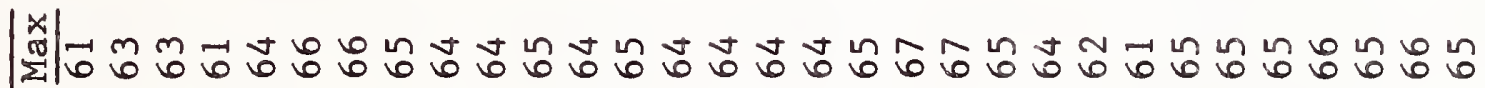
?3.

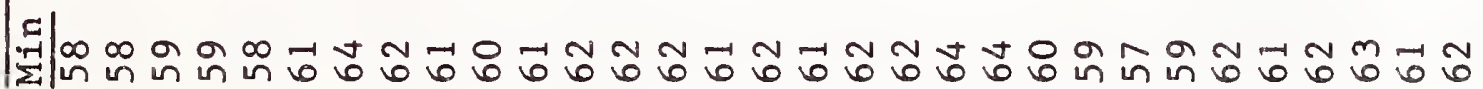

| $\begin{aligned} & x \\ & |x|\end{aligned} \mid$

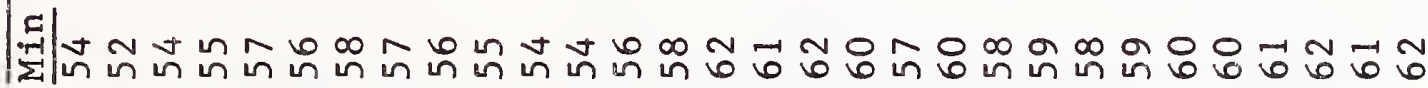

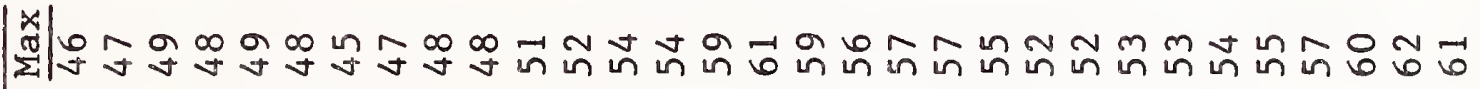

|

|

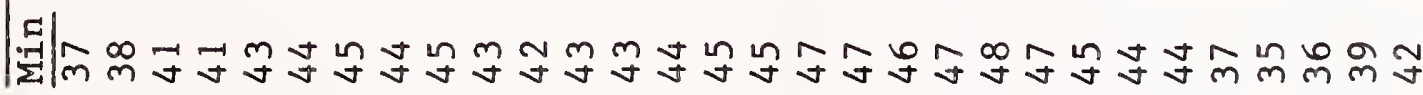


Append1x Table 5. Numbers of aquatic macroinvertebrates collected (per sample period) at the tailwaters of Fort Peck Dam Station, March 1981 to Apr1l 1982.

Sampling Period

\begin{tabular}{lcccccc} 
Taxa & 24 Mar 81 & 4 Aug 81 & 22 & Oct 81 & 22 Apr 82 \\
\hline Ephemerella & a/ & 3 & & & 3 \\
Baet1s & & 3 & 12 & \\
\hline & & 6 & 12 & 3
\end{tabular}

Brachycentrus 2

2

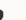

\begin{tabular}{lrrrr} 
Chironomidae & 18 & 7 & & 183 \\
S1mulium & 8 & 132 & 20 & 35 \\
Limnophora & 3 & & 7 & 9 \\
\hline & 29 & 139 & 27 & 227
\end{tabular}

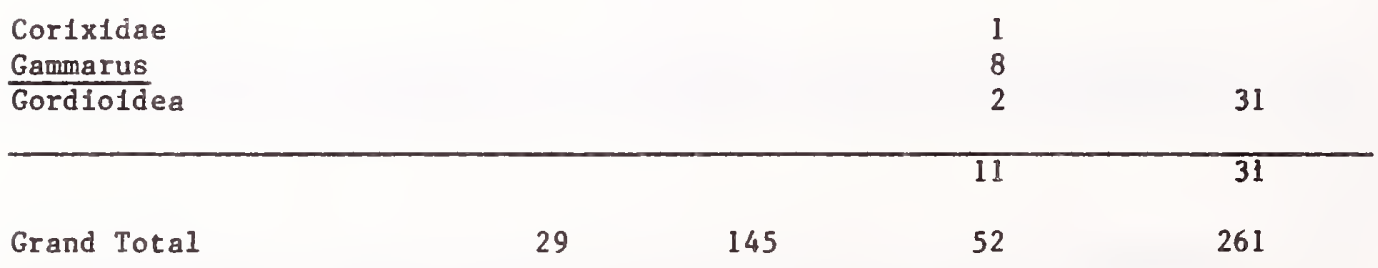

a/ Blank spaces Indicate no organisms of the taxa present in sample.

$303 / 8.1$ 
Append1x Table 6. Numbers of aquatic macrolnvertebrates collected (per sample period) at the Wiota Pumping Station, March 1981 to Apr11 1982.

Sampling Period

\begin{tabular}{lcccccc} 
Taxa & 24 Mar 81 & 4 Aug 81 & 22 Oct 81 & 22 Apr 82 \\
\hline Isoperla & a/ & & 2 \\
\hline & & & \\
\hline
\end{tabular}

\begin{tabular}{lrrrr} 
Ephemere11a & 14 & 176 & 64 & 556 \\
Baet18 & 1 & 35 & 18 & 3 \\
\hline & 15 & 211 & 82 & 559
\end{tabular}

\begin{tabular}{llll} 
Hydropsyche & 4 & 4 & 3 \\
\hline Brachycentrus & 2 & 9 & 13 \\
\hline
\end{tabular}

\begin{tabular}{llllr} 
Chironomidae & 32 & 17 & 10 & 20 \\
S1mulium & 25 & 18 & 11 & 42 \\
Imnophors & & & & 1 \\
\hline & 57 & 35 & 21
\end{tabular}

\begin{tabular}{|c|c|c|c|c|}
\hline $\begin{array}{l}\text { Corixidae } \\
\text { Gammarus } \\
\text { Ol1gachaeta } \\
\text { Physidae }\end{array}$ & 3 & 1 & $\begin{array}{l}2 \\
1 \\
2\end{array}$ & 1 \\
\hline & 3 & 1 & 5 & 1 \\
\hline Grand Total & 75 & 249 & 121 & 628 \\
\hline
\end{tabular}

a/ Blank spaces Indicate no organisms of the taxa present in sample. $303 / 8.1$ 
Appendix Table 7. Numbers of aquatic macrolnvertebrates collected (per sample period) at the Hiway \#13 Bridge Station, March 1981 to Apr11 1982.

\section{Sampling Period}

\begin{tabular}{|c|c|c|c|c|}
\hline Taxa & $24 \operatorname{Mar} 81$ & 4 Aug 81 & 22 Oct 81 & 22 Apr 82 \\
\hline$\frac{\text { Isoperla }}{\text { Isogenoldes }}$ & 4 & a/ & & $\begin{array}{r}65 \\
1\end{array}$ \\
\hline & 4 & & & 66 \\
\hline$\frac{\text { Traverella }}{\text { Analetr1s }}$ & & 1 & 2 & \\
\hline Ephemerella & 71 & 175 & 7 & 1870 \\
\hline Baet1s & & 60 & 29 & 40 \\
\hline
\end{tabular}

\begin{tabular}{lcccc} 
Hydropsyche & 2 & & 17 & 7 \\
$\begin{array}{l}\text { Cheumatopsyche } \\
\text { Brachycentrus }\end{array}$ & 15 & 16 & & 2 \\
\hline & 17 & 16 & 17 & 9
\end{tabular}

\begin{tabular}{lrrr} 
Chironomidae & 36 & 13 & 2 \\
Simulium & 15 & & 13 \\
\hline
\end{tabular}

Simulium

1315

\begin{tabular}{lcc}
$\begin{array}{l}\text { Corixldae } \\
\text { Physidae }\end{array}$ & 3 & 1 \\
\hline & 3 & 265 \\
Grand Total & 146 & 71 \\
a/ Blank spaces indicate no organisms of the taxa present in sample.
\end{tabular}

$303 / 8.1$ 
Appendix Table 8. Numbers of aquatic macroinvertebrates collected (per sample period) at the Hiway \#16 Bridge Station, March 1981 to April 1982.

Sampling Period

$\underline{\text { Taxa }}$

25 Mar 81

7 Jul 81

21 Oct 81

1 May 82

Isoperla

27

1

23

57

27

23

57

Traverella

Analetris

a/

Ametropus

1

4

39

Siphlonurus

Hexagenia

Caenis

Brachycercus

Ephemere1la

Heptagenia

Stenonema

Baetis

Ephoron

1

(21

21

24

Hydropsyche

Cheumatopsyche

Brachycentrus

Neureclipsis

$\begin{array}{llll}1 & 33 & 37\end{array}$

24

39

1

3938

Chironomidae

8

5

39

Simulium

\begin{tabular}{lrrrr} 
& 8 & 5 & 1 & 39 \\
Gomphus & & & & 1 \\
\hline $\begin{array}{l}\text { Corixidae } \\
\text { Oligochaeta } \\
\text { Anostraca }\end{array}$ & 1 & 1 & 5 & 24 \\
& 1 & & 1 \\
\hline Grand Total & 2 & 1 & 5 & 48 \\
\hline S & 82 & 177 & 153 & 391
\end{tabular}

1

a/ Blank spaces 1ndicate no organlsms of the taxa present in aample.

$303 / 8.1$ 
Appendix Table 9. Numbers of aquat1c macrolnvertebrates collected (per sample perfod) at the Nohly Bridge Station, March 1981 to Apr11 1982.

\section{Sampling Period}

\begin{tabular}{|c|c|c|c|c|}
\hline Taxa & $25 \operatorname{Mar} 81$ & 7 Ju1 81 & 21 Oct 81 & 5 May 82 \\
\hline$\frac{\text { Isogenus }}{\text { Isoperla }}$ & 13 & a/ & 29 & $\begin{array}{r}1 \\
175\end{array}$ \\
\hline & 13 & & 29 & 176 \\
\hline Traverella & & & 15 & \\
\hline Analetr1s & 5 & & 15 & 7 \\
\hline$\overline{\text { Ametropus }}$ & & & & 2 \\
\hline Isonychia & & 2 & & \\
\hline Hexagen1a & & & 1 & \\
\hline$\overline{\text { Caen1s }}$ & & & & 1 \\
\hline Ephemerella & 1 & 11 & 1 & 17 \\
\hline Heptagenia & & 6 & 6 & 29 \\
\hline$\overline{\text { Stenonema }}$ & & & & 1 \\
\hline Baet1s & & 6 & 15 & 4 \\
\hline Ephoron & & & 1 & \\
\hline
\end{tabular}

Hydropsyche

17

Cheumatopsyche

Brachycentrus

Neureclips1s

1747

4

1

47

5

19

22

52

21

\begin{tabular}{lll} 
Chironomidae & 2 & 1 \\
Empldadae & & 1 \\
\hline
\end{tabular}

Gomphus

Corixidae

Hyallela

Anostraca

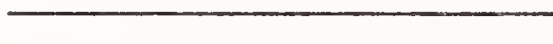

Grand Total

43

2

1

\begin{tabular}{|c|c|c|}
\hline & - & $\begin{array}{l}4 \\
8\end{array}$ \\
\hline 1 & & 12 \\
\hline 34 & 137 & 267 \\
\hline
\end{tabular}

a/ Blank space 1ndicate no organ1sms of the taxa present in sample. 
Appendix Table 10. Zooplankton densities sampled at the upper reach station of the Missourf River, 1985.

\begin{tabular}{|c|c|c|c|c|c|c|c|}
\hline Season & $:$ & Diaptomus & Cyclops & Naupl11 & Daphnia spp & Bosmina & $\begin{array}{l}\text { Total } \\
\text { org/1 }\end{array}$ \\
\hline \multicolumn{8}{|l|}{ Spring } \\
\hline \multirow[t]{3}{*}{$\overline{5 / 25}$} & Main channel & 0.77 & 4.25 & 0.35 & 2.92 & & 8.29 \\
\hline & Main channel & 0.42 & 3.25 & 0.42 & 2.97 & & 7.06 \\
\hline & off-channel pool & 0.03 & 0.36 & 0.24 & 0.45 & & 1.08 \\
\hline \multicolumn{8}{|l|}{ Summer } \\
\hline \multirow[t]{2}{*}{$7 \longdiv { 2 4 }$} & Main channel & 0.12 & 0.10 & 0.02 & 0.07 & & 0.31 \\
\hline & off-channel pool & 0.03 & 0.42 & 0.03 & 0.03 & & 0.51 \\
\hline \multicolumn{8}{|l|}{ Fall } \\
\hline \multirow[t]{2}{*}{$\overline{10 / 3}$} & Main channel & 0.35 & 0.27 & & 0.22 & & 0.84 \\
\hline & of $f$-channel pool & 0.45 & 0.02 & 0.02 & 0.22 & & 0.71 \\
\hline
\end{tabular}

Appendix Table 11. Zooplankton densities sampled at the middle reach station of the Missouri River, 1985.

\begin{tabular}{|c|c|c|c|c|c|c|c|}
\hline Season & & Diaptomus & Cyclops & Naupl11 & Daphnia spp & Bosmina & $\begin{array}{l}\text { Total } \\
\text { org/1 }\end{array}$ \\
\hline$\frac{\text { Spring }}{5 / 25}$ & $\begin{array}{c}\text { Main channel } \\
\text { Main channel } \\
\text { off-channel pool }\end{array}$ & $\begin{array}{l}0.35 \\
0.25 \\
0.48\end{array}$ & $\begin{array}{l}1.20 \\
1.12 \\
1.56\end{array}$ & $\begin{array}{l}0.12 \\
0.04\end{array}$ & $\begin{array}{l}0.52 \\
0.35 \\
0.06\end{array}$ & & $\begin{array}{l}2.07 \\
1.84 \\
2.14\end{array}$ \\
\hline$\frac{\text { Summer }}{7 / 24}$ & $\begin{array}{c}\text { Maln channel } \\
\text { off-channel pool }\end{array}$ & $\begin{array}{l}0.01 \\
0.03\end{array}$ & $\begin{array}{r}\operatorname{tr} \\
11.84\end{array}$ & $\begin{array}{r}\text { tr } \\
1.14\end{array}$ & 6.05 & 30.54 & $\begin{array}{r}0.01 \\
49.60\end{array}$ \\
\hline$\frac{\text { Fall }}{10 / 2}$ & $\begin{array}{c}\text { Main channel } \\
\text { off-channel pool }\end{array}$ & 0.01 & $\begin{array}{c}0.02 \\
\text { No } 8 a \mathrm{mp}\end{array}$ & - & 0.01 & & 0.04 \\
\hline
\end{tabular}

Appendix Table 12. Zooplankton densities sampled at the lower reach station of the Missouri River, 1985.

\begin{tabular}{|c|c|c|c|c|c|c|c|}
\hline Season & & Diaptomus & Cyclops & Naupli1 & Daphnia spp & Bosmina & $\begin{array}{l}\text { Total } \\
\text { org } / 1\end{array}$ \\
\hline \multicolumn{8}{|l|}{ Spring } \\
\hline \multirow[t]{2}{*}{$5 / 25$} & Main channel & 0.21 & 1.32 & 0.21 & 0.12 & & 1.86 \\
\hline & off-channel pool & 2.37 & 30.0 & 2.34 & 0.50 & & 35.21 \\
\hline \multicolumn{8}{|l|}{ Summer } \\
\hline \multirow[t]{2}{*}{$7 / 24$} & Maln channel & & $\operatorname{tr}$ & & & & tr \\
\hline & Off-channel pool & & tr & & 0.01 & 0.02 & 0.03 \\
\hline \multicolumn{8}{|l|}{$\mathrm{Fal1}$} \\
\hline \multirow[t]{2}{*}{$\overline{10 / 2}$} & Main channel & 0.02 & tr & tr & 0.02 & & 0.04 \\
\hline & of $f$-channel pool & 0.01 & 0.03 & tr & tr & & 0.04 \\
\hline
\end{tabular}


Appendix Table 13. Sport fish composition, number and size of fish sampled by electrofishing in the lower Missourl River study sections, 1979 through 1983.

\begin{tabular}{|c|c|c|c|c|c|}
\hline Spectes & $\begin{array}{c}\text { Number } \\
\text { Captured }\end{array}$ & $\begin{array}{c}\text { Average } \\
\text { Length } \\
\text { (1nches) }\end{array}$ & $\begin{array}{l}\text { Length } \\
\text { Range }\end{array}$ & $\begin{array}{c}\text { Average } \\
\text { We Ight } \\
\text { (pounds) }\end{array}$ & $\begin{array}{l}\text { Weight } \\
\text { Range }\end{array}$ \\
\hline \multicolumn{6}{|c|}{ Fort Peck $(30.5$ hrs.) } \\
\hline $\begin{array}{l}\text { Shovelnose sturgeon } \\
\text { Northern pike } \\
\text { Burbot } \\
\text { Sauger } \\
\text { Walleye }\end{array}$ & $\begin{array}{r}8 \\
3 \\
6 \\
17 \\
21\end{array}$ & $\begin{array}{l}25.1^{\text {a/ }} \\
27.7 \\
13.1 \\
17.5 \\
19.1\end{array}$ & $\begin{array}{l}(23.4-29.5) \\
(27.1-29.5) \\
(10.0-26.0) \\
(10.1-21.2) \\
(15.2-26.8)\end{array}$ & $\begin{array}{l}2.12 \\
5.31 \\
0.76 \\
1.61 \\
2.50\end{array}$ & $\begin{array}{l}(1.74-3.15) \\
(4.63-7.00) \\
(0.23-4.4) \\
(0.26-2.64) \\
(1.03-6.94)\end{array}$ \\
\hline
\end{tabular}

Nickels Ferry $(84 \mathrm{hrs.})$

\begin{tabular}{|c|c|c|c|c|c|}
\hline Shovelnose sturgeon & 100 & 26.5 & $(21.2-35.8)$ & 2.50 & $(1.06-6.50)$ \\
\hline Northern pike & 31 & 23.0 & $(9.20-34.7)$ & 4.34 & $(0.15-10.3)$ \\
\hline Burbot & 26 & 15.0 & $(10.3-35.6)$ & 1.01 & $(0.25-12.4)$ \\
\hline Sauger & 644 & 14.8 & $(7.20-24.8)$ & 1.01 & $(0.11-6.70)$ \\
\hline Walleye & 16 & 16.1 & $(6.20-21.1)$ & 1.49 & $(0.06-2.80)$ \\
\hline \multicolumn{6}{|c|}{ Frazer $(88$ hrs.) } \\
\hline Shovelnose sturgeon & 54 & 25.6 & $(23.5-33.5)$ & 2.07 & $(1.43-4.34)$ \\
\hline Northern pike & 32 & 20.9 & $(8.20-36.1)$ & 2.84 & $(0.07-11.0)$ \\
\hline Burbot & 43 & 15.4 & $(6.5-40.5)$ & 1.20 & $(0.06-12.6)$ \\
\hline Sauger & 283 & 14.3 & $(7.00-21.8)$ & 0.96 & $(0.10-2.98)$ \\
\hline Walleye & 22 & 14.7 & $(6.50-24.0)$ & 1.50 & $(0.05-3.63)$ \\
\hline
\end{tabular}

Wolf Polnt (71 hrs.)

\begin{tabular}{|c|c|c|c|c|c|}
\hline Shovelnose sturgeon & 45 & 24.7 & $(17.2-28.9)$ & 1.80 & $(0.70-3.00)$ \\
\hline Northern pike & 34 & 22.4 & $(9.7-40.0)$ & 3.35 & $(0.22-16.1)$ \\
\hline Burbot & 21 & 21.6 & $(9.10-36.5)$ & 3.26 & $(0.14-13.1)$ \\
\hline Sauger & 279 & 13.8 & $(7.00-23.6)$ & 0.86 & $(0.10-4.86)$ \\
\hline Walleye & 15 & 14.3 & $(4.90-22.0)$ & 1.32 & $(0.02-3.57)$ \\
\hline \multicolumn{6}{|c|}{ Chelsea (120 hrs.) } \\
\hline Shovelnose sturgeon & 97 & 24.2 & $(17.4-31.1)$ & 1.78 & $(0.65-3.36)$ \\
\hline Northern pike & 117 & 26.9 & $(6.20-41.0)$ & 5.55 & $(0.04-18.5)$ \\
\hline Burbot & 83 & 16.3 & $(6.50-38.5)$ & 1.31 & $(0.05-10.3)$ \\
\hline Sauger & 442 & 14.0 & $(6.80-23.1)$ & 0.93 & $(0.01-3.62)$ \\
\hline Walleye & 38 & 12.5 & $(6.20-23.3)$ & 1.16 & $(0.06-4.42)$ \\
\hline
\end{tabular}


Appendix Table 13. (Cont.)

\begin{tabular}{|c|c|c|c|c|c|}
\hline Species " & $\begin{array}{c}\text { Number } \\
\text { Captured }\end{array}$ & $\begin{array}{c}\text { Average } \\
\text { Length } \\
\text { (1nches) }\end{array}$ & $\begin{array}{l}\text { Length } \\
\text { Range }\end{array}$ & $\begin{array}{c}\text { Average } \\
\text { We1ght } \\
\text { (pounds) }\end{array}$ & $\begin{array}{l}\text { We1ght } \\
\text { Range }\end{array}$ \\
\hline \multicolumn{6}{|c|}{ Sprole (95 hrs.) } \\
\hline $\begin{array}{l}\text { Shovelnose sturgeon } \\
\text { Northern plke } \\
\text { Burbot } \\
\text { Sauger } \\
\text { Walleye }\end{array}$ & $\begin{array}{r}26 \\
52 \\
35 \\
489 \\
41\end{array}$ & $\begin{array}{l}23.5 \\
23.4 \\
18.8 \\
14.3 \\
13.4\end{array}$ & $\begin{array}{l}(14.5-28.6) \\
(7.90-34.0) \\
(8.30-35.5) \\
(5.10-24.0) \\
(4.30-26.1)\end{array}$ & $\begin{array}{l}1.62 \\
2.42 \\
1.96 \\
1.02 \\
1.49\end{array}$ & $\begin{array}{l}(0.14-3.20) \\
(0.10-11.20) \\
(0.11-10.0) \\
(0.04-4.74) \\
(0.01-6.80)\end{array}$ \\
\hline
\end{tabular}

Brockton ( 54 hrs.)

\begin{tabular}{|c|c|c|c|c|c|}
\hline Shovelnose sturgeon & 9 & 26.0 & $(23.0-27.6)$ & 1.87 & $(1.04-2.32)$ \\
\hline Northern pike & 37 & 23.0 & $(6.70-42.0)$ & 4.25 & $(.06-19.00)$ \\
\hline Burbot & 70 & 17.4 & $(4.40-32.5)$ & 1.68 & $(0.02-9.10)$ \\
\hline Sauger & 389 & 15.1 & $(5.80-22.0)$ & 1.12 & $(0.05-3.54)$ \\
\hline Walleye & 40 & 16.7 & $(8.50-23.3)$ & 1.91 & $(0.13-5.04)$ \\
\hline \multicolumn{6}{|c|}{ Culbertson (232 hrs.) } \\
\hline Shovelnose sturgeon & 33 & 24.4 & $(20.9-30.2)$ & 1.47 & $(0.46-2.92)$ \\
\hline Northern plke & 146 & 23.6 & $(9.50-42.5)$ & 2.99 & $(0.18-21.5)$ \\
\hline Burbot & 300 & 13.7 & $(4.30-35.0)$ & 1.21 & $(.01-10.40)$ \\
\hline Sauger & 1161 & 14.2 & $(4.80-29.6)$ & 1.03 & $(0.02-6.39)$ \\
\hline Walleye & 129 & 16.9 & $(4.40-29.2)$ & 2.24 & $(0.02-10.20)$ \\
\hline
\end{tabular}

a/ Total length given for shovelnose sturgeon.

$\left[2, \omega_{0} \mathrm{i}\right.$ 
Appendix Table 14. Spectes composition, number and size of fish sampled by experimental gill nets in the Fort Peck (dredge ponds) study section, 1979-84.

\begin{tabular}{|c|c|c|c|c|c|c|}
\hline Fish Species & $\begin{array}{c}\text { Number } \\
\text { Captured }\end{array}$ & $\begin{array}{c}\text { Average } \\
\text { Length } \\
\text { (Inches) }\end{array}$ & $\begin{array}{l}\text { Length } \\
\text { Range }\end{array}$ & $\begin{array}{c}\text { Average } \\
\text { Weight } \\
\text { (pounds) }\end{array}$ & & $\begin{array}{l}\text { lght } \\
\text { age }\end{array}$ \\
\hline Pallid sturgeon & 1 & $50.0 \frac{a}{2}$ & - & 20.2 & & - \\
\hline Shovelnose sturgeon & 599 & $25.9^{\mathrm{a} /}$ & $(21.3-36.2)$ & 2.19 & $(0.60$ & $-6.50)$ \\
\hline Goldeye & 2162 & 11.8 & $(7.9-15.0)$ & 0.51 & $(0.14$ & $-1.13)$ \\
\hline Lake whitefish & 1 & 23.0 & - & 6.58 & & - $\quad-1$ \\
\hline Chinook & 1 & 6.4 & - & - & & - \\
\hline Lake trout & 1 & 8.1 & - & 0.14 & & - \\
\hline Northern pike & 40 & 28.1 & $(20.3-40.0)$ & 5.90 & $(1.80$ & $-17.5)$ \\
\hline Rainbow smelt & 35 & 6.9 & - & 0.08 & & - \\
\hline Carp & 51 & 17.9 & $(13.4-20.0)$ & 2.51 & $(0.92$ & $-3.98)$ \\
\hline River carpsucker & 200 & 15.5 & $(13.8-20.0)$ & 1.70 & $(0.96$ & $-3.34)$ \\
\hline Blue sucker & 13 & 25.4 & - & 5.42 & & - \\
\hline Smallmouth buffalo & 11 & 20.6 & $(14.6-27.5)$ & 4.86 & $(1.38$ & $-12.20)$ \\
\hline B1gmouth buffalo & 1 & - & - & - & & - \\
\hline Shorthead redhorse & 35 & 12.9 & $(9.7-16.6)$ & 1.09 & $(0.32$ & $-1.98)$ \\
\hline White sucker & 68 & 13.8 & $(7.4-19.5)$ & 1.27 & $(0.11$ & $-3.15)$ \\
\hline Longnose sucker & 29 & 14.2 & $(8.4-20.0)$ & 1.55 & $(0.10$ & $-3.62)$ \\
\hline Channel catfish & 51 & 18.9 & $(14.4-21.1)$ & 2.08 & $(0.77$ & $-3.36)$ \\
\hline Burbot & 2 & 18.5 & $(12.8-24.2)$ & 1.71 & $(0.43$ & $-2.98)$ \\
\hline Yellow perch & 2 & 5.9 & $(5.5-6.4)$ & 0.15 & $(0.10$ & $-0.20)$ \\
\hline Sauger & 248 & 14.4 & $(9.3-19.9)$ & 0.89 & $(0.24$ & $-2.30)$ \\
\hline Walleye & 105 & 15.3 & $(9.9-23.1)$ & 1.50 & $(0.23$ & $-4.14)$ \\
\hline
\end{tabular}

a/ Total length given for sturgeon. 
Appendix Table 15. Species composition, number and size of fish sampled by experimental g1ll nets in the N1ckels Ferry study section, 1980.

\begin{tabular}{lccccc} 
Fish Species & $\begin{array}{c}\text { Number } \\
\text { Captured }\end{array}$ & $\begin{array}{c}\text { Average } \\
\text { Length } \\
\text { (1nches) }\end{array}$ & $\begin{array}{c}\text { Length } \\
\text { Range }\end{array}$ & $\begin{array}{c}\text { Average } \\
\text { Weight } \\
\text { (pounds) }\end{array}$ & $\begin{array}{l}\text { Weight } \\
\text { Range }\end{array}$ \\
\hline Goldeye & 7 & 12.0 & $11.0-13.2$ & 0.56 & $0.45-0.75$ \\
Carp & 1 & 20.0 & & 3.95 & \\
Blue sucker & 1 & 24.1 & & 3.74 & $1.42-1.78$ \\
Shorthead redhorse & 2 & 15.3 & $15.0-15.6$ & 1.60 & 1.95 \\
Longnose sucker & 1 & 19.7 & & 3.84 &. \\
White sucker & 1 & 15.8 & $10.5-15.8$ & 0.74 & $0.31-1.05$ \\
Sauger & 4 & 13.6 & $10.5-1.6$
\end{tabular}

Appendix Table 16. Species composition, number and size of fish sampled by experimental gill nets in the Frazer study section, 1979-80.

\begin{tabular}{lccccc} 
F1sh Species & $\begin{array}{c}\text { Number } \\
\text { Captured }\end{array}$ & $\begin{array}{c}\text { Average } \\
\text { Length } \\
\text { (1nches) }\end{array}$ & $\begin{array}{c}\text { Length } \\
\text { Range }\end{array}$ & $\begin{array}{c}\text { Average } \\
\text { Weight } \\
\text { (pounds) }\end{array}$ & $\begin{array}{c}\text { We1ght } \\
\text { Range }\end{array}$ \\
\hline Goldeye & 66 & 12.3 & $8.9-14.9$ & 0.59 & $0.21-1.27$ \\
Northern pike & 7 & 28.1 & $24.1-29.5$ & 5.16 & $2.84-7.50$ \\
Carp & 2 & 18.9 & $17.3-20.5$ & 3.93 & $2.64-5.22$ \\
River carpsucker & 13 & 17.2 & $14.2-19.9$ & 2.49 & $1.30-4.50$ \\
Smallmouth buffalo & 1 & 19.1 & & 3.33 & \\
Shorthead redhorse & 1 & 11.4 & & 0.61 & \\
Sauger & 1 & 12.8 & & 1.54
\end{tabular}


Appendix Table 17. Species composition, number and size of fish sampled by experimental g1ll nets in the Wolf Point study section, 1979-80.

\begin{tabular}{|c|c|c|c|c|c|}
\hline Fish Species & $\begin{array}{c}\text { Number } \\
\text { Captured }\end{array}$ & $\begin{array}{c}\text { Average } \\
\text { Length } \\
\text { (1nches) }\end{array}$ & $\begin{array}{l}\text { Length } \\
\text { Range }\end{array}$ & $\begin{array}{c}\text { Average } \\
\text { Welght } \\
\text { (pounds) }\end{array}$ & $\begin{array}{l}\text { Weight } \\
\text { Range }\end{array}$ \\
\hline Shovelnose sturgeon & 7 & 24.1 & $21.8-25.8$ & 1.43 & $1.00-2.00$ \\
\hline Goldeye & 435 & 11.1 & $6.0-14.0$ & 0.45 & $0.06-0.97$ \\
\hline Northern pike & 16 & 26.2 & $9.9-39.1$ & 5.87 & $0.20-18.20$ \\
\hline Carp & 13 & 17.0 & $13.6-22.0$ & 2.44 & $1.25-4.70$ \\
\hline RIver carpsucker & 29 & 14.5 & $10.6-18.1$ & 1.52 & $0.64-3.00$ \\
\hline Smallmouth buffalo & 2 & 19.6 & $18.7-20.6$ & 4.38 & $3.35-5.42$ \\
\hline Shorthead redhorse & 7 & 11.2 & $8.1-14.5$ & 0.72 & $0.24-1.49$ \\
\hline Longnose sucker & 1 & 11.5 & & 0.71 & \\
\hline Yellow perch & 1 & 5.8 & & 0.09 & \\
\hline Sauger & 33 & 12.5 & $8.9-18.8$ & 0.59 & $0.15-2.13$ \\
\hline Walleye & 9 & 14.1 & $10.3-23.7$ & 1.33 & $0.30-5.33$ \\
\hline
\end{tabular}

Appendix Table 18. Species composition, number and size of fish sampled by experimental gill nets in the Chelsea study section, 1979-80.

\begin{tabular}{|c|c|c|c|c|c|}
\hline Fish Species & $\begin{array}{c}\text { Number } \\
\text { Captured }\end{array}$ & $\begin{array}{c}\text { Average } \\
\text { Length } \\
\text { (1nches) }\end{array}$ & $\begin{array}{l}\text { Length } \\
\text { Range }\end{array}$ & $\begin{array}{c}\text { Average ' } \\
\text { Weight } \\
\text { (pounds) }\end{array}$ & $\begin{array}{l}\text { We1ght } \\
\text { Range }\end{array}$ \\
\hline Shovelnose sturgeon & 2 & 21.8 & $20.7-23.0$ & 1.04 & $0.61-1.47$ \\
\hline Goldeye & 134 & 10.2 & $7.4-13.6$ & 0.37 & $0.13-0.77$ \\
\hline Northern pike & 5 & 24.2 & $21.8-25.8$ & 3.70 & $2.80-5.12$ \\
\hline Carp & 3 & 11.7 & $9.6-13.5$ & 0.83 & $0.40-1.27$ \\
\hline River carpsucker & 7 & 14.4 & $13.3-15.6$ & 1.43 & $1.09-1.98$ \\
\hline Shorthead redhorse & 2 & 9.5 & $8.5-10.5$ & 0.34 & $0.24-0.44$ \\
\hline White sucker & 1 & 6.7 & & 0.13 & \\
\hline Sauger & 3 & 11.7 & $11.2-12.4$ & 0.41 & $0.33-0.56$ \\
\hline Walleye & 1 & 17.5 & & 1.88 & \\
\hline
\end{tabular}


Appendix Table 19. Species composition, number and size of fish sampled by experimental gill nets in the Brockton study section, 1979-80.

\begin{tabular}{lrrrrr} 
Fish Spectes & $\begin{array}{c}\text { Number } \\
\text { Captured }\end{array}$ & $\begin{array}{c}\text { Average } \\
\text { Length } \\
\text { (inches) }\end{array}$ & $\begin{array}{c}\text { Length } \\
\text { Range }\end{array}$ & $\begin{array}{c}\text { Average } \\
\text { Weight } \\
\text { (pounds) }\end{array}$ & $\begin{array}{l}\text { Weight } \\
\text { Range }\end{array}$ \\
\hline $\begin{array}{l}\text { Shovelnose sturgeon } \\
\text { Goldeye }\end{array}$ & 4 & 25.8 & $24.6-26.1$ & 1.92 & $1.31-2.62$ \\
Northern pike & 206 & 9.7 & $5.9-14.2$ & 0.35 & $0.06-1.13$ \\
Carp & 9 & 26.5 & $16.7-36.2$ & 5.13 & $1.01-10.70$ \\
River carpsucker & 5 & 16.6 & $14.0-20.9$ & 2.24 & $1.28-4.25$ \\
Blue sucker & 22 & 13.0 & $8.5-17.7$ & 1.22 & $0.35-2.90$ \\
Shorthead redhorse & 1 & 25.1 & & 4.26 & \\
Channel catfish & 17 & 10.2 & $6.5-13.8$ & 0.46 & $0.11-1.12$ \\
Sauger & 2 & 23.1 & $23.1-23.2$ & 4.62 & $4.48-4.76$ \\
Walleye & 22 & 13.0 & $8.1-20.5$ & 0.80 & $0.14-2.67$ \\
& 7 & 14.2 & $8.1-19.8$ & 1.22 & $0.11-2.64$
\end{tabular}

Appendix Table 20. Species composition, number and size of fish sampled by experimental g111 nets in the Culbertson study section, 1980 .

\begin{tabular}{lrrrrr} 
Fish Species & $\begin{array}{c}\text { Number } \\
\text { Captured }\end{array}$ & $\begin{array}{c}\text { Average } \\
\text { Length } \\
\text { (1nches) }\end{array}$ & $\begin{array}{c}\text { Length } \\
\text { Range }\end{array}$ & $\begin{array}{c}\text { Average } \\
\text { Weight } \\
\text { (pounds) }\end{array}$ & $\begin{array}{l}\text { Weight } \\
\text { Range }\end{array}$ \\
\hline Goldeye & 226 & 8.9 & $5.9-13.9$ & 0.28 & $0.06-1.15$ \\
Northern pike & 33 & 24.9 & $17.4-40.6$ & 4.41 & $1.20-18.80$ \\
Carp & 4 & 16.9 & $14.8-21.2$ & 2.33 & $1.42-4.10$ \\
River carpsucker & 27 & 14.4 & $9.3-20.5$ & 1.69 & $0.48-4.92$ \\
Shorthead redhorse & 3 & 13.2 & $11.5-14.5$ & 0.94 & $0.70-1.19$ \\
White bass & 1 & 6.9 & & 0.15 & \\
White crapple & 5 & 6.2 & $5.3-7.6$ & 0.12 & $0.07-0.22$ \\
Sauger & 9 & 14.3 & $8.4-21.0$ & 1.04 & $0.16-2.70$ \\
Walleye & 24 & 17.2 & $10.5-23.2$ & 1.83 & $0.32-4.42$
\end{tabular}


Appendix Table 21. Non-sport fish species composition, number and size of fish sampled by electrofishing in the Fort Peck study section, 1981.

\begin{tabular}{lccccc} 
Fish Spectes & $\begin{array}{c}\text { Number } \\
\text { Sampled }\end{array}$ & $\begin{array}{c}\text { Average } \\
\text { Length } \\
(\text { in })\end{array}$ & $\begin{array}{c}\text { Length } \\
\text { Range } \\
\text { (in) }\end{array}$ & $\begin{array}{c}\text { Average } \\
\text { Weight } \\
(\text { lb })\end{array}$ & $\begin{array}{c}\text { Weight } \\
\text { Range } \\
(1 \mathrm{~b})\end{array}$ \\
\hline Goldeye & 4 & 12.5 & $12.3-12.8$ & 0.55 & $0.53-0.58$ \\
Carp & 46 & 20.8 & $18.5-25.0$ & 4.92 & $3.06-7.60$ \\
River carpsucker & 5 & 15.6 & $14.7-16.7$ & 1.69 & $1.46-1.84$ \\
Smallmouth buffalo & 11 & 20.6 & $18.3-22.8$ & 4.11 & $2.90-6.00$ \\
Bigmouth buffalo & 1 & 25.0 & & 9.00 & \\
Shorthead redhorse & 3 & 15.6 & $13.3-18.1$ & 1.69 & $1.24-2.46$ \\
Longnose sucker & 3 & 11.1 & $8.0-17.2$ & 0.84 & $0.20-2.11$ \\
White sucker & 3 & 16.9 & $15.9-18.3$ & 2.34 & $2.04-2.80$
\end{tabular}

Appendix Table 22. Non-sport fish species composition, number and size of fish sampled by electrofishing in the Nickels Ferry study section, 1981.

\begin{tabular}{lccccc} 
Fish Species & $\begin{array}{c}\text { Number } \\
\text { Sampled }\end{array}$ & $\begin{array}{c}\text { Average } \\
\text { Length } \\
(\text { In })\end{array}$ & $\begin{array}{c}\text { Length } \\
\text { Range } \\
(\text { In })\end{array}$ & $\begin{array}{c}\text { Average } \\
\text { Weight } \\
(1 \mathrm{~b})\end{array}$ & $\begin{array}{c}\text { Weight } \\
\text { Range } \\
(1 \mathrm{~b})\end{array}$ \\
\hline Goldeye & 39 & 11.9 & $9.4-14.1$ & 0.49 & $0.22-0.70$ \\
Carp & 11 & 20.4 & $15.9-25.9$ & 4.07 & $1.72-7.00$ \\
River carpsucker & 8 & 16.7 & $14.6-18.2$ & 2.20 & $1.41-3.22$ \\
Blue sucker & 59 & 25.0 & $22.3-23.9$ & 4.90 & $3.40-8.60$ \\
Smallmouth buffalo & 10 & 21.1 & $20.0-23.6$ & 4.57 & $3.86-5.00$ \\
Bigmouth buffalo & 1 & 16.5 & $12.2-15.1$ & 2.40 & - \\
Shorthead redhorse & 8 & 13.4 & $12.2-1$ & $0.70-1.35$ \\
Longnose sucker & 10 & 16.7 & $11.1-22.2$ & 2.32 & $0.60-5.28$ \\
White sucker & 6 & 13.6 & $9.6-16.6$ & 1.30 & $0.36-2.09$
\end{tabular}


Appendix Table 23. Non-sport fish species composition, number and size of fish sampled by electrofishing in the Frazer study section, 1981.

\begin{tabular}{|c|c|c|c|c|c|}
\hline Fish Spectes & $\begin{array}{l}\text { Number } \\
\text { Sampled }\end{array}$ & $\begin{array}{c}\text { Average } \\
\text { Length } \\
\text { (In) }\end{array}$ & $\begin{array}{c}\text { Length } \\
\text { Range } \\
(1 \mathrm{n}) \\
\end{array}$ & $\begin{array}{c}\text { Average } \\
\text { We1ght } \\
\text { (1b) }\end{array}$ & $\begin{array}{c}\text { Weight } \\
\text { Range } \\
\text { (1b) }\end{array}$ \\
\hline Goldeye & 50 & 11.3 & $9.6-13.7$ & 0.43 & $0.24-0.61$ \\
\hline Carp & 53 & 19.7 & $14.7-25.4$ & 3.78 & $1.84-7.80$ \\
\hline River carpsucker & 15 & 16.6 & $15.2-20.1$ & 2.29 & $1.26-3.04$ \\
\hline Blue sucker & 1 & 24.6 & - & 4.43 & - \\
\hline Smallmouth buffalo & 17 & 19.6 & $15.3-23.5$ & 4.08 & $2.01-7.20$ \\
\hline Bigmouth buffalo & 6 & 23.5 & $20.1-26.6$ & 8.46 & $4.46-11.60$ \\
\hline Shorthead redhorse & 12 & 13.7 & $5.8-17.1$ & 1.35 & $0.09-2.52$ \\
\hline Longnose sucker & 7 & 8.5 & $3.8-12.4$ & 0.34 & $0.01-0.74$ \\
\hline White sucker & 7 & 9.6 & $4.1-17.0$ & 0.63 & $0.07-1.81$ \\
\hline
\end{tabular}

Appendix Table 24. Non-sport fish spectes composition, number and size of fish sampled by electroflshing in the Wolf Point study section, 1981.

\begin{tabular}{|c|c|c|c|c|c|}
\hline Fish Spectes & $\begin{array}{l}\text { Number } \\
\text { Sampled }\end{array}$ & $\begin{array}{r}\text { Average } \\
\text { Length } \\
(1 \mathrm{n}) \\
\end{array}$ & $\begin{array}{c}\text { Length } \\
\text { Range } \\
\text { (In) }\end{array}$ & $\begin{array}{c}\text { Average } \\
\text { Welght } \\
\text { (1b) }\end{array}$ & $\begin{array}{l}\text { Weight } \\
\text { Range } \\
(1 \mathrm{~b})\end{array}$ \\
\hline Goldeye & 24 & 10.6 & $9.0-13.0$ & 0.36 & $0.22-0.60$ \\
\hline Carp & 21 & 18.1 & $15.2-22.6$ & 2.76 & $1.66-5.02$ \\
\hline RIver carpsucker & 21 & 15.0 & $11.0-18.2$ & 1.72 & $0.68-3.72$ \\
\hline Blue sucker & 2 & 26.2 & $26.2-26.3$ & 5.45 & $5.42-5.48$ \\
\hline Smallmouth buffalo & 1 & 20.9 & - & 4.66 & - \\
\hline Bigmouth buffalo & 2 & 20.5 & $20.4-20.6$ & 5.34 & $5.29-5.39$ \\
\hline Shorthead redhorse & 20 & 9.0 & $5.00-17.1$ & 0.53 & $0.04-2.20$ \\
\hline White sucker & 2 & 9.8 & $5.00-14.6$ & 0.65 & $0.05-1.25$ \\
\hline
\end{tabular}


Appendix Table 25. Non-sport fish species composition, number and size of fish sampled by electrofishing in the Chelsea study section, 1981 .

\begin{tabular}{lccccc} 
Flsh Species & $\begin{array}{c}\text { Number } \\
\text { Sampled }\end{array}$ & $\begin{array}{c}\text { Average } \\
\text { Length } \\
(\mathrm{In})\end{array}$ & $\begin{array}{c}\text { Length } \\
\text { Range } \\
(\mathrm{In})\end{array}$ & $\begin{array}{c}\text { Average } \\
\text { Welght } \\
(\mathrm{lb})\end{array}$ & $\begin{array}{c}\text { We1ght } \\
\text { Range } \\
\text { (1b) }\end{array}$ \\
\hline Goldeye & 50 & 10.8 & $8.8-14.1$ & 0.40 & $0.17-0.77$ \\
Carp & 70 & 19.7 & $15.0-25.0$ & 3.47 & $1.39-6.60$ \\
River carpsucker & 17 & 16.7 & $13.1-21.3$ & 2.36 & $1.04-5.10$ \\
Blue sucker & 1 & 25.9 & $20.0-24.2$ & 5.37 & - \\
Bigmouth buffalo & 2 & 22.1 & $20.0-19$ & $5.19-8.60$ \\
Shorthead redhorse & 17 & 9.6 & $5.2-17.1$ & 0.52 & $0.05-1.78$
\end{tabular}

Appendix Table 26. Non-sport fish specles composition, number and size of fish sampled by electrofishing in the Sprole study section, 1981.

\begin{tabular}{|c|c|c|c|c|c|}
\hline $\begin{array}{c}\text { Flsh Species } \\
\end{array}$ & $\begin{array}{l}\text { Number } \\
\text { Sampled }\end{array}$ & $\begin{array}{c}\text { Average } \\
\text { Length } \\
(1 n)\end{array}$ & $\begin{array}{l}\text { Length } \\
\text { Range } \\
(1 n)\end{array}$ & $\begin{array}{c}\text { Average } \\
\text { Welght } \\
\text { (1b) }\end{array}$ & $\begin{array}{c}\text { Weight } \\
\text { Range } \\
(1 \mathrm{~b})\end{array}$ \\
\hline Goldeye & 152 & 11.2 & $8.6-14.6$ & 0.44 & $0.16-1.16$ \\
\hline Carp & 76 & 19.6 & $13.6-25.8$ & 3.77 & $1.28-8.90$ \\
\hline River carpsucker & 11 & 15.0 & $2.2-19.0$ & 1.97 & $0.01-3.79$ \\
\hline Blue sucker & 1 & 26.5 & - & 5.46 & - \\
\hline Smallmouth buffalo & 4 & 21.1 & $19.3-23.8$ & 5.03 & $3.57-7.20$ \\
\hline Bigmouth buffalo & 1 & 27.6 & - & 14.1 & - \\
\hline Shorthead redhorse & 51 & 10.0 & $4.3-17.4$ & 0.56 & $0.03-2.00$ \\
\hline
\end{tabular}



Appendix Table 27. Non-sport f1sh species composition, number and size of fish sampled by
electrofishing in the Brockton study section, 1981 .

\begin{tabular}{|c|c|c|c|c|c|}
\hline Fish Species & $\begin{array}{l}\text { Number } \\
\text { Sampled }\end{array}$ & $\begin{array}{l}\text { Average } \\
\text { Length } \\
\text { (1n) }\end{array}$ & $\begin{array}{c}\text { Length } \\
\text { Range } \\
(1 \mathrm{n})\end{array}$ & $\begin{array}{c}\text { Average } \\
\text { WeIght } \\
\text { (Ib) }\end{array}$ & $\begin{array}{l}\text { Welght } \\
\text { Range } \\
\text { (1b) }\end{array}$ \\
\hline Goldeye & 64 & 10.4 & $7.3-13.6$ & 0.35 & $0.11-0.73$ \\
\hline Carp & 79 & 18.2 & $14.3-26.3$ & 3.02 & $1.43-7.40$ \\
\hline River carpsucker & 13 & 15.5 & $8.2-18.2$ & 1.92 & $0.89-3.19$ \\
\hline Blue sucker & 2 & 28.2 & $27.6-28.8$ & 8.05 & $7.20-8.90$ \\
\hline Smallmouth buffalo & 2 & 21.2 & $20.7-21.7$ & 4.95 & $4.71-5.20$ \\
\hline Bigmouth buffalo & 1 & 22.6 & - & 7.30 & - \\
\hline Shor thead redhorse & 12 & 9.7 & $6.1-14.7$ & 0.47 & $0.08-1.19$ \\
\hline Longnose sucker & 1 & 10.5 & - & 0.41 & - \\
\hline
\end{tabular}
Appendix Table 28. Non-sport fish species composition, number and size of f1sh sampled by
electrofishing in the Culbertson study section, 1981 .

\begin{tabular}{|c|c|c|c|c|c|}
\hline F1sh Species & $\begin{array}{l}\text { Number } \\
\text { Sampled }\end{array}$ & $\begin{array}{c}\text { Average } \\
\text { Length } \\
(1 \mathrm{n})\end{array}$ & $\begin{array}{c}\text { Length } \\
\text { Range } \\
(1 \mathrm{n})\end{array}$ & $\begin{array}{c}\text { Average } \\
\text { Welght } \\
\text { (1b) }\end{array}$ & $\begin{array}{c}\text { We1ght } \\
\text { Range } \\
(1 \mathrm{~b})\end{array}$ \\
\hline Goldeye & 253 & 9.7 & $6.4-14.1$ & 0.28 & $0.07-0.71$ \\
\hline Carp & 56 & 17.8 & $14.3-24.6$ & 2.79 & $1.28-8.20$ \\
\hline River carpsucker & 17 & 15.2 & $9.1-17.8$ & 1.81 & $0.37-2.82$ \\
\hline Blue sucker & 2 & 26.0 & $25.1-26.9$ & 5.90 & $5.70-6.10$ \\
\hline Bigmouth buffalo & 1 & 21.0 & - & 5.70 & - \\
\hline Shorthead redhorse & 14 & 10.1 & $6.3-18.1$ & 0.55 & $0.09-2.48$ \\
\hline
\end{tabular}




\begin{tabular}{|c|c|c|c|c|}
\hline & 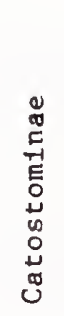 & 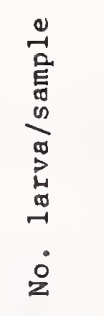 & 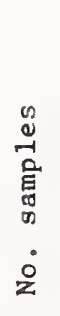 & 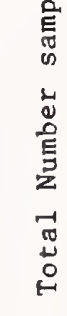 \\
\hline $\begin{array}{l}1979 \\
(5 / 30-7 / 10)\end{array}$ & & 0 & 9 & 0 \\
\hline $\begin{array}{l}1980 \\
(5 / 9-6 / 28)\end{array}$ & & 0 & 5 & 0 \\
\hline $\begin{array}{l}1981 \\
(5 / 18-8 / 4)\end{array}$ & 10 & 5 & 2 & 10 \\
\hline $\begin{array}{l}1982 \\
(5 / 26-6 / 30)\end{array}$ & 1 & 0.20 & 5 & 1 \\
\hline
\end{tabular}

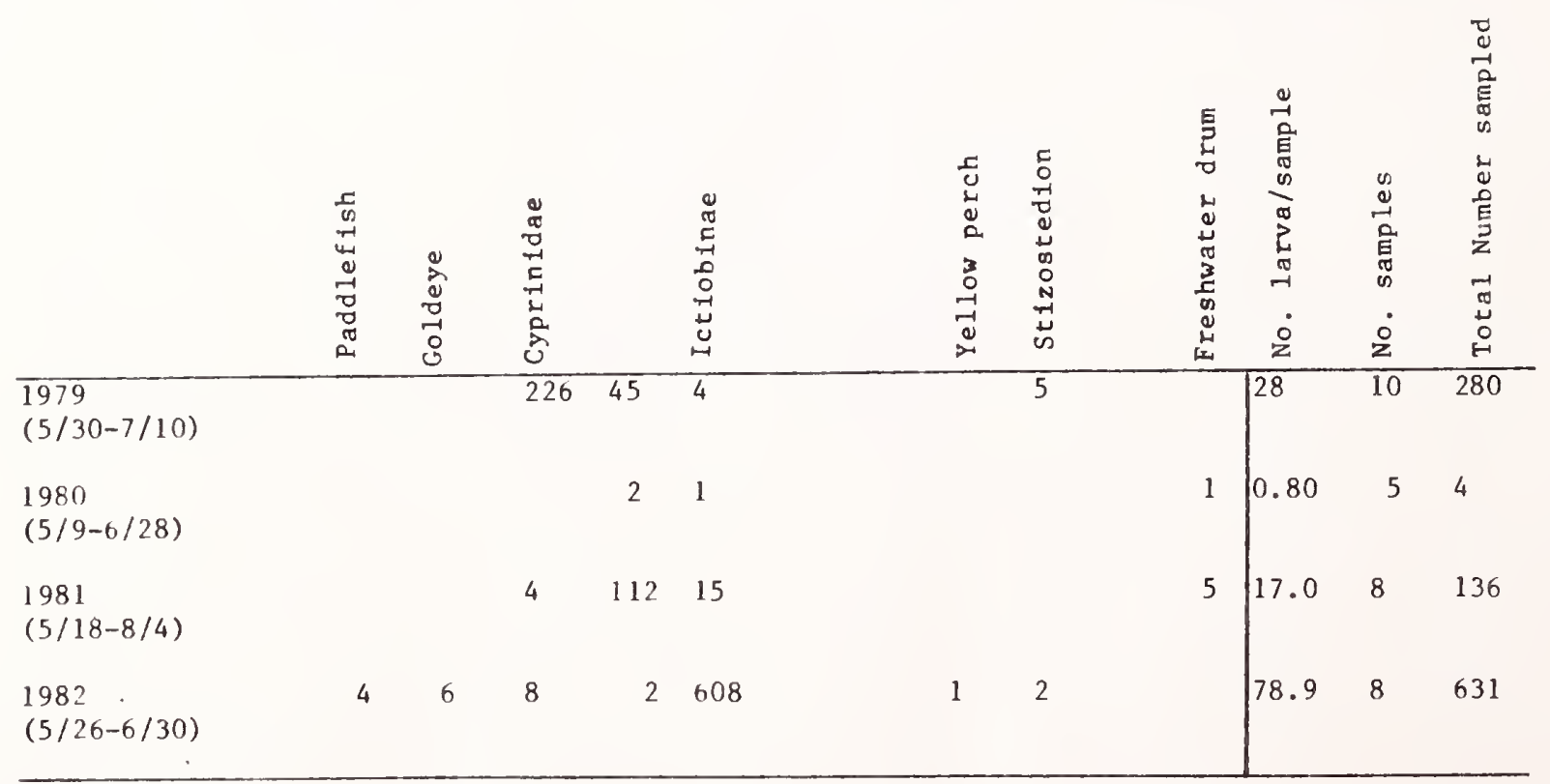




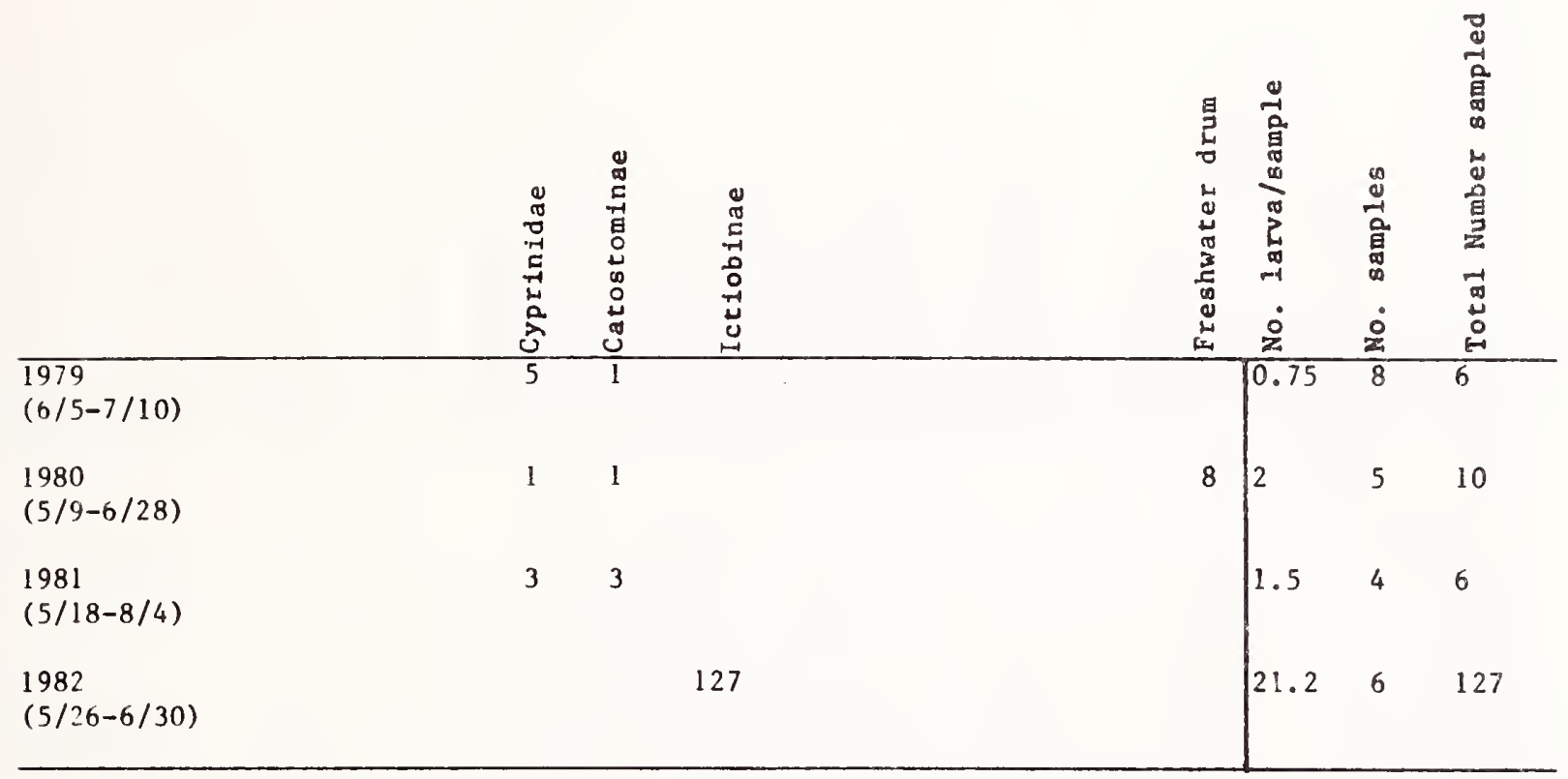

Appendix Table 32. Numbers of larval fish collected (total for year) in the Wolf Polnt section of the Missourt River, 1979-82.

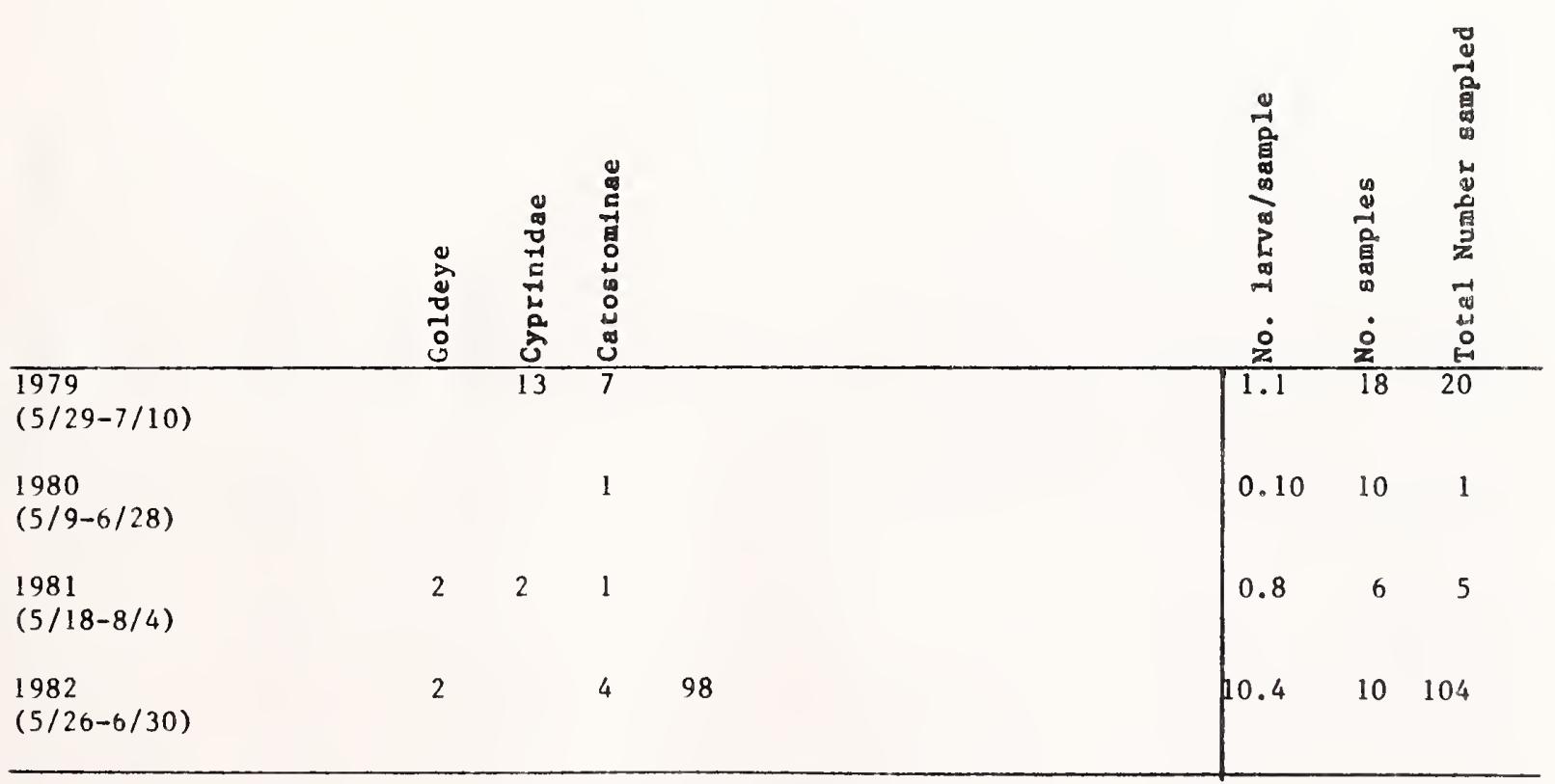




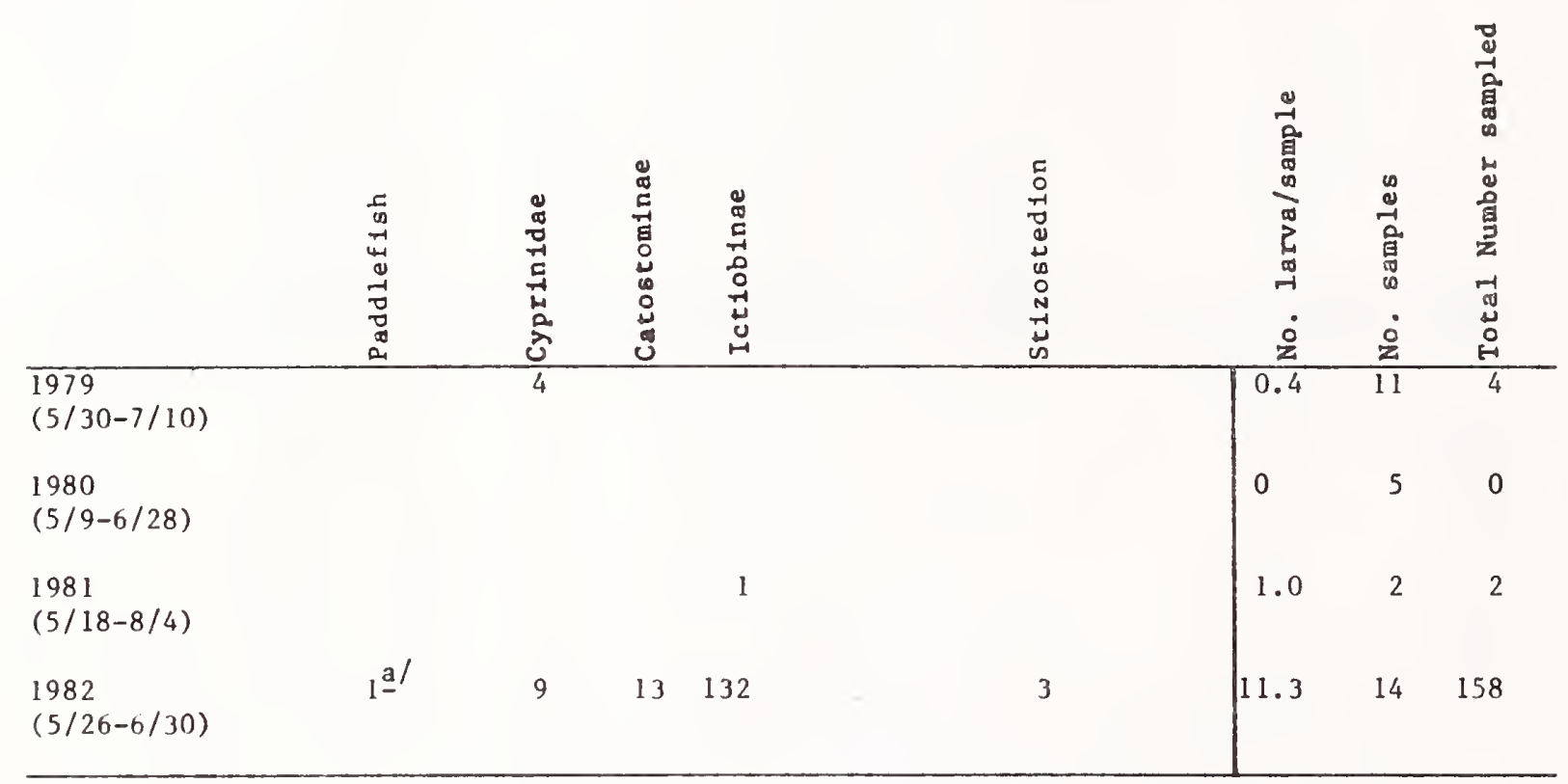

a/questionable Identification

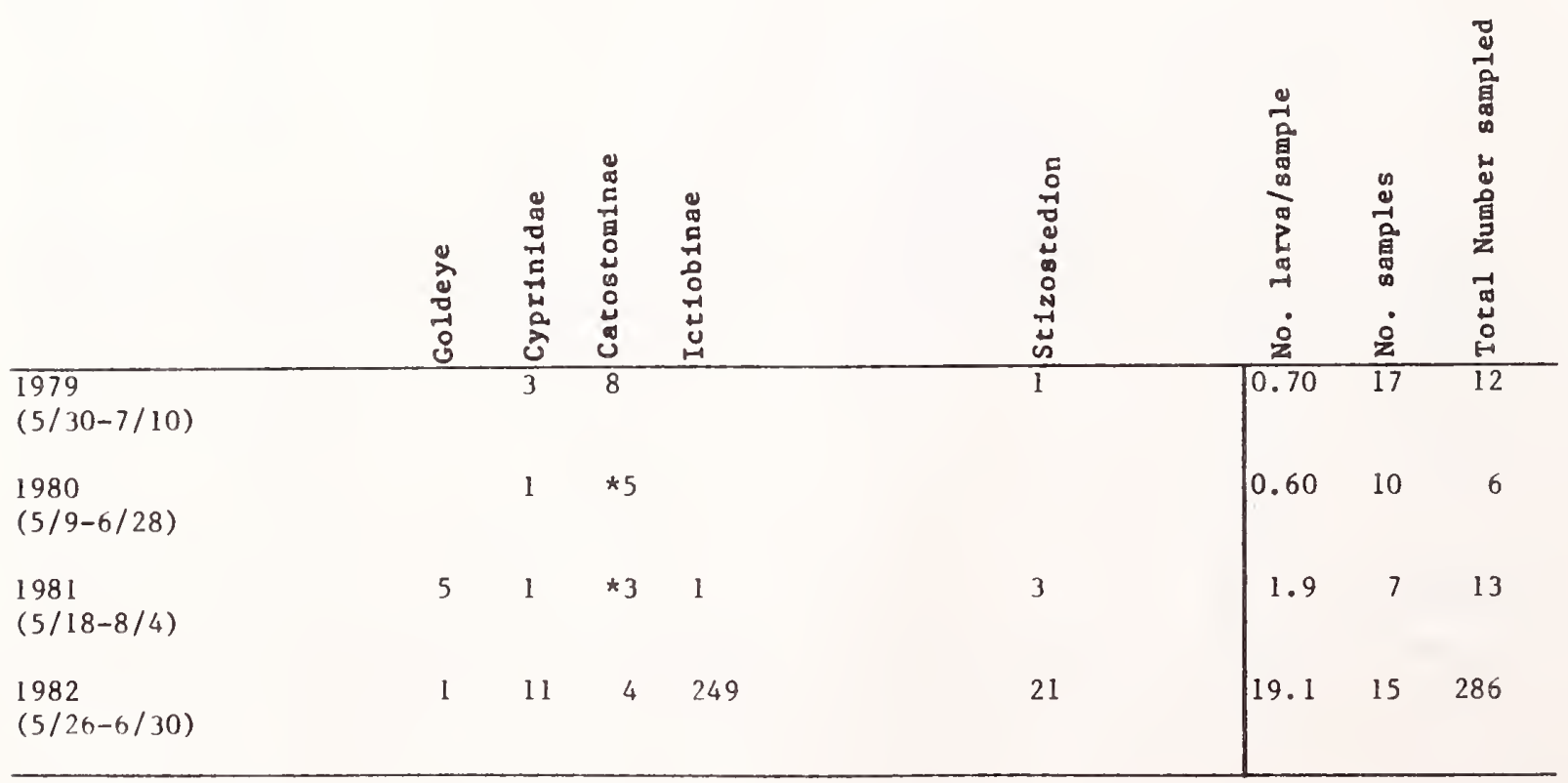

*2 Blue Sucker 


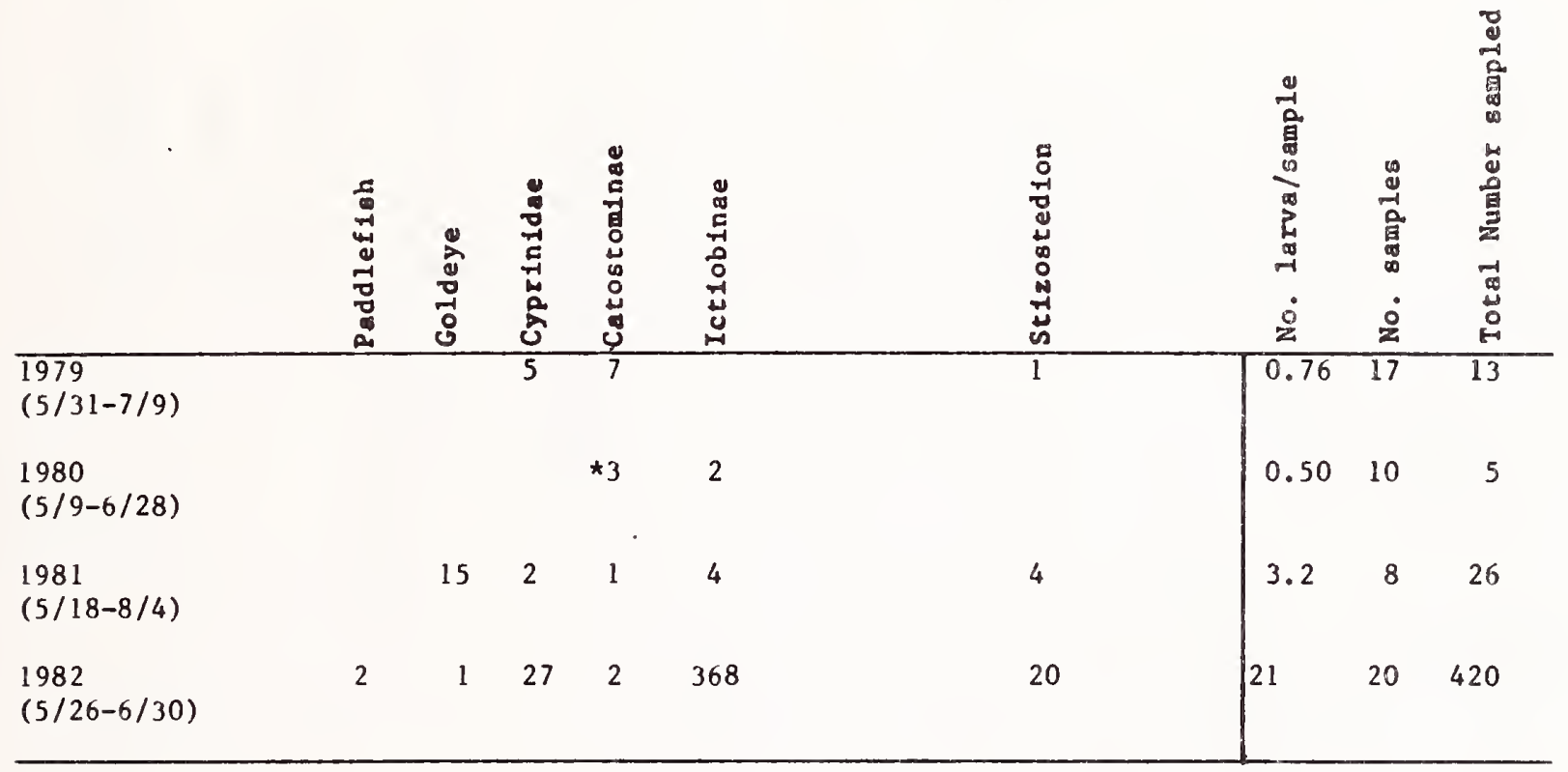

*1-Blue Sucker

Append1x Table 36. Numbers of larval fish collected (total for year) in the Culbertson section of the Missour1 River, 1979-82.

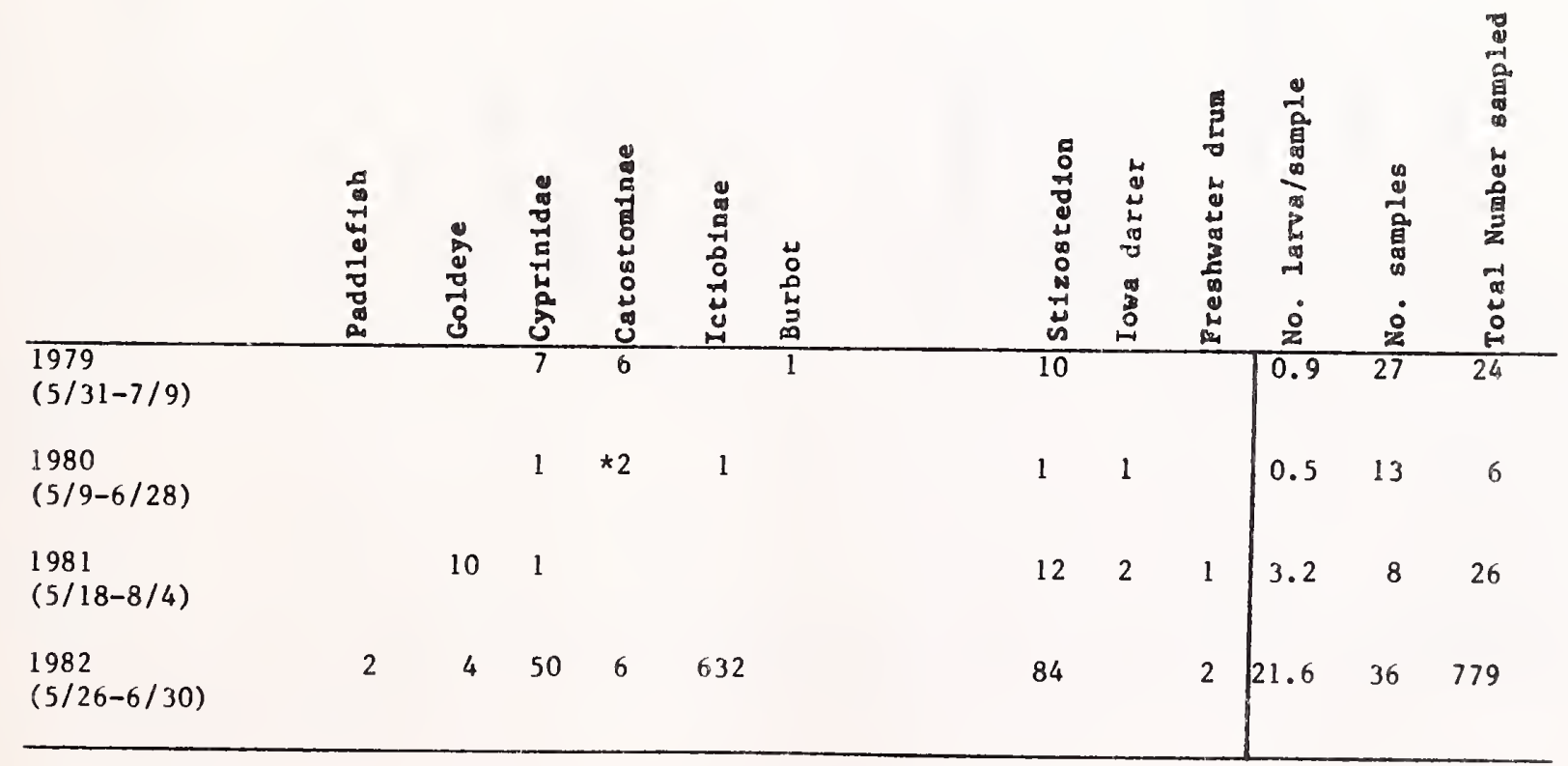

*1-Blue Sucker 
Append1x Table 37. Numbers of larval fish collected (total for year) in the

Milk River section near the confluence with the Missouri River,

1979-82.

\begin{tabular}{|c|c|c|c|c|c|c|c|c|c|c|}
\hline & 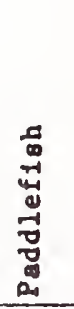 & 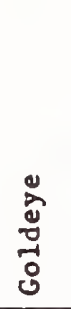 & 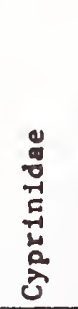 & 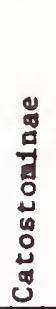 & 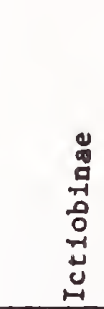 & 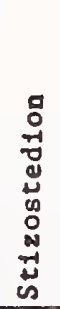 & 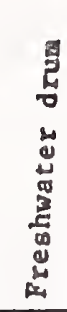 & 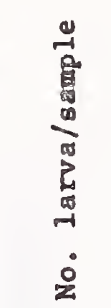 & 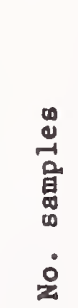 & 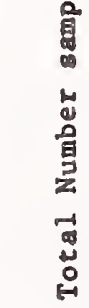 \\
\hline $\begin{array}{l}1979 \\
(6 / 5-7 / 10)\end{array}$ & & 1 & 219 & 10 & 18 & & & 41.3 & 6 & 248 \\
\hline $\begin{array}{l}1980 \\
(5 / 9-6 / 28)\end{array}$ & & & & 2 & 3 & & 100 & 17.5 & 6 & 105 \\
\hline $\begin{array}{l}1981 \\
(5 / 18-8 / 4)\end{array}$ & & 1 & 10 & 3 & 78 & & 8 & 20 & 5 & 100 \\
\hline $\begin{array}{l}1982 \\
(5 / 26-6 / 30)\end{array}$ & 2 & 15 & 24 & 18 & 2914 & 1 & 1 & 228.8 & 13 & 2975 \\
\hline
\end{tabular}

Appendix Table 38. Numbers of larval fish collected (total for year) in the

Poplar River near the confluence with the Missour1 River, 1979-82.

\begin{tabular}{|c|c|c|c|c|c|c|c|c|c|}
\hline & 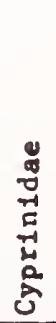 & 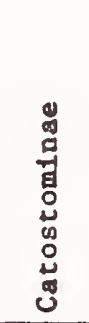 & $\begin{array}{c}n \\
\tilde{z} \\
0 \\
\tilde{\xi} \\
0^{0}\end{array}$ & 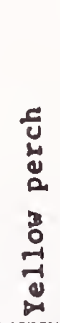 & 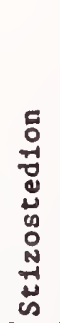 & 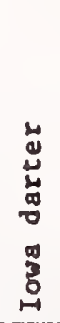 & 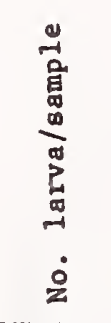 & 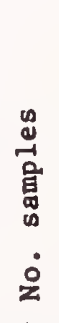 & 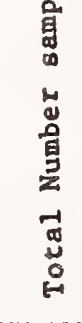 \\
\hline $\begin{array}{l}1979 \\
(5 / 30-7 / 10)\end{array}$ & 1 & 1136 & & & 10 & 16 & 1129.2 & 9 & 1163 \\
\hline $\begin{array}{l}1980 \\
(5 / 9-6 / 28)\end{array}$ & & 25 & 19 & 32 & 13 & & 17.8 & 5 & 89 \\
\hline $\begin{array}{l}1981 \\
(5 / 18-8 / 4)\end{array}$ & 2 & 1 & & 66 & & & 13.8 & 5 & 69 \\
\hline $\begin{array}{l}1982 \\
(5 / 26-6 / 30)\end{array}$ & & 16 & & & & & 5.3 & 3 & 16 \\
\hline
\end{tabular}


Appendix Table 39. Numbers of larval fish collected (total for year) in the Redwater Rlver, near the confluence with the Missourl

River, 1979.

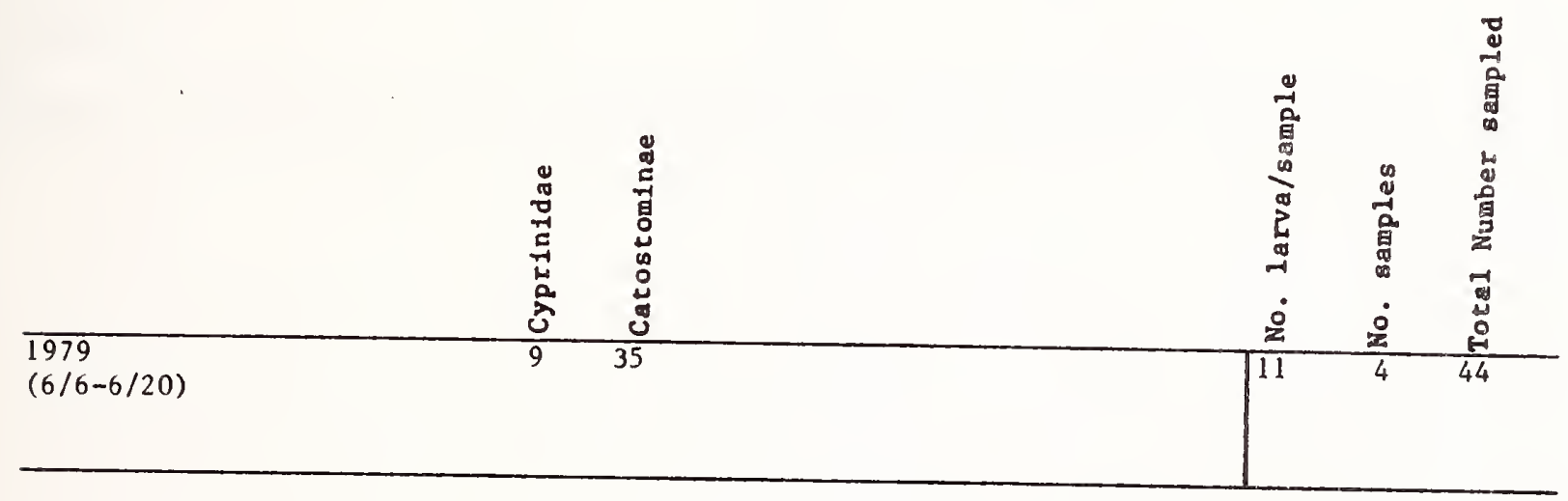

Appendix Table 40. Numbers of larval fish collected (total for year) in the B $1 g$ Muddy Creek near the confluence with the Missourl River, 1979-82.

\begin{tabular}{|c|c|c|c|c|c|c|c|c|c|c|c|}
\hline & 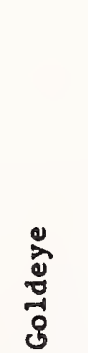 & 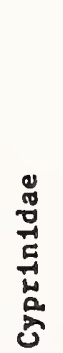 & 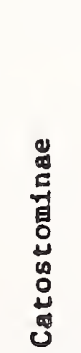 & 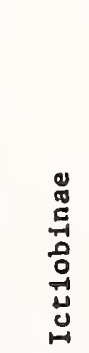 & 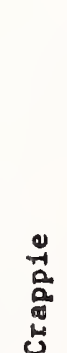 & 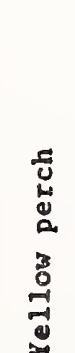 & 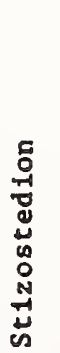 & 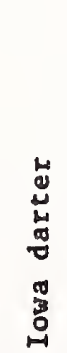 & . & 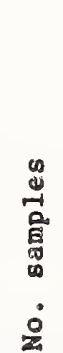 & 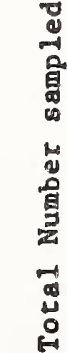 \\
\hline $\begin{array}{l}1979 \\
(5 / 31-7 / 9)\end{array}$ & & 37 & $\star 63$ & 22 & & 14 & 4 & 2 & 16.4 & 9 & 148 \\
\hline $\begin{array}{l}1980 \\
(5 / 9-6 / 28)\end{array}$ & & & & 4 & & & & & 0.8 & 5 & 4 \\
\hline $\begin{array}{l}1981 \\
(5 / 18-8 / 4)\end{array}$ & & 18 & 6 & 1 & 1 & 26 & 2 & & 13.5 & 4 & 54 \\
\hline $\begin{array}{l}1982 \\
(5 / 26-6 / 30)\end{array}$ & 30 & 14 & $\star 4$ & 463 & & & & & 170.3 & 3 & 511 \\
\hline
\end{tabular}

* 11 Blue Suckers (1979)

* 2 Blue Suckers (1982) 
Appendix Table 41. Number of paddlefish counted in electrofishing surveys of the Missouri River during 1979.

\begin{tabular}{lcccc}
\hline Section & $04 / 16-05 / 03$ & $05 / 09-05 / 24$ & $07 / 12-07 / 26$ & $10 / 03-10 / 26$ \\
\hline Nickels Ferry & 0 & 40 & 66 & 0 \\
Frazer & & 16 & 4 & 0 \\
Wolf Point & 0 & 19 & 4 & 0 \\
Chelsea & 0 & 4 & & 0 \\
Sprole & & 3 & 3 & 0 \\
Brockton & 15 & & & 0 \\
Culbertson & & & & 0 \\
\end{tabular}

$\overline{303 / 8.1}$ 
Appendix Table 42. Number of paddlefish counted in electrofishing surveys of the Missouri River during 1980 .

\begin{tabular}{lccccc}
\hline Section & $4 / 1-4 / 23$ & $5 / 21-5 / 30$ & $6 / 17-6 / 23$ & $7 / 7-7 / 23$ & $10 / 7-10 / 31$ \\
\cline { 2 - 6 } Nickels Ferry & 0 & 1 & 4 & 6 & 0 \\
Frazer & 28 & 7 & 1 & 1 & 0 \\
Wolf Point & 1 & 107 & 12 & 22 & 9 \\
Chelsea & 2 & 23 & 26 & 5 & 1 \\
Sprole & 2 & 8 & 14 & 0 & 0 \\
Brockton & 0 & 8 & 2 & 0 & 0 \\
Culbertson & 46 & 9 & 4 & 1 & 0
\end{tabular}

$303 / 8.1$ 


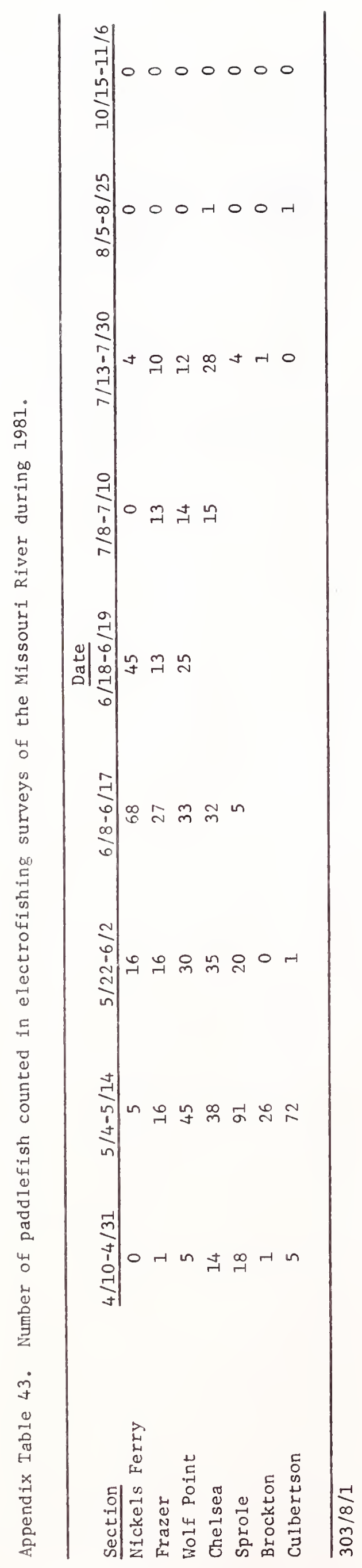


Appendix Table 44. Number of paddlefish counted in electrofishing surveys of the Missouri River during 1982.

\begin{tabular}{lcccc} 
Section & $4 / 13-4 / 30$ & $5 / 3-5 / 24$ & $6 / 7-6 / 10$ & $6 / 21$ \\
\cline { 2 - 5 } Nickels Ferry & 2 & 2 & 155 & 2.20 \\
Frazer & 0 & 4 & 31 \\
Wolf Point & 0 & 116 & \\
Chelsea & 0 & 46 & \\
Sprole & & 4 & \\
Brockton & 20 & 25 & \\
Culbertson & 1 & &
\end{tabular}

$303 / 8.1$ 
Appendix Table 45. Number of paddlefish counted in electrofishing surveys of the Missouri River during 1983.

\begin{tabular}{|c|c|c|c|}
\hline Section & $7 / 21$ & $8 / 2-8 / 4$ & $10 / 12-10 / 20$ \\
\hline Nicke1s Ferry & 29 & 2 & 0 \\
\hline Frazer & & 4 & al \\
\hline Wolf Point & & $1 \stackrel{a}{\prime}$ & $6-\frac{a}{}$ \\
\hline Chelsea & & & \\
\hline Sprole & & & 0 a $/$ \\
\hline Brockton & & & al \\
\hline Culbertson & & & $0-1$ \\
\hline
\end{tabular}

a/ Entire section not sampled.

$303 / 8.1$ 


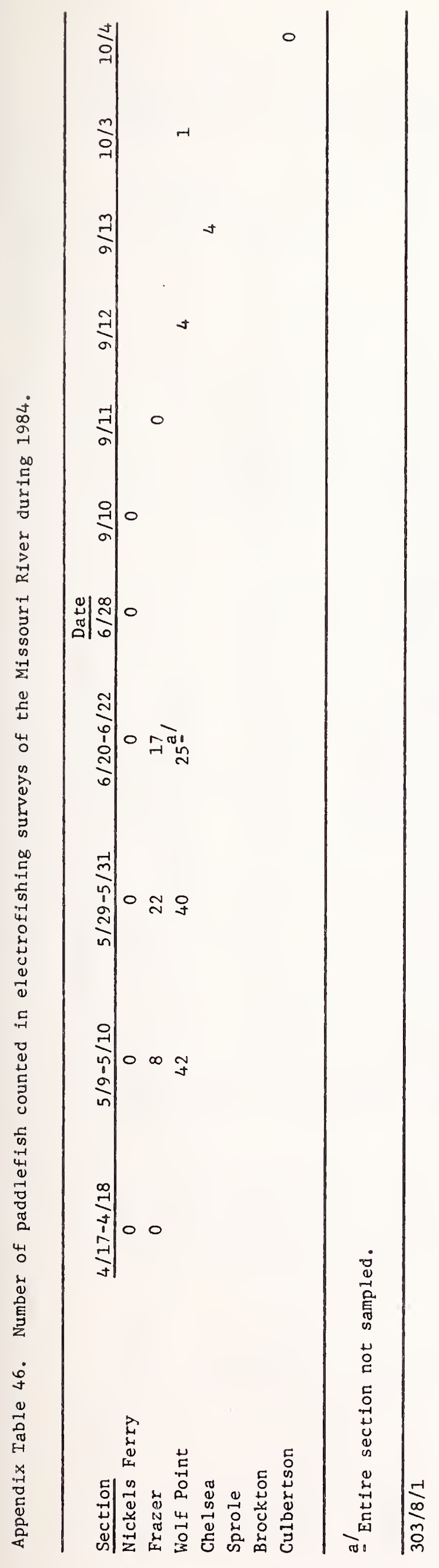


Appendix Table 47. Daily maximum and minimum temperatures $\left({ }^{\circ} \mathrm{F}\right)$ recorded in the rainbow trout spawning side channel (Duck Island) three miles downstream Fort Peck Dam, 1983.

\begin{tabular}{|c|c|c|c|c|c|}
\hline & & & & & \\
\hline Date & Max & Min & Date & Max & Min \\
\hline$\overline{\text { Apri1 }}$ & & & $\overline{\text { May } 1}$ & $\overline{54}$ & $\overline{44}$ \\
\hline & & & 2 & 53 & 45 \\
\hline & & & 3 & 52 & 46 \\
\hline & & & 4 & 53 & 46 \\
\hline & & & 5 & 52 & 46 \\
\hline & & & 6 & 52 & 46 \\
\hline & & & 7 & 54 & 45 \\
\hline & & & 8 & 54 & 46 \\
\hline & & & 9 & 48 & 45 \\
\hline & & & 10 & 45 & 43 \\
\hline & & & 11 & 44 & 42 \\
\hline 12 & 42 & 35 & 12 & 42 & 35 \\
\hline 13 & 43 & 35 & 13 & 50 & 40 \\
\hline 14 & 44 & 35 & 14 & 54 & 49 \\
\hline 15 & 44 & 37 & 15 & 50 & 44 \\
\hline 16 & 47 & 37 & 16 & 48 & 45 \\
\hline 17 & 49 & 40 & 17 & 48 & 45 \\
\hline 18 & 49 & 40 & 18 & 50 & 47 \\
\hline 19 & 49 & 40 & 19 & 52 & 47 \\
\hline 20 & 50 & 42 & 20 & 53 & 47 \\
\hline 21 & 49 & 44 & 21 & 52 & 47 \\
\hline 22 & 53 & 44 & 22 & 56 & 47 \\
\hline 23 & 52 & 44 & 23 & 55 & 49 \\
\hline 24 & 54 & 45 & 24 & 51 & 49 \\
\hline 25 & 50 & 44 & 25 & 56 & 48 \\
\hline 26 & 47 & 43 & 26 & 56 & 50 \\
\hline 27 & 48 & 42 & 27 & 58 & 50 \\
\hline 28 & 51 & 42 & 28 & 51 & 50 \\
\hline 29 & 50 & 42 & 29 & 55 & 49 \\
\hline 30 & 52 & 42 & 30 & 52 & 48 \\
\hline & & & 31 & 55 & 47 \\
\hline
\end{tabular}




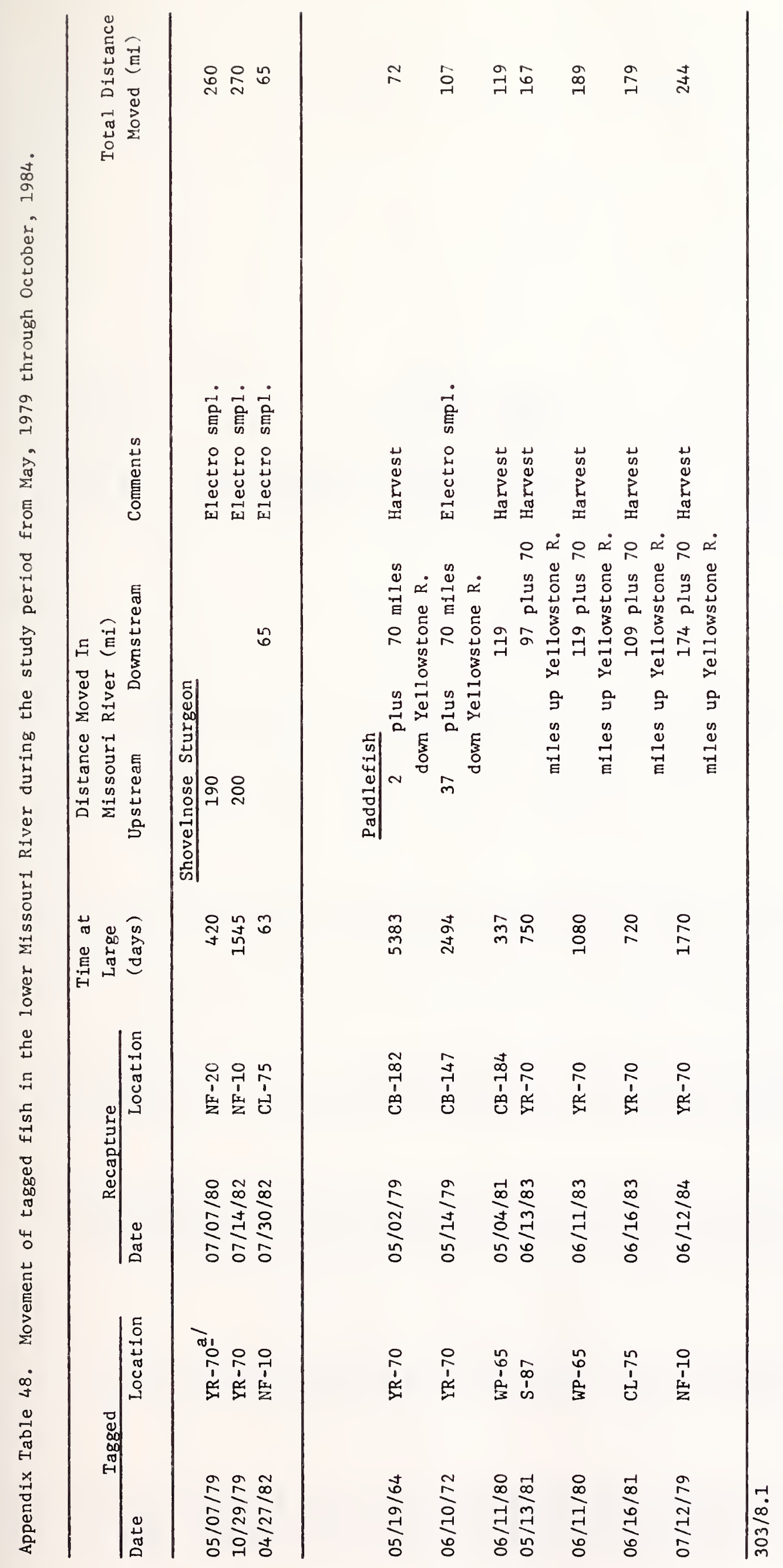


0 I 0000000000007000000000000000000

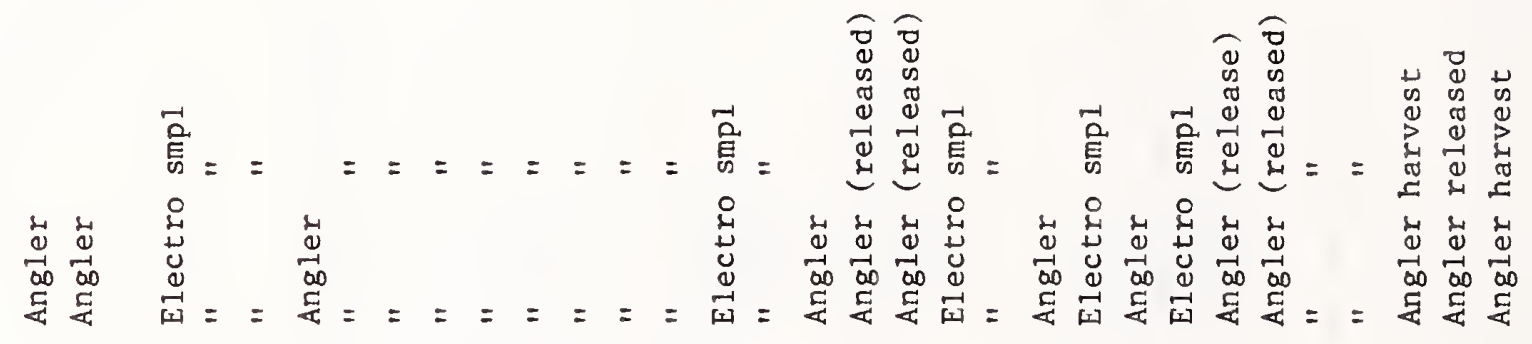

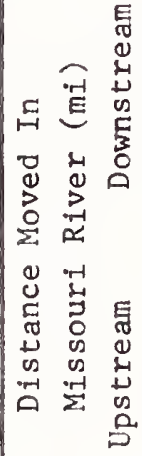

岾

ते

兽 总

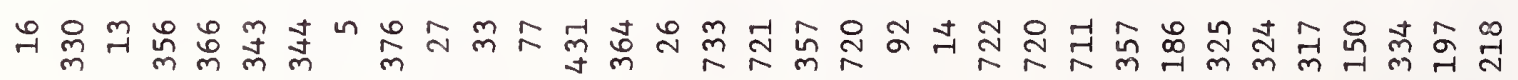

to 00000000000000000000000000000

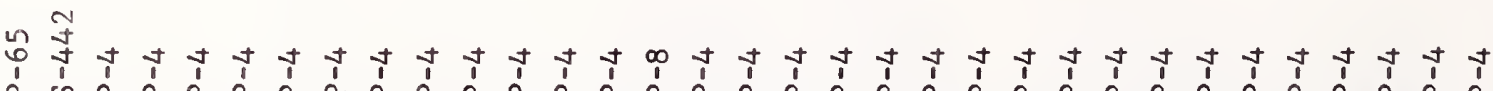

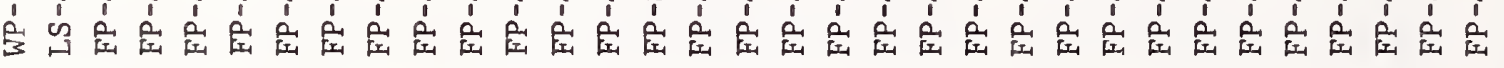

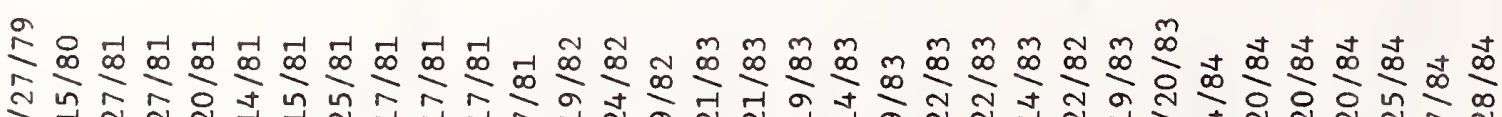

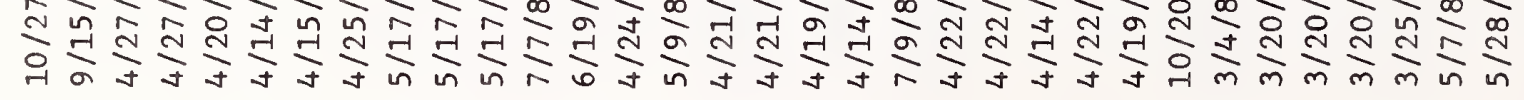

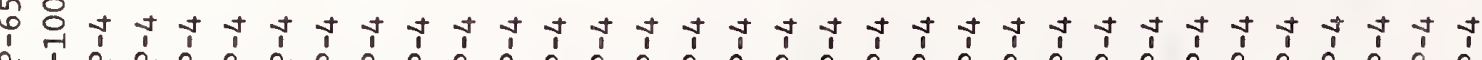

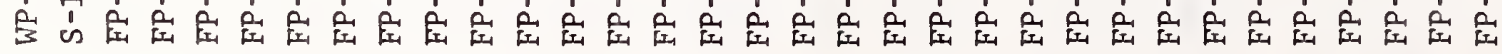

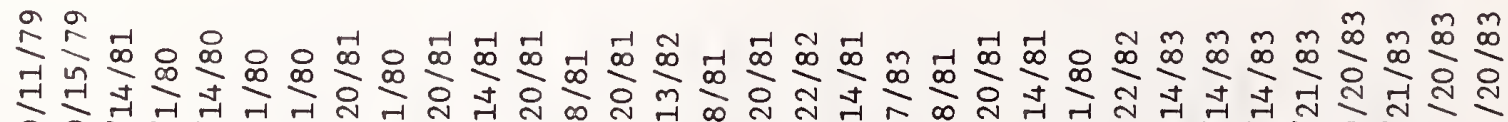

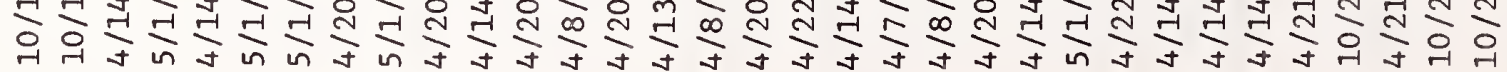




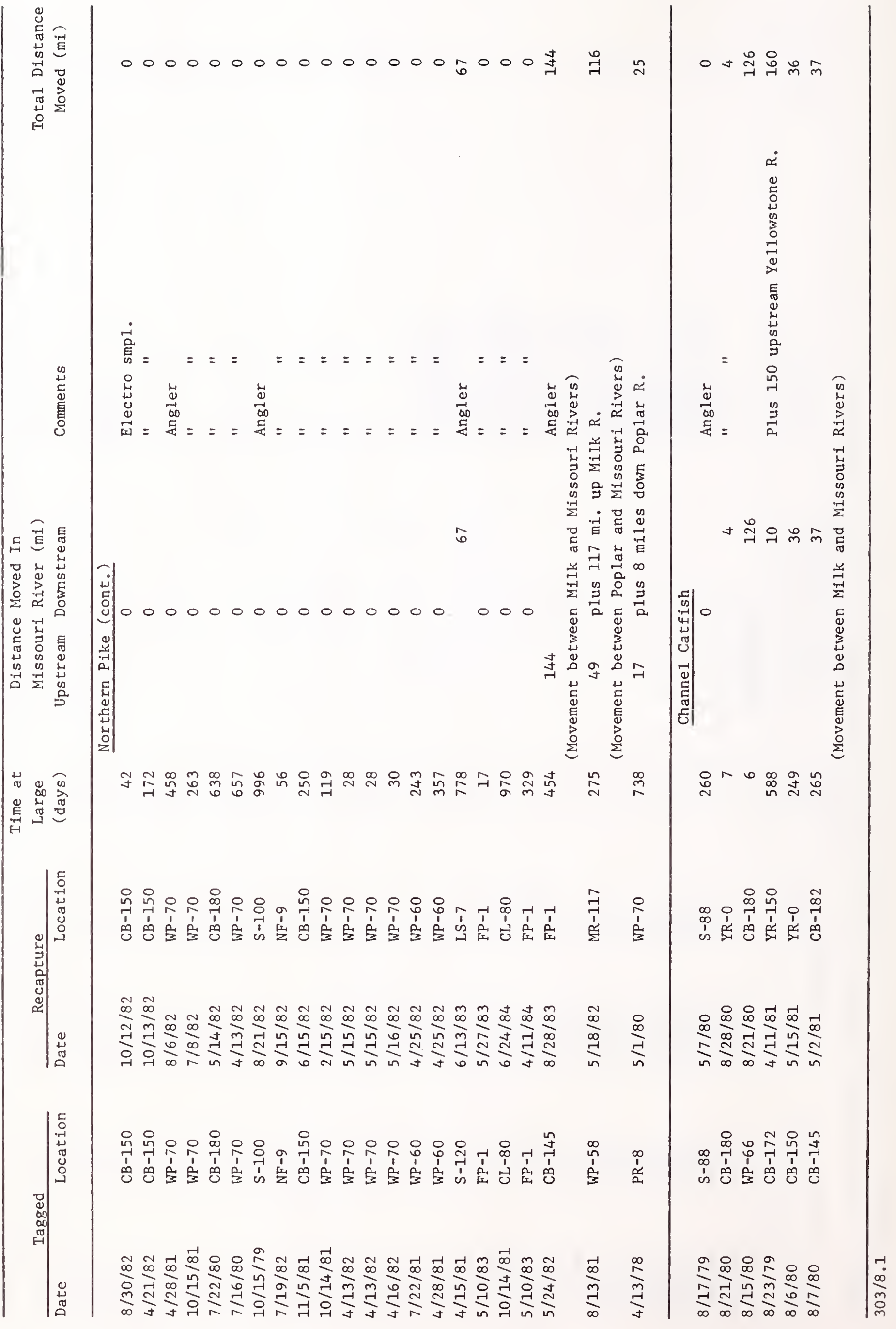




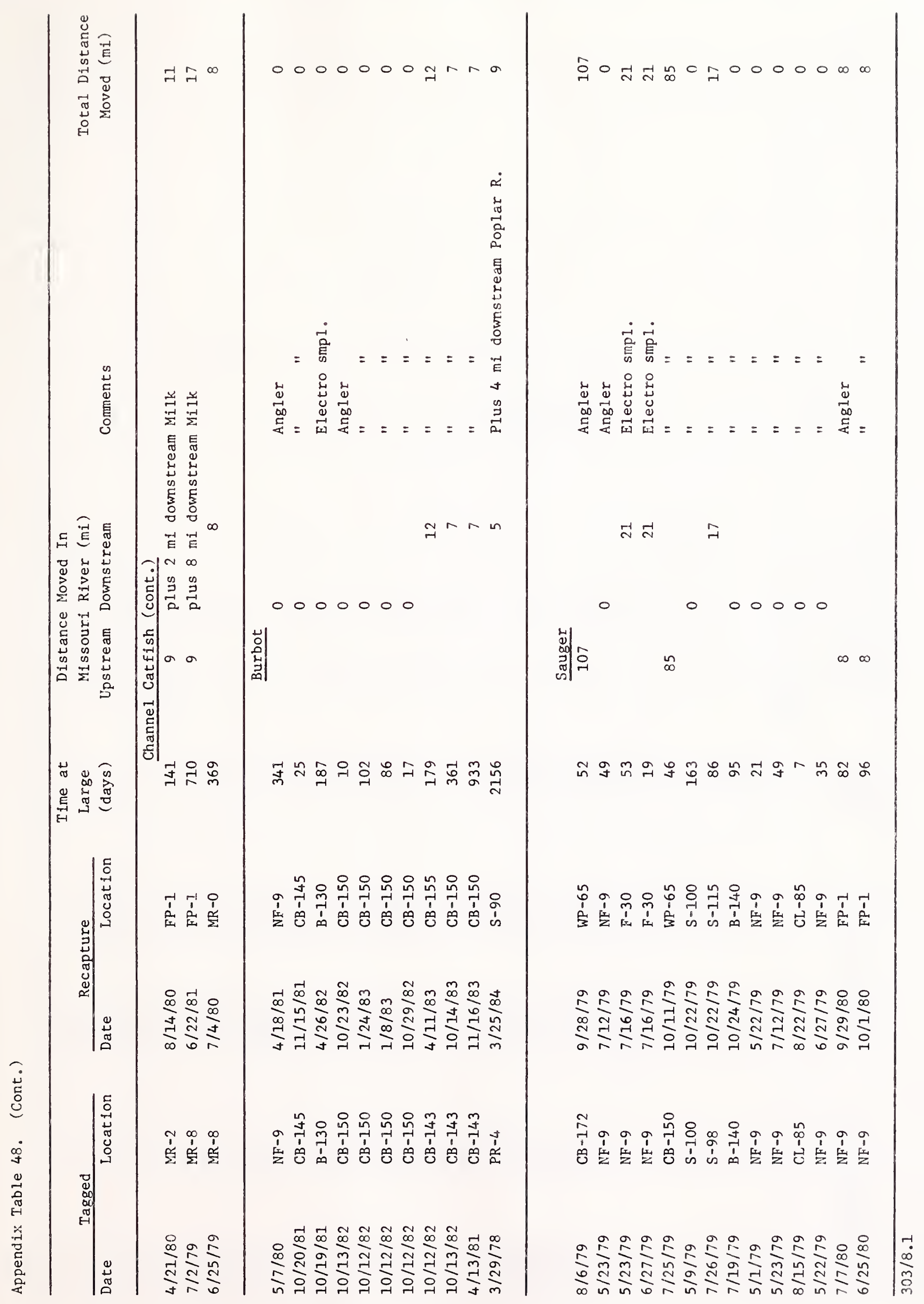




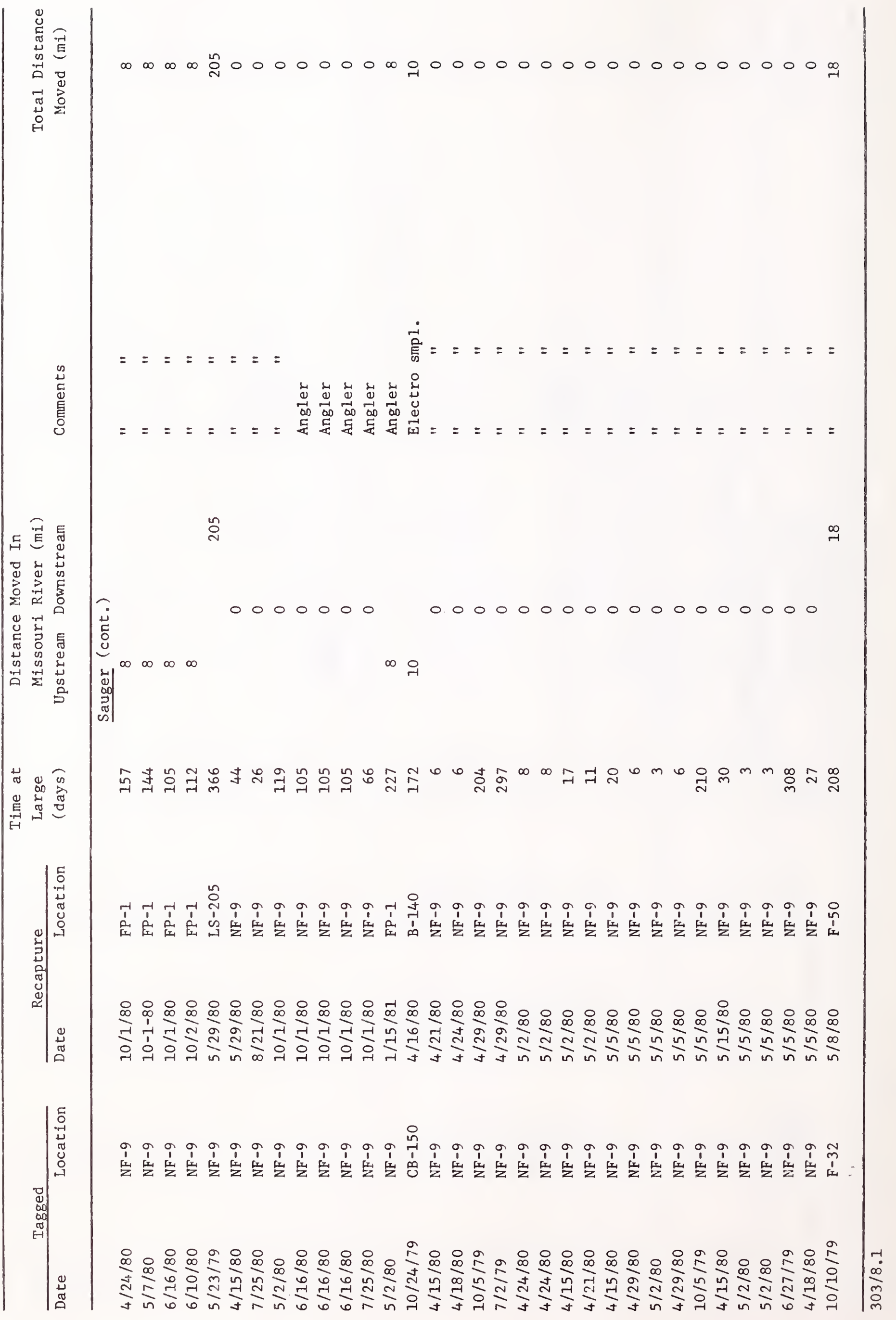




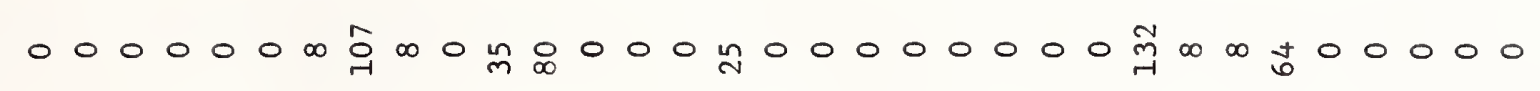

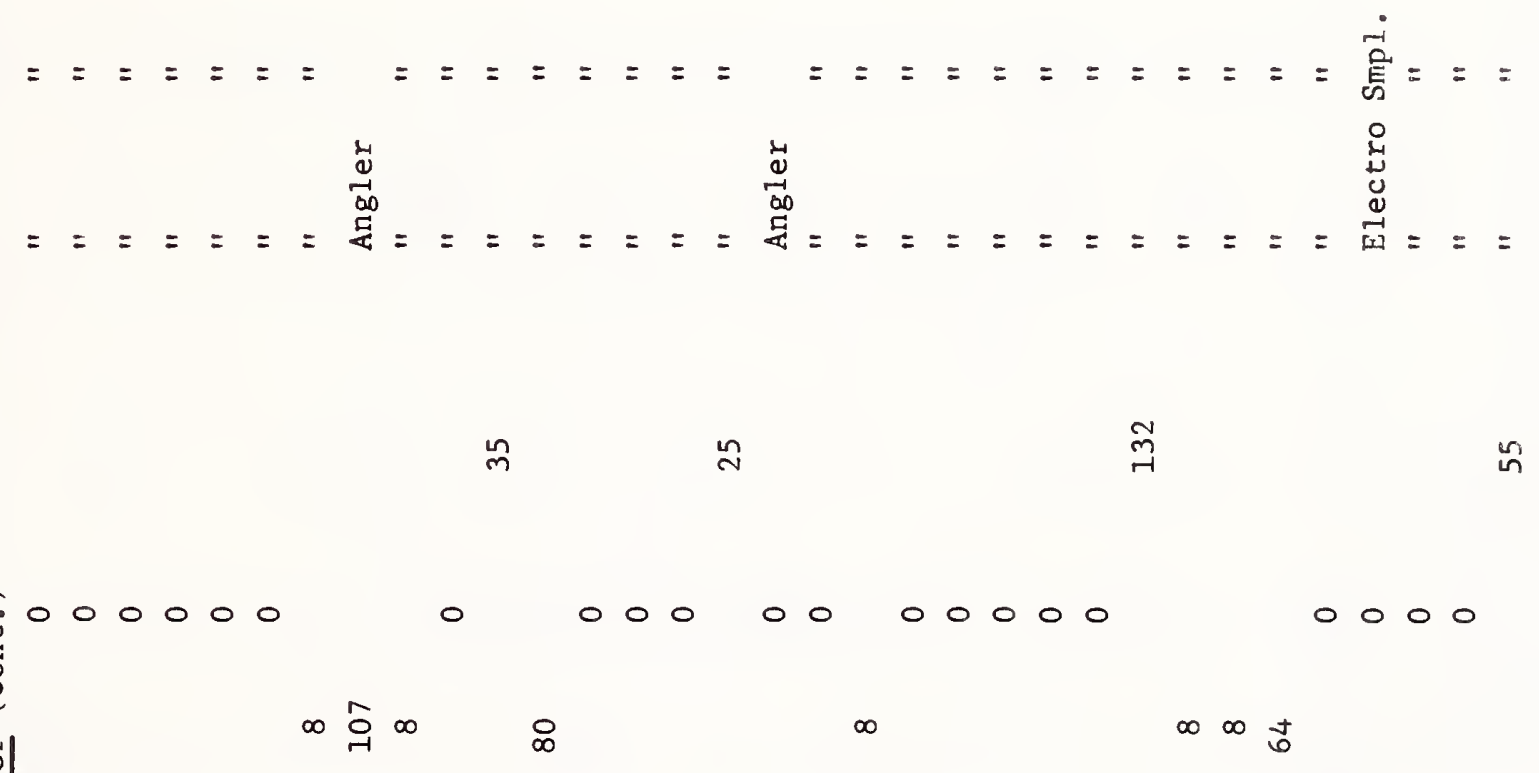

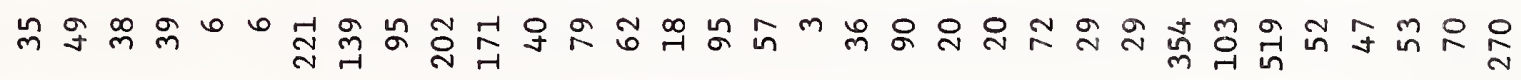

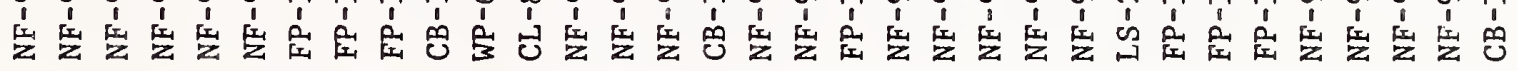

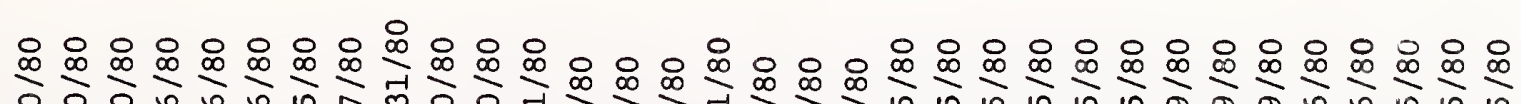
㭊

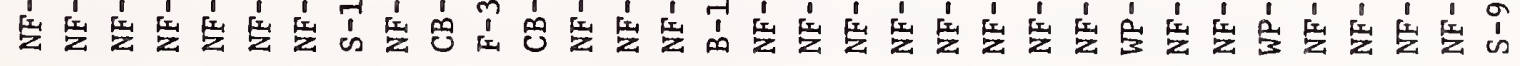

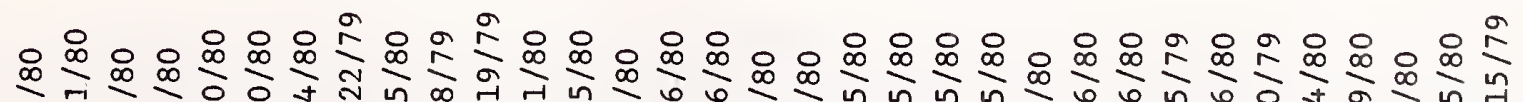

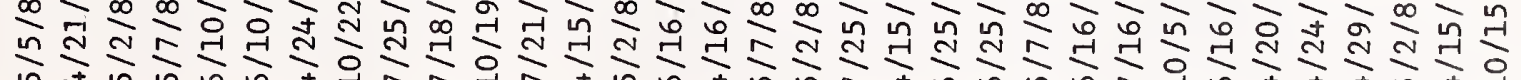




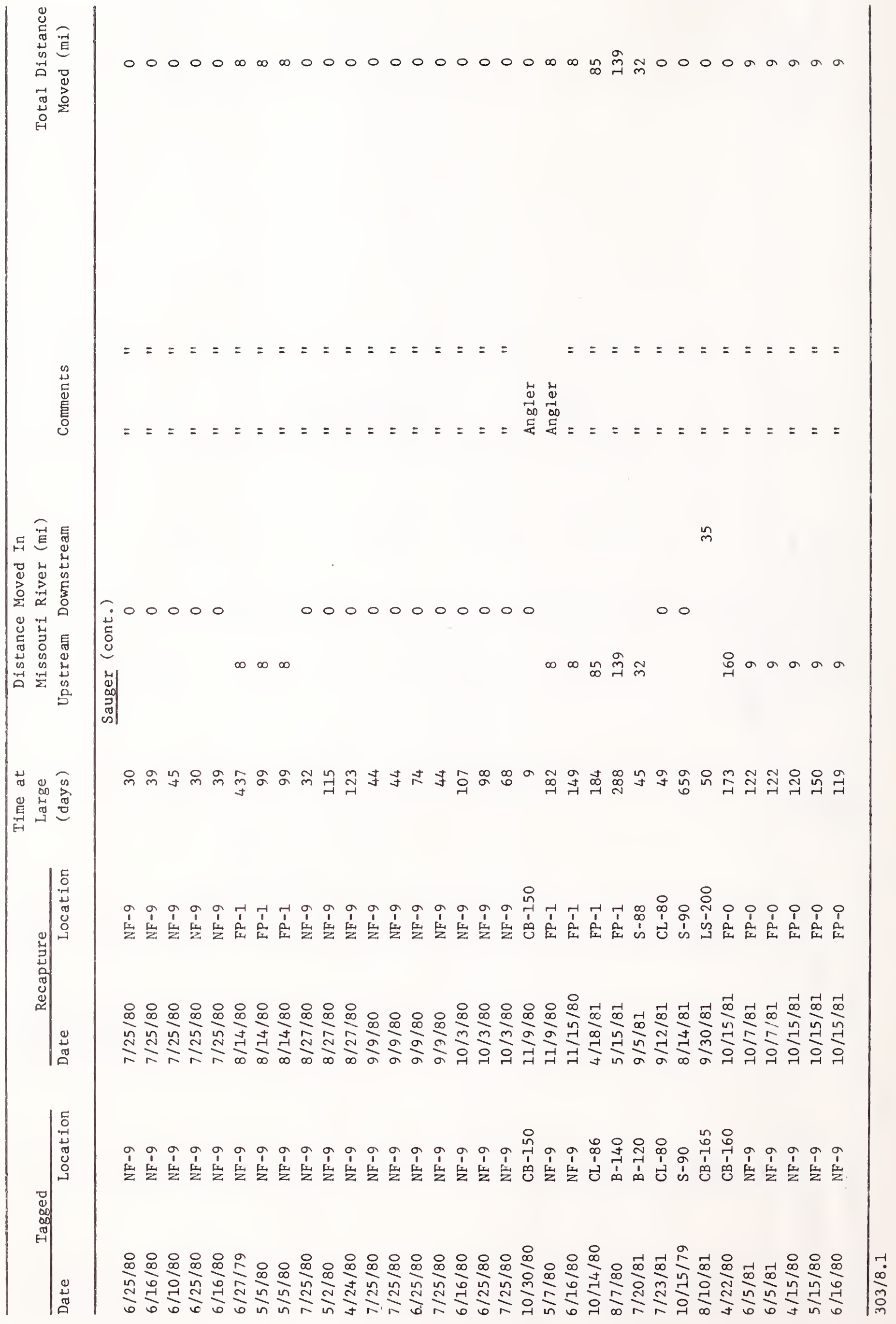




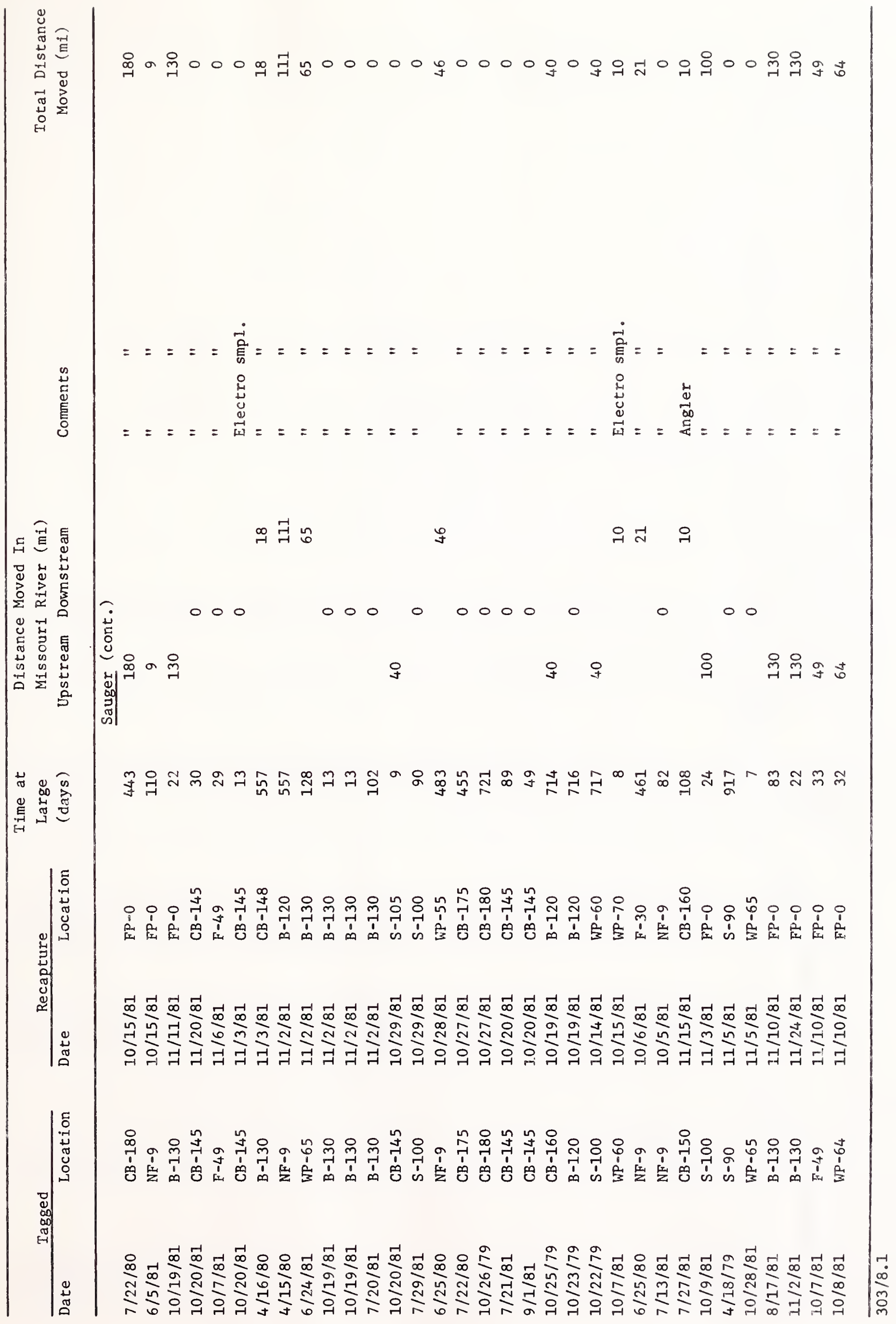




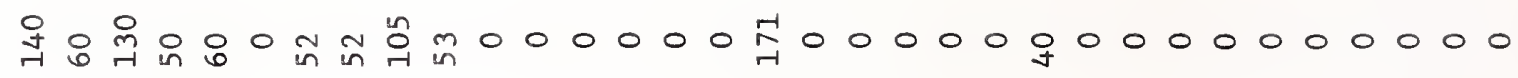

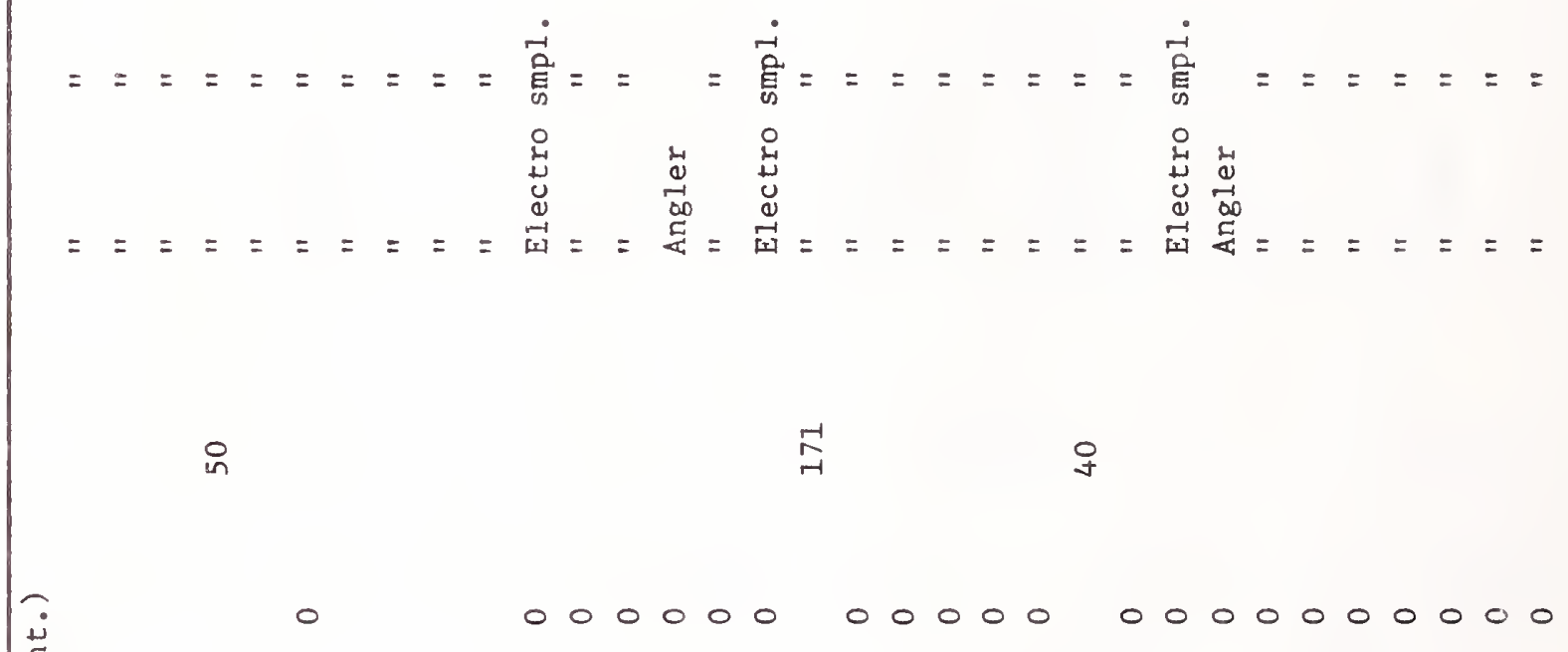

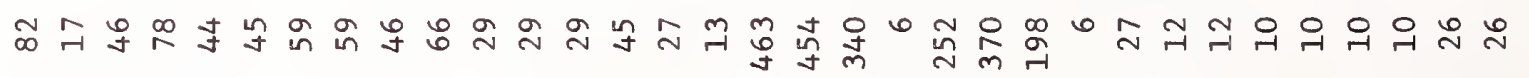

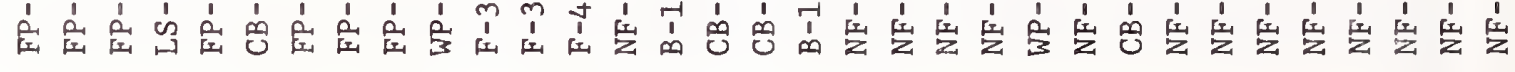

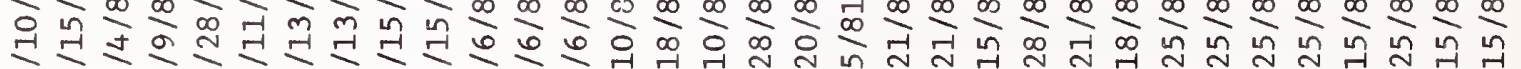

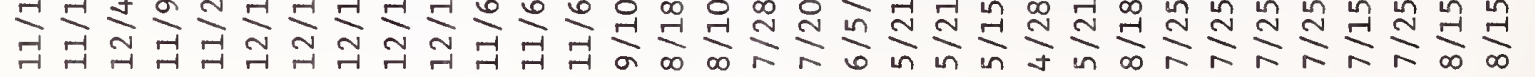

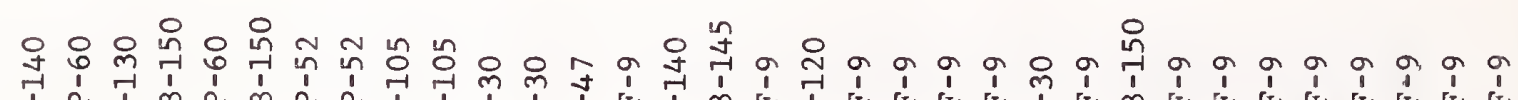

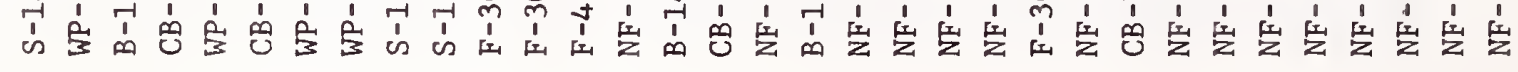




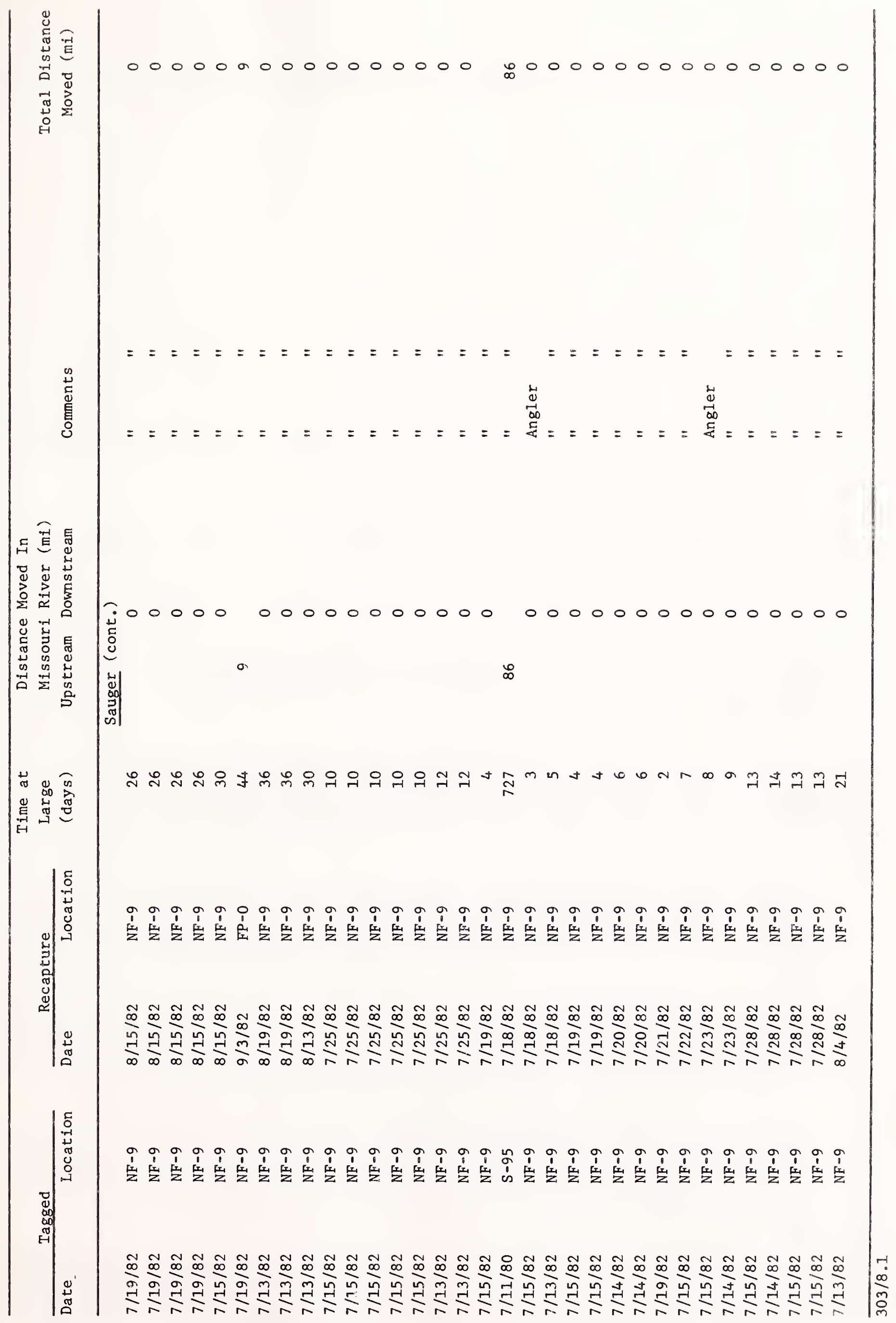




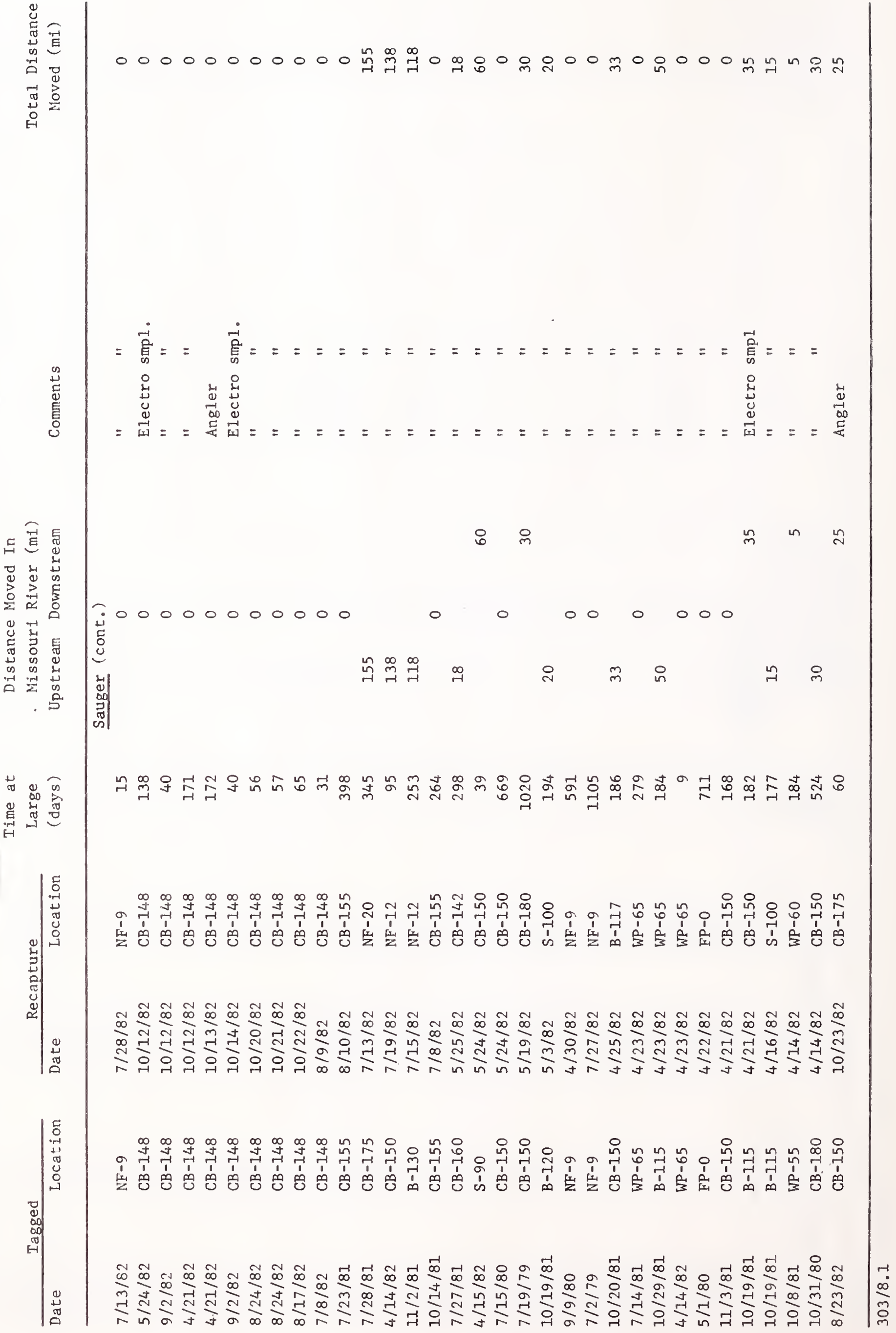




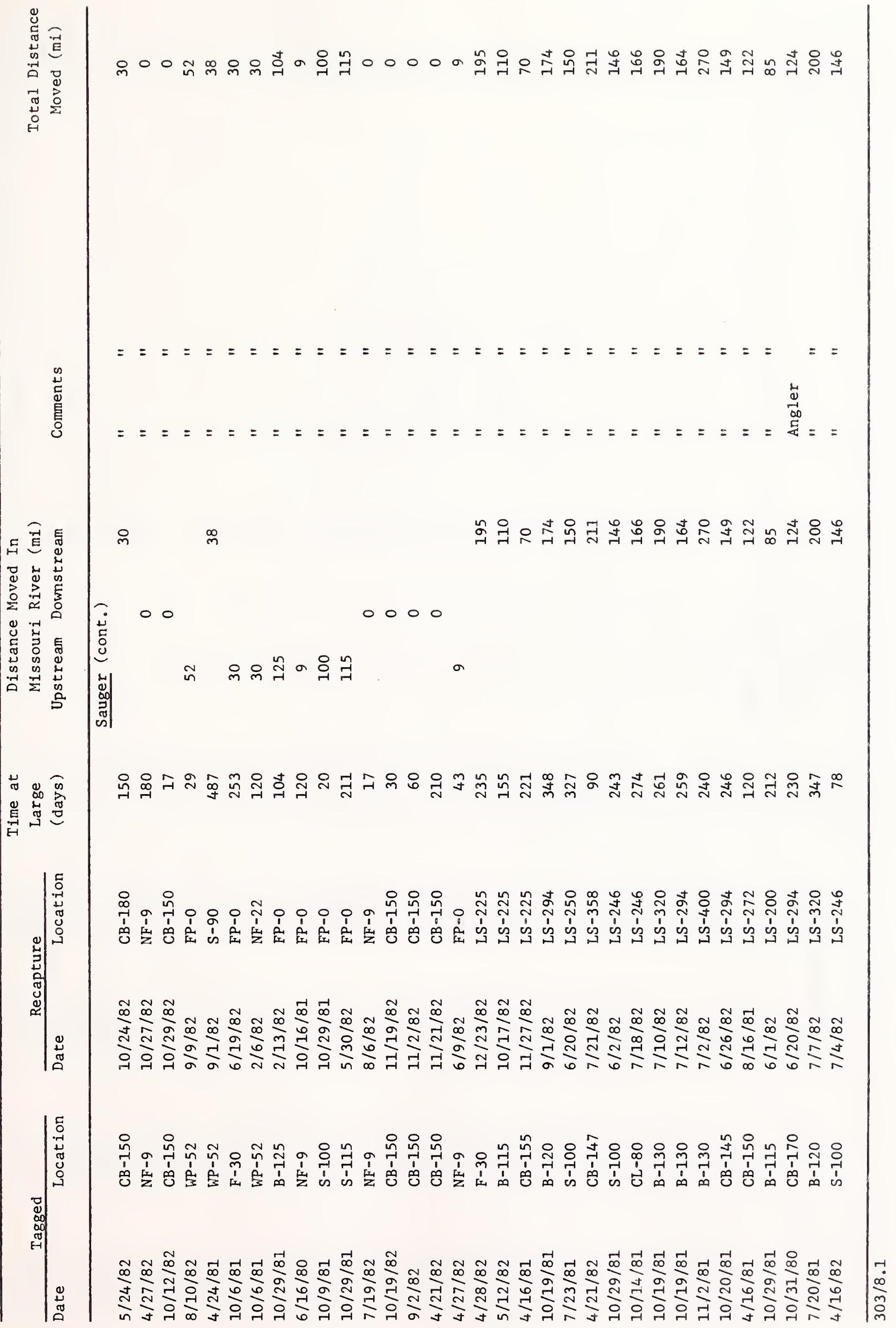




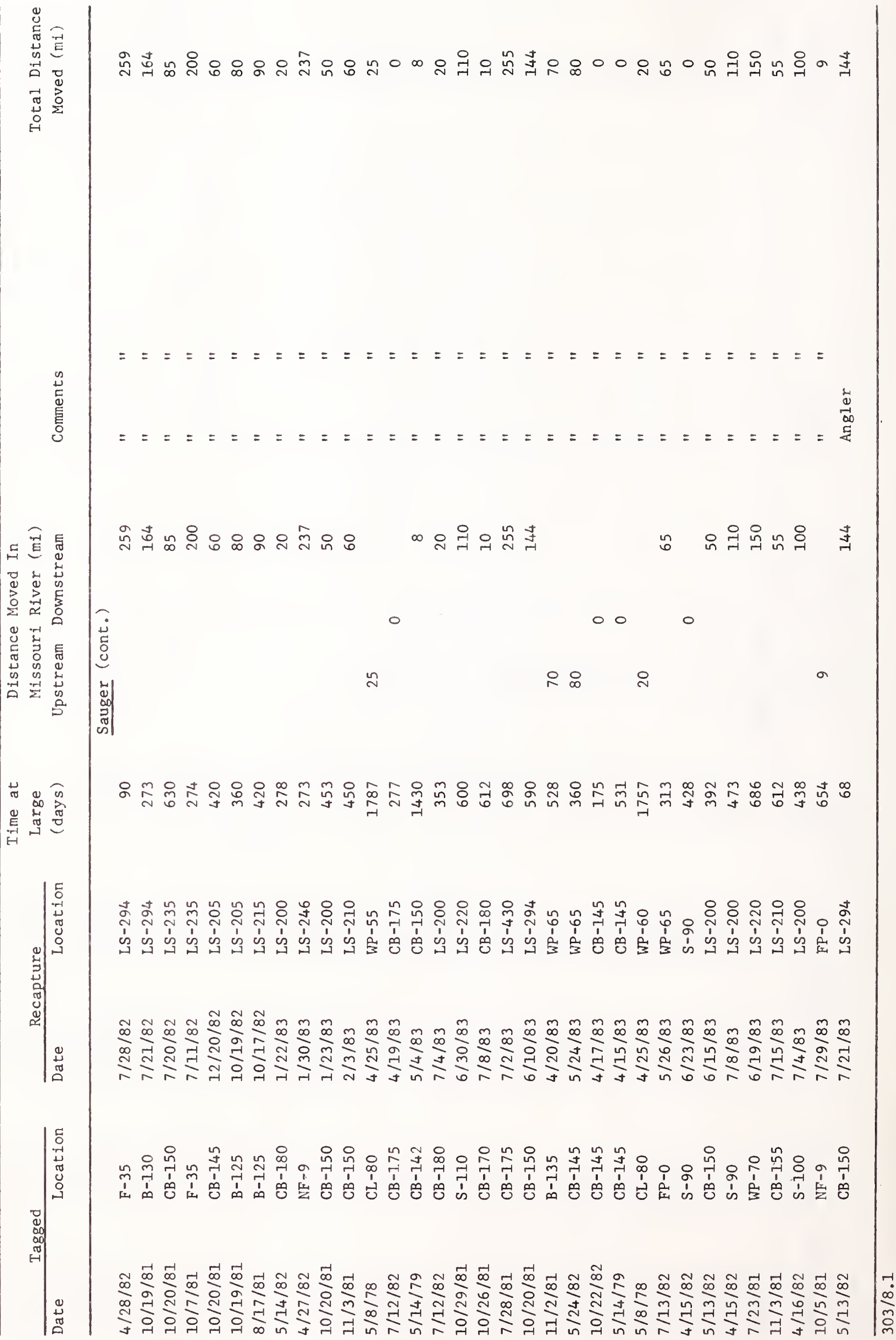




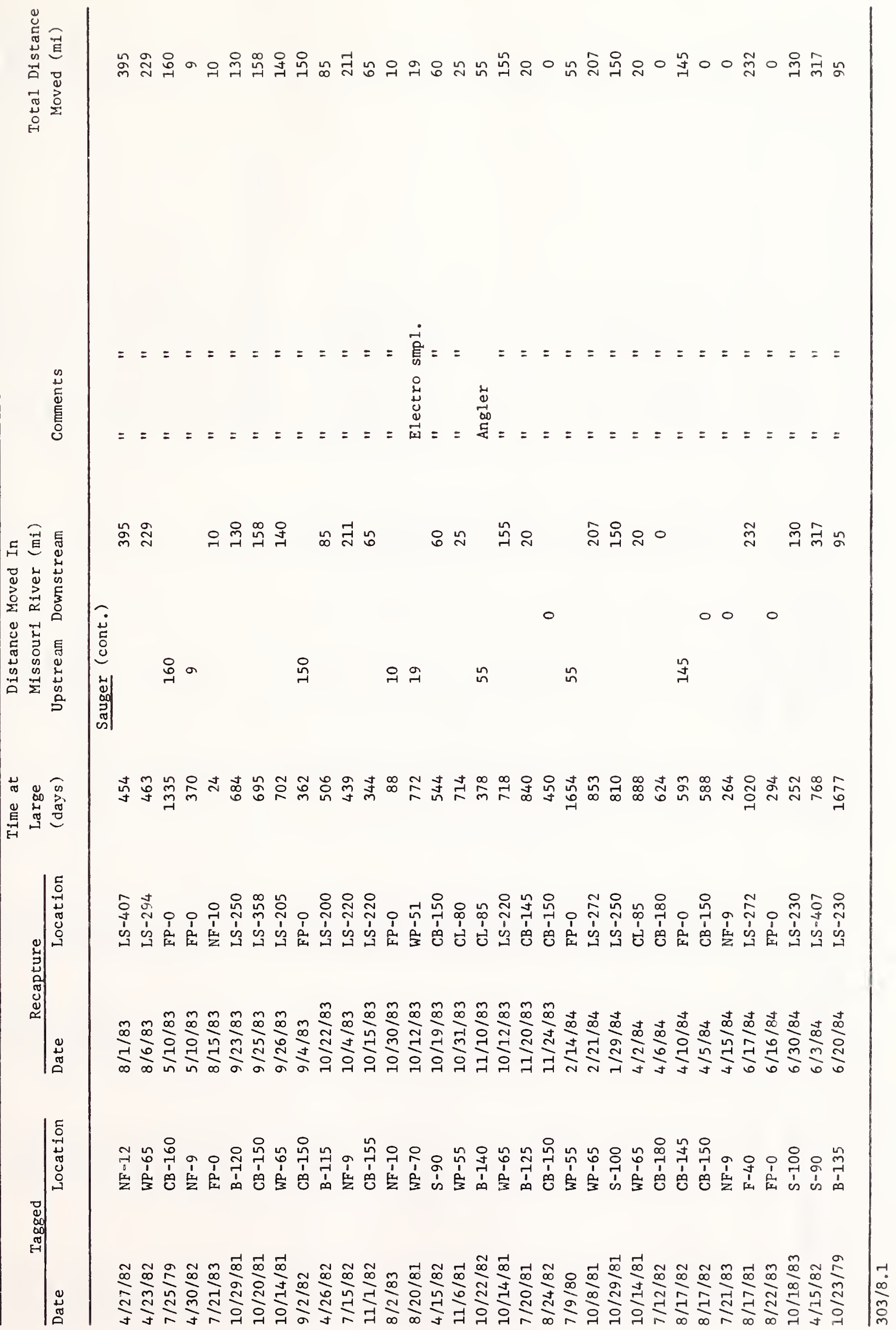




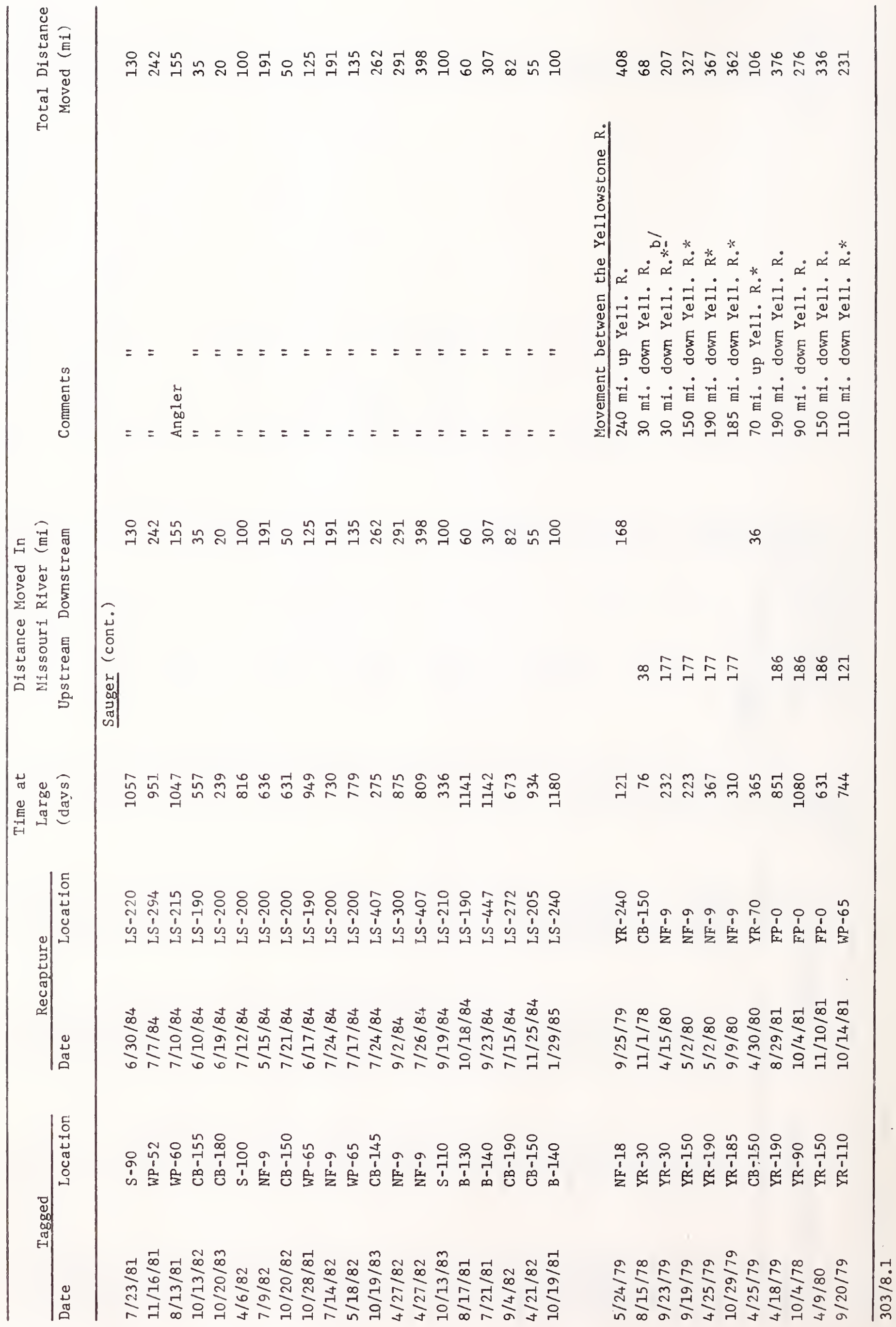




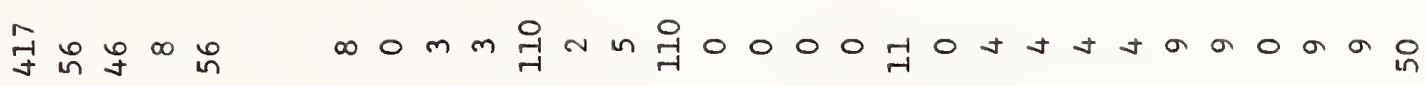

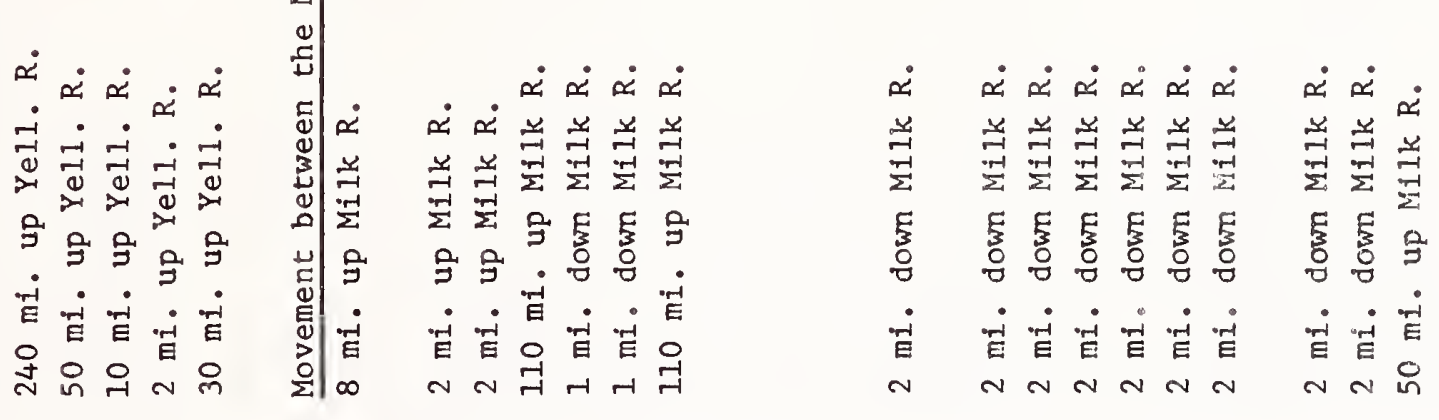

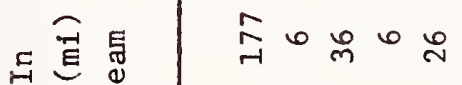

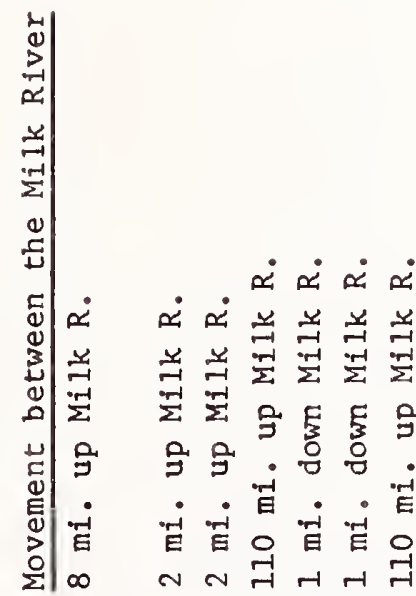

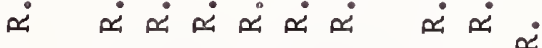

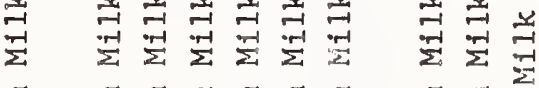

莺

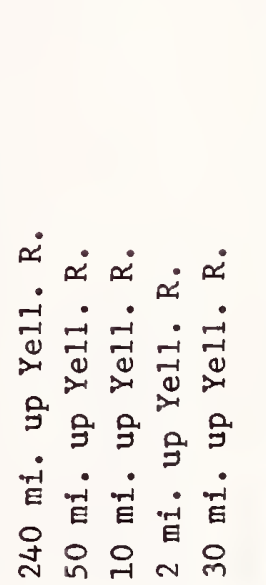

Aิ $\operatorname{mon}^{\circ}$

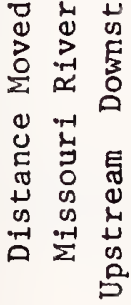

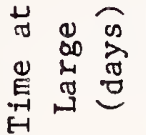

赵

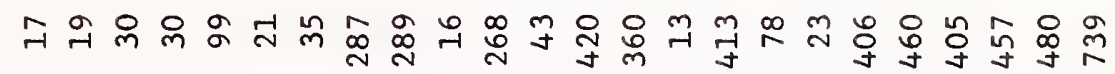

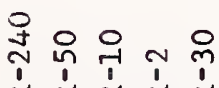

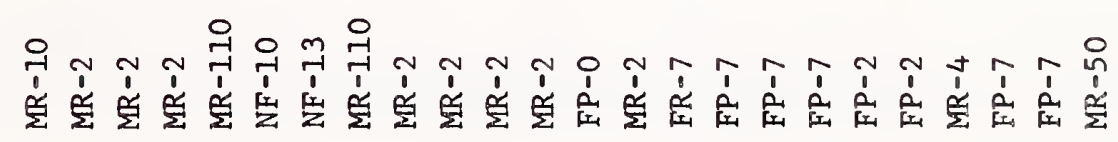
等出出出

(3)

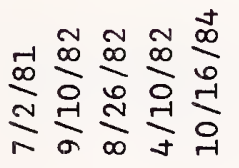

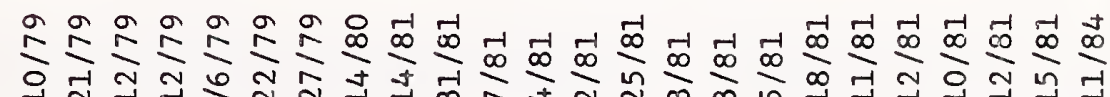

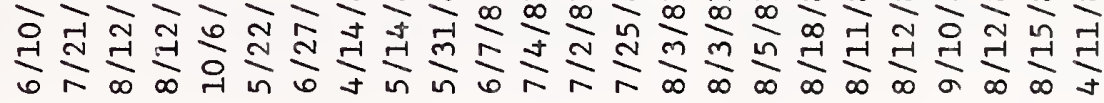

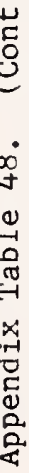

$\overbrace{\mathscr{D}}$

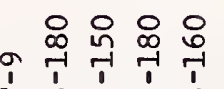

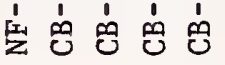

ㄴ.

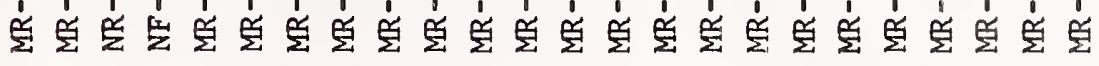

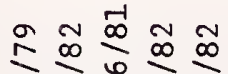

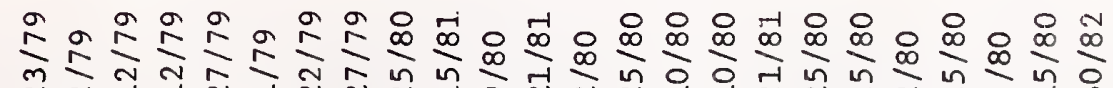

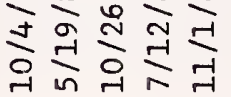

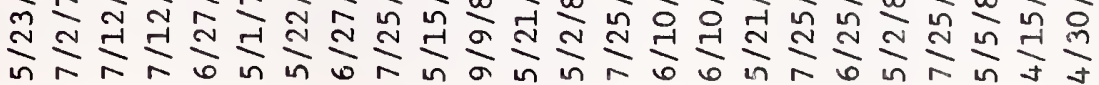




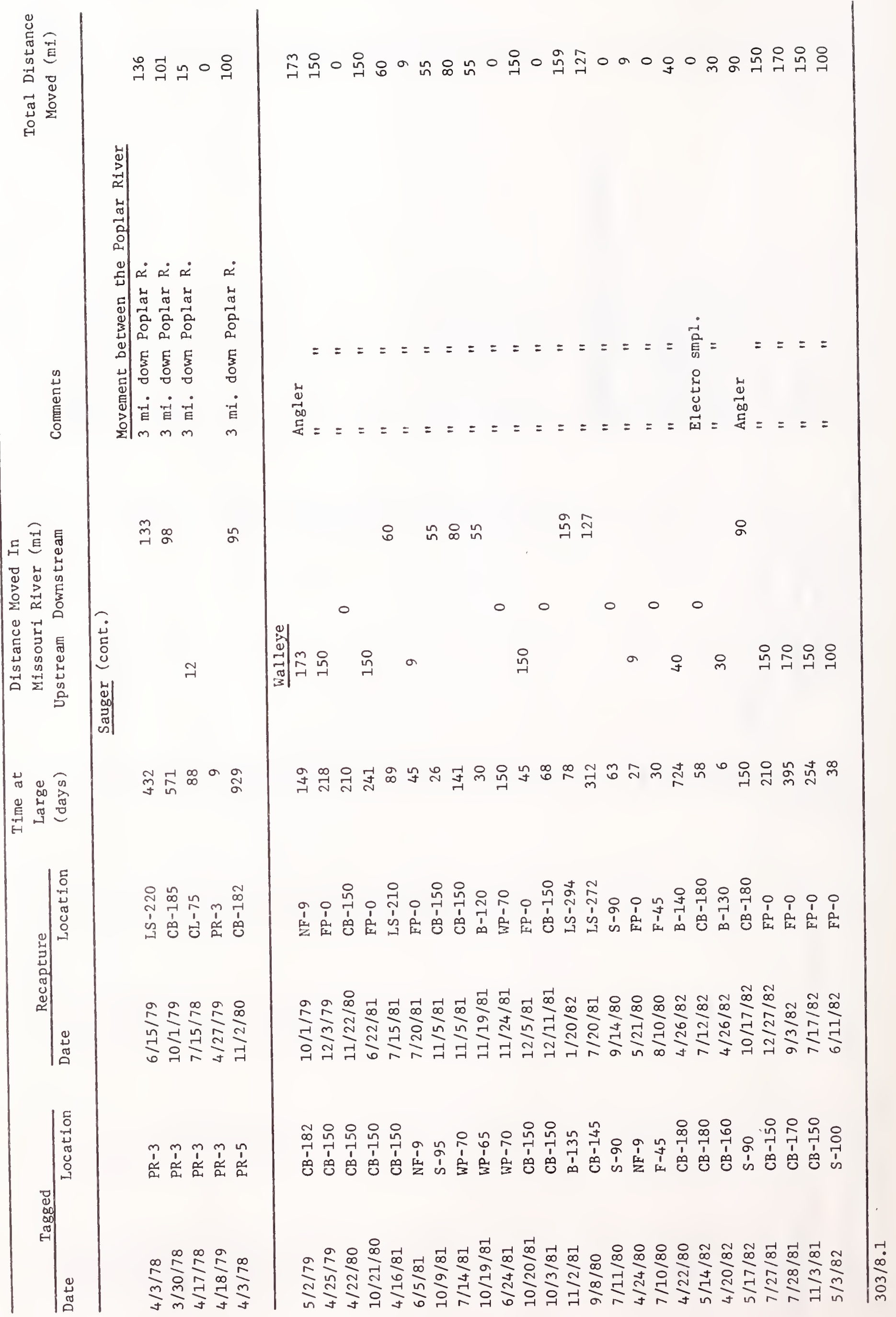




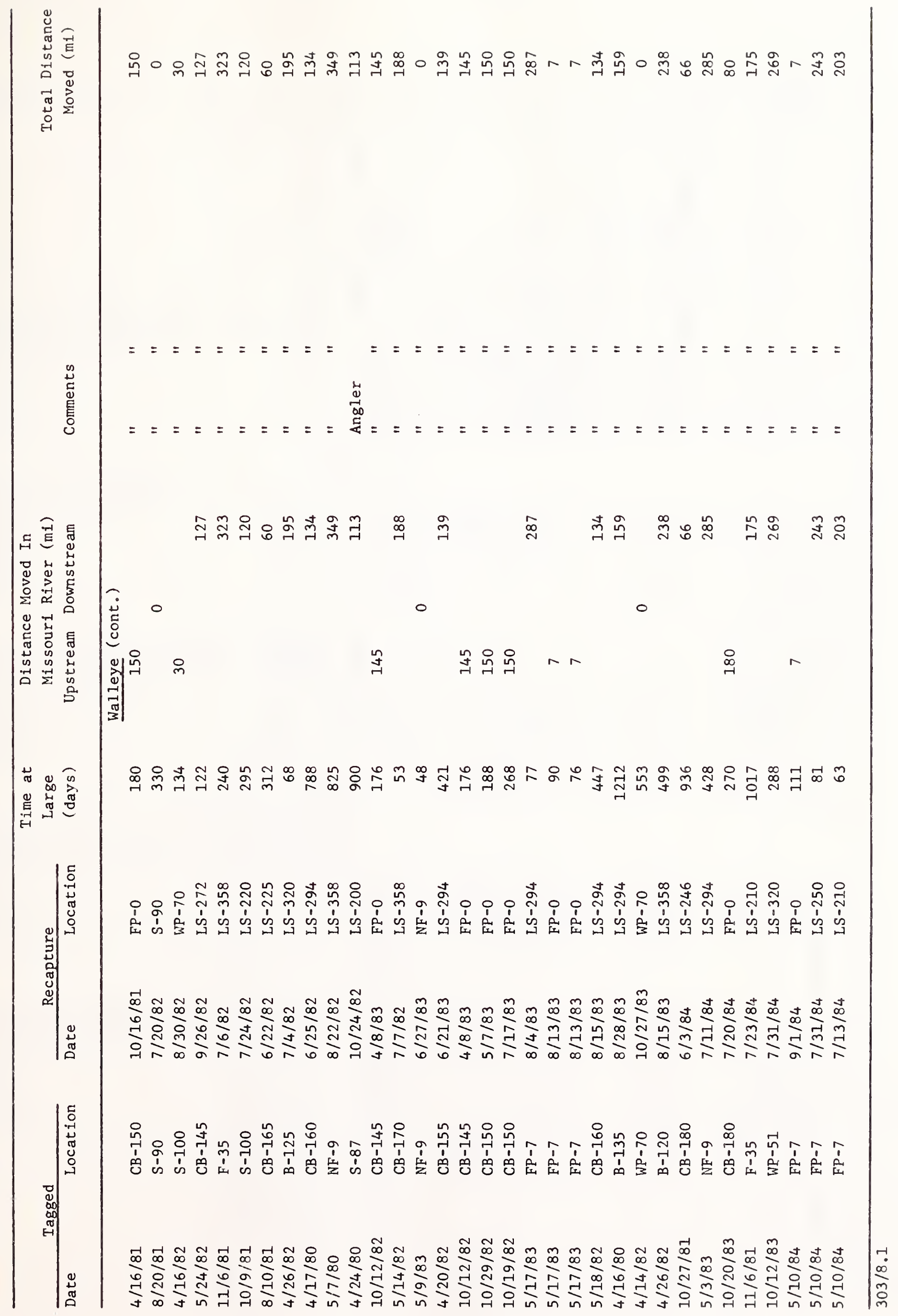




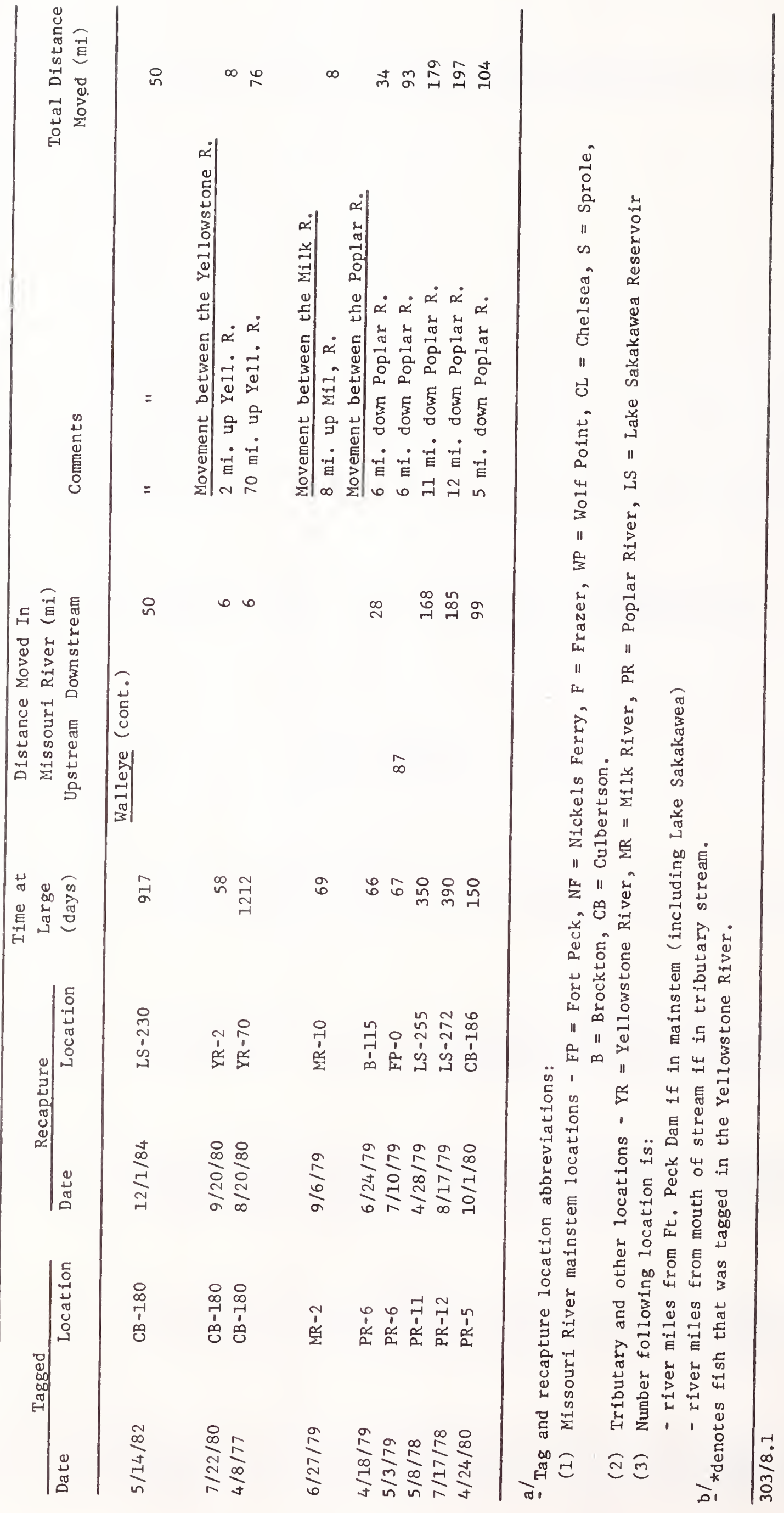


Appendix Table 49. Sport fish composition, number and size of fish sampled by electrofishing in the lower reaches of tributary streams to the lower Missouri River, 1979 through 1984.

\begin{tabular}{|c|c|c|c|c|c|}
\hline Species & $\begin{array}{l}\text { Number } \\
\text { Captured }\end{array}$ & $\begin{array}{l}\text { Average } \\
\text { Length } \\
\text { (inches) }\end{array}$ & $\begin{array}{l}\text { Length } \\
\text { Range }\end{array}$ & $\begin{array}{l}\text { Average } \\
\text { Weight } \\
\text { (pounds) }\end{array}$ & $\begin{array}{l}\text { Weight } \\
\text { Range }\end{array}$ \\
\hline Milk River $(89.9$ hrs.) & $1979-84$ & & & & \\
\hline Shovelnose sturgeon & 0 & -- & -- & -- & -- \\
\hline Northern pike & 21 & 24.1 & $4.6-33.0$ & 4.09 & $0.02-10.20$ \\
\hline Burbot & 9 & 20.0 & $11.5-40.2$ & 3.12 & $0.28-13.50$ \\
\hline Sauger & 918 & 13.5 & $8.4-22.5$ & 0.72 & $0.15-3.37$ \\
\hline Walleye & 38 & 13.4 & $8.6-23.5$ & 0.90 & $0.16-4.10$ \\
\hline L. Porcupine Creek (1.) & 0 hrs.) & & & & \\
\hline Shovelnose sturgeon & 0 & & & & \\
\hline Northern pike & 5 & 27.2 & $12.8-31.7$ & 5.88 & $0.49-8.00$ \\
\hline Burbot & 0 & & & & \\
\hline Sauger & 4 & 14.3 & $11.0-19.9$ & 0.84 & $0.34-1.87$ \\
\hline Walleye & 1 & 5.6 & & 0.05 & \\
\hline
\end{tabular}

\begin{tabular}{lc} 
Redwater River (4.5 hrs) & $1978-80$ \\
\hline Shovelnose sturgeon & 0
\end{tabular}

$\begin{array}{lrrrrr}\text { Northern pike } & 14 & 18.9 & 10.9-23.8 & 1.80 & 0.35-2.71 \\ \text { Burbot } & 9 & 16.7 & 14.6-20.0 & 1.00 & 0.73-1.75 \\ \text { Sauger } & 13 & 13.0 & 9.3-19.9 & 0.73 & 0.18-1.38 \\ \text { Walleye } & 8 & 14.0 & 8.0-17.6 & 1.05 & 0.18-1.99\end{array}$

\begin{tabular}{lc} 
Poplar River $(46.0$ hrs.) & $1979-82$ \\
\hline Shovelnose sturgeon & 0
\end{tabular}

$\begin{array}{lrrrrr}\text { Shovelnose sturgeon } & & & & \\ \text { Northern pike } & 6 & 18.2 & 7.6-31.7 & 1.76 & 0.10-7.60 \\ \text { Burbot } & 63 & 26.5 & 19.8-42.0 & 5.85 & 1.97-16.50 \\ \text { Sauger } & 86 & 13.4 & 9.8-17.9 & 0.63 & 0.20-1.49 \\ \text { Walleye } & 12.9 & 4.8-26.9 & 1.08 & 0.04-8.35\end{array}$

Big Muddy Creek (12.8 hrs.) 1978

\begin{tabular}{|c|c|c|c|c|c|}
\hline Shovelnose sturgeon & 1 & 27.5 & & 2.29 & \\
\hline Northern pike & 30 & 24.0 & $14.6-31.1$ & 3.50 & $0.71-7.10$ \\
\hline Burbot & 8 & 12.5 & $9.0-20.5$ & 0.48 & $0.19-2.04$ \\
\hline Sauger & 5 & 12.5 & $9.9-17.7$ & 0.67 & $0.26-1.26$ \\
\hline Walleye & 8 & 12.6 & $2.7-19.6$ & 1.27 & $0.01-2.93$ \\
\hline
\end{tabular}

$303 / 8.1$ 
Appendix Table 50. Species composition, number and size of fish sampled by experimental gill nets in the Milk River - Glasgow study section, 1984. (A total of four overnight sets)

\begin{tabular}{|c|c|c|c|c|c|}
\hline Irish Species & $\begin{array}{l}\text { Number } \\
\text { Captured }\end{array}$ & $\begin{array}{l}\text { Average } \\
\text { Length } \\
\text { (inches) }\end{array}$ & $\begin{array}{l}\text { Length } \\
\text { Range }\end{array}$ & $\begin{array}{l}\text { Average } \\
\text { Weight } \\
\text { (pounds) }\end{array}$ & $\begin{array}{l}\text { Weight } \\
\text { Range }\end{array}$ \\
\hline Goldeye & 102 & 9.7 & $(6.0-13.8)$ & 0.35 & $(0.08-0.91)$ \\
\hline Northern pike & 3 & 28.6 & $(22.0-32.5)$ & 4.25 & $(3.20-5.20)$ \\
\hline River carpsucker & 11 & 15.6 & $(14.0-17.5)$ & 1.90 & $(1.50-2.70)$ \\
\hline Smallmouth buffalo & 2 & 19.8 & $(18.7-20.9)$ & 3.80 & $(3.20-4.48)$ \\
\hline Shorthead redhorse & 15 & 12.9 & $(10.5-14.5)$ & 0.85 & $(0.48-1.08)$ \\
\hline Channel catfish & 8 & 17.8 & $(14.2-20.0)$ & 1.64 & $(0.78-2.22)$ \\
\hline Sauger & 1 & 13.2 & $\ldots$ & 0.79 & $\ldots$ \\
\hline Walleye & 1 & 18.1 & --- & 1.70 & $-\cdots$ \\
\hline
\end{tabular}

$303 / 8.1$ 
Appendix Table 51. Species composition, number and size of fish sampled by experimental gill nets in the Milk River - Nashua study section, 1984. (A total of four overnight sets)

\begin{tabular}{|c|c|c|c|c|c|}
\hline Hish Species & $\begin{array}{c}\text { Number } \\
\text { Captured }\end{array}$ & $\begin{array}{l}\text { Average } \\
\text { Length } \\
\text { (inches) }\end{array}$ & $\begin{array}{l}\text { Length } \\
\text { Range }\end{array}$ & $\begin{array}{l}\text { Average } \\
\text { Weight } \\
\text { (pounds) }\end{array}$ & $\begin{array}{l}\text { Weight } \\
\text { Range }\end{array}$ \\
\hline Goldeye & 195 & 11.8 & $(7 \cdot 3-15 \cdot 3)$ & 0.56 & $(0.16-1.18)$ \\
\hline Northern pike & 9 & 18.6 & $(12.6-29.1)$ & 1.86 & $(0.48-5.00)$ \\
\hline Carp & 2 & 18.3 & $(16.1-20.1)$ & 2.50 & $(2.05-3.00)$ \\
\hline River carpsucker & 2 & 15.5 & $(15.3-15.7)$ & 1.70 & $(1.68-1.75)$ \\
\hline Smallmouth buffalo & 1 & 22.4 & --- & ---- & $-\cdots$ \\
\hline Shorthead redhorse & 13 & 13.1 & $(9.5-17.5)$ & 0.95 & $(0.26-2.05)$ \\
\hline White sucker & 1 & 12.6 & ---- & 1.00 & $-\ldots$ \\
\hline Channel catfish & 12 & 16.0 & $(7.5-19.3)$ & 1.80 & $(0.35-2.20)$ \\
\hline Sauger & 8 & 12.5 & $(12 \cdot 2-17 \cdot 3)$ & 0.65 & $(0.50-1.25)$ \\
\hline Wa1leye & 2 & 19.7 & $(13.4-26.0)$ & 4.40 & $(0.78-8.00)$ \\
\hline Freshwater drum & 1 & 4.5 & ---- & 0.06 & $---\infty$ \\
\hline
\end{tabular}

$303 / 8.1$ 
Appendix Table 52. Species composition, number and size of fish sampled by experimental gill nets in the Milk River - confluence study section, 1980 and 1984. (A total of eight overnight sets)

\begin{tabular}{lrcccc}
\hline Eish Species & $\begin{array}{c}\text { Number } \\
\text { Captured }\end{array}$ & $\begin{array}{c}\text { Average } \\
\text { Length } \\
\text { (inches) }\end{array}$ & $\begin{array}{c}\text { Length } \\
\text { Range }\end{array}$ & $\begin{array}{c}\text { Average } \\
\text { Weight } \\
\text { (pounds) }\end{array}$ & $\begin{array}{l}\text { Weight } \\
\text { Range }\end{array}$ \\
\hline Shovelnose sturgeon & 4 & 26.8 & $(24.7-30.0)$ & 2.21 & $(1.85-2.80)$ \\
Goldeye & 605 & 12.2 & $(8.4-15.0)$ & 0.60 & $(0.22-1.19)$ \\
Northern pike & 3 & 24.3 & $(18.0-29.1)$ & 3.24 & $(1.10-6.50)$ \\
Carp & 3 & 17.3 & $(16.9-17.7)$ & 2.30 & $(2.10-2.50)$ \\
Blue sucker & 4 & 25.4 & $(25.0-25.6)$ & 4.77 & $(4.45-5.00)$ \\
River carpsucker & 21 & 15.9 & $(13.5-17.7)$ & 1.73 & $(1.22-2.55)$ \\
Smallmouth buffalo & 5 & 1 & & -- not measured -- \\
Bigmouth buffalo & 27 & 15.0 & $(12.0-19.6)$ & 1.50 & $(0.60-3.11)$ \\
Shorthead redhorse & 7 & 18.5 & $(7.9-23.6)$ & 2.50 & $(0.15-4.80)$ \\
Channel catfish & 30 & 13.4 & $(10.1-19.7)$ & 0.66 & $(0.26-2.22)$ \\
Sauger & 5 & 15.4 & $(11.5-17.9)$ & 1.33 & $(0.36-2.10)$ \\
Walleye & & & & &
\end{tabular}

$303 / 8.1$ 
Appendix Table 53. Species composition, numbers and size of fish sampled by experimental gill nets in Little Porcupine Creek near its confluence, 1979-80. (A total of two overnight sets).

\begin{tabular}{lcclcl}
\hline & $\begin{array}{l}\text { Average } \\
\text { Number } \\
\text { Sampled }\end{array}$ & $\begin{array}{l}\text { Length } \\
\text { (1nches) }\end{array}$ & $\begin{array}{l}\text { Length } \\
\text { Range }\end{array}$ & $\begin{array}{l}\text { Average } \\
\text { Weight } \\
\text { (pounds) }\end{array}$ & $\begin{array}{l}\text { Weight } \\
\text { Range }\end{array}$ \\
\hline $\begin{array}{l}\text { Shortnose gar } \\
\text { Goldeye }\end{array}$ & 1 & 24.4 & -- & 1.76 & -- \\
Northern pike & 72 & 11.7 & $(5.9-13.5)$ & 0.51 & $(0.07-0.78)$ \\
River carpsucker & 10 & 29.9 & $(26.2-35.7)$ & 7.71 & $(3.66-13.90)$ \\
Smallmouth buffalo & 6 & 16.9 & $(12.6-19.0)$ & 2.12 & $(0.86-3.75)$ \\
Shorthead redhorse & 1 & 20.0 & $(16.6-23.2)$ & 3.79 & $(2.82-5.60)$ \\
Sauger & 4 & 11.4 & -- & 0.61 & -- \\
Walleye & 1 & 12.5 & $(10.9-14.6)$ & 0.50 & $(0.32-0.74)$ \\
& 16.5 & -- & 1.46 & -- \\
\hline
\end{tabular}

$303 / 8.1$ 
Appendix Table 54. Species composition, numbers and size of fish sampled by experimental gill nets in Redwater River near its

confluence, 1979-80. (A total of three overnight sets).

\begin{tabular}{lcclll}
\hline Fish Species & $\begin{array}{l}\text { Number } \\
\text { Sampled }\end{array}$ & $\begin{array}{l}\text { Average } \\
\text { Length } \\
\text { (inches) }\end{array}$ & $\begin{array}{l}\text { Length } \\
\text { Range }\end{array}$ & $\begin{array}{l}\text { Average } \\
\text { Weight } \\
\text { (pounds) }\end{array}$ & $\begin{array}{l}\text { Weight } \\
\text { Range }\end{array}$ \\
\hline Goldeye & 112 & 10.0 & $(6.1-13.8)$ & 0.34 & $(0.09-1.02)$ \\
iyrthern pike & 6 & 20.5 & $(17.0-25.0)$ & 2.10 & $(1.10-3.74)$ \\
Carp & 12 & 14.1 & $(10.3-21.1)$ & 1.35 & $(0.53-4.16)$ \\
River carpsucker & 70 & 14.8 & $(9.7-19.8)$ & 1.63 & $(0.41-3.60)$ \\
Smallmouth buffalo & 2 & 20.6 & $(17.7-23.4)$ & 3.90 & $(2.50-5.30)$ \\
Shorthead redhorse & 39 & 11.4 & $(6.3-17.4)$ & 0.70 & $(0.09-2.04)$ \\
Channel catfish & 4 & 16.0 & $(13.4-19.5)$ & 1.29 & $(0.64-2.52)$ \\
Black bullhead & 2 & 6.7 & $(6.1-7.3)$ & 0.10 & $(0.09-0.12)$ \\
Sauger & 10 & 10.9 & $(9.6-13.4)$ & 0.36 & $(0.20-0.70)$ \\
Walleye & 3 & 16.4 & $(10.6-20.6)$ & 1.77 & $(0.36-3.06)$ \\
\hline
\end{tabular}

$303 / 8.1$ 
Appendix Table 55. Species composition, numbers and size of fish sampled by experimental gill nets in Poplar River near its confluence 1979-80. (A total of four overnight sets).

\begin{tabular}{lcclcl}
\hline Fish Species & $\begin{array}{l}\text { Number } \\
\text { Sampled }\end{array}$ & $\begin{array}{l}\text { Average } \\
\text { Length } \\
\text { (inches) }\end{array}$ & $\begin{array}{l}\text { Length } \\
\text { Range }\end{array}$ & $\begin{array}{l}\text { Average } \\
\text { Weight } \\
\text { (pounds) }\end{array}$ & $\begin{array}{l}\text { Weight } \\
\text { Range }\end{array}$ \\
\hline Goldeye & 73 & 10.6 & $(6.9-14.0)$ & 0.38 & $(0.10-0.99)$ \\
Northern pike & 5 & 27.3 & $(21.0-32.7)$ & 5.33 & $(2.15-8.40)$ \\
Carp & 3 & 16.2 & $(9.9-24.7)$ & 2.63 & $(0.47-6.20)$ \\
River carpsucker & 4 & 14.8 & $(14.0-15.3)$ & 1.40 & $(1.19-1.53)$ \\
Smallmouth buffalo & 5 & 19.9 & $(17.6-23.4)$ & 4.41 & $(2.72-7.50)$ \\
Shorthead redhorse & 10 & 12.6 & $(7.0-16.0)$ & 0.89 & $(0.30-0.81)$ \\
Channel catfish & 9 & 14.4 & $(10.6-24.9)$ & 1.44 & $(0.32-6.70)$ \\
Sauger & 3 & 11.1 & $(9.0-12.4)$ & 0.38 & $(0.19-0.48)$ \\
Walleye & 1 & 16.2 & - & 1.20 & - \\
\end{tabular}

$303 / 8.1$ 
Appendix Table 56. Species composition, numbers and size of fish sampled by experimental gill nets in Big Muddy Creek near its confluence, 1980. (A total of four overnight sets).

\begin{tabular}{lccccc}
\hline Fish Species & $\begin{array}{l}\text { Number } \\
\text { Sampled }\end{array}$ & $\begin{array}{l}\text { Average } \\
\text { Length } \\
\text { (inches) }\end{array}$ & $\begin{array}{l}\text { Length } \\
\text { Range }\end{array}$ & $\begin{array}{l}\text { Average } \\
\text { Weight } \\
\text { (pounds) }\end{array}$ & $\begin{array}{l}\text { Weight } \\
\text { Range }\end{array}$ \\
\hline Goldeye & 154 & 9.6 & $(6.6-13.4)$ & 0.30 & $(0.08-1.00)$ \\
Nicrthern pike & 11 & 24.7 & $(19.1-32.5)$ & 3.88 & $(1.84-6.90)$ \\
Carp & 8 & 15.4 & $(13.5-21.0)$ & 1.78 & $(1.13-4.40)$ \\
River carpsucker & 3 & 14.0 & $(13.2-15.5)$ & 1.33 & $(1.11-1.60)$ \\
Blue sucker & 1 & 23.4 & -- & 4.30 & -- \\
Shorthead redhorse & 2 & 13.9 & $(11.9-15.9)$ & 1.11 & $(0.67-1.55)$ \\
Channel catfish & 1 & 22.7 & -- & 3.98 & -- \\
Burbot & 1 & 22.0 & -- & 2.58 & -- \\
Sauger & 14 & 13.5 & $(9.4-19.6)$ & 0.78 & $(0.18-2.40)$ \\
Walleye & 12 & 16.6 & $(10.3-21.6)$ & 1.98 & $(0.29-3.98)$ \\
Freshwater drum & 1 & 14.7 & -- & 1.48 & - \\
& & & & & - \\
\hline
\end{tabular}

$303 / 8.1$ 


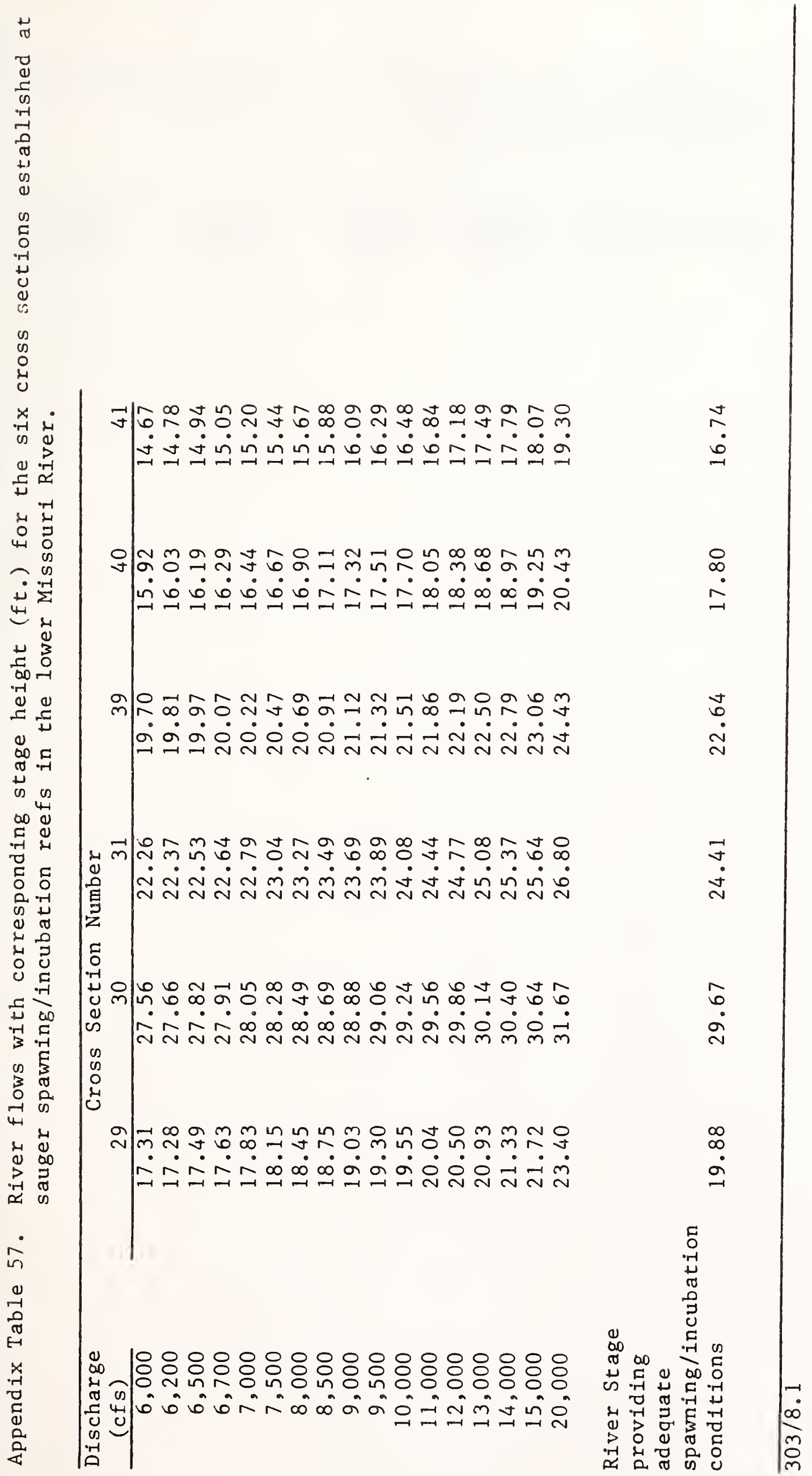


Appendix Table 58. A summary of shovelnose sturgeon tagging and harvest data from the lower Missouri and lower Milk rivers 1979-84. Total number harvested and harvest rate percentage (in parentheses) are given for each year.

\begin{tabular}{|c|c|c|c|c|c|c|c|}
\hline Tagging & Number & \multicolumn{6}{|c|}{ Tag Recovery Year } \\
\hline Year & Tagged & 1979 & 1980 & 1981 & 1982 & 1983 & 1984 \\
\hline 1979 & 30 & 0 & 0 & 0 & 0 & 0 & $\overline{0}$ \\
\hline 1980 & 122 & & 0 & 0 & 0 & 0 & 0 \\
\hline 1081 & 84 & & & 0 & 0 & 0 & 0 \\
\hline 1982 & 102. & & & & 0 & 0 & 0 \\
\hline 1983 & 0 & & & & & 0 & 0 \\
\hline 1984 & 0 & & & & & & \\
\hline
\end{tabular}

$303 / 8.1$ 
Appendix Table 59. A summary of paddlefish tagging and harvest data from the lower Missouri River 1979-84. Total number harvested and harvest rate percentage (in parentheses) are given for each year.

\begin{tabular}{|c|c|c|c|c|c|c|c|}
\hline Tagging & Number & \multicolumn{6}{|c|}{ Tag Recovery Year } \\
\hline Year & Tagged & $\overline{1979}$ & 1980 & 1981 & 1982 & 1983 & 1984 \\
\hline 1979 & 41 & 0 & 0 & 0 & 0 & 0 & $\frac{1}{(2.4)}$ \\
\hline 1980 & 27 & - & 0 & $\begin{array}{c}1 \\
(3.7)\end{array}$ & 0 & $\begin{array}{c}1 \\
(3.8)\end{array}$ & 0 \\
\hline 1981 & 60 & & - & 0 & 0 & $\begin{array}{c}2 \\
(3.3)\end{array}$ & 0 \\
\hline 1982 & 21 & & & - & 0 & 0 & 0 \\
\hline 1983 & 0 & & & & - & - & - \\
\hline 1984 & 1 & & & & & - & 0 \\
\hline
\end{tabular}

$303 / 8.1$ 
Appendix Table 60. A summary of rainbow trout tagging and harvest data from the lower Missouri River 1979-84. Total number harvested and harvest rate percentage (in parentheses) are given for each year.

\begin{tabular}{|c|c|c|c|c|c|c|c|}
\hline Tagging & Number & \multicolumn{6}{|c|}{ Tag Recovery Year } \\
\hline Year & Tagged & 1979 & 1980 & 1981 & 1982 & 1983 & 1984 \\
\hline$\overline{1979}$ & $4-$ & $\begin{array}{c}\frac{1}{(25.0)} \\
\left(\frac{1}{3}\right)\end{array}$ & $\begin{array}{c}\frac{1}{(33.3)}\end{array}$ & $\overline{0}$ & $\overline{0}$ & $\overline{0}$ & $\overline{0}$ \\
\hline 1980 & 22 & - & 0 & $\begin{array}{c}2 \\
(9.1)\end{array}$ & 0 & 0 & 0 \\
\hline 1981 & 50 & & - & $\begin{array}{c}4 \\
(8.0)\end{array}$ & $\begin{array}{c}2 \\
(5.0)\end{array}$ & $\begin{array}{c}1 \\
(2.3)\end{array}$ & 0 \\
\hline 1982 & 9 & & & - & $\begin{array}{c}1 \\
(11.1)\end{array}$ & $\begin{array}{c}2 \\
(28.6)\end{array}$ & - \\
\hline 1983 & 122 & & & & - & 0 & $\begin{array}{c}2 \\
(1.6\end{array}$ \\
\hline 1984 & 7 & & & & & - & 0 \\
\hline
\end{tabular}

a/ Not all of these fish were from the tailwaters population.

$303 / 8.1$ 
Appendix Table 61. A summary of northern pike tagging and harvest data from the lower Missouri and lower Milk rivers, 1979-84. Total number harvested and harvest rate percentage (in parentheses) are given for each year.

\begin{tabular}{|c|c|c|c|c|c|c|c|}
\hline Tagging & Number & \multicolumn{6}{|c|}{ Tag Recovery Year } \\
\hline Year & Tagged & 1979 & 1980 & 1981 & 1982 & 1983 & 1984 \\
\hline 1979 & 98 & $\begin{array}{c}1 \\
(1.0)\end{array}$ & $\begin{array}{c}1 \\
(1.0)\end{array}$ & $\begin{array}{c}1 \\
(1.0)\end{array}$ & $\begin{array}{c}1 \\
(1.1)\end{array}$ & $\begin{array}{c}1 \\
(1.1)\end{array}$ & 0 \\
\hline 1980 & 114 & - & $\begin{array}{c}2 \\
(1.8)\end{array}$ & 0 & 0 & 0 & 0 \\
\hline 1981 & 128 & - & - & $\begin{array}{c}3 \\
(2.3)\end{array}$ & $\begin{array}{c}5 \\
(4.0)\end{array}$ & $\begin{array}{c}1 \\
(0.8)\end{array}$ & $\begin{array}{c}1 \\
(0.8)\end{array}$ \\
\hline 1982 & 143 & & & - & $\begin{array}{c}5 \\
(3.5)\end{array}$ & $\begin{array}{c}2 \\
(1.4)\end{array}$ & $\begin{array}{c}1 \\
(0.7)\end{array}$ \\
\hline 1983 & 13 & & & & - & $\begin{array}{c}1 \\
(7.7)\end{array}$ & $\begin{array}{c}1 \\
(7.7)\end{array}$ \\
\hline 1984 & 0 & & & & & - & - \\
\hline & $\overline{496}$ & & & & & & \\
\hline
\end{tabular}

$303 / 8.1$ 
Appendix Table 62. A summary of channel catfish tagging and harvest data from the lower Missouri and lower Milk rivers, 1979-84. Total number harvested and harvest rate percentage (in parentheses) are given for each year.

\begin{tabular}{|c|c|c|c|c|c|c|c|}
\hline Tagging & Number & & & Reco & Year & & \\
\hline Year & Tagged & 1979 & 1980 & 1981 & 1982 & 1983 & 1984 \\
\hline$\overline{1979}$ & 51 & 0 & $\begin{array}{c}\frac{2}{(3.9)} \\
\end{array}$ & $\frac{2}{(4.1)}$ & 0 & $\overline{0}$ & 0 \\
\hline$: 930$ & 98 & - & $\begin{array}{c}1 \\
(1.0)\end{array}$ & $\begin{array}{c}2 \\
(2.1)\end{array}$ & 0 & 0 & 0 \\
\hline 1981 & 3 & & - & 0 & 0 & 0 & 0 \\
\hline 1982 & 3 & & & - & 0 & 0 & 0 \\
\hline 1983 & 0 & & & & - & - & - \\
\hline 1984 & 0 & & & & & - & - \\
\hline
\end{tabular}

$303 / 8.1$ 
Appendix Table 63. A summary of burbot tagging and harvest data from the lower Missouri and lower Milk rivers, 1979-84. Total number harvested and harvest rate percentage (in parentheses) are given for each year.

\begin{tabular}{|c|c|c|c|c|c|c|c|}
\hline Tagging & Number & \multicolumn{6}{|c|}{ Tag Recovery Year } \\
\hline Year & Tagged & 1979 & 1980 & 1981 & 1982 & 1983 & 1984 \\
\hline 1979 & 24 & 0 & 0 & 0 & 0 & 0 & $\overline{0}$ \\
\hline 1980 & 18 & - & - & 0 & 0 & 0 & 0 \\
\hline 1981 & 94 & & - & $\begin{array}{c}2 \\
(2.0)\end{array}$ & 0 & $\begin{array}{c}1 \\
(1.1)\end{array}$ & 0 \\
\hline 1982 & 57 & & & - & $\begin{array}{c}4^{4} \\
(7.0)\end{array}$ & $\begin{array}{c}2 \\
(3.8)\end{array}$ & 0 \\
\hline 1983 & 0 & & & & & - & \\
\hline 1984 & 0 & & & & & & \\
\hline
\end{tabular}

$303 / 8.1$ 
Appendix Table 64. A summary of sauger tagging and harvest data from the lower Missouri and lower Milk rivers, 1979-84. Total number harvested and harvest rate percentage (in parentheses) are given for each year.

\begin{tabular}{|c|c|c|c|c|c|c|c|}
\hline Tagging & Number & \multicolumn{6}{|c|}{ Tag Recovery Year } \\
\hline Year & Tagged & 1979 & 1980 & 1981 & 1982 & 1983 & 1984 \\
\hline 1979 & 856 & $\begin{array}{c}7 \\
(0.8)\end{array}$ & $\begin{array}{c}6 \\
(0.7)\end{array}$ & $\begin{array}{c}2 \\
(0.2)\end{array}$ & 0 & $\begin{array}{c}3 \\
(0.3)\end{array}$ & $\begin{array}{c}1 \\
(0.1)\end{array}$ \\
\hline$i 980$ & 1054 & - & $\begin{array}{c}31 \\
(2.9)\end{array}$ & $\begin{array}{c}21 \\
(2.0)\end{array}$ & $\begin{array}{c}2 \\
(0.2)\end{array}$ & $\begin{array}{c}2 \\
(0.2)\end{array}$ & 0 \\
\hline 1981 & 1201 & - & - & $\begin{array}{c}32 \\
(2.6)\end{array}$ & $\begin{array}{c}27 \\
(2.3)\end{array}$ & $\begin{array}{c}14 \\
(1.2)\end{array}$ & $\begin{array}{c}8 \\
(0.7)\end{array}$ \\
\hline 1982 & 1303 & - & - & - & $\begin{array}{c}63 \\
(5.1)\end{array}$ & $\begin{array}{l}20 \\
(1.6)\end{array}$ & $\begin{array}{l}16 \\
(1.3)\end{array}$ \\
\hline 1983 & 85 & - & & & - & $\begin{array}{c}4^{4} \\
(4.7)\end{array}$ & $\begin{array}{c}6 \\
(7.4)\end{array}$ \\
\hline 1984 & 31 & - & & & & - & \\
\hline & 4530 & & & & & & \\
\hline
\end{tabular}

$303 / 8.1$ 
Appendix Table 65. A summary of walleye tagging and harvest data from the lower Missouri and lower Milk rivers, 1979-84. Total number harvested and harvest rate percentage (in parentheses) are given for each year.

\begin{tabular}{|c|c|c|c|c|c|c|c|}
\hline Tagging & Number & \multicolumn{6}{|c|}{ Tag Recovery Year } \\
\hline Year & Tagged & 1979 & 1980 & 1981 & 1982 & 1983 & 1984 \\
\hline$\overline{1979}$ & 46 & $\begin{array}{c}\frac{5}{(10.9)} \\
(10.9\end{array}$ & 0 & 0 & 0 & $\overline{0}$ & 0 \\
\hline 1980 & 83 & - & $\begin{array}{c}7 \\
(8.4)\end{array}$ & $\begin{array}{c}3 \\
(3.9)\end{array}$ & $\begin{array}{c}3 \\
(4.1)\end{array}$ & $\begin{array}{c}1 \\
(1.4)\end{array}$ & 0 \\
\hline 1981 & 87 & - & - & $\begin{array}{c}10 \\
(11.5)\end{array}$ & $\begin{array}{c}7^{7} \\
(9.1)\end{array}$ & 0 & $\begin{array}{c}2 \\
(2.9))\end{array}$ \\
\hline 1982 & 119 & & & - & $\begin{array}{c}5 \\
((4.2)\end{array}$ & $\begin{array}{c}9 \\
(7.9)\end{array}$ & $\begin{array}{c}1 \\
(1.0)\end{array}$ \\
\hline 1983 & 30 & & & & - & $\begin{array}{c}3 \\
(10.0)\end{array}$ & $\begin{array}{c}3 \\
(10.0)\end{array}$ \\
\hline 1984 & 25 & & & & & - & $\begin{array}{c}3 \\
(12.0)\end{array}$ \\
\hline & $\overline{390}$ & & & & & & \\
\hline
\end{tabular}

$303 / 8.1$ 


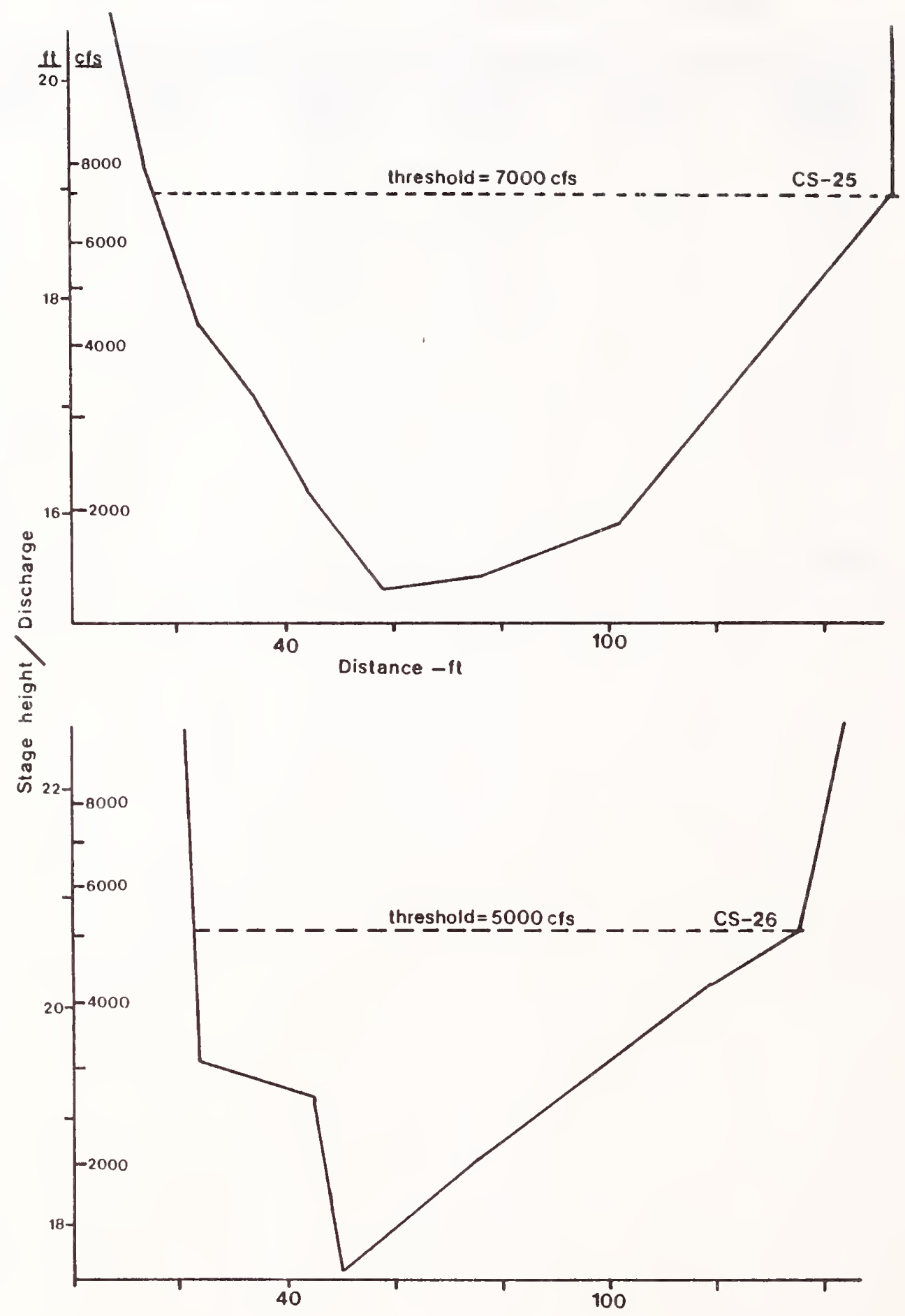

Appendix Figure 1. Cross section profiles of the Sprole rearing pool and river flow and corresponding stage height which will maintain the pool at an adequate condition. 


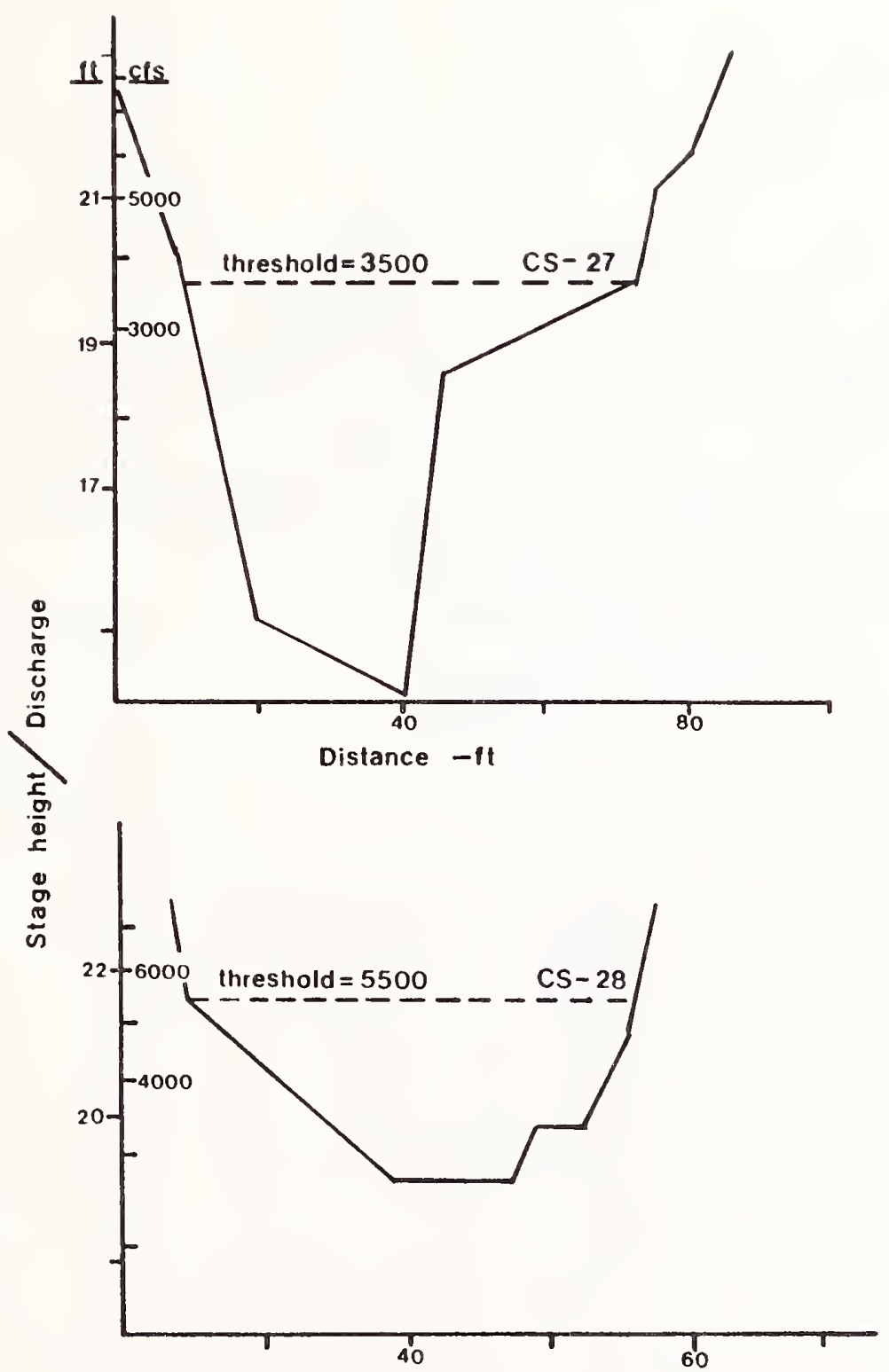

Appendix Figure 2. Cross section profiles of the Brockton 1 rearing pool and river flow and corresponding stage height which will maintain the pool at an adequate condition. 

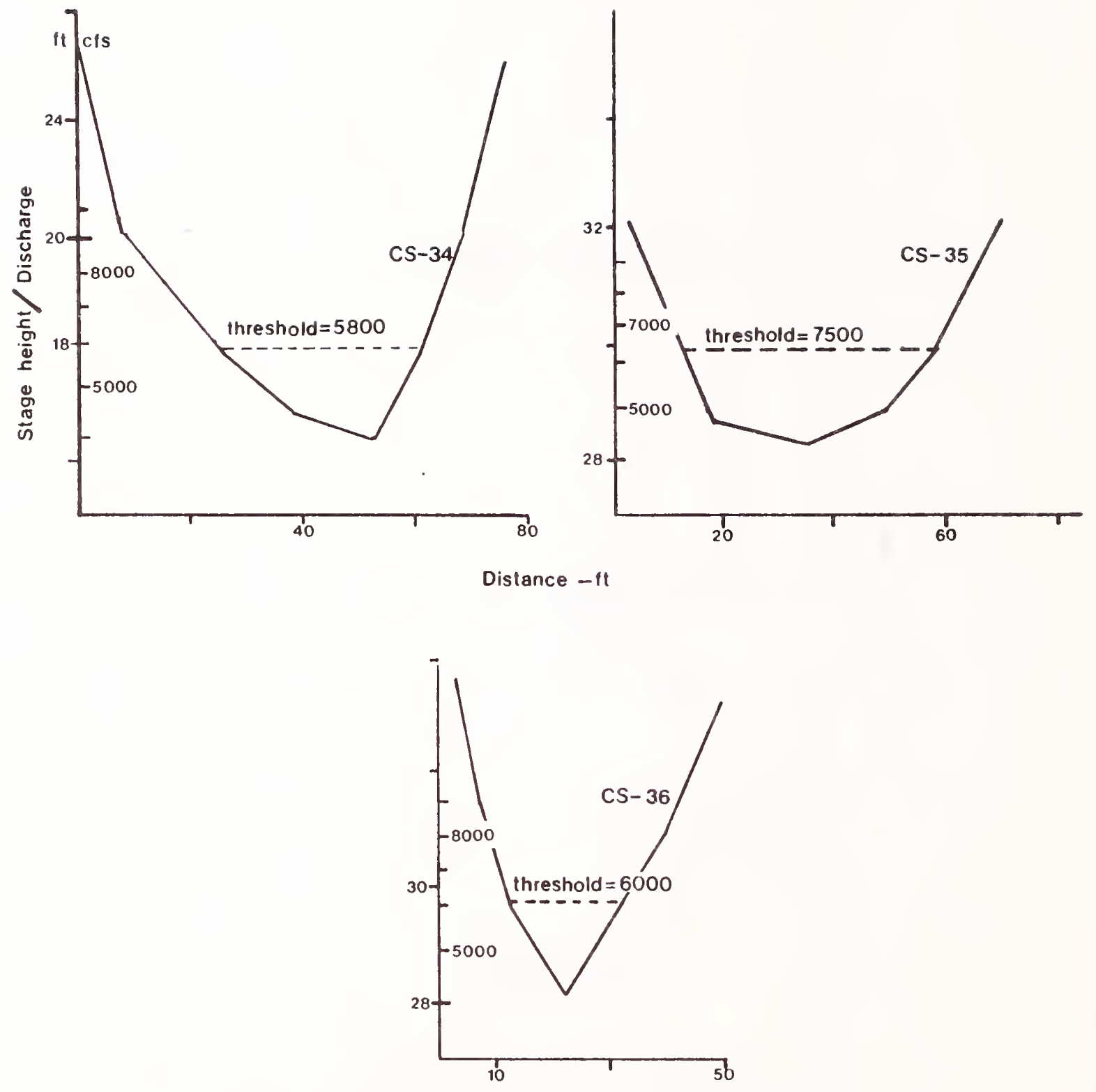

Appendix Figure 3. Cross section profiles of the Brockton 2 rearing pool and river flow and corresponding stage height which will maintain the pool at an adequate condition. 


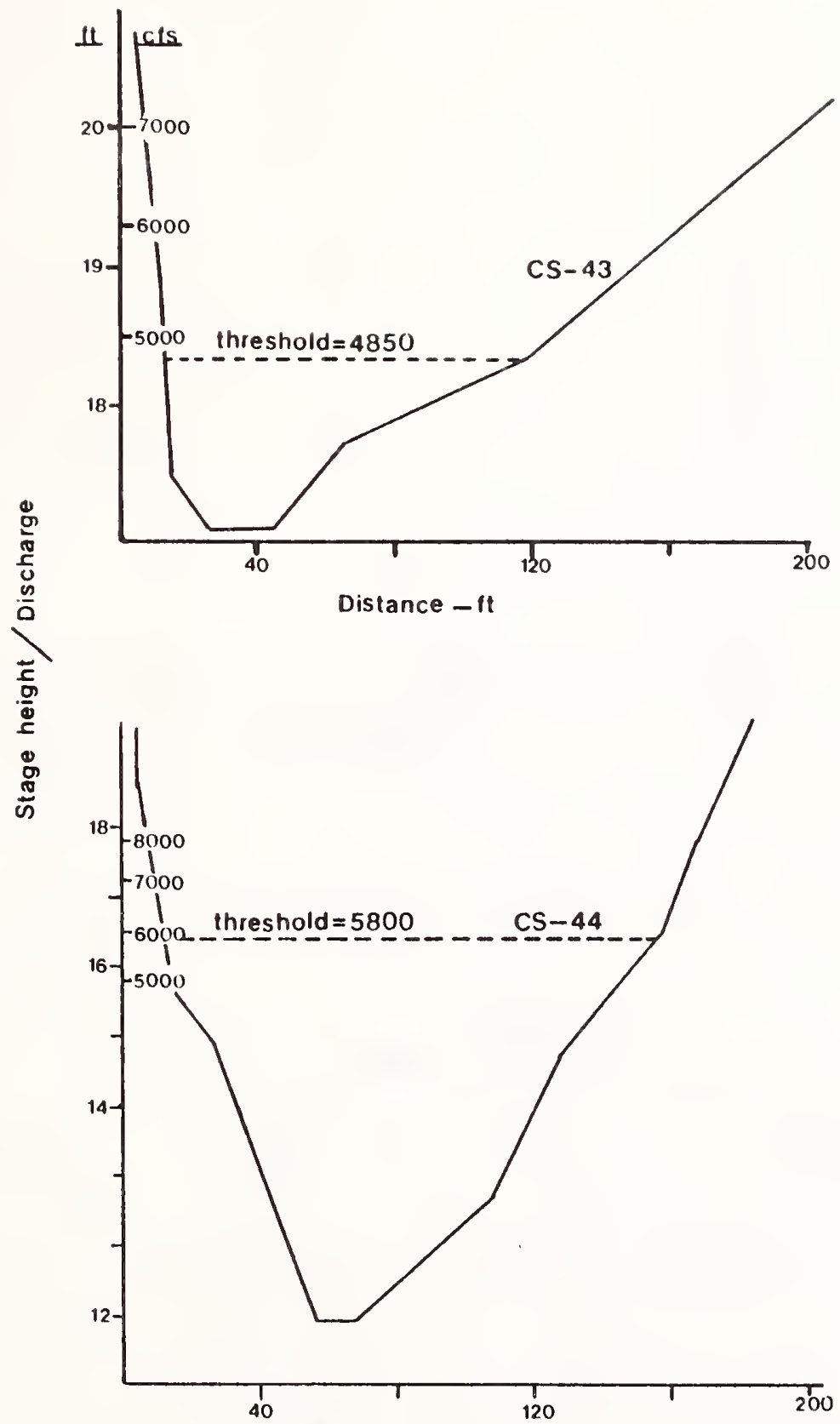

Appendix Figure 4. Cross section profiles of the Culbertson rearing pool and river flow and corresponding siage height which will maintain the pool at an adequate condition. 

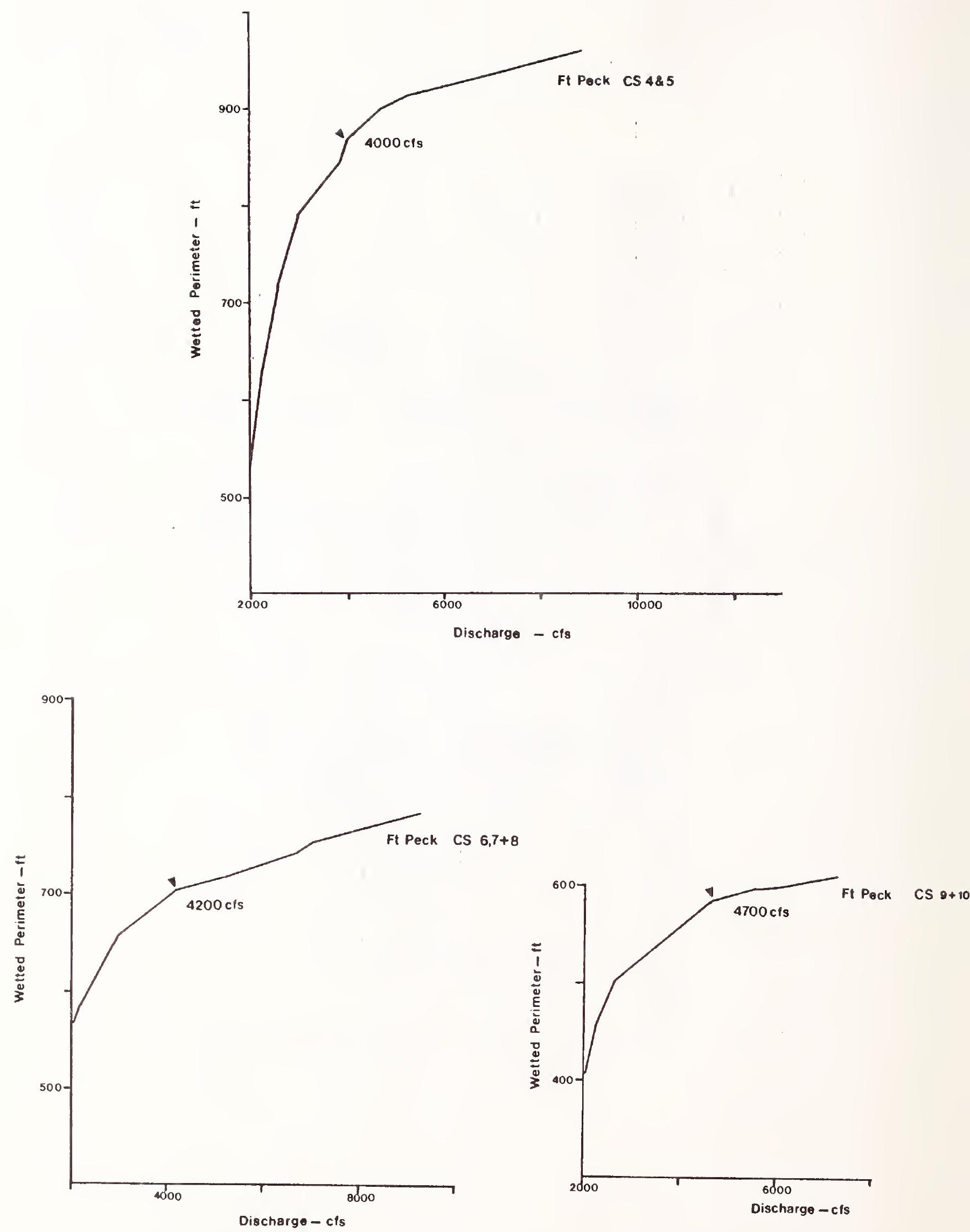

Appendix Figure 5. Wetted perimeter-discharge relationships for three different riffle sites located on the Missouri River in the Fort Peck section. Each curve is a composite of two or three cross sections; inflection points are marked. 

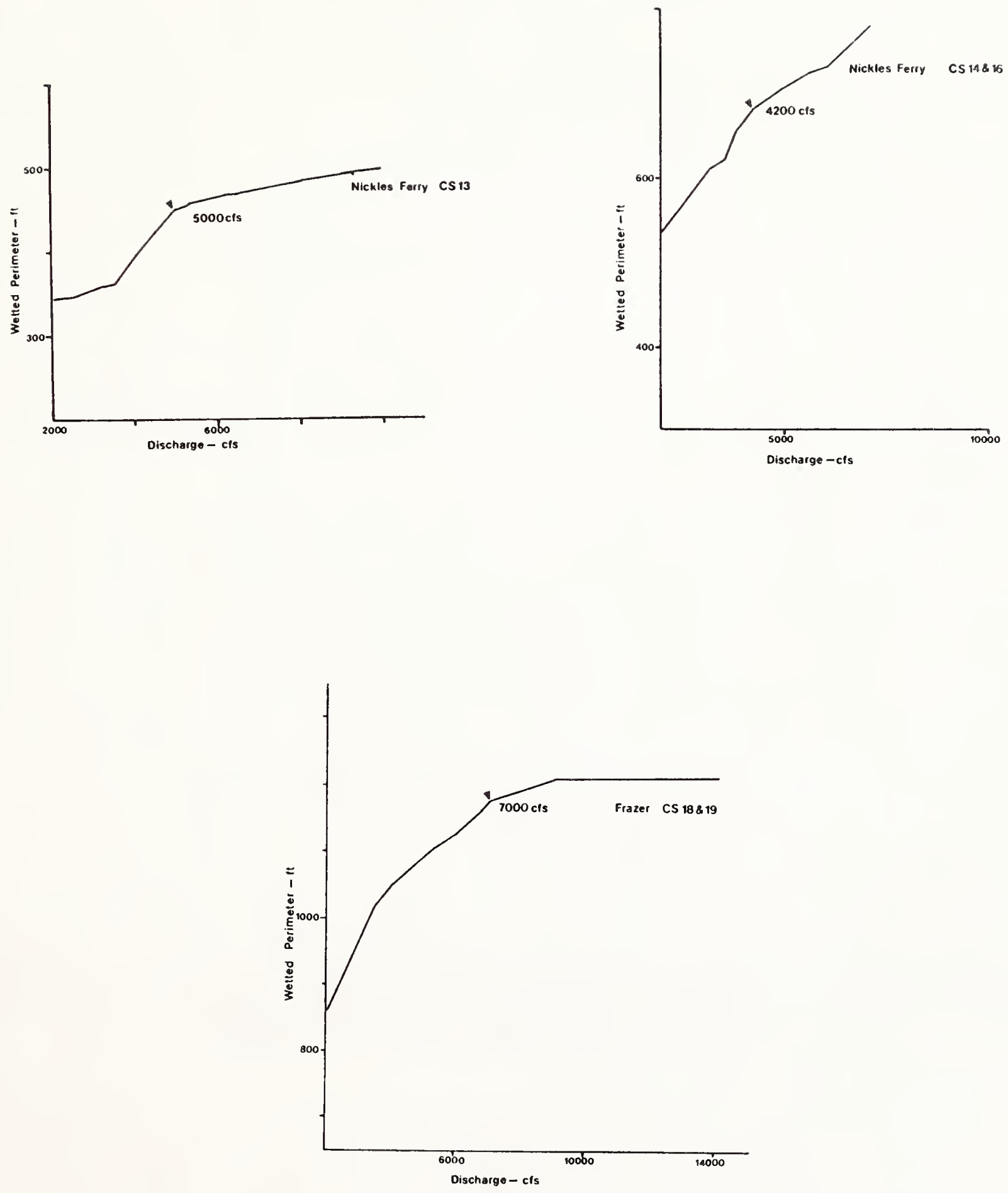

Appendix Figure 6. Wetted perimeter-discharge relationships for three different riffle sites located on the Missouri River in the Nickels Ferry and Frazer study sections.

Each curve represents one or a composite of two cross sections; inflection points are marked. 


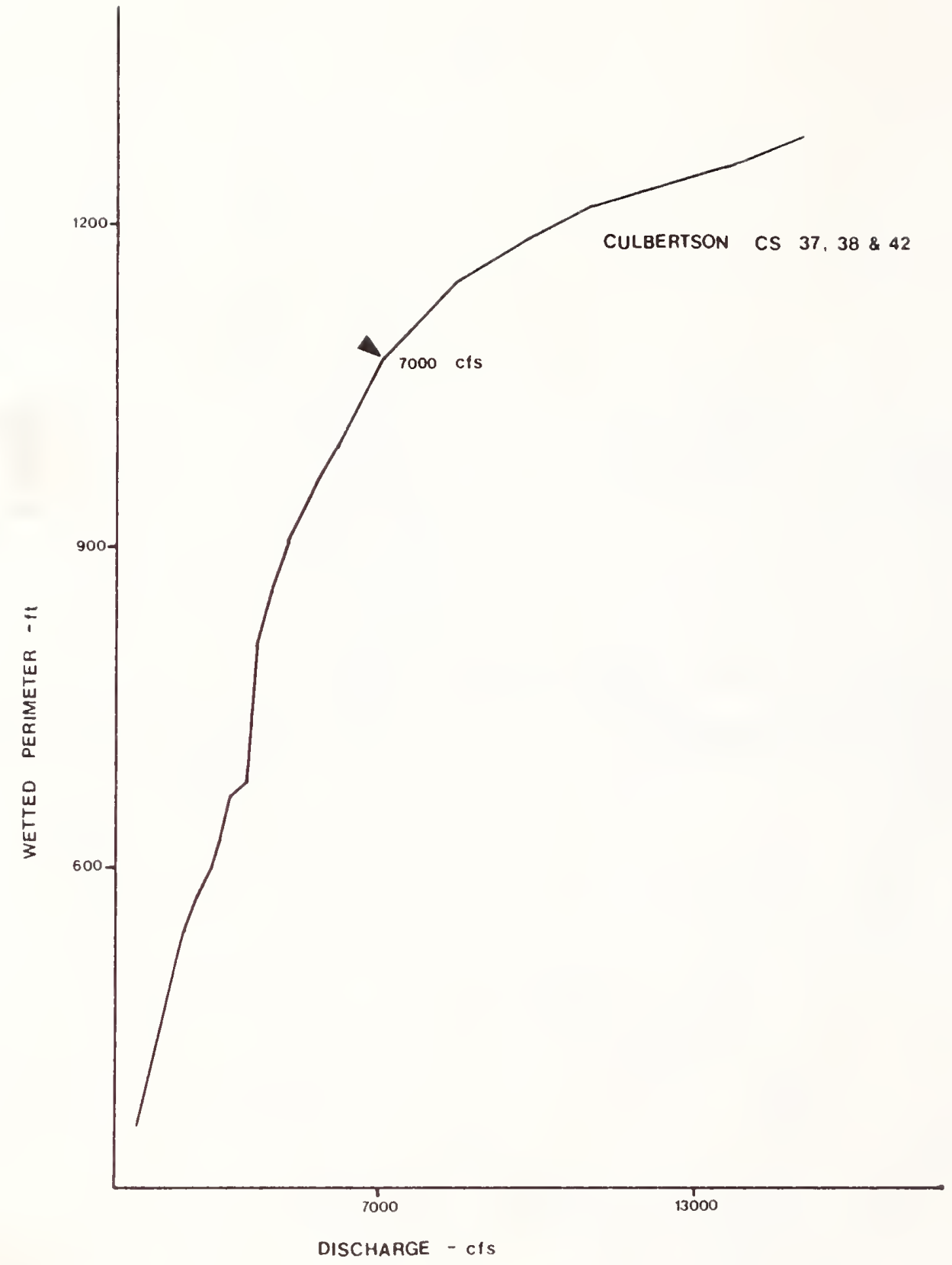

Appendix Figure 7. Wetted perimeter-discharge relationship for a composite of three riffle cross sections located on the Missouri River in the Culbertson study section. 

